\title{
ETHIOPIA \\ Employment and Jobs Study
}

December 2017

Poverty Global Practice

Africa Region

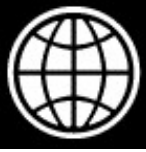

Document of the World Bank

For Official Use Only 


\section{ABBREVIATIONS AND ACRONYMS}

$\begin{array}{ll}\text { CSA } & \text { Central Statistics Agency } \\ \text { GTP } & \text { Economic Development and Poverty Reduction Strategy } \\ \text { ES } & \text { Enterprise Survey } \\ \text { ESS } & \text { Ethiopian Socioeconomic Survey } \\ \text { ETB } & \text { Ethiopian Birr } \\ \text { GDP } & \text { Gross Domestic Product } \\ \text { GoE } & \text { Government of Ethiopia } \\ \text { GTP } & \text { Growth and Transformation Plan } \\ \text { HCES } & \text { Household Consumption Expenditure Survey } \\ \text { ILO } & \text { International Labor Organization } \\ \text { LFS } & \text { Labor Force Survey } \\ \text { NEET } & \text { Not in employment, education, or training } \\ \text { PHC } & \text { Population and Housing Census } \\ \text { PPP } & \text { Purchasing Power Parity } \\ \text { USD } & \text { United States Dollars } \\ \text { WDI } & \text { World Development Indicators } \\ \text { WPP } & \text { World Population Prospects }\end{array}$

\begin{tabular}{|rl|}
\hline Vice President: & Makhtar Diop \\
Senior Director: & Carolina Sanchez-Paramo \\
Country Director: & Carolyn Turk \\
Practice Manager: & Pierella Paci \\
Task Team Leader: & Tom Bundervoet \\
\hline
\end{tabular}




\section{Table of Contents}

ABBREVIATIONS AND ACRONYMS ..................................................................... 2

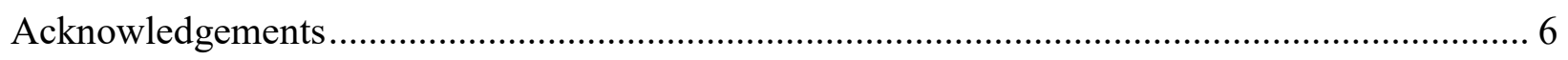

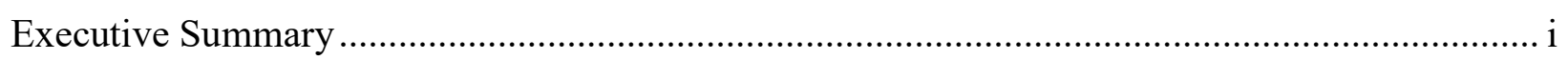

1. Positive employment trends, in particular since 2005 and in urban areas ............................ i

Strong nonfarm employment growth, linked to labor mobility ..................................... i

Services driving growth in employment and productivity...........................................iii

Employment remains dominated by agriculture and non-wage work .............................. iv

2. Youth employment improved, though rural youth are lagging........................................ vi

3. Improving youth employment outcomes ............................................................... ix

Chapter I. A bird's eye view of employment and growth in Ethiopia...................................... 1

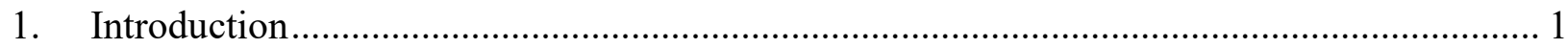

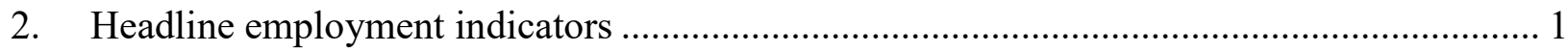

A "typical" labor market, that has been improving over time ........................................... 1

Large differences across gender, age and space ......................................................... 3

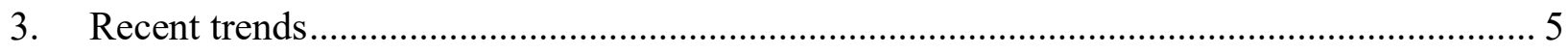

4. Employment, productivity, and economic growth............................................... 9

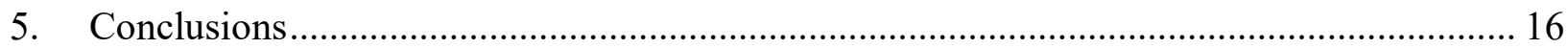

Chapter II. A profile of workers and jobs, then and now .................................................... 17

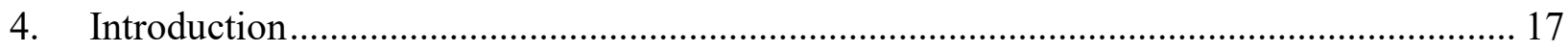

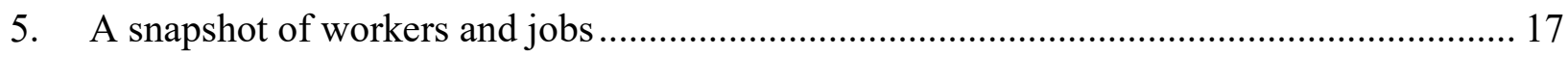

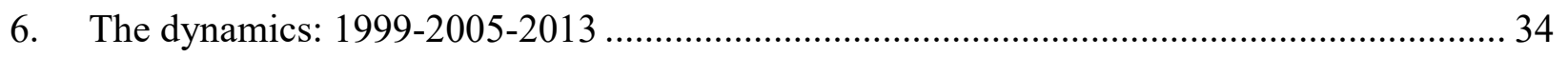

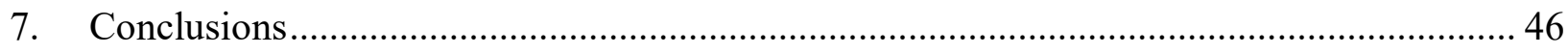

Chapter III. Youth in Ethiopia's labor market ............................................................. 48

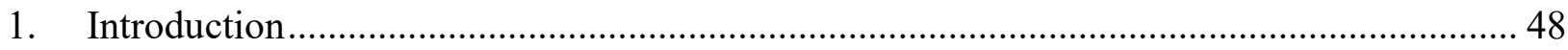

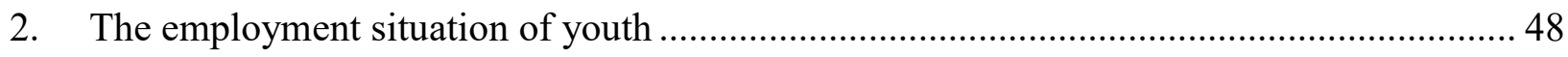

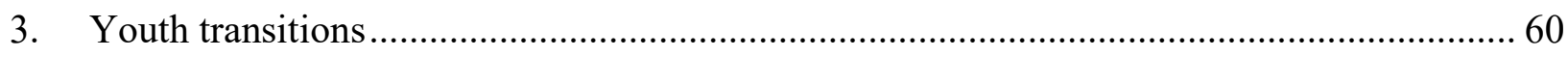

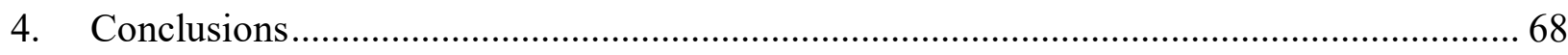

Going Forward: How to improve employment outcomes for Ethiopia's youth? ...................... 70

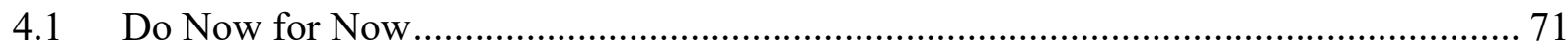

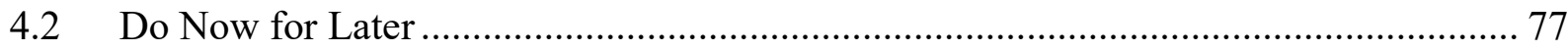




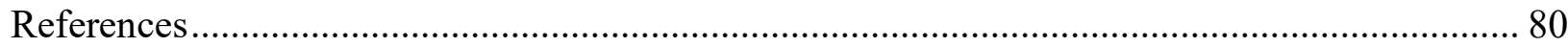

Annex 1: Enterprise Surveys and Credit Constraints ………................................................... 83

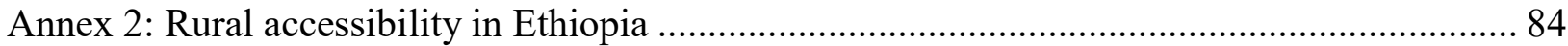

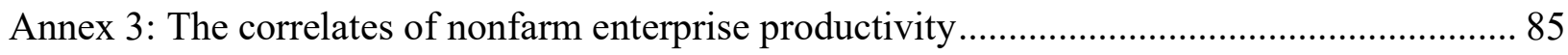

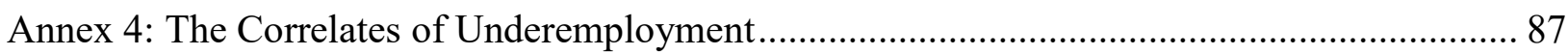

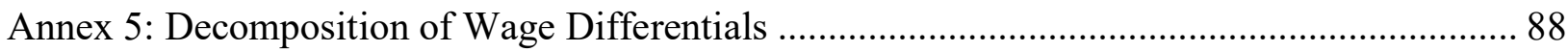

Annex 6: Effect of Different Treatment of Water and Firewood collectors in 2013 .................... 89

Annex 7: A pseudo-panel analysis of the move to nonfarm and wage employment..................... 90

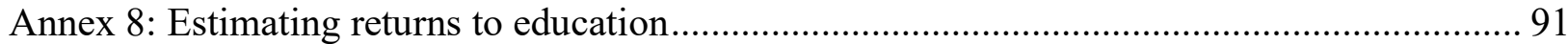

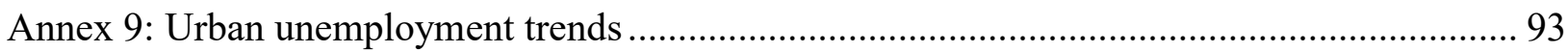

Annex 10: The role of education in explaining employment category........................................ 94

Annex 11: Qualitative study on rural youth employment........................................................ 96

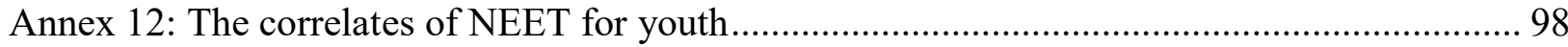

Annex 13: The correlates of nonfarm diversification ................................................................ 101 


\section{Acknowledgements}

This study was prepared by a core team comprised of Tom Bundervoet (task team leader, GPV01), Habtamu Fuje Neda (Economist, GPV01), Marco Ranzani (Economist, GPV01), Simon Lange (Junior Professional Officer, GPV01), Atsushi Iimi (Senior Economist, GTI01), and Eyasu Tsehaye (Economist, GPV01). The qualitative research presented in this study was conducted by BDS-CDR and supervised by Manex Bule Yonis (Consultant, GPV01). A good part of this report draws on four background papers:

1. "Employment Dynamics and Transitions out of Agriculture in Ethiopia", by Habtamu Fuje Neda

2. "The Ethiopian Labor Market, 1999-2013: Youth in the Spotlight", by Marco Ranzani

3. "The Service Sector as an Engine of Job Creation: How to Keep the Momentum?", by Simon Lange

4. "Rural Youth Employment in Ethiopia: Final Report", by BDS-CDR

The report was prepared under the general supervision of Pablo Fajnzylber (Practice Manager, GPV01), Pierella Paci (Practice Manager, GPV01), Michael Geiger (Acting Program Leader, AFCE3), and Carrie Turk (Country Director, AFCE2). Peer reviewers were Ruth Hill (Senior Economist, GPV06), Dean Jolliffe (Lead Economist, DECSU), Marie Laura Sanchez Puerta (Senior Economist, GPSJB) and Kathleen Beegle (Program Leader, AFCW1). Valuable comments and suggestions were also received from Government of Ethiopia's National Planning Commission (NPC). Finally, Yemsrach Kinfe Edey (Team Assistant, AFCE3) and Candace Gebre (Consultant, GPV01) provided excellent logistical and research assistance in the preparation of this report.

The findings, interpretations, and conclusions expressed herein are those of the authors, and do not necessarily reflect the views of the World Bank's Board of Executive Directors or the countries they represent. The World Bank does not guarantee the accuracy of the data included in this report, nor does it endorse the boundaries, colors, denominations, and other information shown on any map in this report. 


\section{Executive Summary}

As many developing countries around the world, Ethiopia is faced with the challenge of generating employment for a rapidly-growing and youthful population. Ethiopia's workingage population, currently estimated at 54.7 million, is projected to grow by two million per year over the coming decade and this growth is unlikely to slow any time soon given persistently high fertility rates ${ }^{1}$. The fast-growing labor force, combined with improving education levels, the drive for industrialization, and the increased scarcity of agricultural land, will have far-reaching consequences for the social and economic structure of the country, the nature of work, and labor mobility and the growth of town and cities.

This jobs and employment study focuses on employment dynamics in Ethiopia between 1999 and 2016. Using data from a variety of sources, mainly the Labor Force Surveys (1999, 2005 and 2013) and the Ethiopia Socioeconomic Surveys (2012, 2014 and 2016), the report looks at what workers in Ethiopia are doing, how employment has changed over the past fifteen years, and how inter- and intra-sectoral employment dynamics have been associated with productivity and economic growth. The report also aims to identify which groups have been doing well on the employment front and which groups are lagging. To add context and depth, the quantitative analysis has been complemented by a qualitative research study on rural youth employment, conducted in April and May 2017 in 16 woredas in the four most populous regions of Ethiopia.

\section{Positive employment trends, in particular since 2005 and in urban areas} Strong nonfarm employment growth, linked to labor mobility

Ethiopia's strong economic growth since the turn of the century has not been jobless. Between 1999 and 2013, the economy grew at an average of over nine percent per year, resulting in a more than two-fold increase in GDP per capita. Over the same period, employment grew faster than the working-age population, resulting in a decrease in unemployment. While agriculture absorbed most of the new workers since 1999, nonfarm employment grew fast from a low base, driving large decrease in urban unemployment until 2013 (Figure 1). The relatively faster pace of employment growth in the nonfarm sector, especially in wage-employment and since 2005 , led to a modest decline in the share of agriculture in employment from 78 percent in 1999 to 74 percent in 2013 (Figure 2).

1 Projections based on World Population Prospects, medium-fertility scenario. 
Figure 1: Strong nonfarm job creation pushed down the urban unemployment rate...

(Unemployment rate, relaxed definition))

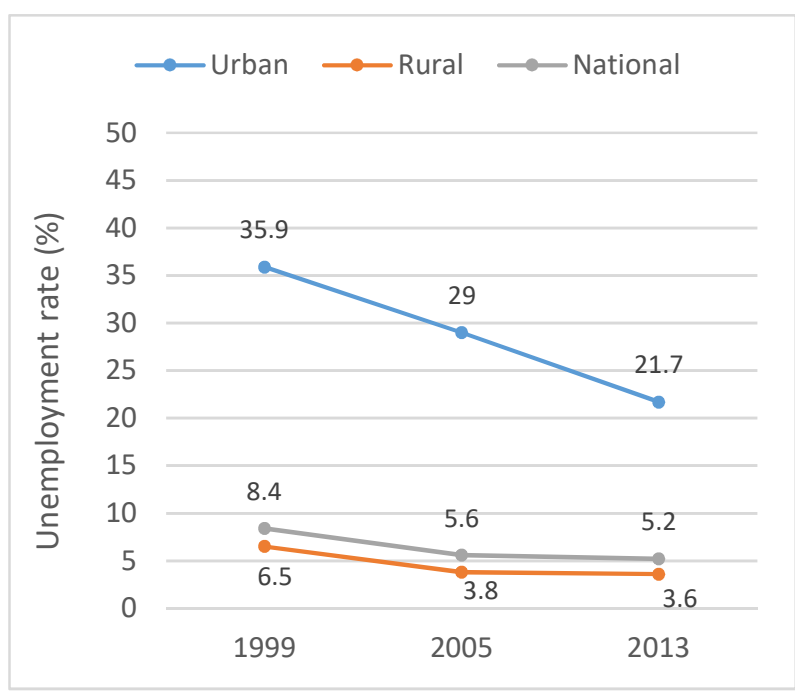

Source: LFS, 1999; 2005; 2013. WB staff calculations.
Figure 2: And led to a modest decrease in agriculture's employment share

(Sectoral composition of employment)

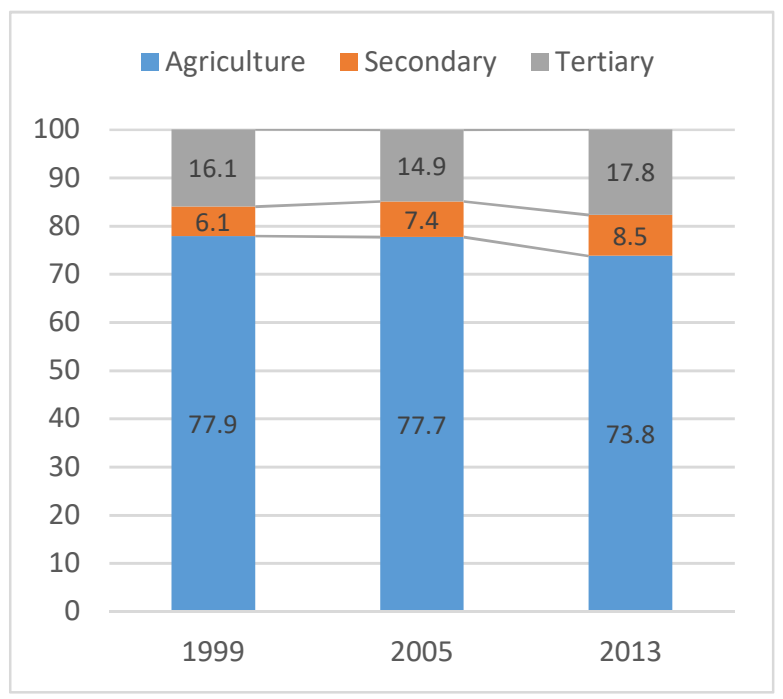

Source: LFS, 1999; 2005; 2013. WB staff calculations.

The timid move to nonfarm employment since 2005 was mainly driven by young men and closely linked to increasing labor mobility. In 2013, men in their mid-to-late twenties were far more likely to work in nonfarm wage employment compared to similar cohorts in 2005 and 1999 (Figure 3). The move to nonfarm wage employment has been tightly linked to labor mobility. Though internal migration in Ethiopia remains relatively low, it has increased since 2005 and rural to urban movements have become the most frequent type of internal population movements. Young men in particular have moved to urban areas (Figure 4), and this move has been strongly correlated with the observed increase in nonfarm employment and wage employment. The limited structural transformation in employment between 1999 and 2013 has been largely driven by migration: Over the 1999-2013 period, a 1 percentage point increase in the share of a cohort living in urban areas was associated with a 1.4 percentage point decrease in agricultural employment in the cohort and a similar increase in the share of wage employment in the cohort. 
Figure 3: Young men are increasingly employed in wage employment...

(Share of employed men in non-wage employment, by age and year)

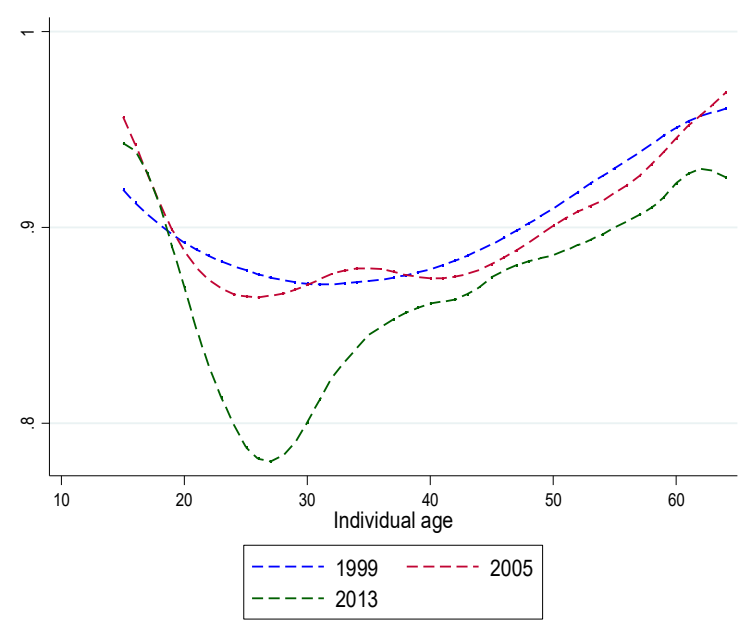

Source: LFS, 1999; 2005; 2013. WB staff calculations.
Figure 4: ...and this has been tightly linked to migration to urban areas

(Share of cohort living in cities, by year, males) ${ }^{2}$

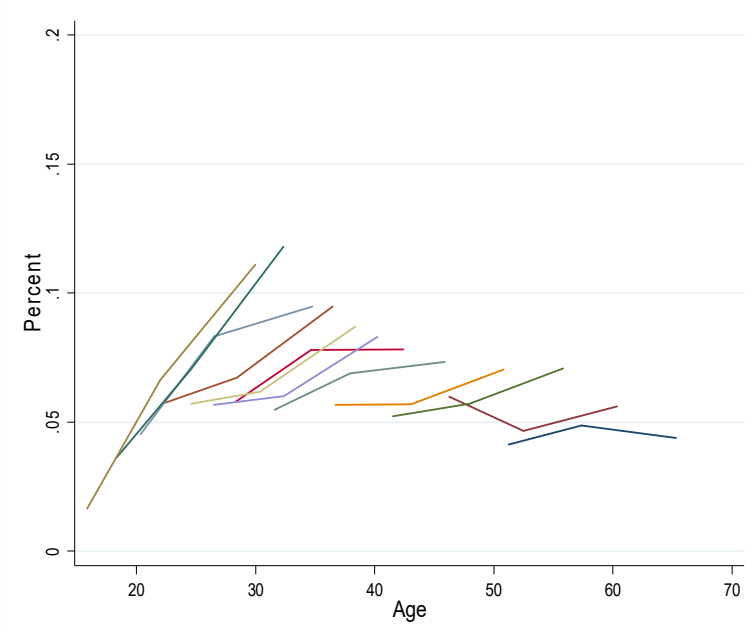

Source: LFS, 1999; 2005; 2013. WB staff calculations.

In line with the positive employment trends in urban areas, real wages increased substantially. Expressed in 2013 prices, median monthly wages increased from ETB 788 in 2005 to ETB 979 in 2013 and, based on the ESS, to ETB 1,158 in 2016, an increase of 3.5 percent per year. At US\$165 per month in PPP terms in 2016, wages remain however low.

Services driving growth in employment and productivity

As in many African countries, employment growth in the nonfarm sector was concentrated in services. Close to 70 percent of nonfarm job creation between 1999 and 2013 happened in the service sector, resulting in an increase of the tertiary sector's employment share (Figure 2). The public sector accounted for most of the increase in nonfarm employment since 1999, followed by community-and family-oriented services (Figure 42). Though employment in manufacturing also expanded considerably, its share of total employment did not increase due to the low employment base and the rapidly expanding labor force. Employment in manufacturing is however expected to increase more rapidly in coming years as a result of the Government's industrialization strategy.

\footnotetext{
${ }^{2}$ Each line in figure follows a fixed cohort through time. The starting point of each line is the share of the cohort living in urban areas in 1999. The mid-point of the line shows the share of that same cohort living in urban areas in 2005, and the end point of the line is the share of the same cohort living in urban areas by 2013. An upward sloping line means that people in the cohort have tended to move to urban areas between 1999 and 2013.
} 
Figure 5: The public sector and services added the bulk of nonfarm jobs since 1999

(Net nonfarm job additions, 1999-2013)

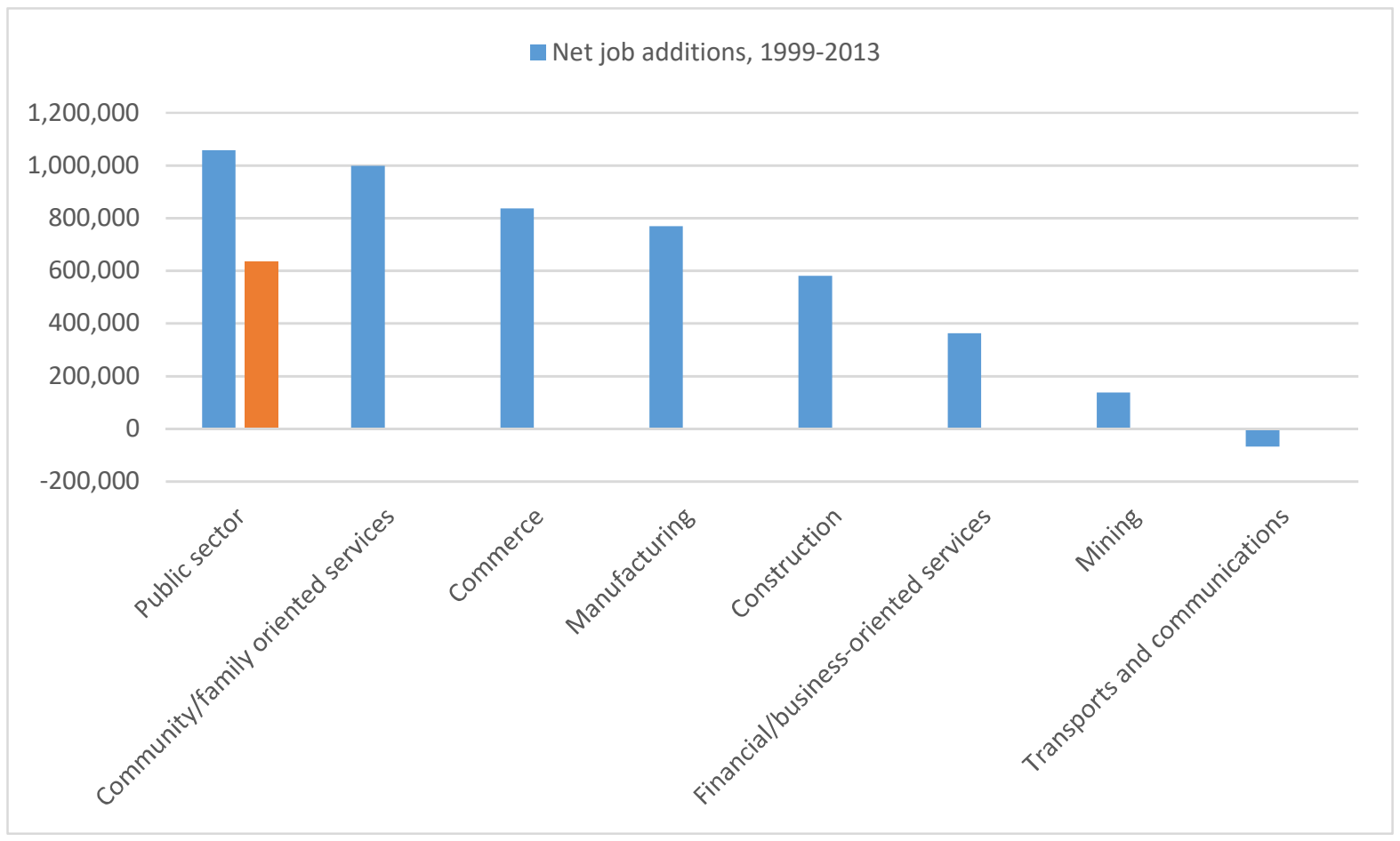

Source: LFS, 1999; 2013.

Services also accounted for the largest part of the growth in labor productivity and per capita value-added. Output per worker between 2005 and 2013 increased by 67 percent, mainly driven by productivity improvements in agriculture and wholesale and retail trade. Taken together, productivity improvements in the services sector and intersectoral shifts towards the services sector explained 51 percent of the growth in per capita GDP between 2005 and 2013. Productivity increased substantially in manufacturing and construction as well, but their low employment base meant that their contribution to overall growth in per capita GDP remained modest (at four percent for manufacturing and eight percent for construction). In contrast to many other African countries, the expansion of employment in services in Ethiopia has not been associated with declining average productivity levels in services, suggesting ample potential for further employment creation going forward.

\section{Employment remains dominated by agriculture and non-wage work}

Despite the notable improvements since the turn of the century, employment outcomes for a large part of the Ethiopian population remain precarious. In 2013, over 70 percent of employed working-age Ethiopians still had their main occupation in agriculture, for the most part in smallholder farming on increasingly fragmented plots. Wage-employment in the nonfarm sector-the type of employment that tends to have the highest average earnings-accounted for 10 percent of employment. Self-employment in the nonfarm sector, mainly in small household-run enterprises or own-account subsistence activities (e.g. fetching water and firewood), accounted for 
19 percent of workers. Compared to men, women tend to be overrepresented in non-waged employment and underrepresented in paid employment (in 2013, eight percent of women had their main occupation in nonfarm wage employment, compared to 12 percent for men). Women also earn substantially less than men, a gap that is only partially explained by differences in endowments and job characteristics.

Figure 6: Most workers are engaged in agriculture and self-employment

(Share of workers by job category, 2013)

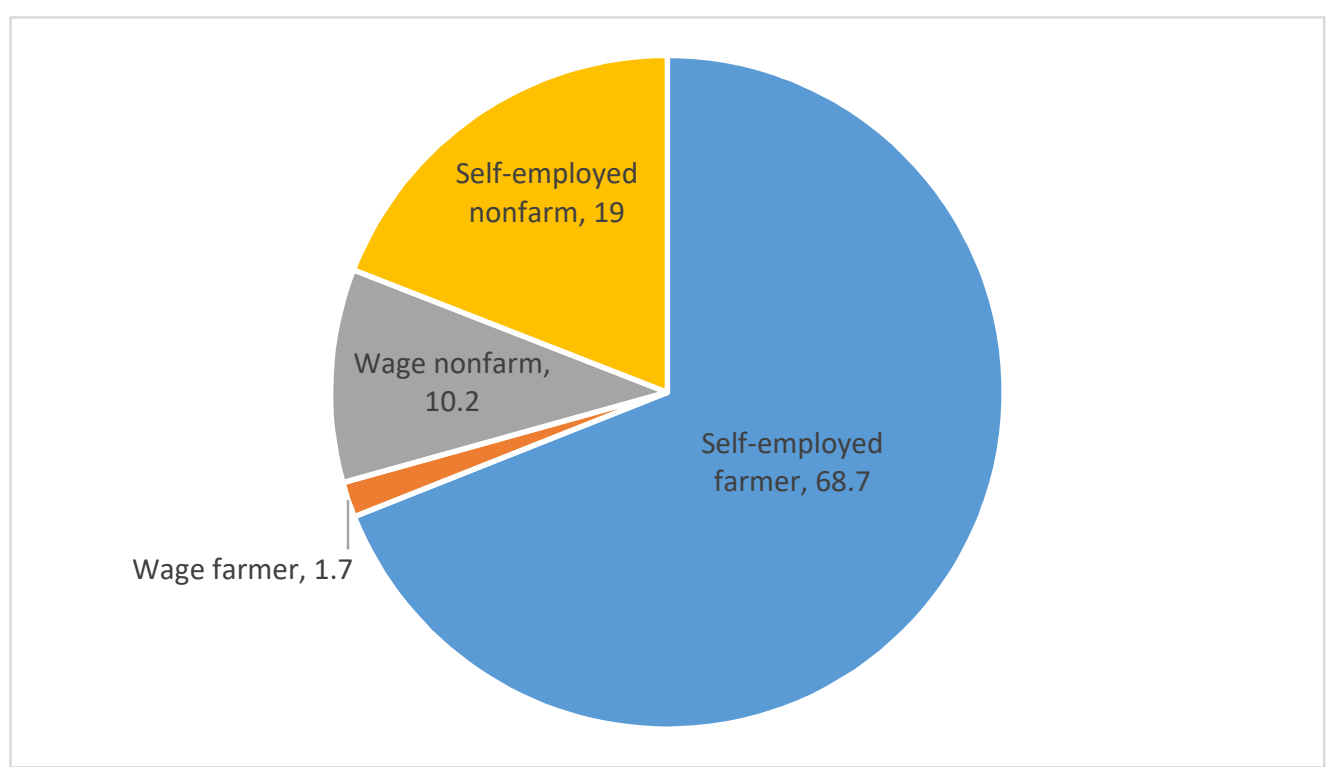

Source: LFS, 2013. World Bank staff calculations

The employment structure differs substantially between rural and urban areas. In rural areas, employment is dominated by agriculture and unpaid work-a pattern that did not discernibly change between 1999 and 2013. Nonfarm activities in rural areas remain limited (Figure 7), mainly related to low levels of connectivity and market access. Despite significant infrastructural investments, rural accessibility remains low, constraining the development of markets for nonfarm activity. Limited access to markets and low demand for goods and services are the most frequently cited constraints for nonfarm enterprise operators in rural areas. Urban areas look completely different, with wage-employment being the dominant type of work, followed by self-employment in small businesses. 
Figure 7: The employment structure differs considerably between rural and urban areas

(Share of workers by job category, 2013)

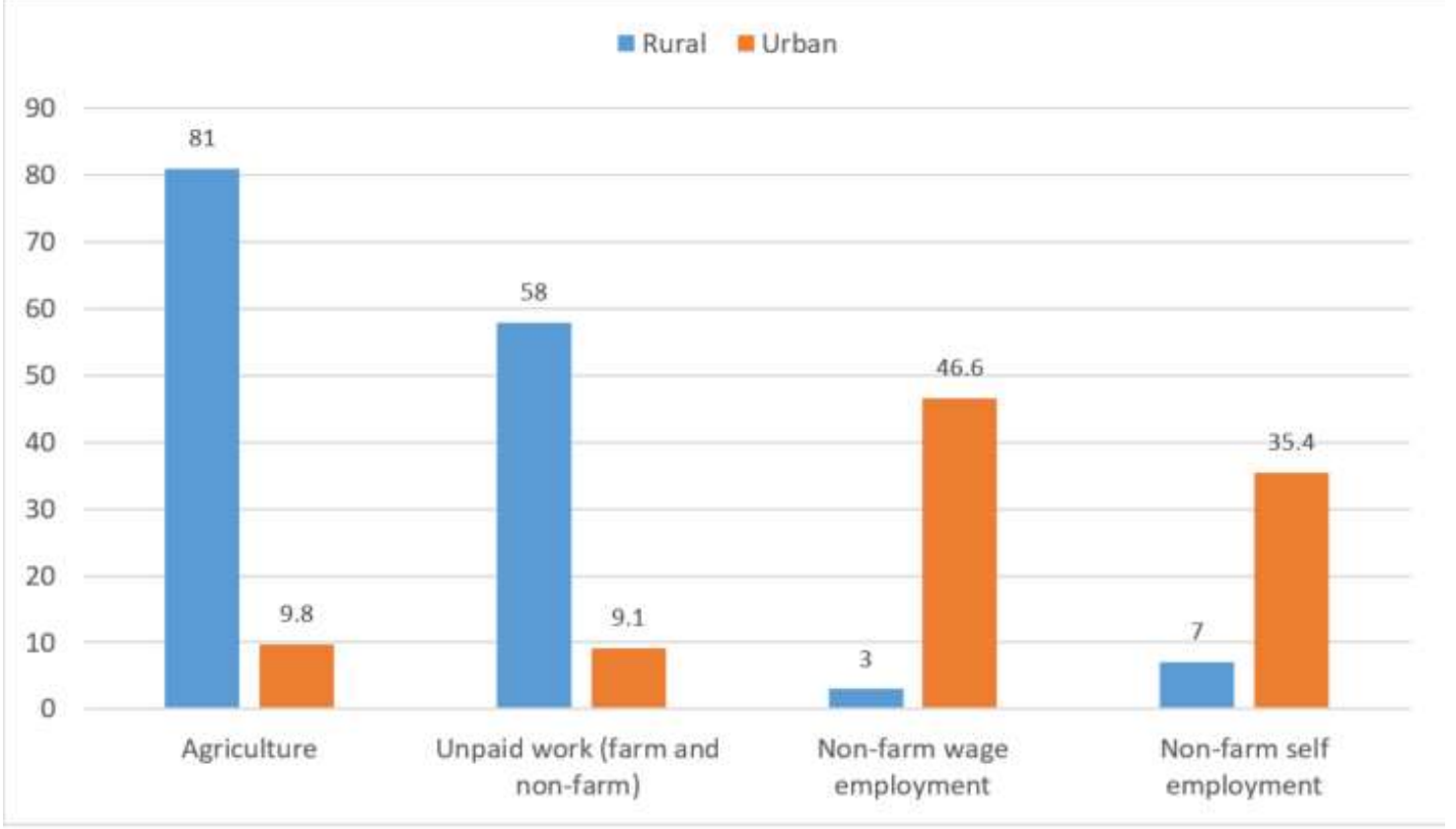

Source: LFS, 2013. World Bank staff calculations

\section{Youth employment improved, though rural youth are lagging}

Youth employment outcomes in Ethiopia improved between 1999 and 2013, in particular in urban areas. Youth unemployment in the 21 main cities dropped from 44 percent in 1999 to 26 percent in 2013, still higher than that of the overall population but the pace of decline has been faster for youth (Figure 8$)^{3}$. Half of young workers in urban areas are engaged in wage employment and have benefited from real wage growth. Urban youth also are relatively well-educated, with 25 percent having completed tertiary education (and many more still in the process of completing it), and only six percent never having been to school (Figure 9).

3 We focus on the 21 main cities because the rural-urban distinction in the LFS surveys is not consistent over time. In the 2007 Census, some previously rural clusters were reclassified as urban, which complicates the comparison between the 2013 LFS and the 2005 and 1999 LFS. 
Figure 8: Urban youth unemployment dropped sharply between 1999 and 2013

(Unemployment rate, relaxed definition)

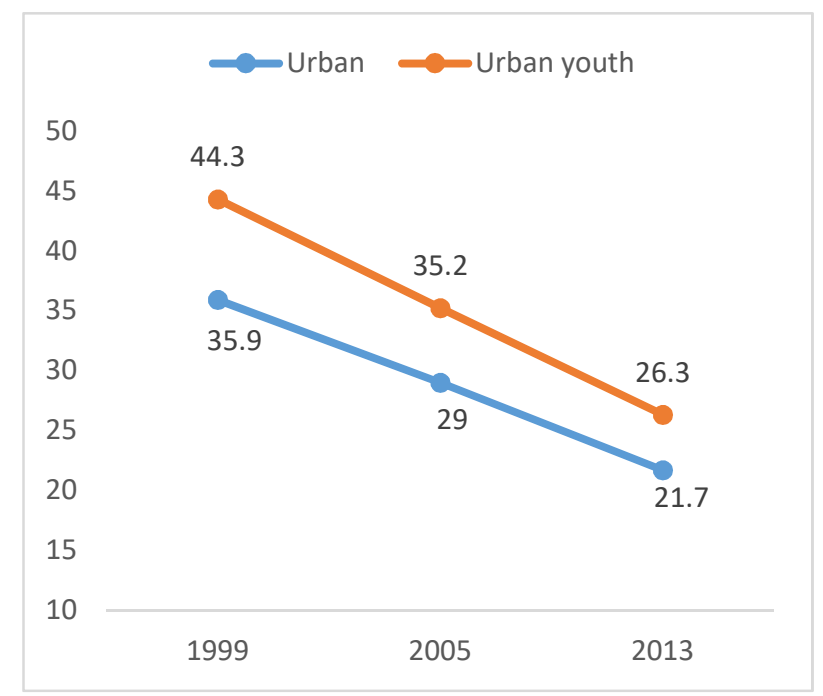

Note: To obtain consistency in urban definition across survey rounds, "urban" is defined as the 21 main cities in Ethiopia Source: LFS, 1999; 2005; 2013. WB staff calculations.
Figure 9: In contrast to urban youth, rural youth remain largely uneducated

(Highest level of education achieved, 2016)

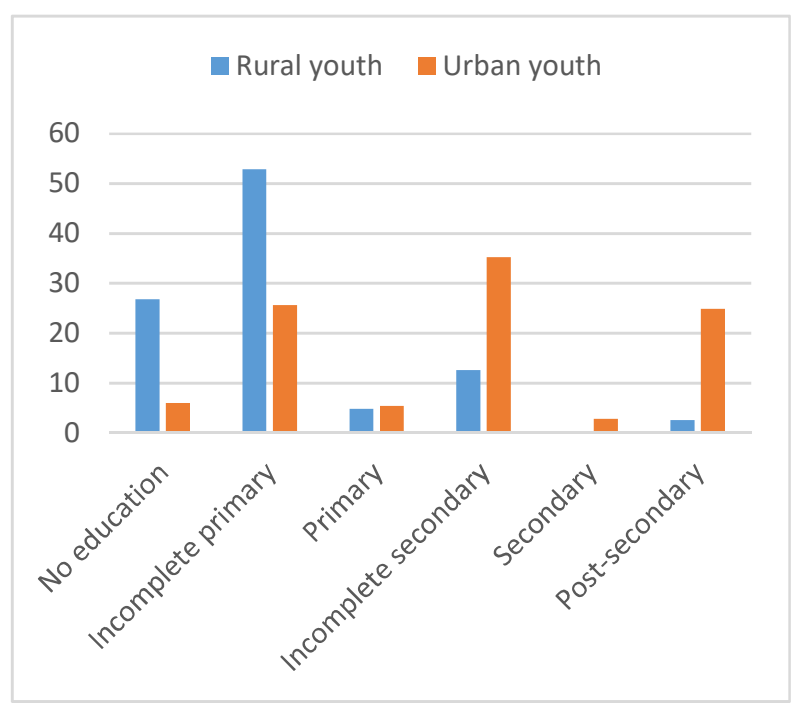

Source: DHS, 2016. WB staff calculations.

Compared to urban youth, youth in rural areas appear to have fared less well. In 2013, young workers in rural areas were mainly engaged in providing unpaid labor to their households, a pattern that did not change since 1999. The most notable change in rural employment structure was a decrease in the share of young men that are "independent farmers"-farmers who cultivate lands on which they have a title-presumably linked to the decreasing share of young men that have a land title of their own. Most worryingly though, rural youth remain largely uneducated. In 2016, 27 percent of rural 15-29-year-olds had never been to school, and close to 80 percent had not completed primary education (Figure 9). The school-to-work transition starts early in rural areas, with 34 percent of rural 11-to-12-year-olds combining school with work and over 20 percent being completely out-of-school. 
Figure 10: The employment structure of rural youth did not change much between 1999 and 2013

(Type of occupation of employed rural youth, 1999 and 2013 )

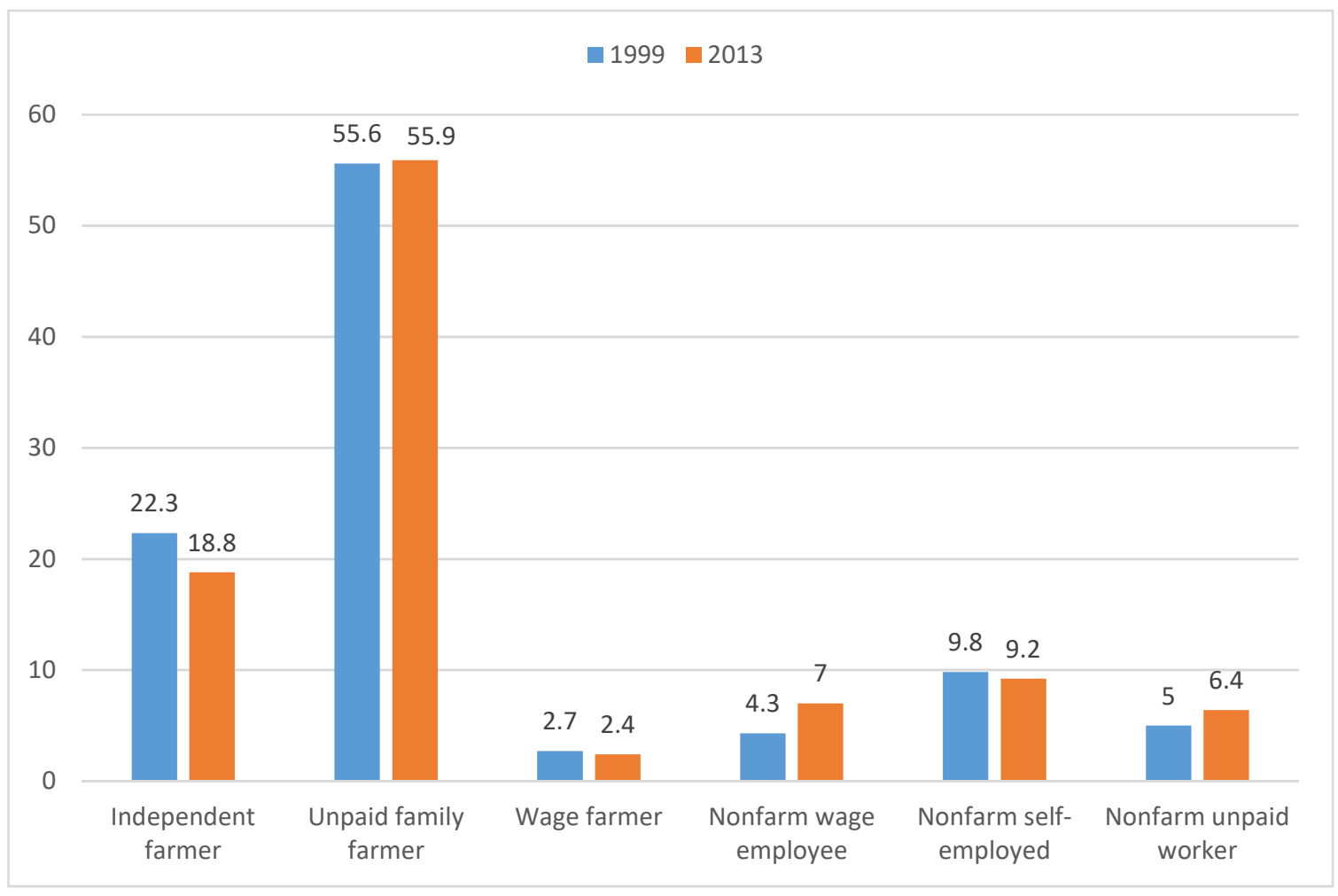

Source: LFS, 1999; 2013. World Bank staff calculations

While education levels of the youth, in particular in rural areas, remain too low, the role of higher levels of education in securing "good" employment has weakened ${ }^{4}$. While completing secondary education or more is still associated with a sharply higher likelihood of being formally wage-employed, mainly in the public sector, the association between attaining higher levels of education and obtaining a public-sector wage job has weakened between 2005 and 2013. Compared to 2005, better educated individuals in 2013 were more likely to be self-employed in the nonfarm sector and more likely to be unpaid household labor. Though the data do not allow establishing the reason behind this, it is possible that the supply of relatively higher-educated workers is growing faster than formal nonfarm wage-employment, pushing relatively better educated people into other forms of employment. Formal sector wage-employment grew by approximately 1.1 million between 2005 and 2013, while the number of secondary-or-higher educated individuals grew by 1.4 million.

While urban youth tends to be high up the political agenda in any country, the most pressing youth challenge Ethiopia faces today is in rural areas, where the majority of youth live. Employment outcomes in urban areas have been on a positive trend since 1999, and especially since 2005. Urban youth unemployment has dropped sharply, and the share of young urbanites with post-secondary education has more than six-folded (from four percent in 1999 to almost 25 percent in 2016). Rural youth in contrast remain largely uneducated and predominantly engaged in unpaid household labor. Though open unemployment in rural areas is low, 14 percent of rural

${ }^{4}$ We consider formal sector wage-employment as "good" employment. On average, earnings in formal sector wage-employment are higher than in other sector or employment types. 
youth are not in education, employment, or training (NEET), and this rises to 29 percent for uneducated rural youth (Figure 55). While in earlier times uneducated rural youth would transition into smallholder agriculture, this pathway is becoming less accessible due to increasing land constraints in certain parts of the country. To deal with this situation, the set of employment opportunities little-educated youths have access to will need to be expanded beyond agriculture ${ }^{5}$.

Figure 11: A sizable share of Ethiopia's youth is not in employment, education, or training

(Share of youth who are not in employment, education, or training, by region, sex and education)

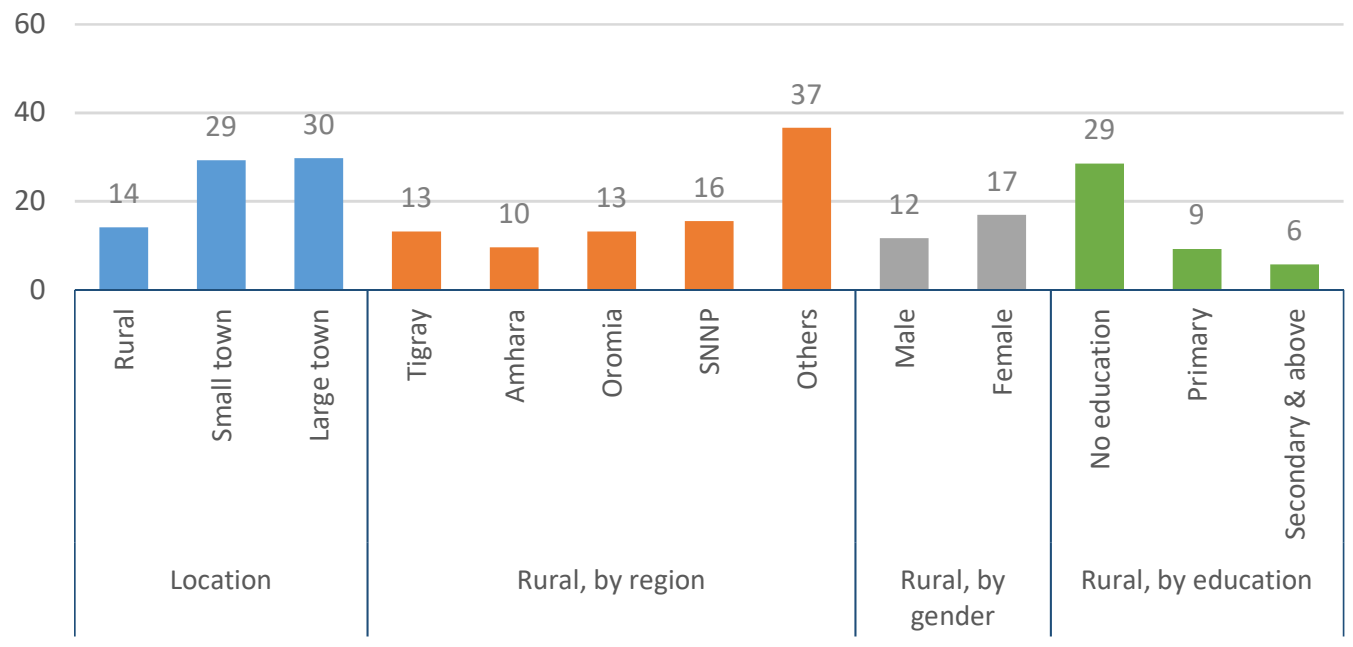

Source: ESS3.

\section{Improving youth employment outcomes}

The Government of Ethiopia has recently adopted a Rural Job Opportunity Creation Strategy laying out a framework for action on youth employment in rural areas. Successfully operationalizing the strategy will require interventions, improvements, and innovations in different sectors and dimensions. It will require attention to improving access to and completion of quality basic education and training to improve young people's productivity, both on and off the farm, while at the same time facilitating youth's access to productive assets, mainly land and finance. It will require strengthening rural-urban linkages and assessing the role that the more than 1,500 rural towns in the country can play in boosting the rural nonfarm economy and providing nonfarm livelihood diversification options. It will also require a critical review of the current employment strategies and interventions to assess whether they are effective and how they could be improved. Based on the analysis and qualitative research conducted for this study and the existing research on youth employment in Ethiopia and beyond, Table 1 summarizes important actions to improve youths' employment outcomes, both in the short and longer-run. These interventions should not be seen in isolation, but rather as complementary as part of a set of programs aiming to improve employment outcomes for young people in Ethiopia.

\footnotetext{
${ }^{5}$ The government of Ethiopia has adopted a Rural Job Opportunity Creation strategy with the objective to expand employment opportunities for youth in rural areas.
} 
Table 1: Potential actions to improve youth employment in Ethiopia

"Do now for now" "Do now for later"

Actions to affect current cohorts of Actions to affect future cohorts of youth

youth

1. Improve functioning of land rental markets to facilitate youths' access to land
Many rural youth still aspire to an agricultural livelihood but do not have access to (sufficient) land. Research shows that land rentals in Ethiopia increase overall productivity. A better-functioning land rental market could improve employment and increase agricultural output, and also act as a brake on distress migration.

2. Facilitate productive labor mobility

The limited structural transformation in employment has been driven by rural to urban migration. Research from Ethiopia and elsewhere show large private welfare effects from internal migration, both to rural areas or to towns and cities. As Ethiopia's cities and towns continue to grow and industrial parks are established, higher labor mobility can address the imbalances between where the jobs are and where the people are and speed up the structural transformation.

3. Facilitate access to finance

The qualitative research identified the lack of access to finance as one of the main obstacles to better employment in rural areas. MFI loans are all but inaccessible for rural youth from poor family backgrounds and youth did not consider the cooperative model of obtaining finance as an attractive option. For certain groups of youth, grants may be a better option than loans.

4. Facilitate the services sector
While education levels of rural youth remain low, urban youth are increasingly better educated. While the manufacturing agenda will create wage jobs for low-skilled people, unemployment in urban areas is highest for the secondary-educated. Creating wage employment for increasingly educated urban populations will require an increase in labor demand in services.

5. Improve basic education in rural In contrast to urban youth, rural youth areas productivity improvements in agriculture and their diversification to higher productivity nonfarm activities. Improving basic education in rural areas is an absolute priority. 
6. Towns and rural-urban linkages
The rural nonfarm economy in Ethiopia is small, mainly due to remoteness and lack of market access. There are over 1,500 towns (less than 50,000 people) in Ethiopia, and infrastructure investments in and around towns to create bigger agglomerations and better link them with the rural hinterlands has the potential to substantially increase employment opportunities for the surrounding populations while also strengthening backward linkages through increased demand for agricultural products.

7. Fertility and family planning
Due to persistently high fertility rates, Ethiopia's working-age population is projected to grow by 2 million per year in the coming 10 years. This not only adds to the employment challenge, but also means that the education system needs to absorb a larger number of children in every subsequent year. A critical review of the National Population Policy is warranted to look into the causes of the stalling fertility rates. 


\section{Chapter I. A bird's eye view of employment and growth in Ethiopia}

\section{Introduction}

This chapter provides a brief overview of growth and employment trends in Ethiopia between 1999 and 2016. Section 2 focuses on the longer-term trends between 1999 and 2013 and presents standard labor market indicators based on the 1999, 2005, and 2013 Labor Force Surveys (LFS). Section 3 presents the short-term trends based on the 2012, 2014, and 2016 Ethiopian Socioeconomic Surveys (ESS) while Section 4 decomposes Ethiopia's economic growth to get a better understanding of the relation between employment and growth. The final section concludes.

\section{Headline employment indicators}

\section{A "typical" labor market, that has been improving over time}

Focusing on headline indicators, Ethiopia's labor market is largely typical of a low-income country. In 2013, the date of the last LFS, the employment rate was high (81 percent), unemployment was low (five percent using the relaxed definition) but underemployment far higher (22 percent), and almost three-quarters of employment was in agriculture (Table 2) ${ }^{6}$. As usual in largely rural low-income countries, the low unemployment rates reflect the need to work to earn a living rather than strong labor demand. Urban unemployment was high (17 percent), while rural unemployment was negligible at two percent ${ }^{7}$. The share of working-age population in total population stood at 52 percent in 2013, reflecting a young population with a high dependency rate of 92 percent (meaning that there are 92 dependents for each 100 people of working-age) ${ }^{8}$.

Table 2: Key labor market indicators, 1999-2005-2013

\begin{tabular}{lcccc}
\hline & 1999 & 2005 & 2013 & Change \\
\hline Working-age population as a fraction of total population & 49.6 & 49.6 & 52.1 & 2.5 \\
Labor force participation rate & 83.0 & 86.2 & 85.7 & 2.6 \\
Unemployment rate - relaxed def. & 8.4 & 5.6 & 5.2 & -3.2 \\
Employment-to-working-age-population ratio (last 7days) & 76.1 & 81.4 & 81.2 & 5.2 \\
Employment-to-working-age-population ratio (last 12 months)* & 77.8 & 91.7 & 80.8 & 3 \\
Agricultural employment (\% of total employment) & 77.9 & 77.7 & 73.8 & -4.2 \\
Waged employment in non-agricultural sectors (\% of non-agricultural employment) & 31.8 & 35.2 & 38.6 & 2.7 \\
Waged employment in non-agricultural sectors (\% of total employment) & 7 & 7.8 & 10.1 & 3.1 \\
Waged employment in private formal sector (\% of total employment)** & 1.6 & 1.6 & 2.1 & 0.5 \\
\hline
\end{tabular}

6 The definitions employed in this study are based on the ILO international standards pre-2013 (13th ICLS). An individual is considered employed if he worked for at least 1 hour in any productive activity, including waged work, production of goods and services for sale, unpaid family work, etc. According to the ILO relaxed definition of unemployment and in line with the standards of the Ethiopian CSA, an individual is classified as unemployed if he did not work at least 1 hour in the reference week and he was available for work in the reference period. The third criterion "seeking work", i.e. someone actively looked for work in a specified recent period, identifies together with the first two the unemployed according to the ILO strict definition of unemployment. Following the practice in Ethiopia, we will not use this strict definition. Underemployment is defined as working less than 35 hours per week but wanting to work more. See Box 1 for the exact definitions.

7 According to the Urban Employment and Unemployment Survey, urban unemployment was 17 percent in 2016, the same as in 2013 (NPC, 2017).

8 In the 2016 DHS, the working-age population accounted for 49 percent of total population. 


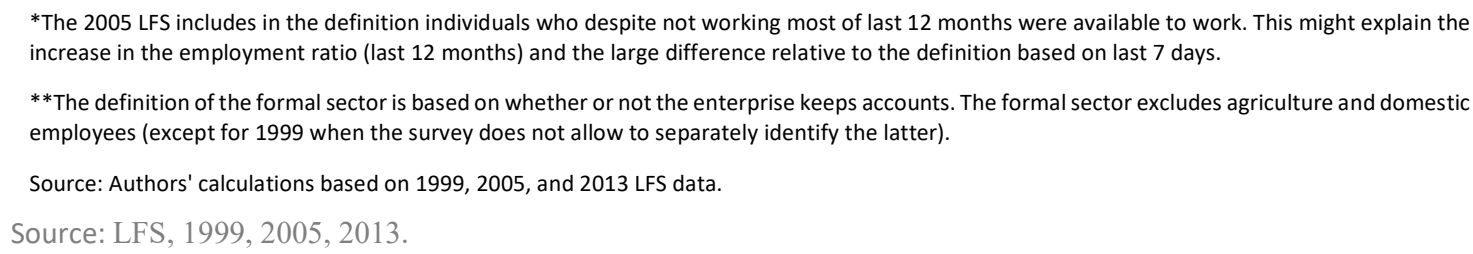

\section{Box 1 Labor Market Definitions}

\begin{tabular}{|c|c|}
\hline Labor market & $\begin{array}{l}\text { The place where labor services are bought, sold, and exchanged. The labor market } \\
\text { comprises waged and salaried workers and their employers, but also nonwage family } \\
\text { enterprise workers and the self-employed (who implicitly "sell" their labor to } \\
\text { themselves), who make up the largest share of workers in Ethiopia. }\end{array}$ \\
\hline Labor force & The sum of the employed and unemployed of working age. \\
\hline Employed & $\begin{array}{l}\text { A working-age individual who performed any form of work for at least one hour in the } \\
\text { week prior to the survey. }\end{array}$ \\
\hline Employment rate & $\begin{array}{l}\text { The share of working-age individuals who are employed. Also called the employment- } \\
\text { to-working-age-population-ratio. }\end{array}$ \\
\hline $\begin{array}{l}\text { Labor force } \\
\text { participation rate }\end{array}$ & $\begin{array}{l}\text { The share of working-age individuals who participate in the labor force (i.e. are either } \\
\text { employed or unemployed). }\end{array}$ \\
\hline Unemployed & $\begin{array}{l}\text { A working-age individual who did not work at least one hour in the reference week, } \\
\text { but was available for work and actively looked for work in a specified recent period. }\end{array}$ \\
\hline $\begin{array}{l}\text { Unemployed - relaxed } \\
\text { def. }\end{array}$ & $\begin{array}{l}\text { A working-age individual who did not work at least one hour in the reference week, } \\
\text { but was available for work. This definition is used in Ethiopia. }\end{array}$ \\
\hline Inactive & A working-age person who is neither employed nor actively looking for work. \\
\hline Underemployed & $\begin{array}{l}\text { A working-age individual who is employed, but works fewer than } 35 \text { hours per week } \\
\text { and would like to work more. }\end{array}$ \\
\hline NEET & A working-age person who is not in employment, education, or training. \\
\hline Waged worker & A worker who has declared being paid a waged or salary for his or her work. \\
\hline Employer & $\begin{array}{l}\text { A person who is said to be in charge of a household nonfarm enterprise or a household } \\
\text { farm that hires paid labor from outside the household. }\end{array}$ \\
\hline Self-employed & $\begin{array}{l}\text { A person who works for oneself, making income from the profits of one's activity. } \\
\text { Because the distinction can be blurred in a household between self-employment and } \\
\text { unpaid family workers who contribute to a household activity, the report considers as } \\
\text { self-employed all workers reporting to be self-employed or unpaid family workers on } \\
\text { a household farm or household enterprise. }\end{array}$ \\
\hline Informal sector & $\begin{array}{l}\text { Any private sector employment, excluding employment in agriculture, in private } \\
\text { households (domestic worker), and in producers' cooperatives, where the individual } \\
\text { declares himself/herself to be working in an enterprise that keeps books of account. } \\
\text { For the sake of comparability across survey rounds, this definition excludes criteria } \\
\text { based on whether the enterprise has a license or whether the production unit produces } \\
\text { mainly for the market. }\end{array}$ \\
\hline $\begin{array}{l}\text { Working-age } \\
\text { population }\end{array}$ & The population between 15 and 64 years of age. \\
\hline Youth & The population between 15 and 29 years of age \\
\hline Young worker & A person between 15 and 29 years of age who is employed \\
\hline $\begin{array}{l}\text { Earnings from waged } \\
\text { work }\end{array}$ & Total cash and in-kind payments as declared in the survey. \\
\hline Low-earner & $\begin{array}{l}\text { An employed individual whose earnings are below the national poverty line of ETB } \\
3,781 \text { in December } 2010 \text { prices. }\end{array}$ \\
\hline
\end{tabular}

Between 1999 and 2013, standard labor market indicators improved. Unemployment (relaxed definition) decreased from eight to five percent, while the employment rate and labor force participation increased (over the whole 1999-2013 period - Table 2). The share of working-age population in total population also increased (and is projected to increase further), which may be 
a boon for growth if sufficient jobs can be created. Urban areas in particular have been performing well: Urban unemployment dropped from 36 percent in 1999 to 29 percent in 2005 and 22 percent in 2013, on the back of strong growth in nonfarm employment from a low base (Figure 12). The growth in nonfarm employment was concentrated post-2005, resulting in a modest decrease in agriculture's share of employment (Table 2). Despite the strong increase, nonfarm wage employment remained relatively rare, with only 10 percent of Ethiopian workers working for wages in the nonfarm sector in 2013. The formal private sector remained small in 2013, accounting for a mere two percent of employment.

Figure 12: Unemployment decreased substantially in urban Ethiopia

(Unemployment rate-relaxed definition, 1999-2005-2013)

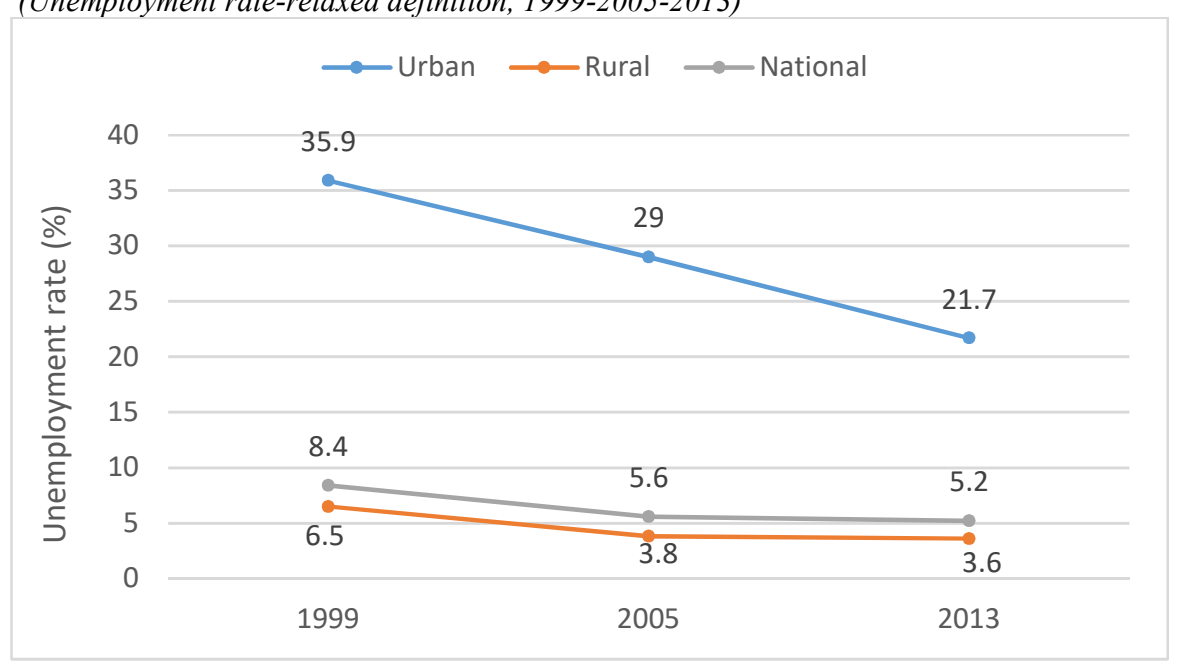

Note: “Urban" includes the 21 largest cities and towns in Ethiopia. Source: LFS, 1999; 2005; 2013.

\section{Large differences across gender, age and space}

Large differences hide behind national figures. Across space, the main difference is between urban and rural areas and, within rural areas, between Afar and Somali regions at the one hand and the other regions at the other. In 2013, the employment rate was as high as 86 percent in rural areas compared to 63 percent in urban areas (Figure 13). In urban areas, employment rates were lower in large cities (54 percent) than small towns (66 percent $)^{10}$. Unemployment rates were seven times higher in urban than in rural areas (LFS, 2013). There are also important regional disparities. While the largely agricultural regions of Oromiya, Amhara, Tigray, SNNPR and Benishangul Gumuz have high employment rates (around 80 percent or higher), pastoral Somali has a fairly low employment rate (69 percent). Unemployment is low in all rural regions, except for pastoral Afar, where unemployment approaches eight percent (Figure 14). In all mainly or uniquely urban regions (Addis Ababa, Dire Dawa and Harari), unemployment declined sharply, especially since 2005.

9 The reported unemployment figures are different from the ones in the official report of the 2013 LFS due to a change in the definition of urban and areas following the 2007 census. To obtain a consistent comparison over time, we defined 21 cities as urban and all the rest as "rest of the country". The "rest of the country" category is largely rural, but does include a number of towns that would be classified as urban in 2013 but as rural in previous LFS rounds. 10 ESS3, 2016. 
Figure 13: The employment rate is lowest in urban areas

(Employment rate by region, 1999-2005-2013)

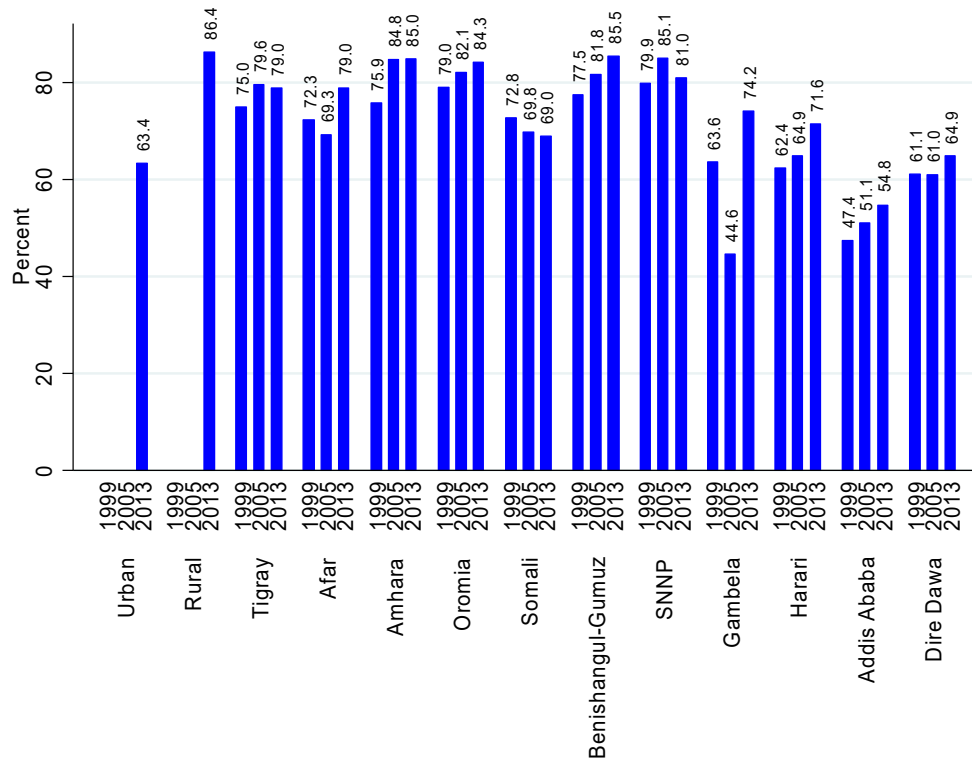

Source: LFS, 1999, 2005, 2013;
Figure 14: Unemployment is highest in Addis, Dire Dawa and Harari (Unemployment rate by region, 1999-2005-2013)

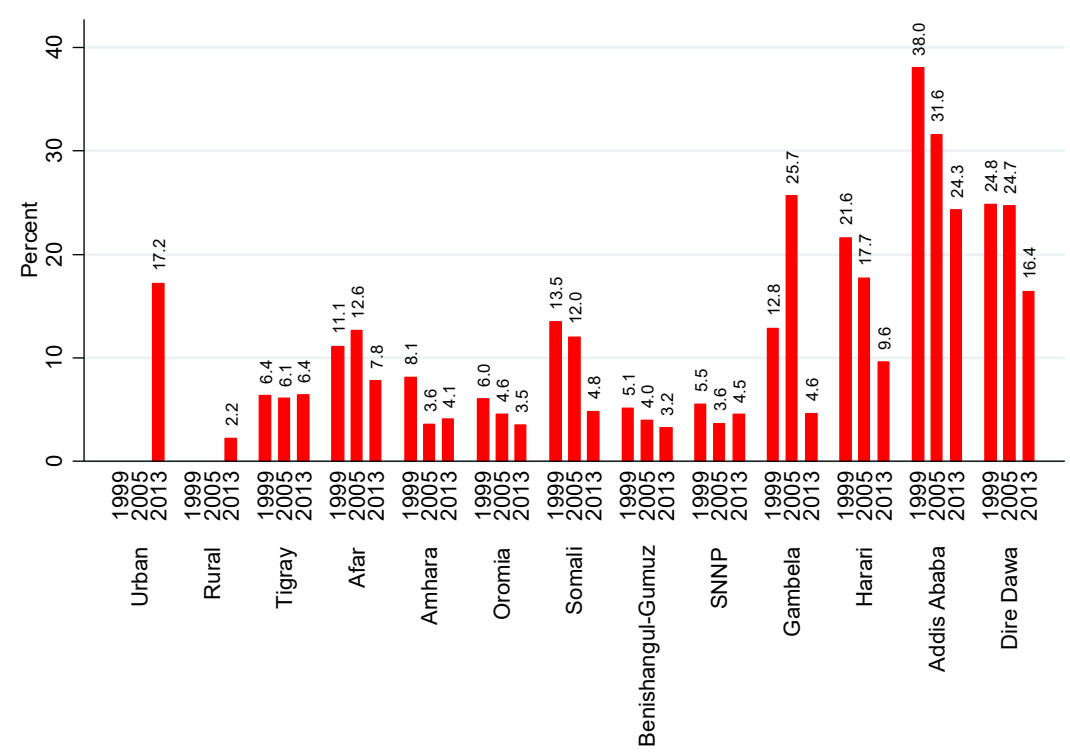

Source: LFS, 1999, 2005, 2013 
Labor market indicators are worse for women and youth. Youth (15 to 29 years-old) have lower labor force participation rates, lower employment rates, and higher unemployment rates than older persons (30 to 64 years-old). Younger workers also are more likely to earn wages that are below the national poverty line (the so-called low-earnings rate) ${ }^{11}$ : In 2013, 29 percent of young workers earned below the poverty line, compared to 13 percent of older workers (Table 3 ). Women also have systematically worse outcomes than men: In each age group, women's employment rates and labor force participation rates are lower, and unemployment higher, than those for men. Female employment rates and labor force participation are particularly low in Somali region and in the urban areas of Addis, Dire Dawa and Harari. In urban areas, 27 percent of young women were unemployed in 2013 (rising to 32 percent in Addis). For young women who do work (for wages), one-third earn below the poverty line (LFS, 2013).

\section{Recent trends}

The Ethiopian Socioeconomic Surveys (ESS) suggest that recent employment trends have largely been positive. The employment rate in rural areas has consistently increased since 2012 (from 77 percent of the working-age population in 2012 to 85 percent in 2016), while employment rates in small towns and large cities have increased since 2014 (Figure 15). The employment rate increased for both men and women and across all regions, with the exception of the "other" regions (which groups the regions of Afar, Gambella, Somali, and Benishangul Gumuz) ${ }^{12}$. Employment rates improved across all education categories. Though the broad-based increase in employment rates is a positive sign, it says nothing about the quality of employment and how this has evolved in recent years.

Figure 15: A broad-based increase in employment rates since 2012

(Employment rate by location, region, and education)

a) By Location

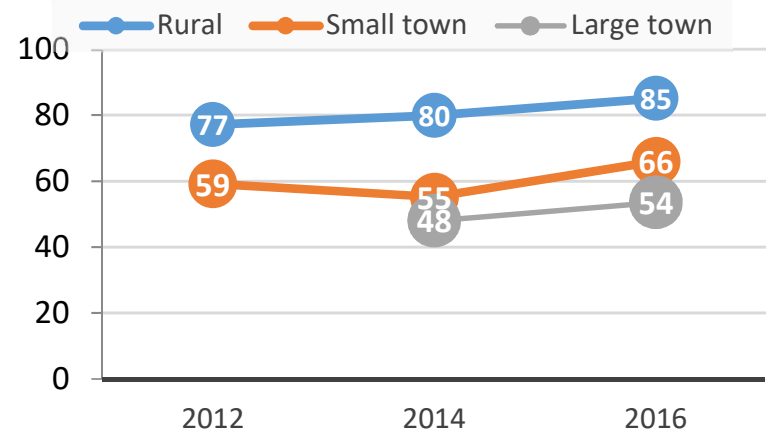

b) By region in rural areas and small towns

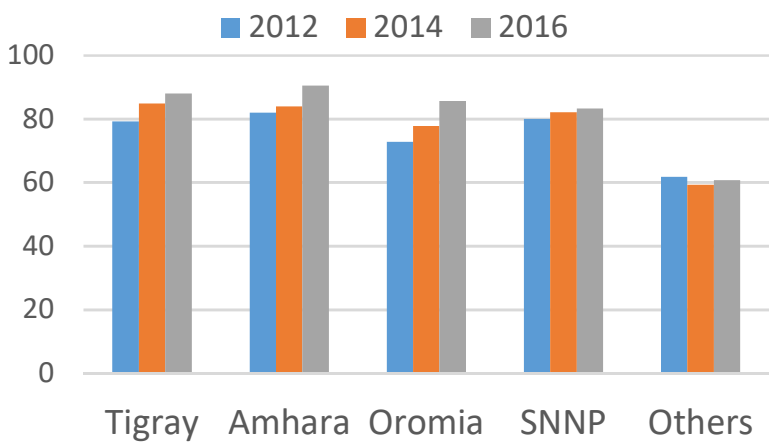

c) By gender in rural areas and small towns

d) By education in rural areas and small towns

11 The national poverty line amounts to ETB 3,781 per adult per year in December 2010 prices. For this exercise, the poverty line has been updated to 2013 prices and compared with the wage distribution. Note that the calculation of the low-earnings rate only refers to workers who work for wages, which is only 12 percent of all Ethiopian workers.

${ }^{12}$ The ESS is not representative at the regional level for the smaller Regional States. 

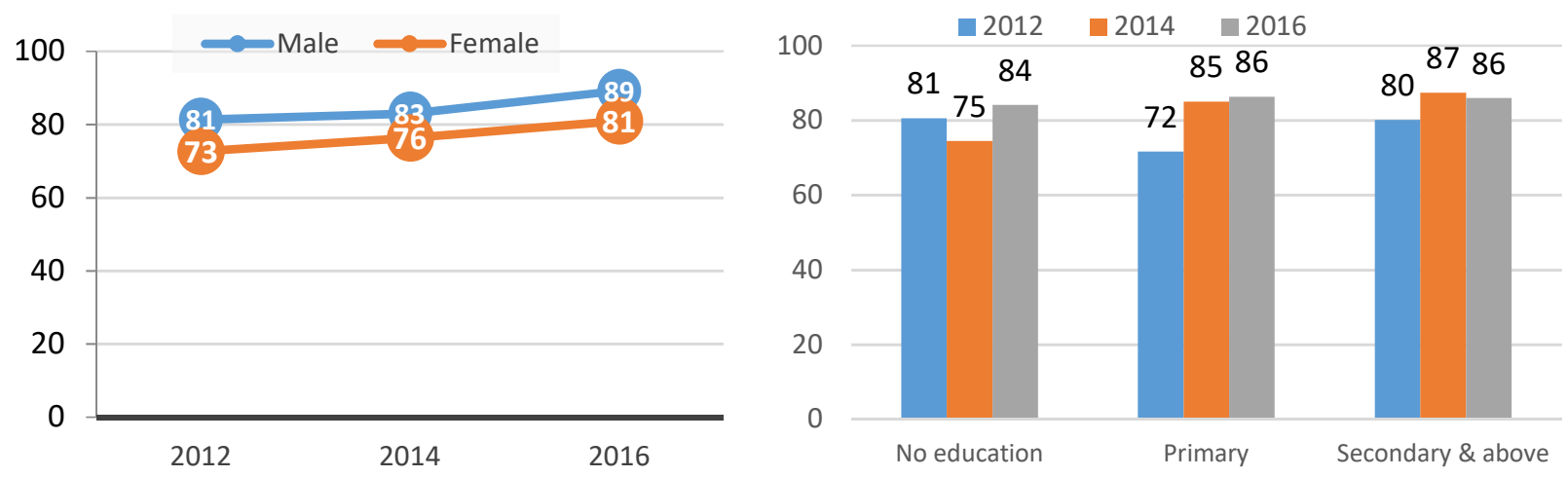
Table 3: Key labor market indicators disaggregated by age and sex, 2013

\begin{tabular}{|c|c|c|c|c|c|c|c|c|c|}
\hline & & \multicolumn{2}{|c|}{$\begin{array}{l}\text { Labor force } \\
\text { participation }\end{array}$} & \multicolumn{2}{|c|}{$\begin{array}{l}\text { Employment } \\
\text { ratio }\end{array}$} & \multicolumn{2}{|c|}{$\begin{array}{l}\text { Unemployment } \\
\text { rate }\end{array}$} & \multicolumn{2}{|c|}{$\begin{array}{c}\text { Low-earnings } \\
\text { rate (waged } \\
\text { workers) }\end{array}$} \\
\hline & & $15-29$ & $30-64$ & $15-29$ & $30-64$ & $15-29$ & $30-64$ & $15-29$ & $30-64$ \\
\hline \multicolumn{2}{|l|}{ Total } & 81.9 & 89.6 & 76.3 & 86.5 & 6.9 & 3.5 & 28.7 & 13.3 \\
\hline \multirow{7}{*}{ Gender } & Male & 85.6 & 97.0 & 81.6 & 95.4 & 4.7 & 1.6 & 24.3 & 10.9 \\
\hline & Female & 78.5 & 82.4 & 71.3 & 77.7 & 9.2 & 5.7 & 34.6 & 19.5 \\
\hline & Tigray & 81.2 & 87.7 & 74.7 & 83.4 & 8.0 & 4.9 & 26.1 & 14.9 \\
\hline & Afar & 84.0 & 87.5 & 76.8 & 81.5 & 8.6 & 6.9 & 29.5 & 17.8 \\
\hline & Amhara & 86.1 & 90.9 & 81.3 & 88.5 & 5.6 & 2.7 & 32.4 & 19.5 \\
\hline & Oromia & 84.3 & 90.8 & 79.9 & 89.2 & 5.2 & 1.8 & 29.8 & 14.4 \\
\hline & Somali & 63.8 & 80.4 & 59.1 & 78.0 & 7.4 & 2.9 & 17.9 & 5.9 \\
\hline \multirow[t]{6}{*}{ Region } & $\begin{array}{l}\text { Benishangul } \\
\text { Gumuz }\end{array}$ & 84.3 & 93.3 & 80.6 & 91.5 & 4.4 & 1.9 & 16.2 & 9.0 \\
\hline & SNNP & 80.1 & 89.8 & 74.9 & 87.4 & 6.5 & 2.7 & 30.7 & 17.3 \\
\hline & Gambela & 67.7 & 89.6 & 62.8 & 87.5 & 7.2 & 2.4 & 9.9 & 4.8 \\
\hline & Harari & 69.8 & 88.3 & 60.8 & 82.1 & 12.9 & 7.0 & 14.5 & 7.4 \\
\hline & Addis Ababa & 64.6 & 81.0 & 46.5 & 64.0 & 28.0 & 21.0 & 24.4 & 6.0 \\
\hline & Dire Dawa & 70.5 & 84.8 & 56.1 & 73.8 & 20.4 & 13.0 & 27.8 & 9.9 \\
\hline
\end{tabular}

Source: LFS, 1999, 2005, 2013.

Though employment rates increased, the share of the working-age population who are not in employment, education, or training (NEET) remained largely unchanged. Compared to the unemployment rate, the NEET indicator has several properties that make it useful to identify vulnerable and/or excluded groups in the labor market (Box 2) ${ }^{13}$. In rural areas, NEET remained stable at about 12 to 13 percent of working-age population between 2012 and 2016, in towns it increased non-significantly from 23 percent to 26 percent, while in cities it remained largely unchanged at 30 percent (between 2014 and 2016 - Figure 17) ${ }^{14}$. On a regional level, NEET increased in SNNP and "other" regions, decreased in Oromiya, and remained fairly stable in Tigray and Amhara.

\section{Box 2 NEET vs Unemployed}

In many low-income countries, unemployment rates are low at the national level but substantially higher among better educated people in urban areas. Ethiopia is no exception: The 2013 unemployment rate was higher in urban (17 percent) than in rural areas (two percent), and higher among secondary - and tertiary-educated labor force participants (16 percent and nine percent, respectively) than among the uneducated (less than three percent).

$13 \mathrm{~A}$ more mundane reason to use NEET and not the unemployment rate is that the ESS surveys do not allow calculating unemployment, as there is no information on whether out-of-work people are willing to work and actively seeking employment.

14 It may be counterintuitive that NEET is remaining stable or even increasing while employment rates are increasing too. This can be explained by the increasing number of non-employed working-age persons that are not in school. 
The ILO-defined unemployment rate is prone to misinterpretation in low-income countries, as a naïve view on the numbers would suggest that the relatively highly educated in urban areas (often from better-off families) are in fact the most vulnerable group on the labor market. Given the large cohorts of young and uneducated workers in rural areas who are underemployed in unpaid household labor or idle without looking for work, such a view would be mistaken.

"Not in employment, education, or training" (NEET) may better capture the extent of vulnerability, marginalization, and exclusion in little-developed labor markets. While unemployment and NEET are correlated, there are several important differences in characteristics that makes NEET a valuable addition to standard employment indicators. To illustrate, Figure 16 compares NEET and unemployment in Ethiopia based on the 2013 LFS. Relative to unemployment, NEET is much more prevalent among uneducated people and in rural areas. While women have higher unemployment rates than men, their rates of NEET are much higher still, highlighting the particular constraints faced by women to participate in the labor market ${ }^{15}$. Overall, while fewer than two million work-age Ethiopians were unemployed in 2013, more than five million were NEET, most of them in rural areas (three million) and most of them uneducated (almost four million NEET people did not complete primary school).

Figure 16: Relative to unemployment, NEET is more prevalent in rural areas and among the uneducated

(Incidence of NEET and unemployment, 2013)

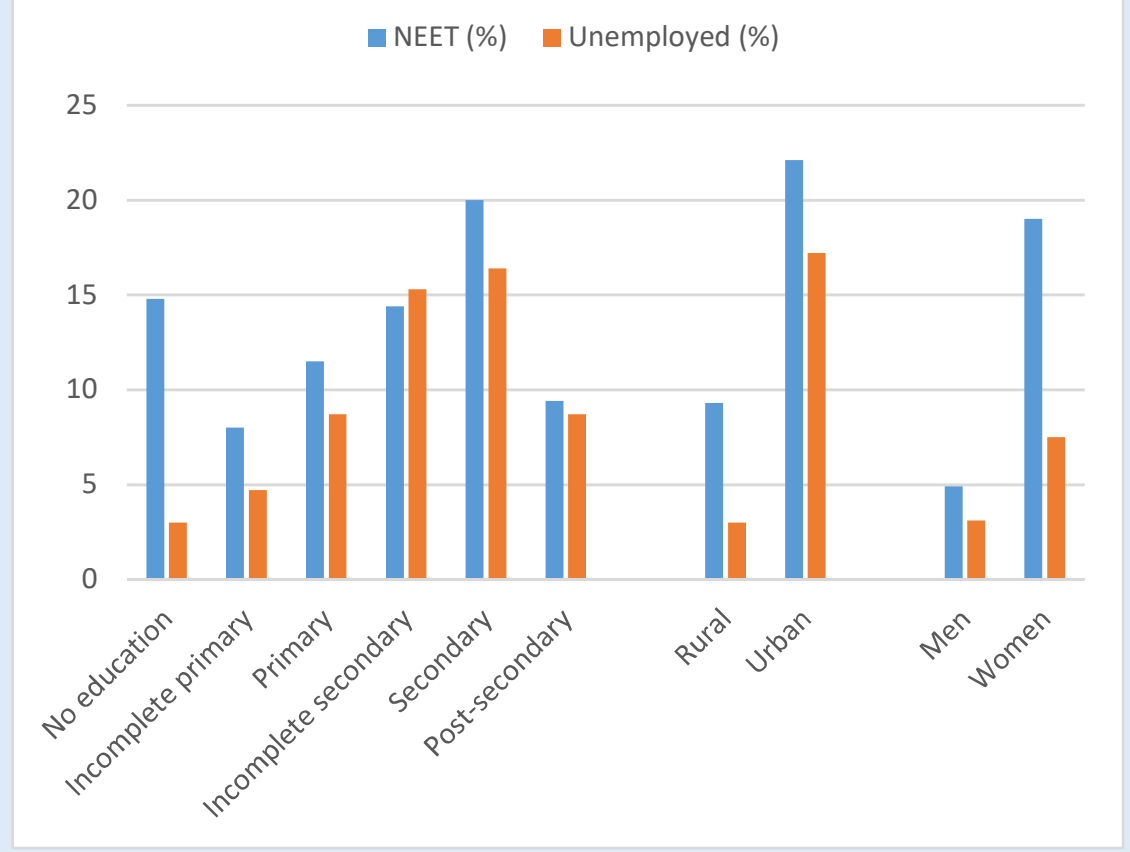

Source: LFS, 2013

NEET and unemployment thus beset partly overlapping, partly different groups. Relative to unemployment, NEET is higher in rural areas, among women, and among the uneducated, which reflects the main merit of the NEET indicator: Its capacity to identify groups that are most vulnerable and at higher risk of exclusion from the labor market. NEET is particularly applicable to youth, as it measures a state of complete idleness (in the sense of not being employed nor investing in skills to improve future employability) at a crucial time when skills and work experiences should be accumulated. According to ILO: "Because they are neither improving their future employability through investments in skills nor gaining experience through employment, NEETs are particularly at risk of both labor market and social inclusion" ILO, 2013).

\footnotetext{
${ }^{15}$ Obvious constraint for women's participation into the labor market, especially in urban areas, are traditional household roles and the absence of affordable child care. This is manifested in the NEET figures: While the incidence of NEET in urban areas does not differ much between single women (17 percent) and single men (15 percent), it amounts to 42 percent for married women and 7 percent for married men. Once women get married and start a family, they appear to face large constraints in staying engaged in the labor market. Unexpectedly though, NEET is higher among married women without children than among married women with children (in urban areas).
} 
Figure 17: NEET remained largely unchanged

(Share of working-age population not in employment, education, or training, 2012-2016)

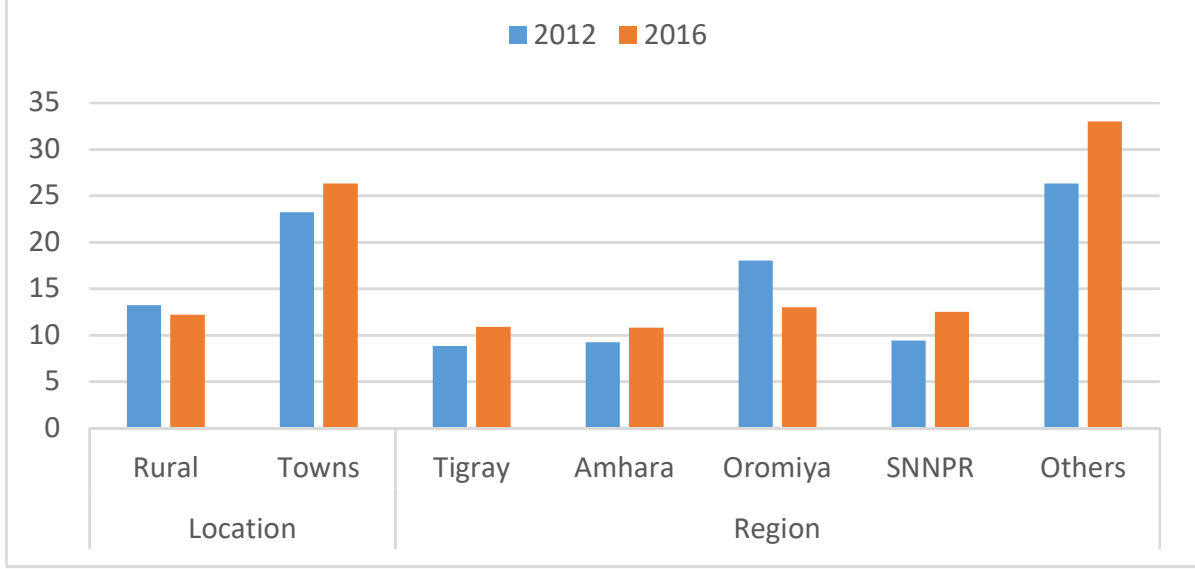

Source: ESS, 2012; 2016.

\section{Employment, productivity, and economic growth}

Looking back over the past decade, Ethiopia's economic growth has been accompanied by strong growth in employment. Between 2005 and 2013, employment grew by 34 percent, marginally faster than the growth in working-age population, leading to the decrease in unemployment mentioned earlier (Table 4). Agriculture absorbed the bulk of new workers between 2005 and 2013, while the service sector created most employment outside of agriculture (70 percent of new nonfarm employment between 2005 and 2013 was in the service sector - Table 5). Within services, "other activities" (which include community and family oriented services, hotels and restaurants, financial services) and wholesale and retail were the main job creators. Employment in construction and manufacturing increased by 0.37 million workers each (Table 5).

Table 4: Employment, productivity and population, 2005-2013

\begin{tabular}{lccc}
\hline \hline & $\mathbf{2 0 0 5}$ & $\mathbf{2 0 1 3}$ & \% change \\
\hline GDP (value added) (in 1000000's) & 282,424 & 630,720 & 123.3 \\
Total population & $63,200,000$ & $80,400,000$ & 27.2 \\
Total population of working age & $31,400,000$ & $41,900,000$ & 33.4 \\
Total number of employed & 25,497 & 34,033 & 33.5 \\
GDP (value added) per capita & 4,467 & 7,845 & 75.55 \\
Output per worker & 11,077 & 18,533 & 67.31 \\
Share of population of working age & 49.68 & 52.11 & 2.43 \\
\hline \hline
\end{tabular}

Note: GDP numbers exclude taxes and subsidies. All monetary values in 2010/11 ETB. Source: LFS, 2005, 2013, and national GDP estimates from the National Planning Commission 
Table 5: Employment by sector ('1000s), 2005-2013

\begin{tabular}{lcccc}
\hline \hline & $\mathbf{2 0 0 5}$ & $\mathbf{2 0 1 3}$ & \% change & \% contribution \\
\hline Agriculture & 19,806 & 25,089 & 26.7 & 61.9 \\
Mining, Utilities & 106 & 348 & 227.6 & 2.8 \\
Manufacturing & 1,360 & 1,730 & 27.2 & 4.3 \\
Construction & 420 & 795 & 89.4 & 4.4 \\
Wholesale \& Retail & 1,472 & 2,206 & 49.9 & 8.6 \\
Transport \& Communications & 843 & 798 & -5.3 & -0.5 \\
Other service activities & 1,491 & 3,067 & 105.7 & 18.5 \\
Total & $\mathbf{2 5 , 4 9 7}$ & $\mathbf{3 4 , 0 3 3}$ & $\mathbf{3 3 . 5}$ & $\mathbf{1 0 0 . 0}$ \\
\hline \hline
\end{tabular}

Note: last column shows the contribution of the sector to overall employment growth between 2005 and 2013. Source: LFS, $2005,2013$.

Average labor productivity increased substantially between 2005 and 2013. Output per worker increased by 67 percent, mainly driven by productivity improvements in agriculture and wholesale and retail trade (Table 6). Output per worker increased substantially in manufacturing and construction as well, but their low employment base meant that their contribution to overall growth in labor productivity remained modest at six percent for manufacturing and seven percent for construction (Table 6). Despite the large increase, output per worker in manufacturing remained low in 2013, higher only than in the agricultural sector (Figure 18). The shift in employment from agriculture to the nonfarm sector since 2005, mainly towards services, has nevertheless been important, accounting for 22 percent of the growth in labor productivity. More substantial shifts towards nonfarm employment have the potential to further increase labor productivity, adding to the rate of economic growth. The inter-sectoral component can mainly be accounted for by increased employment shares in construction, wholesale and retail trade, and other service activities.

Table 6: Decomposition of changes in total output per worker into within-sector changes and intersectoral shifts

Contribution to Change in Contribution to Change in Total Output per Worker Total Output per Worker $(\%)$

\begin{tabular}{lcc}
\hline & & \\
Agriculture & $2,048.1$ & 27.5 \\
Mining, Utilities & -120.2 & -1.6 \\
Manufacturing & 442.7 & 5.9 \\
Construction & 555.5 & 7.4 \\
Wholesale \& Retail & $1,183.6$ & 15.9 \\
Transport \& Communications & 640.8 & 8.6 \\
Other Activities & $1,059.5$ & 14.2 \\
Inter-sectoral shift & $1,646.0$ & 22.1 \\
\hline Total change in output per worker & $\mathbf{7 , 4 5 6 . 0}$ & 100.0 \\
\hline
\end{tabular}

Source: LFS, 2005, 2013; National GDP estimates from the National Planning Commission 
Figure 18: Labor productivity increased sharply in most sectors

(Output per worker by sector, 2005-2013, 2010/11 ETB)

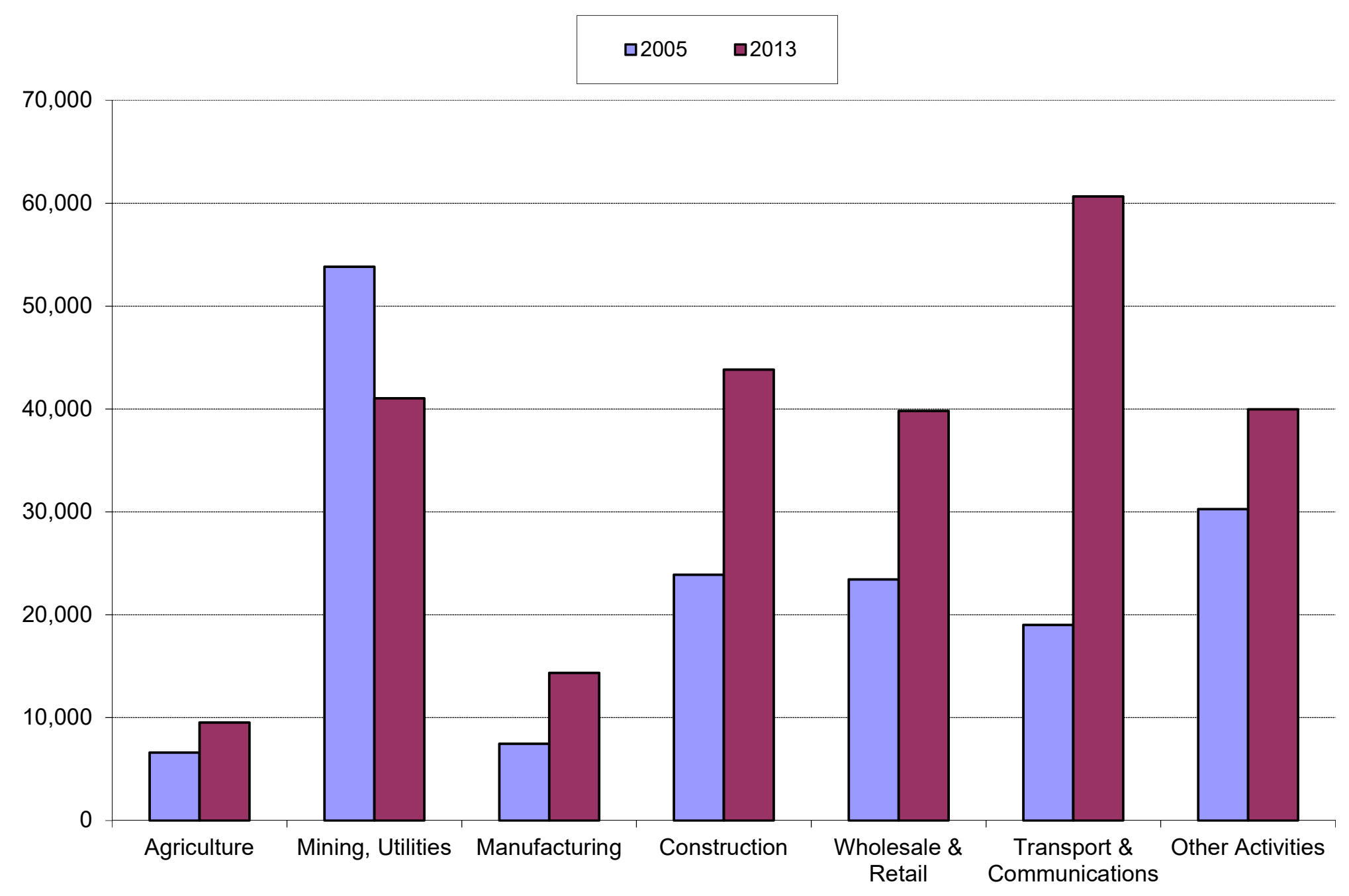

Note: "Urban" includes the 21 largest cities and towns in Ethiopia. Source: LFS, 1999; 2005; 2013. 
In an accounting sense, 90 percent of the increase in per capita GDP between 2005 and 2013 can be explained by improvements in labor productivity. Productivity improvements in agriculture accounted for 25 percent of the increase in per capita GDP, while the intersectoral shift contributed another 20 percent (Figure 19). The different services sectors explained 35 percent of the growth in per capita GDP, mainly commerce. The construction and manufacturing sector each accounted for seven and five percent of the growth in GDP per capita, respectively. The remaining growth in per capita GDP can be explained by demographic changes, that is, the increasing share of working-age population in total population.

Though merely descriptive, this decomposition exercise nevertheless has some substantive implications. First, though the intersectoral shift out of agriculture has been small, it nevertheless accounted for 22 percent of the growth in GDP per capita. This can be explained by much higher average labor productivity in the nonfarm sector, which has led to large static efficiency gains. Sustaining and strengthening the shift of labor out of agriculture through, for instance, facilitating internal migration or strengthening urban pull factors, would help sustain economic growth going forward. The second implication relates to the job creation potential of the services sector. This sector has created most non-farm employment between 2005 and 2013, and despite the influx of workers average output per worker in the sector has increased. This highlights the considerable potential of the service sector in Ethiopia in creating jobs for a rapidly growing workforce and in sustaining the structural transformation of employment. The service sector is however highly constrained (Box 3). 
Figure 19: Agriculture, wholesale and retail, and the intersectoral shift contributed most to GDP per capita growth

(Contribution of changes in within-sector output per worker and intersectoral shifts to the change in GDP per capita between 2005 and 2013)

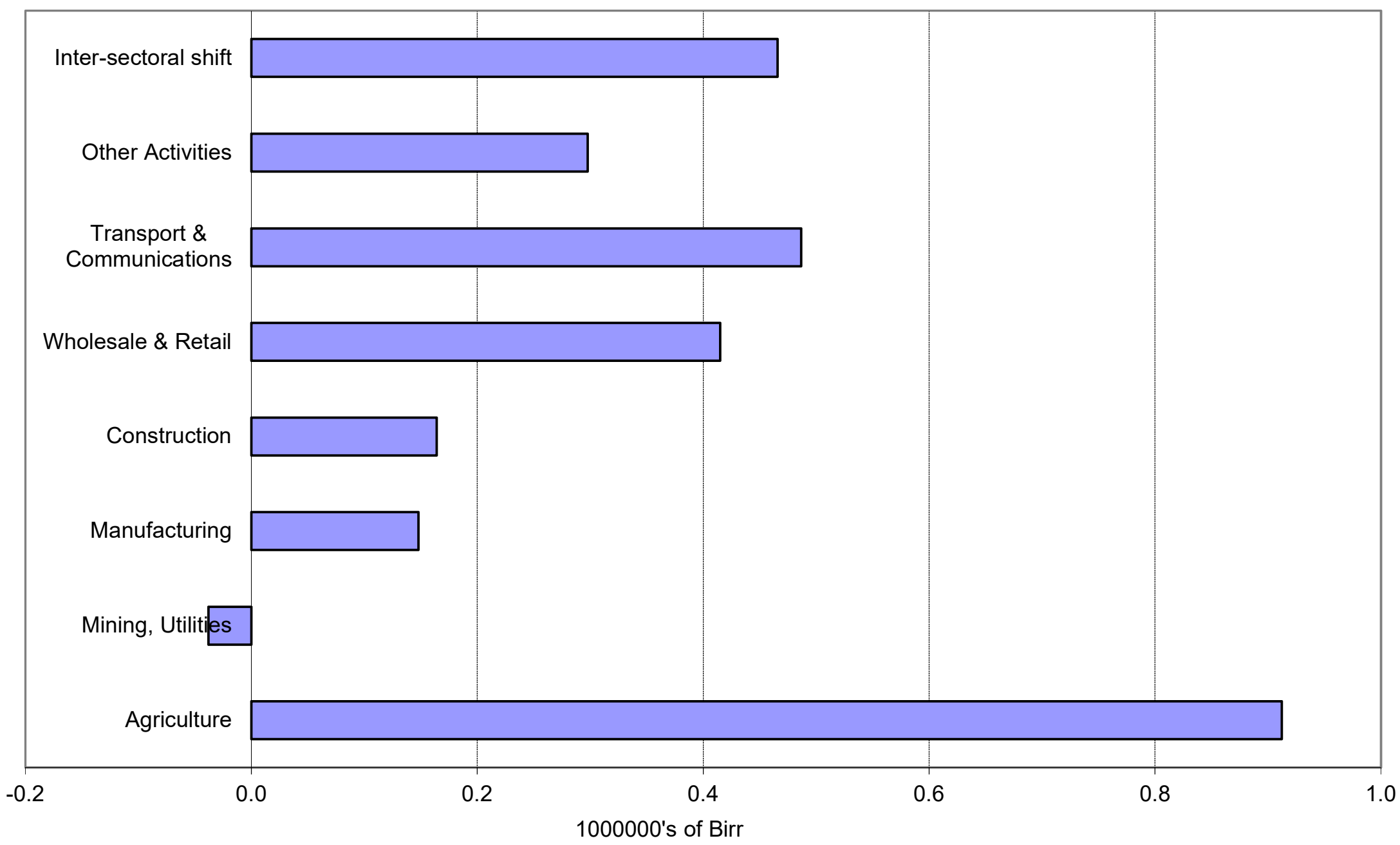

Source: LFS, 2005; 2013. National GDP estimates 


\section{Box 3}

\section{Credit constraints could be holding back job creation in Ethiopia's}

services sector

Formal private-sector firms in Ethiopia are credit-constrained. According to the World Bank's 2015 Enterprise Surveys (ES), demand for credit in Ethiopia's private sector firms is high, with 60 percent of firms in the sample having applied for a loan (Figure 20). This high demand suggests that most firms see opportunities to expand and that lack of investment opportunities is not a binding constraint. Of all firms that demanded a loan however, roughly two-thirds failed to obtain one, resulting in a high share of firms that are credit-constrained ${ }^{16}$. Though creditconstraints are universal, service firms are more likely to be constrained than manufacturing firms: Of those firms that indicated demand for credit, 42 percent of firms in the service sector were credit-constrained compared to 50 percent in manufacturing.

Figure 20: Demand for credit in Ethiopia's private sector is high

(Share of firms that are credit-constrained, by country)

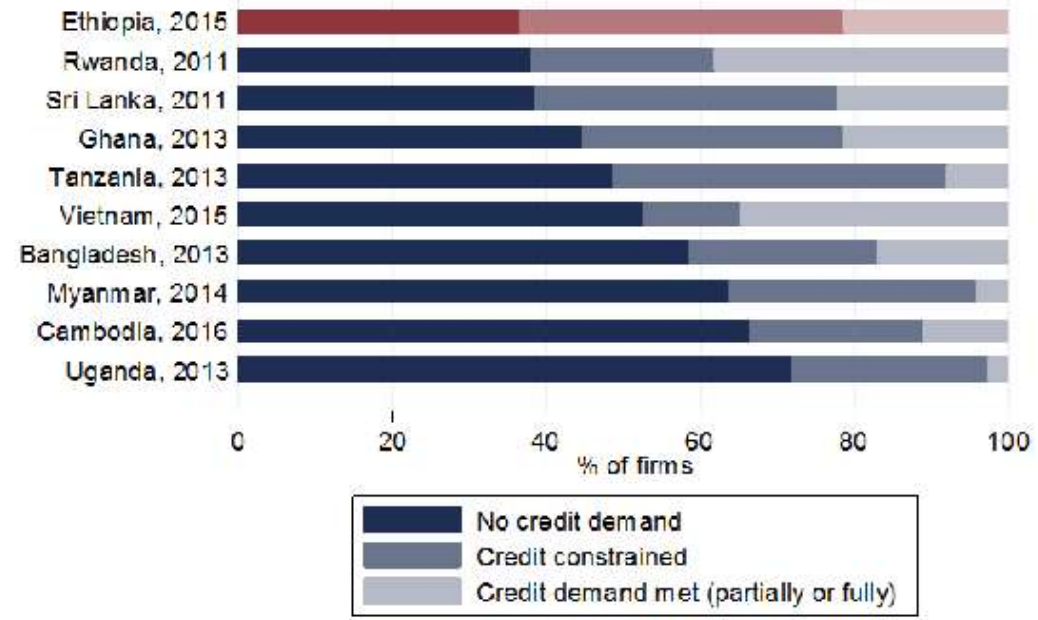

Source: ES, 2015.

Credit constraints in the service sector have increased since 2011, while they have eased among manufacturing firms. The share firms in the service sector whose credit demand was met (i.e. obtained a loan) decreased slightly between 2011 and 2014, while in the manufacturing sector this share more than doubled. These trends match the perceptions of managers: The share of managers perceiving access to finance as the main obstacle increased from 30 percent to 50 percent among services firms and decreased from 30 percent to 19 percent in manufacturing. Small services firms in particular have become more credit-constrained. Over 60 percent of service firms with less than 10 employees were credit-constrained in 2014, up from about 40 percent in 2011 (Figure 22). While still substantial, credit constraints eased for medium-scale service firms (10 to 49, while large services firms almost faced no credit constraints whatsoever by 2014. Demand for loans was very low among large service firms, likely because they have other means of financing investments.

Figure 21: Small services firms became more credit-constrained

(Share of services firms that are credit-constrained, 2010 and 2014)

16 Credit constraints are defined as in Bigsten et al (2013). Please consult Annex 1 for more details. 


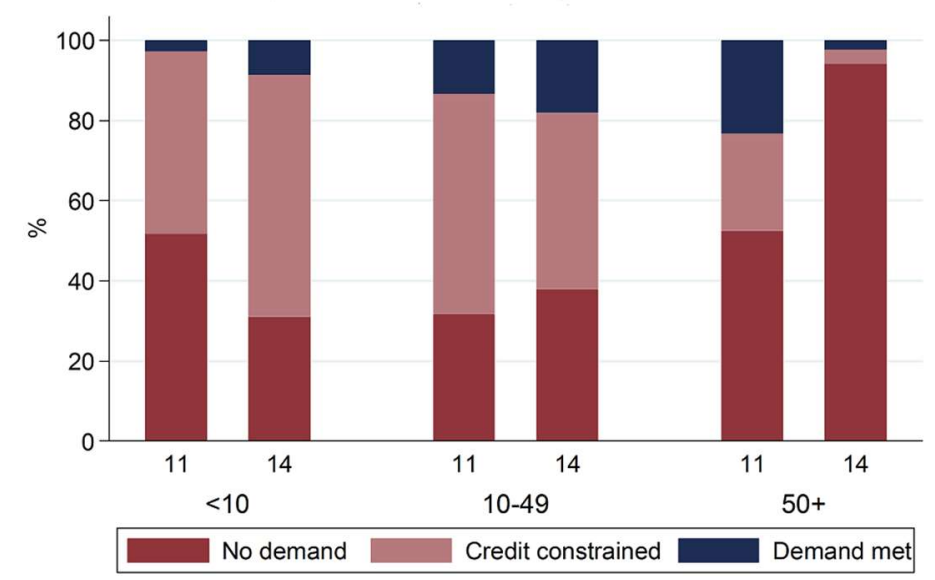

Source: ES, 2011; 2015.

The mere fact that services firms are highly credit-constrained does not necessarily mean that these constraints are binding. To explore whether credit constraints are holding back job creation, Figure 22 summarizes the results of a regression of employment growth on an indicator for being credit-constrained and a set of control variables ${ }^{17}$. Conditional on demand, obtaining a loan is associated with a significant increase in employment in the service sector, suggesting that expanding access to credit may have significant employment effects. The estimated effects are economically significant and suggest an increase in employment by 12 to 32 percent for firms with fewer than 25 employees and 19 to $27 \%$ for firms with more than 25 employees, depending on whether weights are employed in the estimation. Confidence bands around point estimates for large firms tend to be wider as the number of observations used in the estimation is lower. As a result, only the estimates for small firms are significantly different from zero in both specifications. There is no evidence for an effect of credit constraints on employment growth for manufacturing firms (Figure 22 ).

Dynamics in the service sector have played a major role in Ethiopia's economic growth and job creation over the past decade $^{\mathbf{1 8}}$. Services created the bulk of jobs in the nonfarm sector and growth in output per worker in the service sector accounted for close to 40 percent of growth in per capita GDP between 2005 and 2013. The sector's contribution to overall value added is now greater than that of agriculture and sustaining this momentum can be a key element of a strategy aimed at creating employment in the short- to medium-run. While manufacturing has seen comparable rates of growth in labor productivity, the sector is too small to make a significant contribution to employment growth in the short-run. A more balanced sectoral provision of credit may have substantial employment pay-offs in the short-to-medium term, especially for secondary-educated youth in urban areas, who currently experience the highest unemployment rates.

17 See Annex 1 for the details of the analysis.

18 A more elaborate analysis of the importance of the services sector for Ethiopia's economy can be found in World Bank, 2016. 
Figure 22: The employment effects of removing credit constraints are higher in the services sector

(Effect of removing credit constraints for firms with credit demand - point estimates and confidence bands)

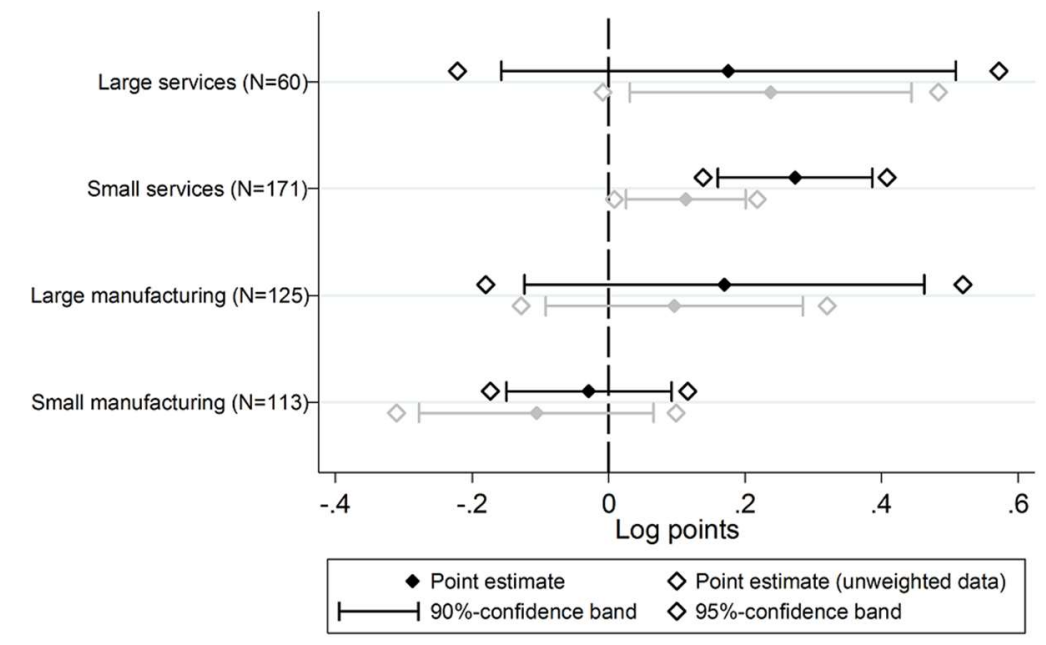

Note: The figure depicts estimates and 90\%- and 95\%-confidence bands from regressions of log employment and log sales per workers on an indicator variable of being unconstrained in terms of credit. The regressions include a number of controls (Annex 1). Results in gray indicate results based on unweighted regressions. Source: ES, 2015.

\section{Conclusions}

Standard labor market indicators in Ethiopia have improved since 1999. The unemployment rate dropped, mainly driven by a strong increase in nonfarm employment in cities since 2005, and the employment share of agriculture modestly declined. The positive trends seem to have persisted in recent years, as witnessed by a continued increase in employment rates. The share of workingage people in Ethiopia who are not in employment, education, or training, a measure of exclusion from both the labor market and the educational system, stagnated over the past four years at around 16 percent, and is especially high in cities at 30 percent.

\section{Growth in average labor productivity accounted for 90 percent of growth in GDP per capita} between 2005 and 2013. Growth in output per worker in the services sector was the main contributor to overall economic growth. While labor productivity also increased in manufacturing and construction, the employment share of these sectors was still too small to make significant contributions to GDP growth. The shift out of agriculture, although small, contributed substantially to the growth in labor productivity through static efficiency gains. The service sector has potential for sustained job creation going forward-a crucial feature given the rapidly expanding labor forcebut is heavily credit-constrained, even more so than manufacturing firms. 


\section{Chapter II. A profile of workers and jobs, then and now}

\section{Introduction}

This chapter focuses on individual employment dynamics and changes in the employment structure in Ethiopia between 1999 and 2016. The chapter starts by describing the recent employment situation based on the 2013 LFS and 2016 ESS. Whenever possible, we use the most recent data (the 2016 ESS) to sketch the current profile of workers and jobs in Ethiopia. Whenever the ESS lacks data on a certain indicator, we revert to the 2013 LFS. After profiling the current characteristics of workers and jobs, Section 3 examines the main trends since 1999. The final section concludes.

\section{A snapshot of workers and jobs}

\section{A large, young, and relatively unskilled labor force}

Despite marked improvements over the past 17 years, Ethiopia's labor force remains lowskilled. In 2016, 78 percent of the labor force had not completed primary education, and only seven percent completed secondary education or more (Figure 23). These low levels nevertheless represent substantial progress since 1999: The share of the labor force that never went to school dropped from 72 percent in 1999 to 43 percent in 2016, while the share with post-secondary education increased from one to five percent. As a result of the expansion in access to education in the recent decade, education outcomes are substantially better for young labor market participants than for older generations: In 2016, 57 percent of workers aged 30 or over had never been to school, compared to 25 percent of young labor force participants (15 to 29-years-old). Conversely, 21 percent of young labor force participants attained more than primary education, compared to nine percent of older generations. 
Figure 23: Despite progress, the labor force remains largely unskilled

(Share of labor force participants by educational attainment, 1999-2005-2013-2016)

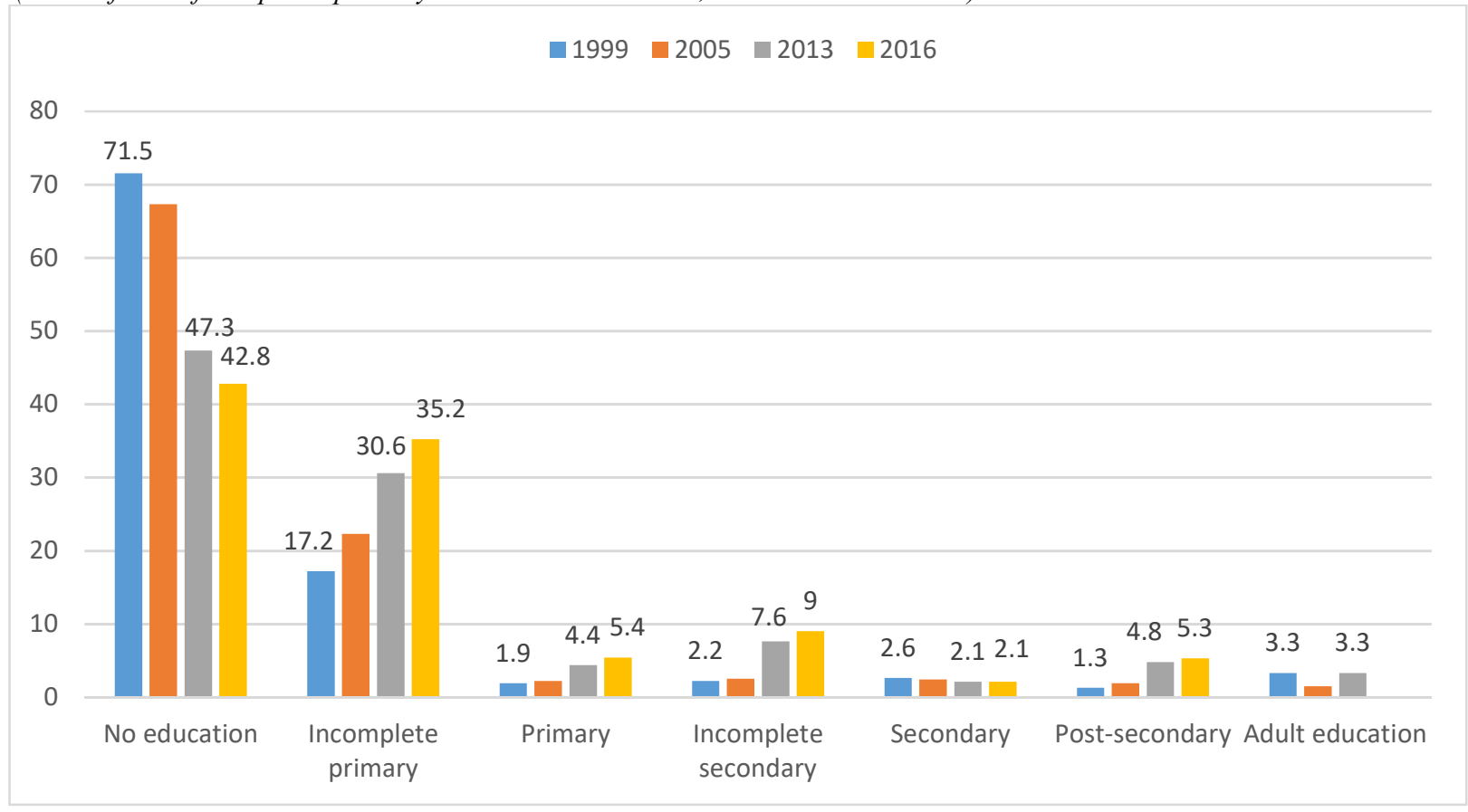

Source: LFS, 1999; 2005; 2013; ESS, 2016;

Employment dominated by agriculture and self-employment

Agriculture provides employment to the bulk of Ethiopian workers. In 2013, 70 percent of workers had their main occupation in agriculture, mainly as self-employed workers on household farms (Figure 24) ${ }^{1920}$. As a primary occupation, working for wages on other people's farms ("wage farmer" in Figure 24) is rare, accounting for just below two percent of employment. Selfemployment in the nonfarm sector, mainly in household-run enterprises or own-account subsistence activities (e.g. fetching firewood), accounted for 19 percent of workers ${ }^{21}$. 10 percent of workers were wage employed in the nonfarm sector (Box 4). Overall, self-employment accounted for almost 90 percent of all employment in Ethiopia in $2013^{22}$.

19 The LFS questionnaire distinguishes between "self-employed" and "unpaid family workers". For a household farm and a household business, the head of household is considered self-employed while the other household members also working on the farm or in the business are considered unpaid family workers. Given that establishing each worker's exact role in a household farm or enterprise is not possible with the LFS data, we will pool the self-employed and the unpaid family workers in one category, called the self-employed. 20 The 2016 ESS does not allow to determine a worker's main job. As a result, these figures are based on the 2013 LFS.

${ }^{21}$ Given that the category of employers (people employing other people for a wage) is so small ( 0.4 percent), we do not include them in the graphs.

22 Water and firewood fetching is an important activity for women in Ethiopia, and depending on how this activity is classified the share of agriculture in employment will differ. In 2013, 20 percent of employed women in Ethiopia had their main occupation as collectors of water and firewood. Looking at the industrial classification (ISIC) of this occupation, about 46 percent of water and firewood collectors were classified under "agriculture, forestry, and fishing", 15 percent under "activities of households as employers of domestic personnel", and 32 percent as "undifferentiated service-producing activities of private households for own use". Reclassifying all water and firewood collectors as unpaid farm labor, as we suspect was done in the 1999 and 2005 LFS, would mean the share of agriculture in employment amounted to 73.8 percent in 2013 
Figure 24: Most workers are engaged in agriculture and self-employment

(Share of workers by job category, 2013)

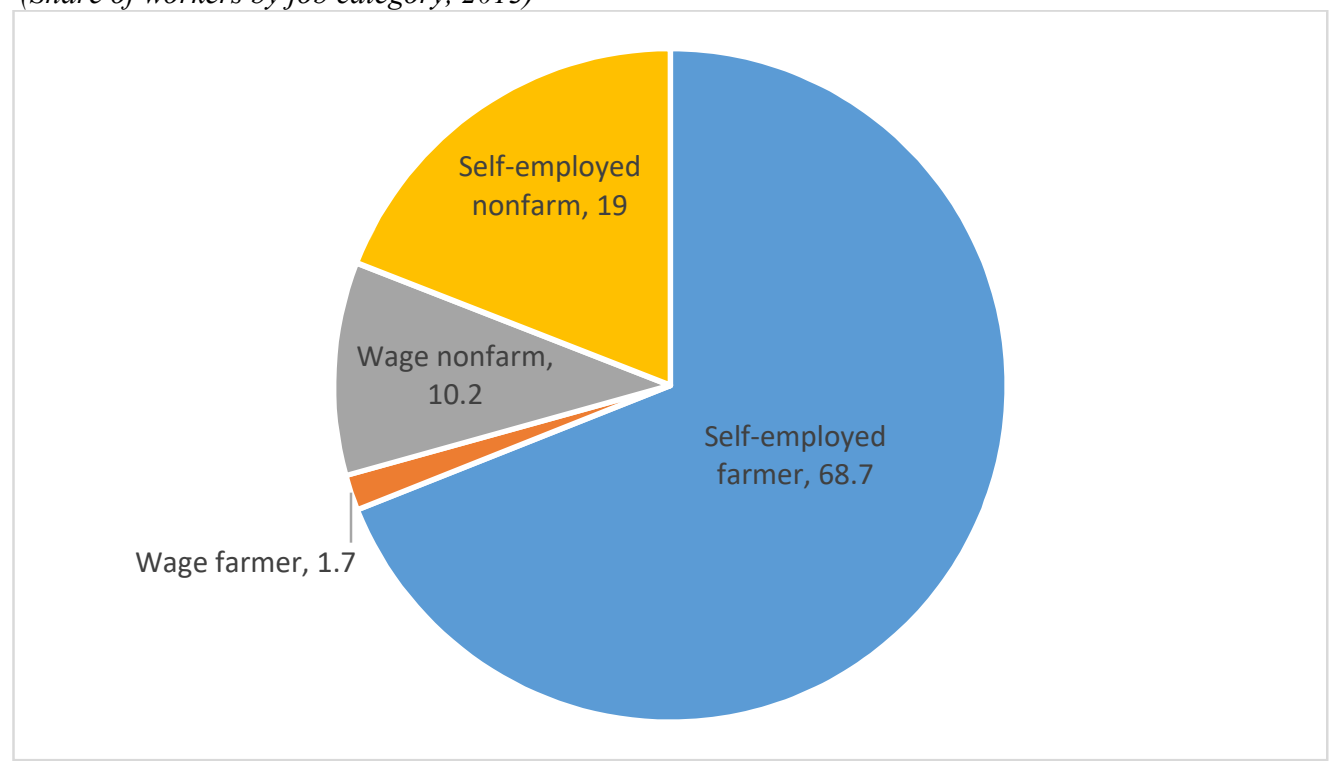

Source: LFS, 2013. World Bank staff calculations

Focusing on all occupations rather than only the main one, agriculture becomes more ubiquitous still. In rural areas, 96 percent of workers work in agriculture, either as a main or a secondary occupation (Figure 25). The nonfarm sector in rural areas is small, with three percent of workers working for wages in the nonfarm sector and 11 percent running a small nonfarm enterprise of some type. More than half of workers in small towns also work in agriculture, but the nonfarm sector is much more important, in particular self-employment in small household enterprises (almost half of workers in small towns work in nonfarm self-employment). Nonfarm wage employment is dominant in the big cities, followed by self-employment.

Figure 25: Agriculture dominates in rural areas and small towns

(Share of workers engaged in a particular occupation, 2016)

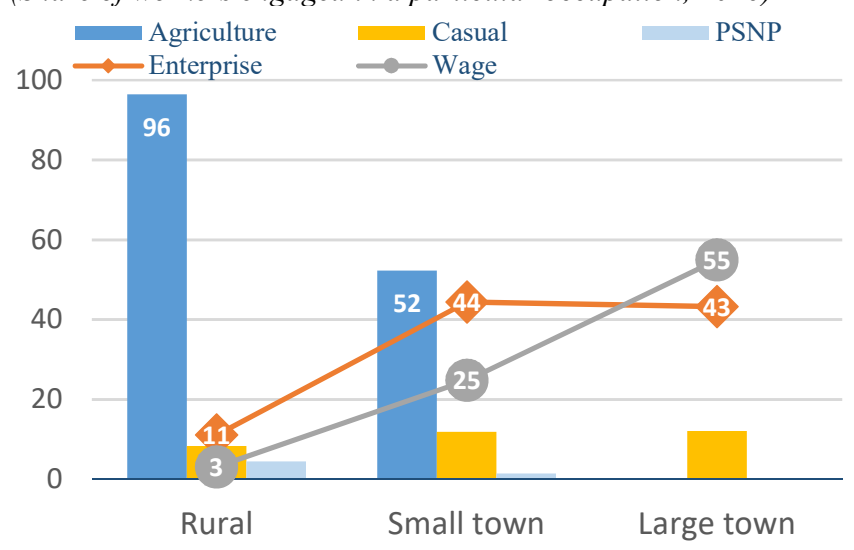




\section{Box 4 What are Ethiopia's wage workers doing?}

Both in 2013 and 2016, about 10 percent of workers in Ethiopia were wage-employed in the nonfarm sector. The government is by far the largest employer in the nonfarm sector, providing employment to over one-third of non-farm wage workers (Figure 26). Including state-owned enterprises, the share of the public sector in total nonfarm wage employment rises to 50 percent, compared to 32 percent for low-income SSA in general ${ }^{23}$. Five other sectors account for each 11 percent of non-farm wage-employment: Construction, manufacturing, financial- and businessoriented services, transports and communications, and community and family-oriented services. Compared to other countries in the region, trade is fairly small, accounting for only five percent of non-farm wage employment (trade accounts for 14 percent of nonfarm wage employment in low-income Africa) ${ }^{24}$. Over 80 percent of nonfarm wage employment is in the formal sector.

Figure 26: Government provides the bulk of the wage jobs

(Sector share of non-farm wage-employment, 2013)

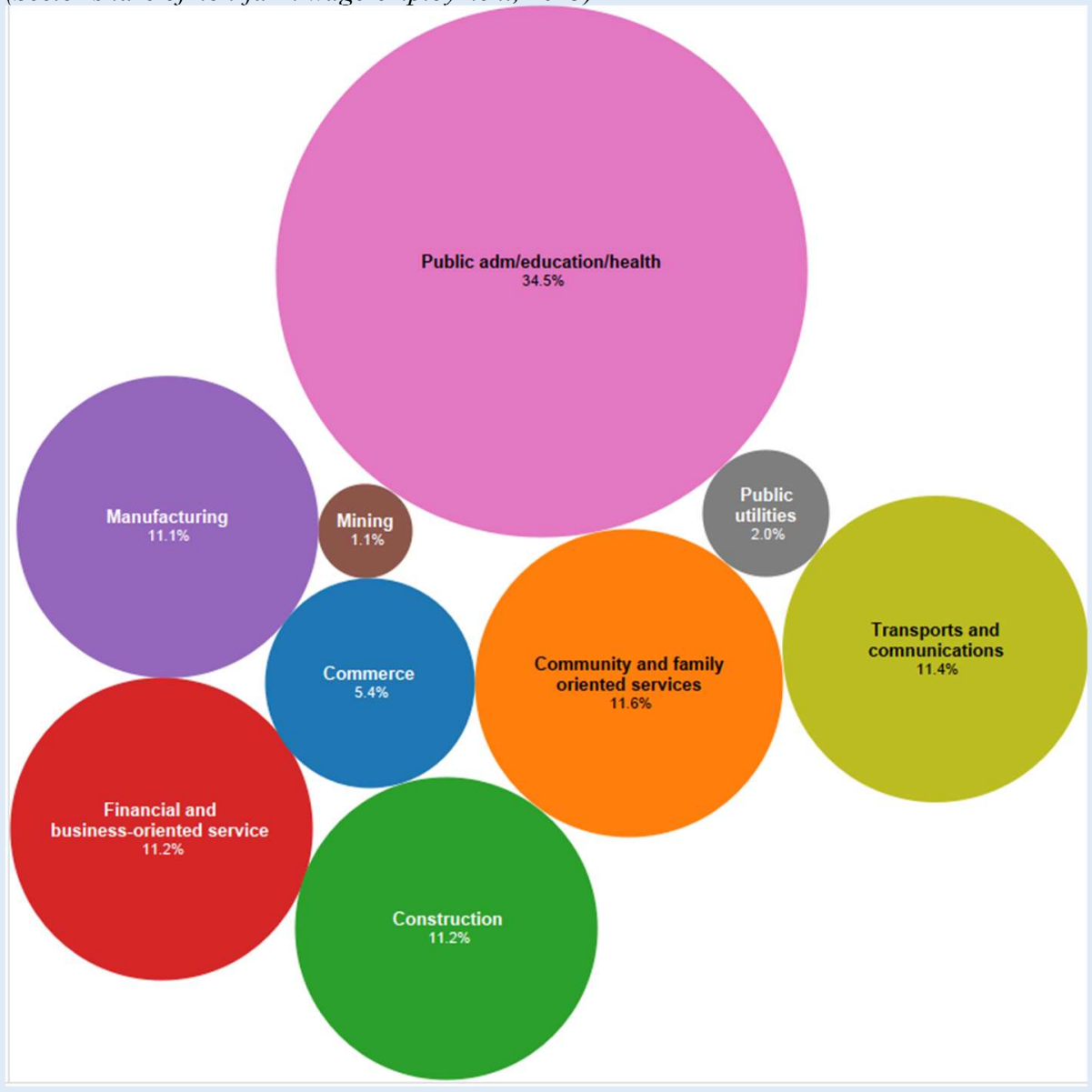

Source: LFS, 2013.

The employment structure differs considerably across gender but is remarkably similar across age. Women are less likely to work in agriculture in their main occupation and also less likely to be engaged in nonfarm wage employment (Figure 27). They are however more than twice

23 This is based on the World Bank's 12D2 database and uses for each low-income country in Sub-Sahara Africa the most recently available survey.

24 Idem. 
as likely to be self-employed in the nonfarm sector. Women's overrepresentation in the nonfarm sector is mainly due to one particular activity: Water and firewood collection, which is considered a nonfarm activity and which predominantly falls on women ${ }^{25}$. Young workers, here defined as workers between 15 and 29 years of age, are largely doing similar occupations as the previous generations, though they are somewhat less likely to be self-employed on the farm and more likely to be in the nonfarm sector (Figure 28) ${ }^{26}$.

Regional disparities in employment structure mainly stem from differences in agricultural potential and urbanization levels. In regions with high agricultural potential, such as Amhara, Oromia, parts of SNNPR, and Benishangul-Gumuz, a higher-than-average share of workers is engaged in agriculture and the nonfarm sector is correspondingly small (Figure 29). In more arid regions, the nonfarm sector is larger (Tigray, Afar, and Gambela). This hints at push factors for diversification, with households and workers in less fertile or drier regions more likely to engage in nonfarm activity ${ }^{27}$. Somali region appears to be an exception, with about three-quarters of workers engaged in agriculture despite the region being largely arid. A closer look at the occupation codes however shows this is due to the large share of livestock farmers there (who are classified as agriculture $)^{28}$. Nonfarm occupations largely dominate in the mainly urban regions of Harari, and in the chartered cities of Dire Dawa and Addis Ababa. In Addis, wage employment in the nonfarm sector largely dominates (70 percent of workers in Addis are wage-employed in the nonfarm sector), a peculiarity for African capitals also highlighted in the fifth Ethiopian Economic Update (World Bank, 2016).

25 Of all workers with a main occupation in water and firewood collection, 93 percent are women.

26 This is also explained by their higher engagement in water and firewood collection.

27 World Bank (2016) and Schmidt and Bekele (2016) also find evidence of push factors driving the limited diversification into nonfarm occupations in rural areas.

28 In Afar region as well, agriculture largely consists of livestock farming. 
Figure 27: Women are underrepresented in wage work and overrepresented in the non-farm sector

(Employment share by job category for men and women, 2013)

Men $\square$ Women

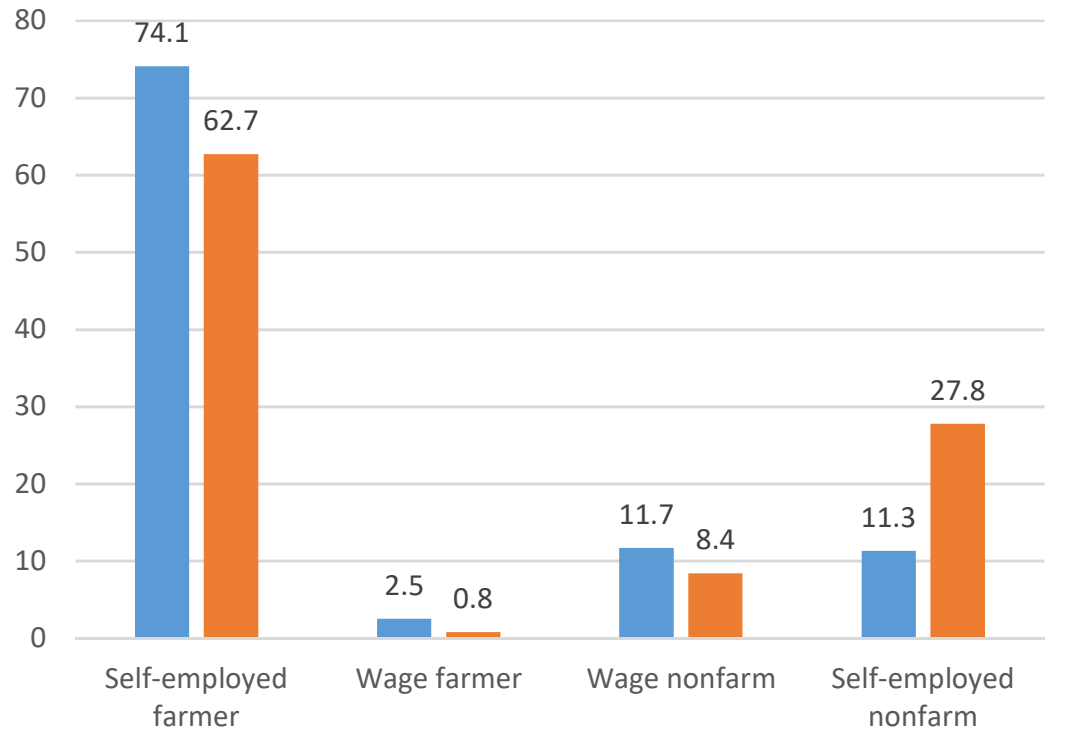

Source: LFS, 2013
Figure 28: Young and older workers are largely engaged in similar occupations (Employment share by job category for youth and older workers, 2013)

$$
\text { - Youth (15-29) Older workers (30-64) }
$$

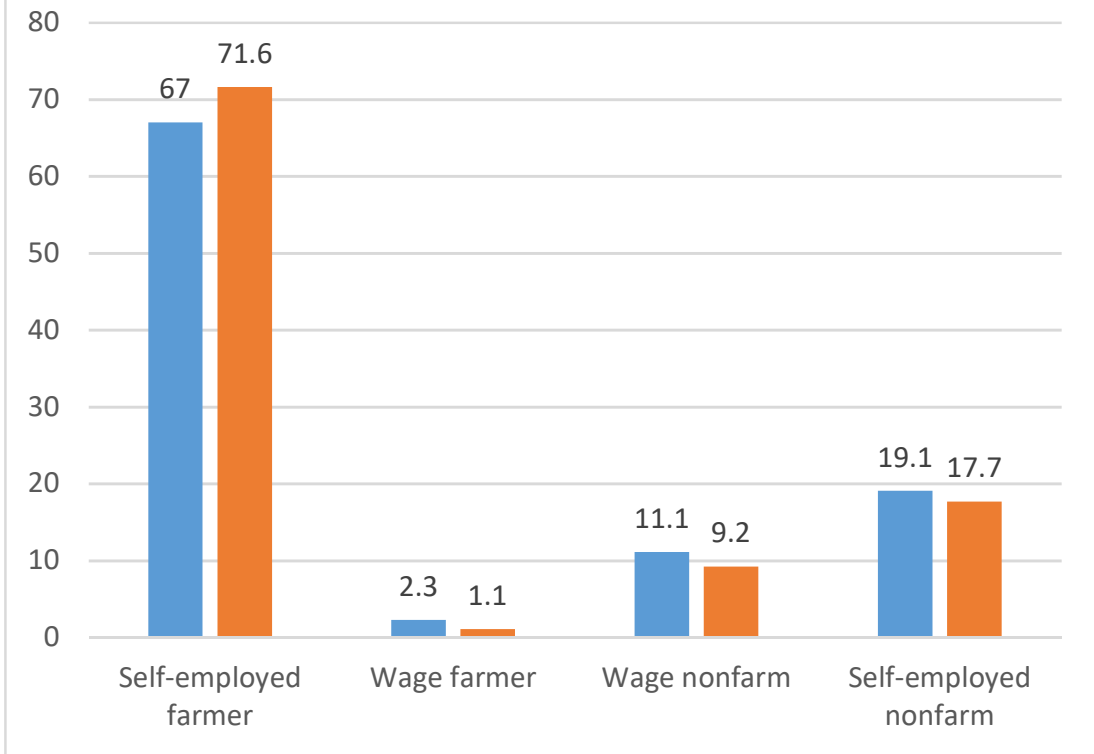

Source: LFS, 2013 
Figure 29: Employment structure differs considerably by region

(Share of workers by job category and region, 2013)

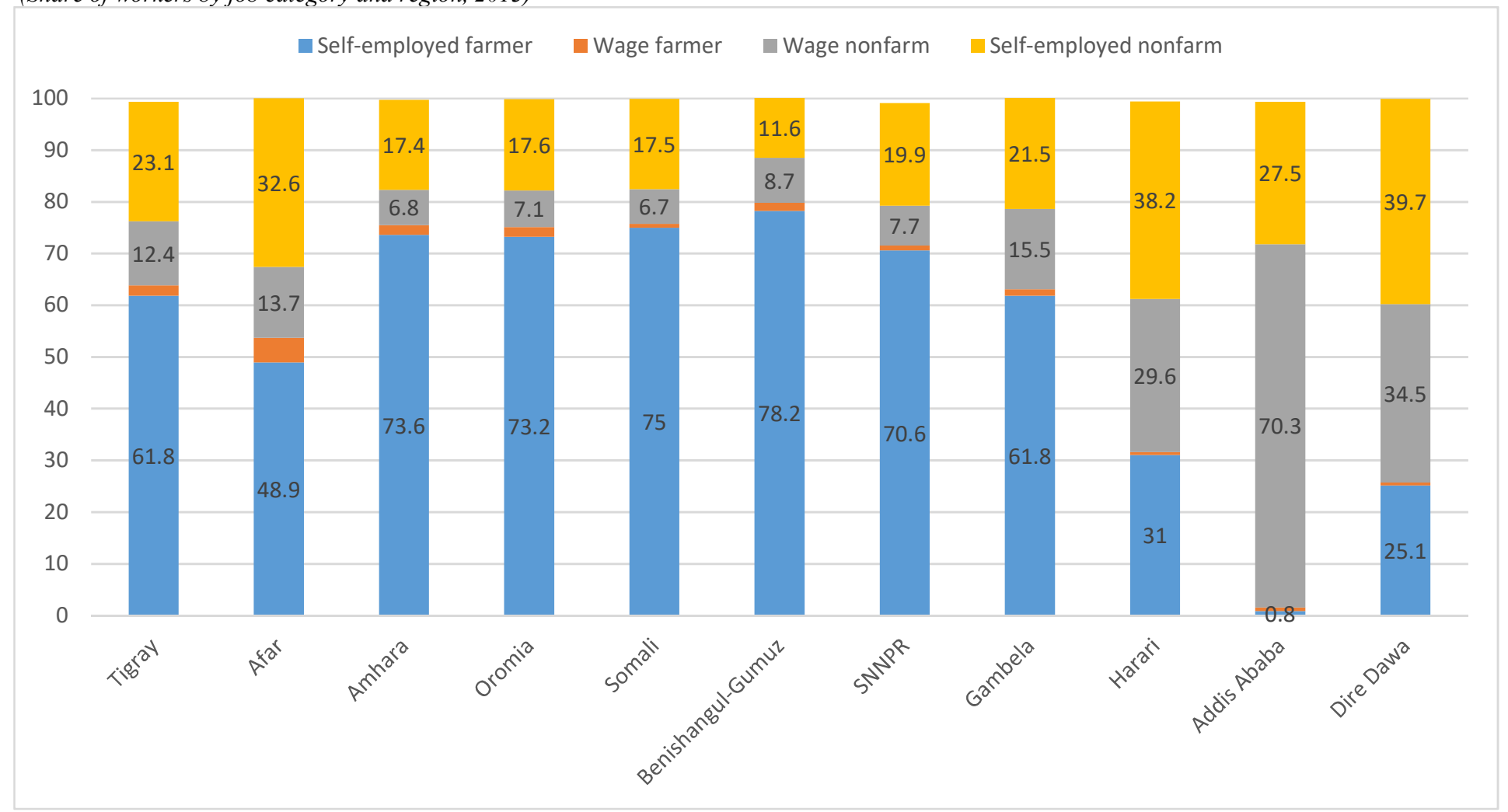

Source: LFS, 2013. 
Education is strongly related to job category. The share of workers with a main job in agriculture decreases as the level of education increases, from 80 percent of workers with no education at all to about four percent of workers with post-secondary education (Figure 30). At the other end, nonfarm wage employment dominates among workers with secondary (51 percent) and post-secondary ( 82 percent) education. This reflects the spatial concentration of skills, with 80 percent of workers who completed secondary education or more living in urban areas. Nonfarm self-employment increases in importance with rising education levels and peaks among workers who completed secondary education (35 percent), after which it drops off sharply for workers with tertiary education. This finding is in line with the urban labor market study, which found a deficit of wage employment opportunities in urban Ethiopia for workers with secondary education. Many workers with incomplete and complete secondary education are likely pushed into selfemployment in small nonfarm enterprises by the dearth of wage employment opportunities (see Box 5 for a profile of these enterprises in Ethiopia).

Figure 30: The uneducated are employed in agriculture, while the educated are wage-employed in the non-farm sector (Employment category by education level, 2013)

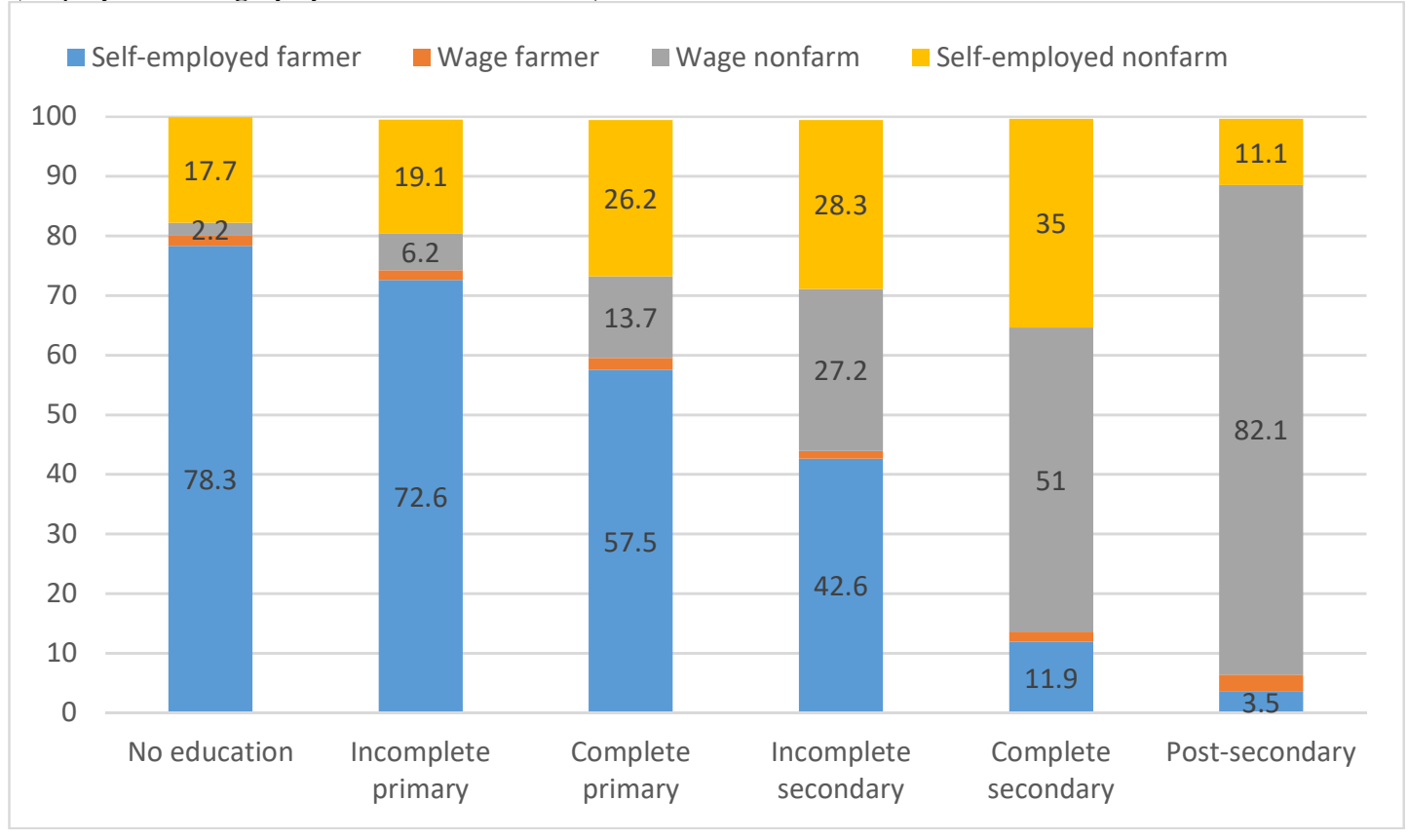

Source: LFS, 2013.

Tertiary education sharply increases the probability of being employed by the public sector and has a modest effect on employment in the formal private sector. Relative to uneducated workers, workers with tertiary education are 69 percentage points wore likely to work in the public sector and seven percentage points more likely to be in the formal private sector (Figure 33). Close to 70 percent of all tertiary-educated workers are employed in the public sector. The probability of working in the informal sector is fairly independent of education, and secondary-educated workers are most likely to be in nonfarm self-employment. The effect of education on employment category is largely similar for male and female workers.

\section{Box 5 A profile of household enterprises in Ethiopia}

Nonfarm self-employment in Ethiopia is mainly in so-called household enterprises. The term household enterprise refers to a business activity owned and operated by one or more household members and covers a wide 
expanse of business activities -petty trading, retail of prepared foods, street hawking, tailoring, beauty parlors, electricians, brick layers, et. The vast majority of household enterprises are engaged in commerce - street vendors and petty trading, are unincorporated and not registered for social security or tax purposes. Most are informal. In 2016, 38 percent of households in Ethiopia ran some kind of household enterprise and 18 percent of employed adults worked in a household enterprise, either as a primary or secondary occupation. Household enterprises are particularly prevalent in towns: Two in three Ethiopian households in towns run a household enterprise, and 44 percent of employed working-age adults in towns work in them.

How do household enterprises in Ethiopia look like? With a modal size of one and a median of two workers, household enterprises are small (Panel A of Figure 31). They mostly depend uniquely on household labor, with only 12 percent hiring external (non-household) workers for wages. Both men and women own and run household enterprises (at exactly the same rate in the sample), though woman-owned enterprises tend to be smaller and less likely to hire external labor. The bulk of household enterprises ( 75 percent) are run by a person who either never went to school or only obtained a couple of years of primary education. This pattern reflects the low education levels of the Ethiopian population rather than an overrepresentation of uneducated workers in household enterprises: The likelihood of running a household enterprise peaks at 18 percent for people who completed secondary education, and is largely flat at 10-11 percent for people with other levels of education (ranging from no education to tertiary).

Figure 31: Household enterprise are small, young, and mainly engaged in trade

(Characteristics of household enterprises and their owners)

\section{A. HHEs are small...}

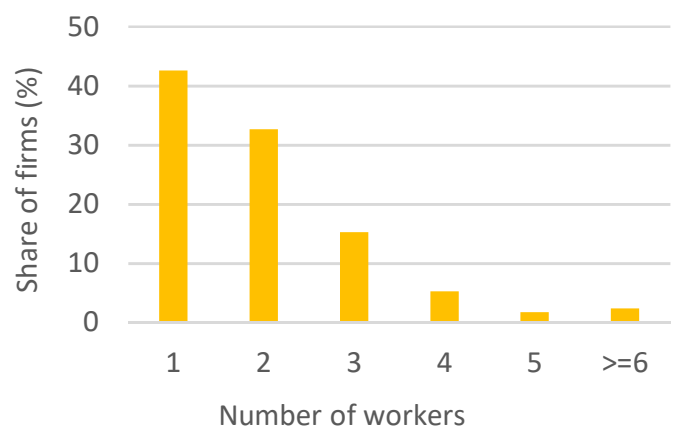

C. HHEs tend to be young...

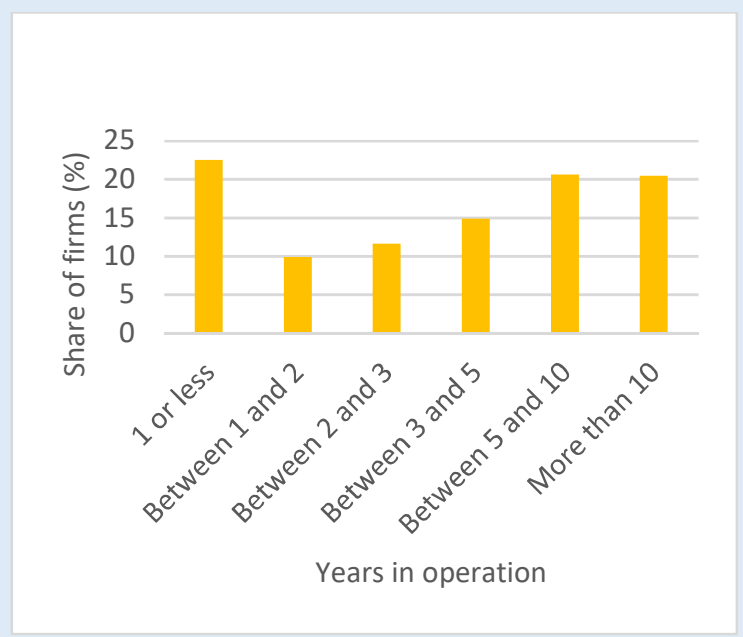

Source: ESS2; ESS3. World Bank staff calculations
B. ...though tend to increase in size with owner's education

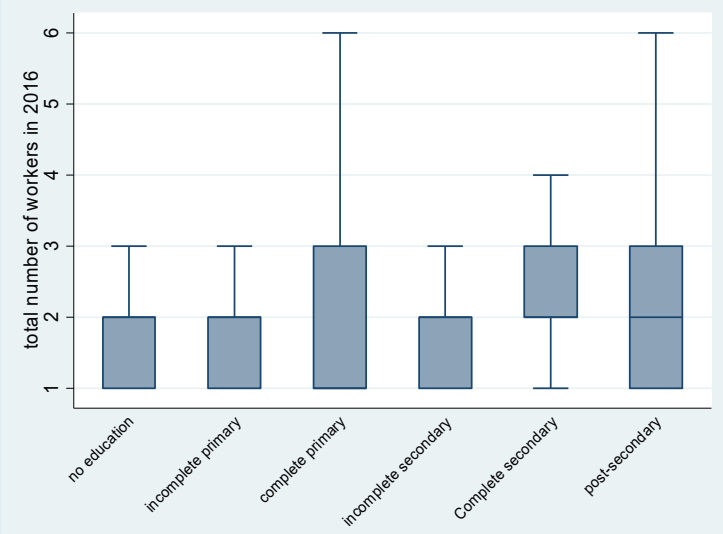

D. ....and are mainly engaged in trade and manufacturing

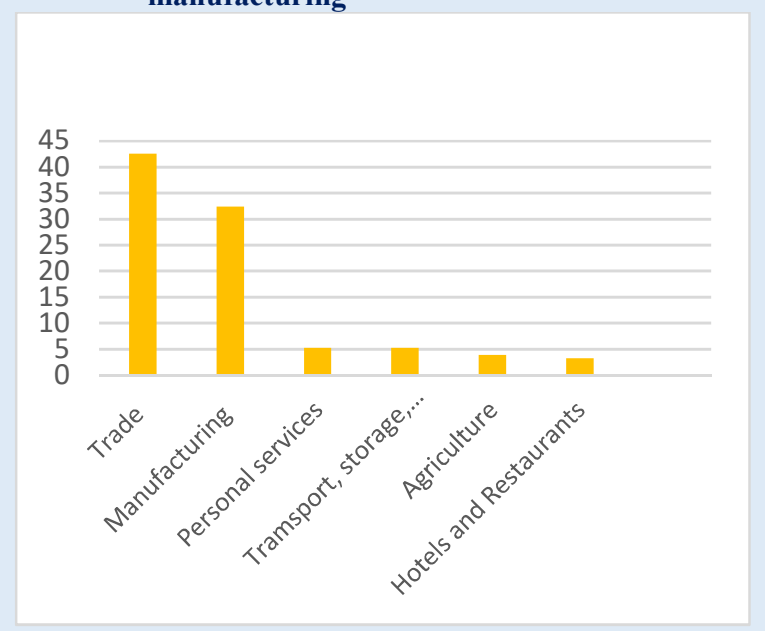


Household enterprises tend to be young. Over 22 percent of household enterprises interviewed in 2016 had been in operation for less than one year, and 32 percent had been in operation for less than two years. The youthfulness of HHEs reflect a high degree of churning, with enterprises exiting the market soon after they have established and new enterprises being started: Of all HHEs that were active in 2014 (during the ESS2), 40 percent had ceased operations by 2016, and one-third of enterprises active in 2016 (during the ESS3) were new. There is a marked gender effect, with women-owned HHEs being substantially younger (perhaps related to lower enterprise survival rates). However, over 20 percent of HHEs had been in operation for 10 years or more, indicating that HHEs can provide steady long-term employment, at least for the owner. HHEs are mainly active in trade and manufacturing (mostly of food products), which together account for 75 percent of all enterprises. Most household enterprises are operated at the household's home ( 38 percent), followed by traditional markets ( 29 percent) and shops in commercial areas (11 percent).

Labor productivity in most household enterprises is low, though a small share of enterprises attains very high productivity levels ${ }^{29}$. Median monthly sales per worker in the full sample of HHEs amounted to ETB 667 (US\$78 in PPP) in 2016, though the mean was a lot higher at ETB 4,121 (PPP US\$480). Owner's education is a main correlate of labor productivity, with especially completed primary education or more being associated with significantly higher productivity (panel A of Figure 32). There is no discernible difference in labor productivity between HHEs owned by an uneducated person or owned by a person with only a few years of primary. Among the three main economic sectors for HHEs, wholesale and retail trade has by far the highest levels of labor productivity, and manufacturing the lowest (Panel B in Figure 32). HHEs with more than one worker have lower levels of labor productivity, but only if the workers are household members ${ }^{30}$. In contrast, HHEs that manage to hire external labor for wages have far higher levels of productivity and are distinct from the enterprises that uniquely rely on non-waged household labor. As expected, labor productivity in HHEs is highest in cities and lowest in rural areas (panel D of Figure 32), which is linked to access to markets. Within rural areas, HHEs located in areas in the top quartile of rural accessibility have substantially higher sales per worker than enterprises in the bottom three rural access quartiles ${ }^{31}$. Finally, the relation between longevity of the HHEs and labor productivity is unclear: The oldest HHEs (that have been in operation for 10 years or more) have the lowest median labor productivity but the highest mean productivity. This points towards important heterogeneity, with the bulk of old HHEs consisting of low-productivity subsistence enterprises owned by persons with very limited alternative livelihood options, but with a small share of highly successful enterprises that are not merely surviving but thriving.

Figure 32: Labor productivity in household enterprises varies widely

(Log of monthly sales per worker, by selected characteristics)

$$
\text { A. By education of owner }
$$

B. By sector

\footnotetext{
${ }^{29}$ Following Nagler and Naude (2016), we define labor productivity as average monthly sales per worker.

${ }^{30}$ The finding that HHEs that employ more than one household member have lower labor productivity should be interpreted with caution, as the definition of labor productivity we use does not take account of the number of hours a worker works. If contributing household members only work a couple of hours per day or per week in the enterprise, they will nevertheless be counted as full-time workers, even they though their contribution in terms of labor volume may be limited. This will exert a downward bias on the estimate of sales per worker. 31 Rural accessibility is measured by the Rural Accessibility Index (RAI). The RAI measures the share of the population in a woreda that lives within $2 \mathrm{~km}$ of the nearest road in "good or fair" condition in rural areas. The RAl combines georeferenced data on the road network with information on road condition and spatial information on the distribution of the rural population. Overall, the RAl for Ethiopia was estimated at 22 percent in 2016 (World Bank, 2016). Half of woredas had a RAl lower than 17 percent, meaning that less than 17 percent of the rural population in these woredas lived within $2 \mathrm{~km}$ of a road in good or fair condition. Annex maps the RAI for Ethiopia.
} 


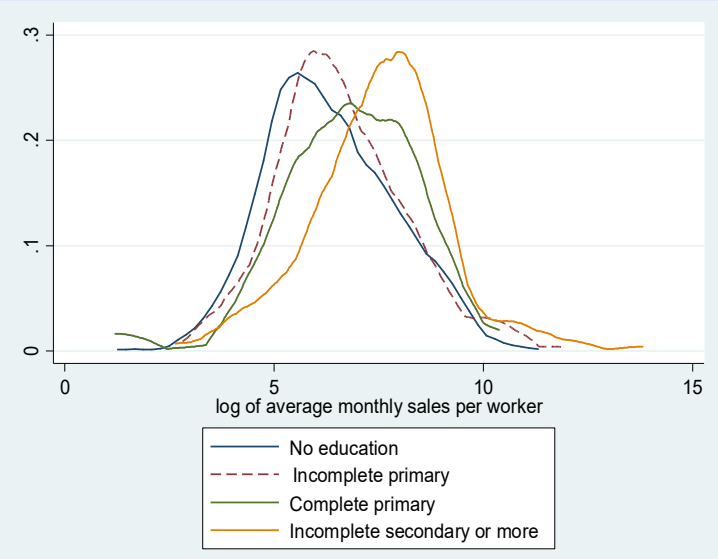

C. By size

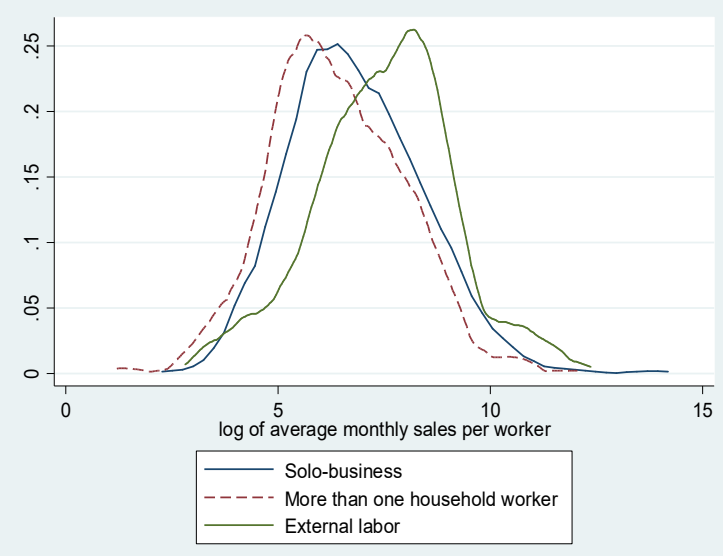

E. By rural accessibility

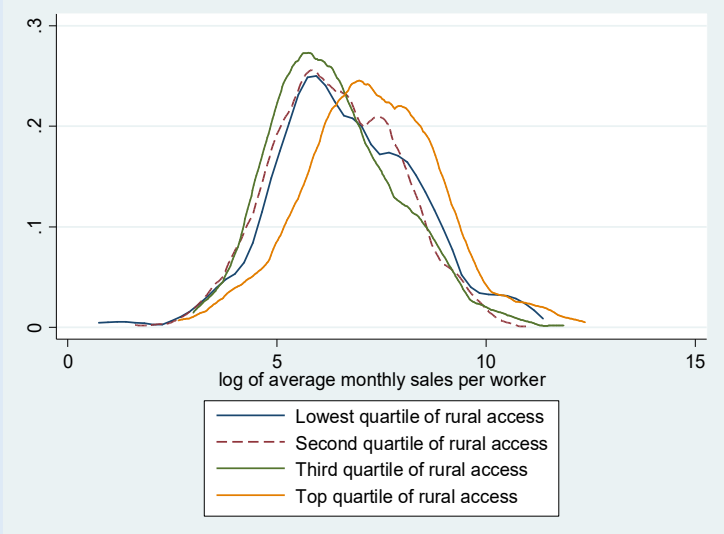

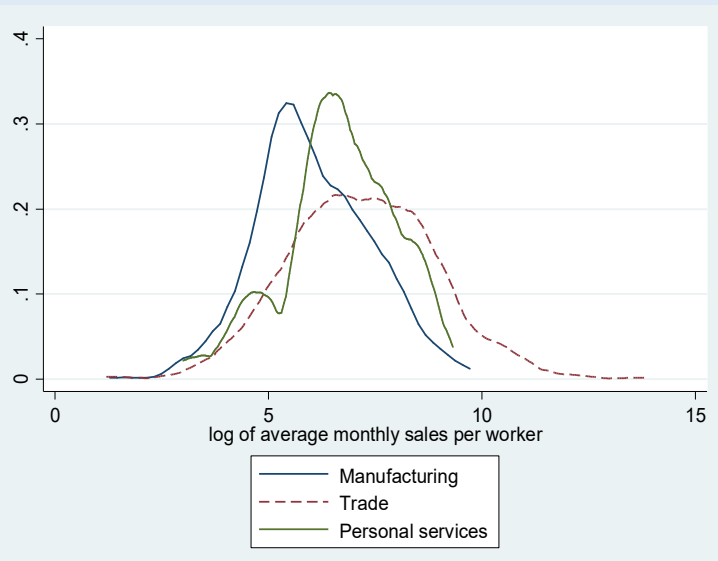

D. By location

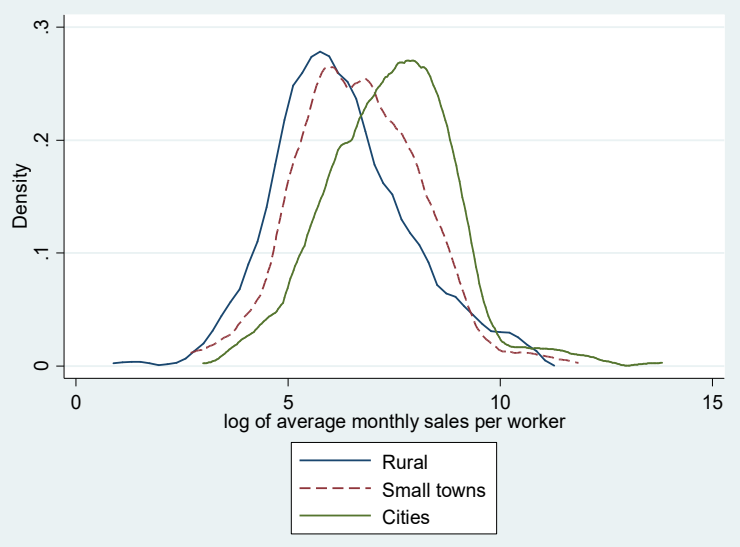

F. By enterprise age

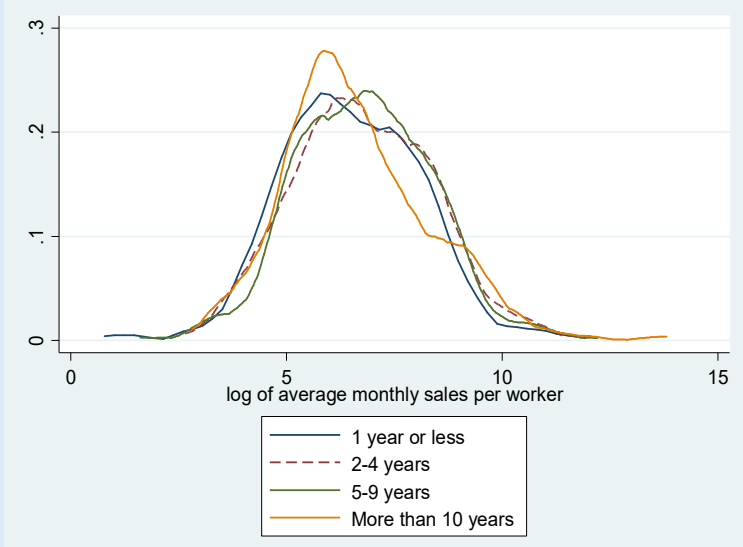

Source: ESS3. World Bank staff calculations

While the above figures are illustrative, they do not control for other factors that simultaneously affect labor productivity. In Annex 1, we present the results of a regression of the log of labor productivity on a series of firm and owner characteristics. As expected, labor productivity increases with the owner's education, with productivity being 14 percent higher in HHEs headed by a person with completed primary education (not significant) and 87 percent higher if the owner completed secondary education. Controlling for other characteristics, having hired labor is not significantly associated with higher labor productivity, though having more than one household worker is 
associated with lower productivity. Older HHEs have higher levels of labor productivity, though it is not clear whether this is an experience or "learning by doing" effect or driven by more productive enterprises being more likely to survive and grow old. Relative to rural areas, sales per worker are 28 percent higher in towns and 89 percent in cities. There is a persistent gender effect, with labor productivity in female-owned enterprises being 65 percent lower than in male-owned ones, all else equal.

Despite their importance, self-employment in household enterprises is less common in Ethiopia than in many other African countries, particularly in rural areas. In the six countries that are covered by the LSMS-ISA surveys (Ethiopia, Malawi, Uganda, Tanzania, Niger and Nigeria), on average 42 percent of rural households run a nonfarm household enterprise. In rural Ethiopia, this drops to 23 percent (Nagler and Naude, 2016). Constraints related to market access are mentioned as the main obstacle to operating a household enterprise in rural Ethiopia, mainly the physical absence of (or high distance to) markets and the low demand for goods and services in rural

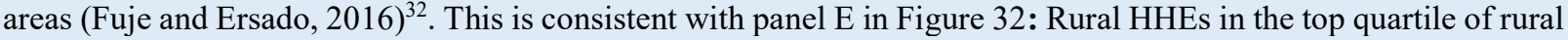
accessibility have significantly higher productivity than HHEs in the three bottom quartiles, controlling for other covariates.

Figure 33: Higher educated workers are more likely to have access to higher paying jobs (Marginal effect of having a given educational level relative to having no schooling on the probability of working in each sector - 2013)

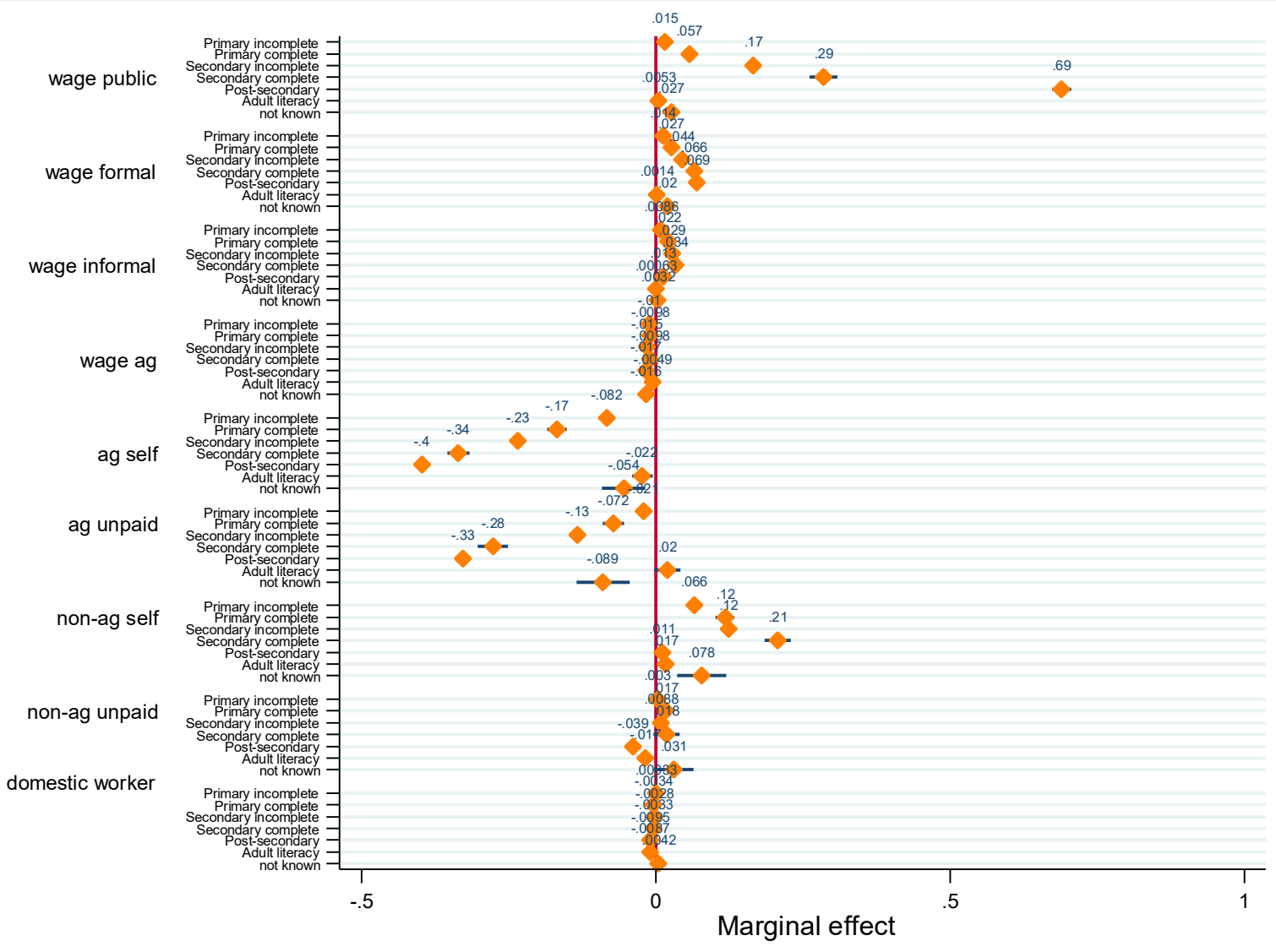

Source: LFS, 2013.

32 Constraints related to access to markets and market information were mentioned as the main constraint in operating and expanding a HHE in rural Ethiopia by 57 percent of respondents. 
Employment structure is only marginally related to rural accessibility, though this is mainly because rural Ethiopia is poorly connected. Using the woreda-level Rural Accessibility Index, workers in the highest quintile of connectivity are largely engaged in similar occupations and sectors as workers in the lowest connectivity quintile (Figure 34). Though this appears surprising, it is less so when factoring in that even in the highest connectivity quintile the average RAI amounts to less than 50 percent (meaning that less than half of the population lives within $2 \mathrm{~km}$ of a good or fair road). Employment structures do however start to change at high levels of rural connectivity: In the few woredas where at least three quarters of people have access to a road (third bar in Figure 34), the employment share of agriculture drops to 66 percent (from a rural average of 87 percent) while the share of non-farm self-employment quadruples (from the rural average of seven percent to 28 percent). However, only three rural woredas included in the 2013 LFS had a RAI of 75 percent or more. Using the market accessibility index as an alternative indicator of connectivity to markets does not change the picture: The share of rural workers with a main job in agriculture remains roughly constant until a market access index of 0.6 , after which it drops substantially (Figure 35). However, less than two percent of rural workers live in a woreda with such a high market access.

Figure 34: Only at very high levels of rural accessibility does the employment structure start to change

(Employment category by level of rural accessibility, 2013)

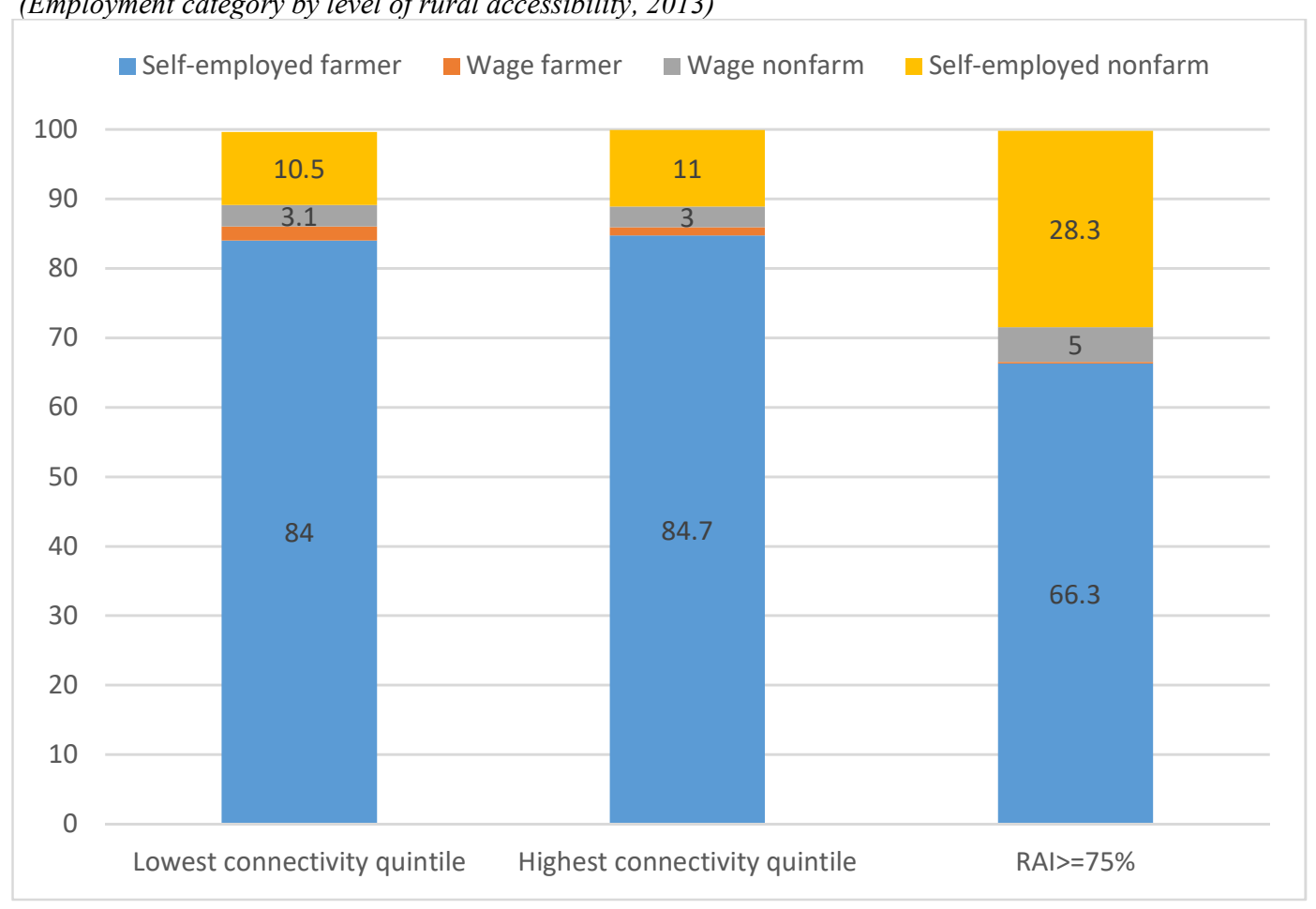

Note: RAI means Rural Accessibility Index. Source: LFS, 2013. 
Figure 35: ... and the picture is similar for access to markets

(Employment category by market accessibility, 2013)

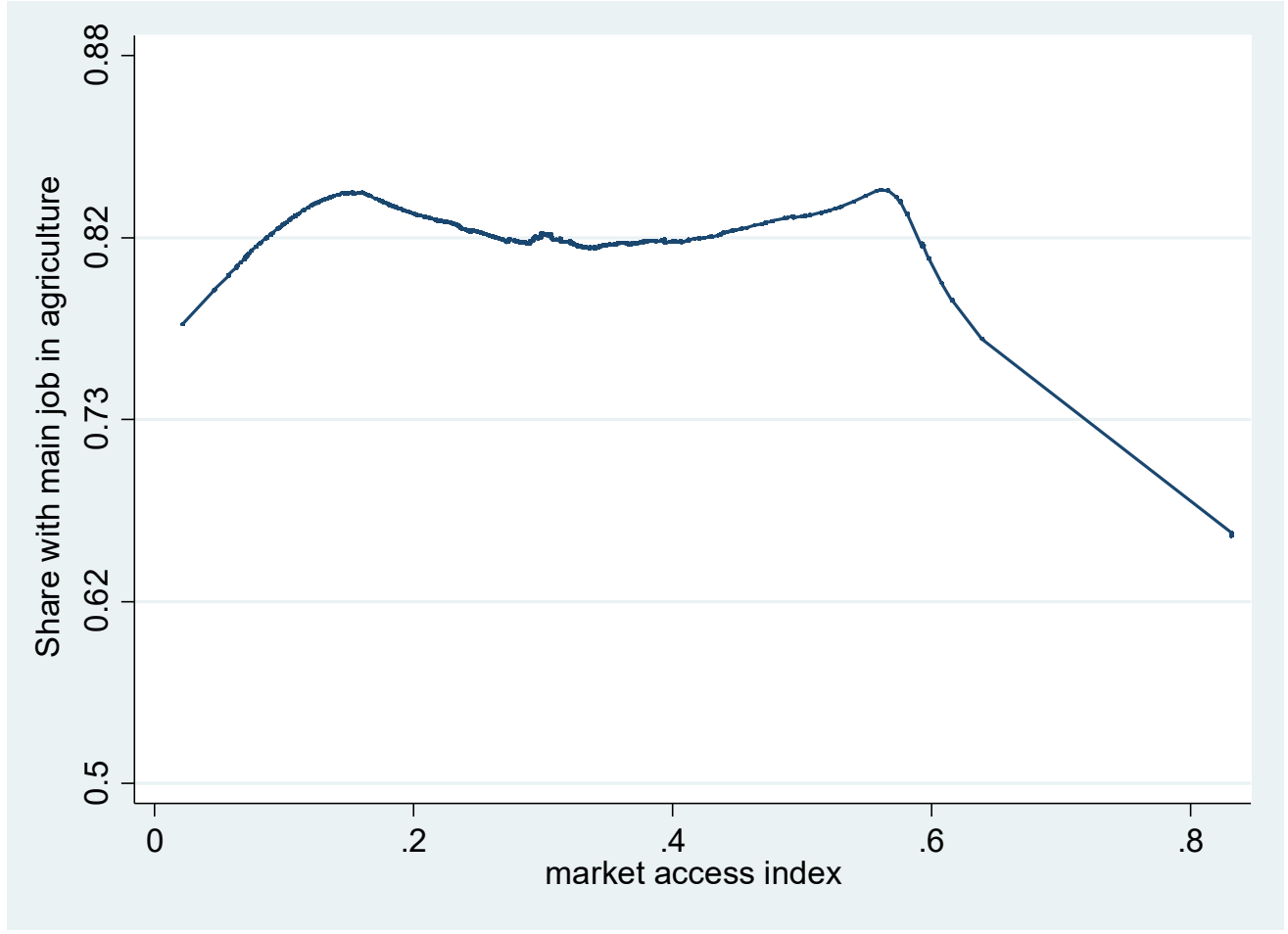

Note: The market access index is a XXXX. Source: LFS, 2013.

\section{Relatively high rates of underemployment and low earnings despite multiple jobs}

As often observed in low-income rural settings, a fair share of Ethiopian workers work several jobs. In 2013, 37 percent of workers had more than one job, with a wide disparity between rural (42 percent with more than one job) and urban (18 percent) workers. Having multiple jobs is mainly prevalent among little-educated workers who, presumably, need to take up extra jobs to try to make ends meet (Figure 36). The likelihood of having more than one job is strongly related to the number of hours worked in the main job: The fewer hours worked in the main job, the higher the likelihood of having additional jobs (Figure 37). This is consistent with workers that are underemployed in their main job, mainly the little-educated working in agriculture, taking up additional activities to increase working hours and earnings ${ }^{33}$.

33 According to the 2016 ESS, rural workers spend about 68 days per year working in agriculture (from land preparation to harvest), leaving ample time to take up secondary occupations. 
Figure 36: Little-educated workers tend to have more than one job

(Share of workers with multiple jobs, by education)

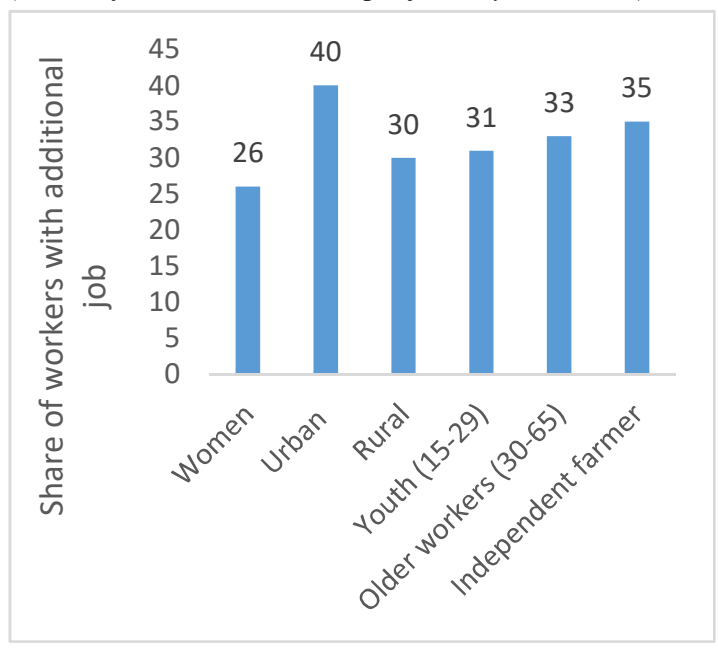

Source: LFS, 2013.
Figure 37: Having multiple jobs is strongly related to hours worked in the main job

(Likelihood of having multiple jobs by hours worked in main job)

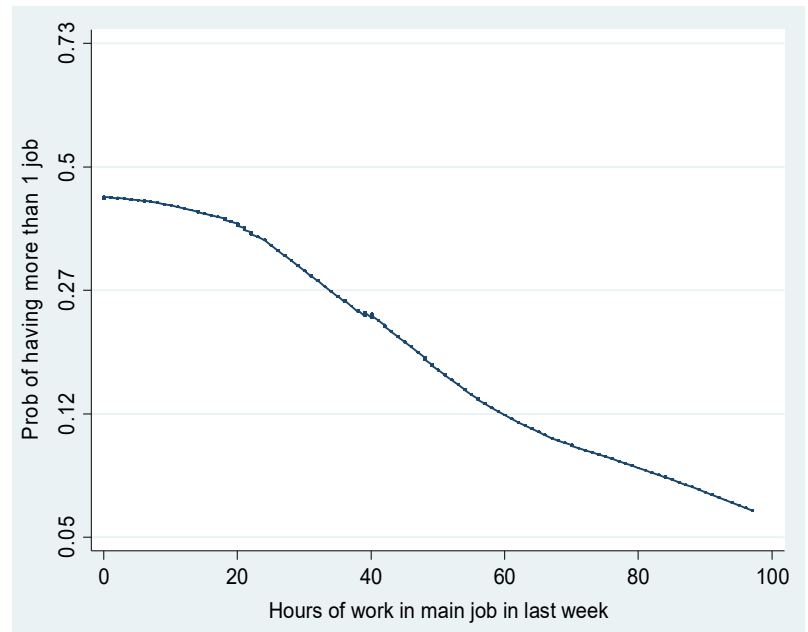

Source: LFS, 2013.

Taking up additional jobs helps to combat underemployment, but only partly so. Median hours worked in the main job amounted to 28 per week in 2013, rising to 32 hours when additional jobs are counted ${ }^{34}$. Despite the contribution of secondary jobs, median working hours fall short of full-time employment and time-related underemployment remains relatively high ${ }^{35}$. Defining underemployment as working less than 35 hours per week and wanting to work more, about 22 percent of Ethiopian workers are underemployed ${ }^{36}$. Underemployment is higher among women (25 percent) and in rural areas (23 percent), and among workers in non-waged employment, both in agriculture and beyond (Table 7). Working hours are highest and underemployment lowest among wage employees in the nonfarm sector, where most workers are permanent employees in the public and private sector. A regression analysis (Annex 2) confirms that gender and location are the main correlates of underemployment, with the agricultural-production regions most affected (Tigray, Oromia, Amhara, SNNPR and Benishangul-Gumuz) ${ }^{37}$.

Table 7: Working hours are low, and underemployment relatively high

(Share of labor force participants by educational attainment, 1999-2005-2013)

\begin{tabular}{lcc}
\hline \hline & $\begin{array}{c}\text { Median hours worked per week } \\
\text { (all jobs) }\end{array}$ & Underemployment (\%) \\
\hline Men & 38 & 19.3 \\
Women & 26 & 25.3 \\
Urban & 40 & 18 \\
Rural & 30 & 23 \\
Youth (15-29) & 31 & 22.5 \\
Older workers (30-65) & 33 & 21.8
\end{tabular}

\footnotetext{
${ }^{34}$ Data on weekly working hours need to be interpreted with caution due to the seasonal nature of the dominant economic activity (agriculture) in Ethiopia.

${ }^{35}$ According to Ethiopian legislation, normal working hours shall not exceed 8 hours per day or 48 hours per week for workers covered by Labour Proclamation No. 377/2003 or employees in private organizations; normal working hours for civil servants are 39 per week.

${ }^{36}$ More than half of Ethiopian workers work less than 35 hours a week. However, only a share of those express the desire to work more 37 Fieldwork for the 2013 LFS was conducted between end May and mid-June. This overlaps with Belg harvest for Belg-receiving areas and planting for the Meher season. If LFS were implemented in August-September, working hours would likely be lower.
} 


\begin{tabular}{lll} 
Self-employed farmer & 30 & 22.9 \\
Wage farmer & 45 & 14.4 \\
Wage nonfarm & 44 & 12.1 \\
Self-employment nonfarm & 38 & 25.2 \\
Total & 32 & 22.1 \\
\hline \hline
\end{tabular}

Source: LFS, 2013.

Overall, labor earnings are low. As the LFS only collects information on earnings of wage employees, we only have information on earnings of 12 percent of workers - those who earn wages-which is an important caveat. Most of the wage work ( 70 percent) is in urban areas. Since in most low-income countries urban wage-workers are on average better-off than the overall population, the earnings reported here will be an overestimation of average labor earnings of the employed population in Ethiopia.

Real monthly median wage earnings amounted to ETB 979 in 2013, ETB 1,000 in 2014, and $\mathbf{1 , 1 5 8}$ in $\mathbf{2 0 1 6}^{\mathbf{3 8}}$. In purchasing power parity (PPP) terms, this translates to US\$140 per month (2013) and US\$165 (2016). Despite the relatively small ESS samples, the 2014 and 2016 data are nationally representative and point towards steady real wage growth between 2013 and 2016, confirming the findings of the urban labor market study (World Bank, 2016). Median wage earnings are highest in the public sector (Table 8), though there is a small share of workers in the formal private sector earning very high wages (red bars to the right-hand-side of Figure 38$)^{39}$. The wage differential between the public and private sector is largely due to better endowments of public sector workers ${ }^{40}$. In contrast, a substantial share of the wage differential between men and women is unexplained: 37 percent of the wage difference between men and women is due to women earning less for similar work (Annex 5). Wages are lowest for domestic workers and agricultural wage employees. Overall, one in five wage workers earned below the national poverty line in 2013 and are so-called low-earners. The low-earnings rate is highest among wage workers in agriculture (58 percent) and domestic workers ( 75 percent). The low-earnings rate slightly decreased to 17 percent by 2016 .

\begin{tabular}{|c|c|c|}
\hline & $\begin{array}{l}\text { Median monthly } \\
\text { earnings }\end{array}$ & $\begin{array}{c}\text { Low-earnings } \\
\text { rate }\end{array}$ \\
\hline Total & 979 & 22 \\
\hline Men & 1,114 & 17.4 \\
\hline Women & 749 & 29.3 \\
\hline No education & 400 & 54 \\
\hline Primary incomplete & 500 & 40.5 \\
\hline Primary complete & 700 & 23.7 \\
\hline
\end{tabular}

38 These are expressed in 2013 prices, using CSA inflation data. The 2013 estimate is based on the LFS, while the 2014 and 2016 estimates are based on ESS2 and ESS3.

39 The breakdown by sectors is based on the 2013 LFS to exploit the larger sample size.

40 A Oaxaca-Blinder decomposition shows that close to 90 percent of the hourly wage differential between public and private formal sector wage workers can be explained by better endowments of public sector workers, notably education and experience (Annex III). 


\begin{tabular}{lcc} 
Secondary incomplete & 900 & 15.4 \\
Secondary complete & 1,200 & 5 \\
Post-secondary & 1,750 & 1.2 \\
Adult literacy & 550 & 36.3 \\
& & \\
Agriculture & 350 & 58 \\
Manufacturing & 800 & 19.7 \\
Construction & 900 & 14.3 \\
Commerce & 700 & 27.9 \\
Transports and communications & 897 & 25.9 \\
Financial and business oriented services & 1,719 & 3.6 \\
& & \\
Public & 1,427 & 5.5 \\
Formal & 1,000 & 11.6 \\
Informal & 600 & 32.2 \\
Domestic Worker & 300 & 74.9 \\
\hline \hline Note: Some workers cannot be classified in any of the sectors (7.3 percent of workers in 2013). The overall average is \\
calculated on all workers including those that cannot be categorized in any of the sectors. \\
Source: LFS, 2013.
\end{tabular}

Education pays off in terms of higher wages. Wage workers with tertiary education earn about four times as much as workers without any education at all, though, as will be explained further, returns to education have nevertheless decreased substantially since 2005 . The figures in Table 8 highlight the importance of primary education: Wages for workers who completed primary education are 75 percent higher relative to workers without education, and completing primary is associated with a sharp drop in the likelihood of being a low earner. Primary school attendance and especially completion rates remain however low. Net attendance in primary school amounted to 71 percent in 2016 (and dropped to 59 percent in the lowest quintile), and only half of children actually completed primary school in the school year $2014 / 15^{41}$.

41 Based on the 2016 DHS and the 2014/15 education statistical yearbook, respectively. 
Figure 38: Public sector employees earn the highest wages, followed by the formal and informal private sector

(Log hourly earnings of wage workers, 2013)

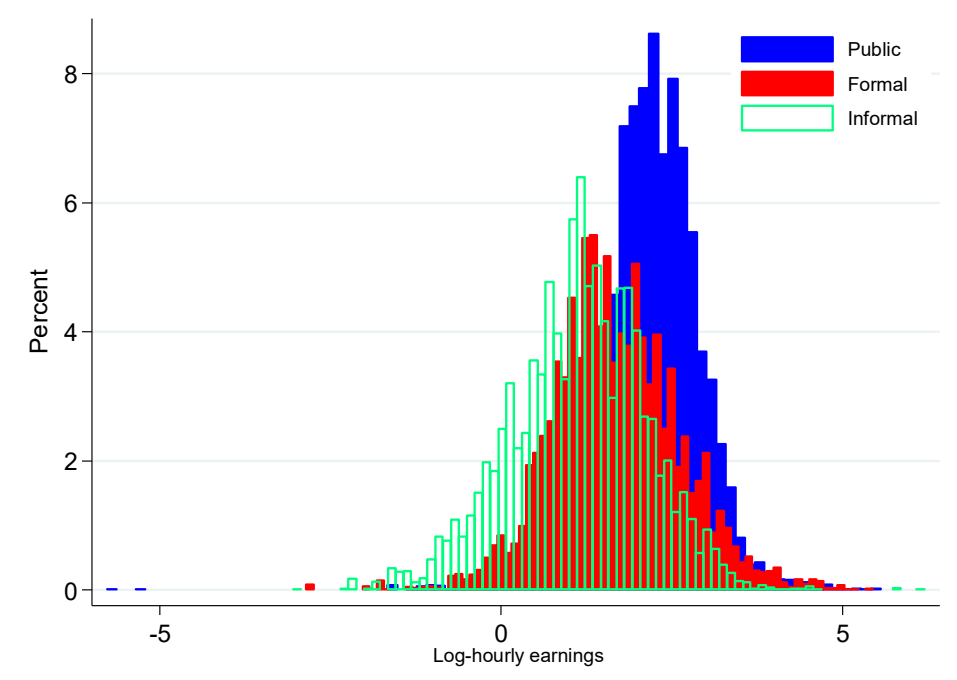

Source: LFS, 2013.

\section{The dynamics: 1999-2005-2013}

Despite strong growth in nonfarm employment, agriculture added most of the jobs and the structural shift remained modest

Employment growth between 1999 and 2013 was strong. The number of employed people grew by 66 percent (13.5 million), outpacing the growth in the working-age population and leading to a decrease in unemployment (Figure 39). Agriculture absorbed most of the new workers since 1999, though the non-agricultural sector grew faster in relative terms, from a low base. Non-agricultural employment almost doubled between 1999 and 2013, corresponding to 4.4 million more workers (Box 5), whereas agricultural employment increased by close to 60 percent, translating into an addition of more than 9 million workers. There was a particularly large increase in wage employment in the nonfarm sector-by two million workers-though the low base means its employment share is still fairly small. The increase in nonfarm wage employment was mostly driven by the expansion of the public sector $(+1$ million workers), while employment growth in the private sector remained relatively modest (an increase of less than 0.5 million workers in 14 years) ${ }^{42}$. Note that despite strong growth between 1999 and 2013, the "modern" segment of the labor market, composed of the public and the formal private sector, remained small, providing employment to 2.4 million workers.

42 The numbers in Figure 39 do not always add up since for some observations the data we need to classify workers in a certain sector are missing. 
Figure 39: Strong employment growth since 1999

(Decomposition of the workforce by type of employment in 2013 and changes since 1999)

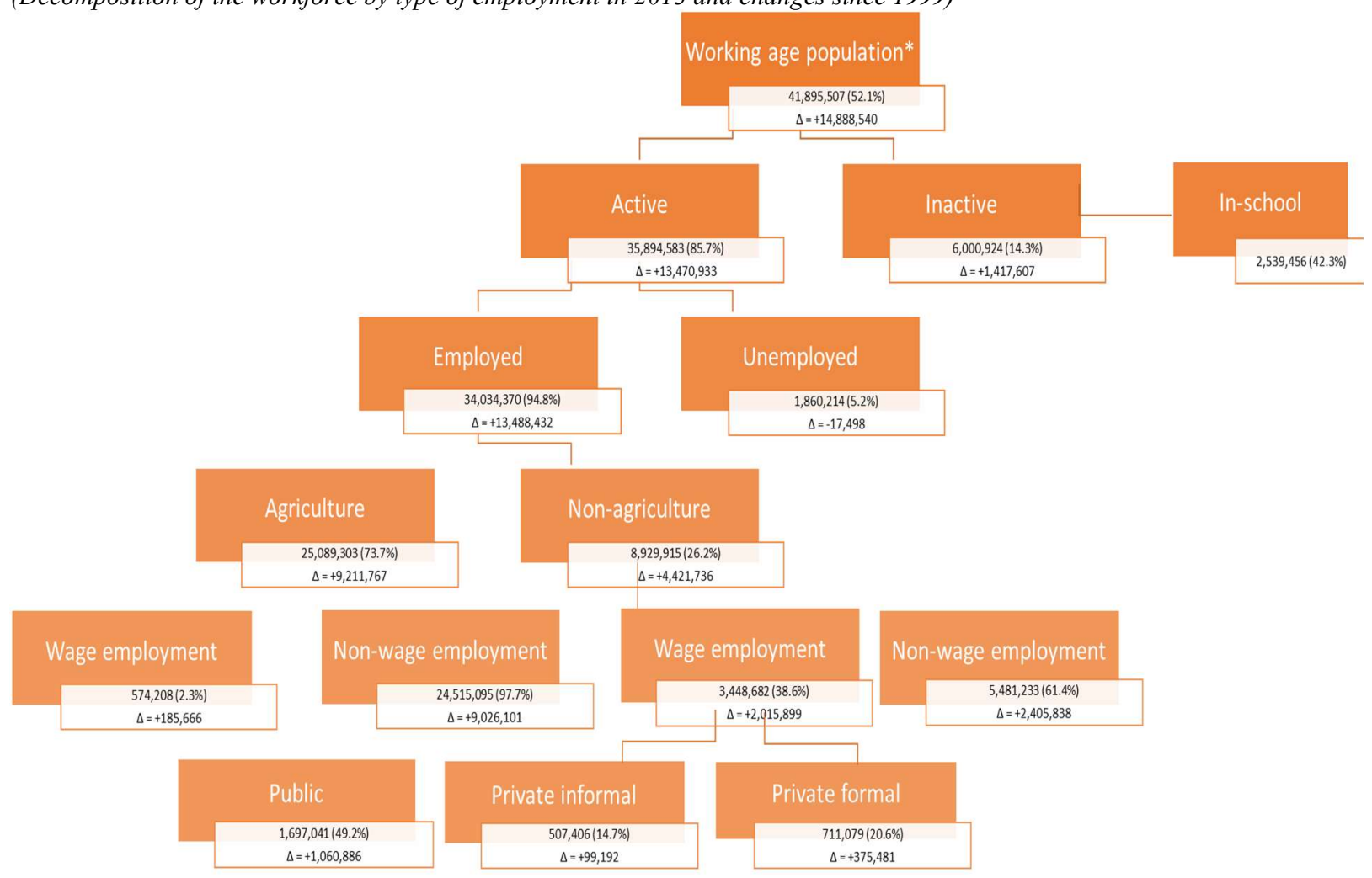

Source: LFS, 1999; 2013.

Box 6
Public sector and services

Dissecting the increase in nonfarm employment

Between 1999 and 2013, the number of workers employed in the nonfarm sector in Ethiopia doubled. In 2013, about 8.9 million workers worked in the non-farm sector in their main job, up from 4.5 million 14 years earlier. Where have the non-farm occupations been created? Figure 40 shows job (actually: worker) additions by sector since 1999. Overall, the public sector added most of the nonfarm jobs since 1999 (slightly over 1 million), closely followed by the fairly non-descript category of "community and family services" (slightly less than 1 million). The increase in public sector employment is split between government services (0.6 million - orange bar in Figure 40$)$ and employment in public enterprises ( 0.4 million). Commerce, manufacturing, and construction also added a substantial number of jobs. Overall, services added 2.8 million workers, accounting for 63 percent of the increase in nonfarm employment between 1999 and 2013. Manufacturing employment increased by 80 percent, while employment in mining increased 11-fold, though remained low given the extremely low base.

Figure 40: Services and the public sector accounted for most of the increase in non-farm employment

(Net nonfarm job additions by sector, 1999-2013) 


\section{$1,200,000$}

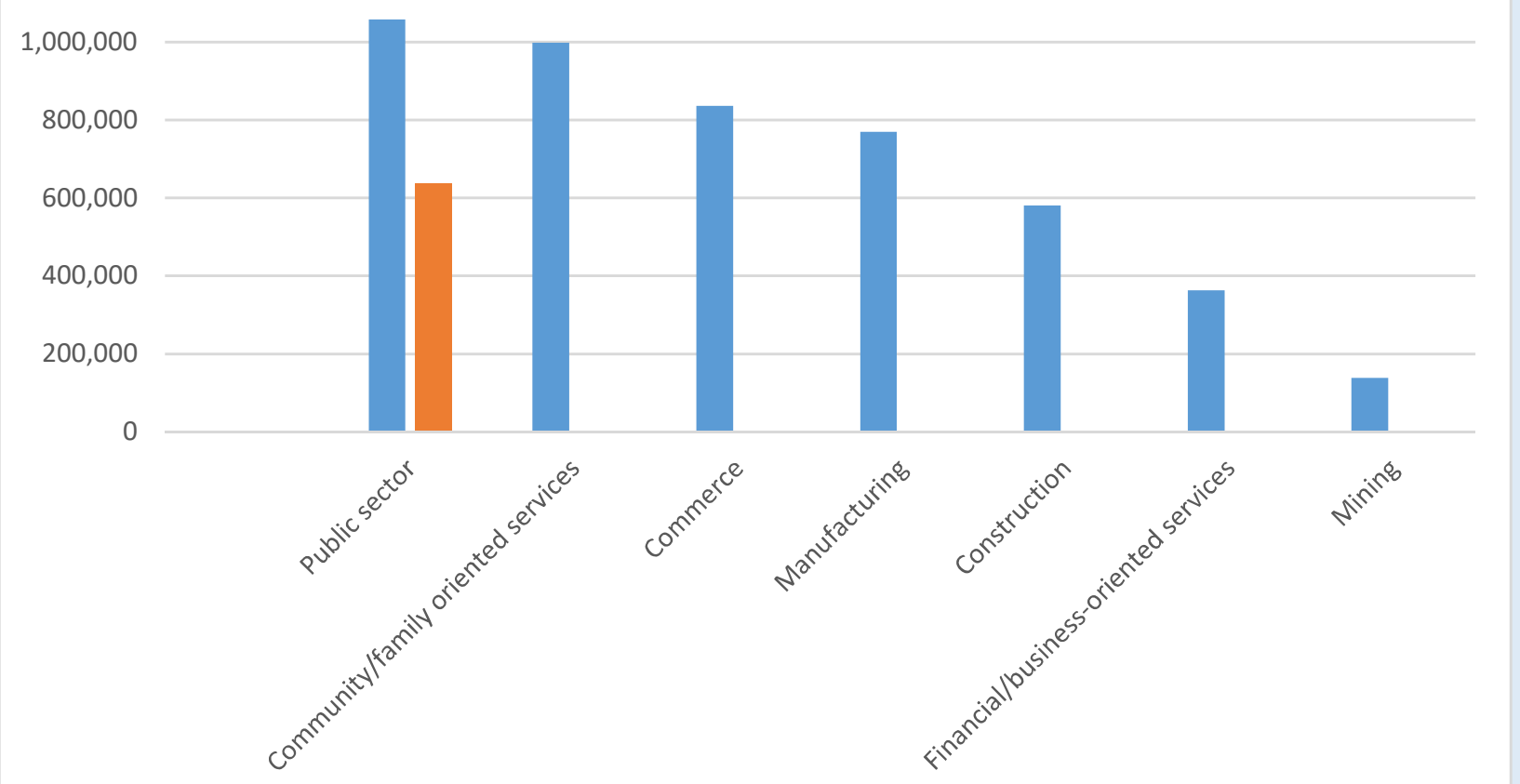

Note: Orange bar represents the increase in employment in government services (excluding public enterprises). Source: LFS, 1999; 2013.

Agriculture continued to absorb the bulk of unskilled labor. Of the total increase in agricultural employment of 9.2 million, close to 90 percent ( 8.2 million) was accounted for by low-skilled workers (with low-skilled defined as not having completed more than primary education). In the nonfarm sector, community and family services ${ }^{43}$ added the bulk of low-skilled labor, followed by commerce, manufacturing, construction, and mining (Figure 41). The public sector accounted for close to half of job creation for skilled workers (with skilled defined as at least incomplete secondary), with commerce, financial-and business services and transports and communications also adding a substantial number of nonfarm jobs. 
Figure 41: Services, trade and manufacturing added the bulk of low-skilled jobs between 1999 and 2013

(Job additions by sector and skill level, 1999-2013)

Net job additions - unskilled $\quad$ Net job additions - skilled

Community and family oriented services

Public administration

Financial and business-oriented services

Transports and communications

Commerce
Construction
Public utilities
Manufacturing
Mining

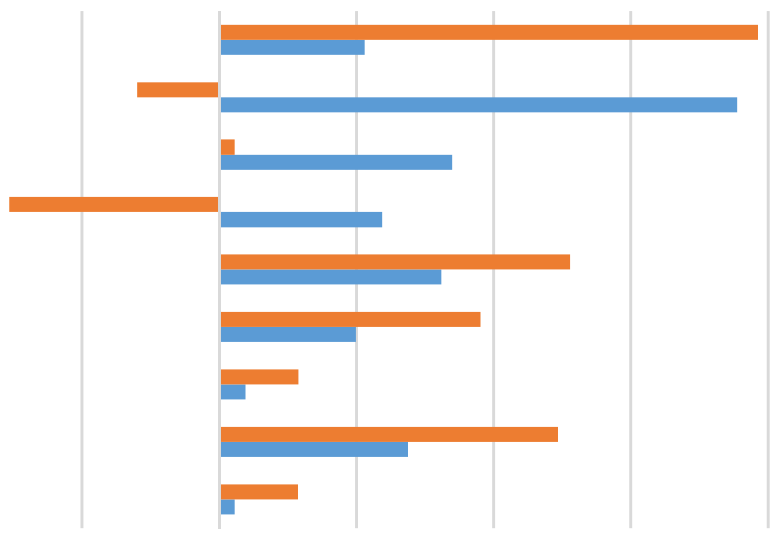

$-400,000-200,000$

0

$200,000 \quad 400,000 \quad 600,000 \quad 800,000 \quad 1,000,000$

Note: "Skilled" defined as having completed more than primary education. Source: LFS, 1999; 2013.

In line with the faster job growth in the nonfarm sector, agriculture's share of employment decreased modestly, although only since 2005. Between 1999 and 2005, the share of workers with a main job on the farm stagnated at 78 percent, but decreased by four percentage points

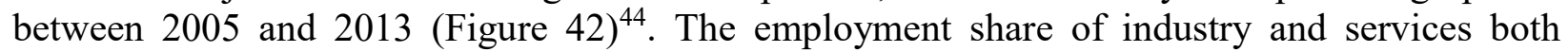
increased, mainly in wage employment. The share of workers with a main job as wage-employee in the nonfarm sector increased from seven percent in 1999 to ten percent in 2013 (Table 9), while the share of self-employed in the nonfarm sector remained largely the same.

\footnotetext{
44 The attentive reader may have noticed that agriculture's share of employment in 2013 differs between Figure 24 (70 percent) and Figure 42 (74 percent). The disparity can be explained by the different treatment of water and firewood collectors across LFS rounds. In 1999/05, collectors of firewood for own consumption were not considered as being in the labor force. In 2013, they were considered as part of the labor force and were sometimes classified as agricultural and sometimes as non-agricultural workers. To get a consistent trend through time, we classified firewood and water collectors as agricultural workers. For the 2013 snapshot however (Figure 24), we used the classification as included in the survey data. Excluding water and firewood collectors from the labor force, as Schmidt and Bekele (2016) have done, does not result in a different trend in agriculture's share of employment, but biases the labor force participation rates (Annex IV).
} 
Figure 42: A modest sectoral shift since 2005

(Sectoral employment shares, 1999-2005-2013)

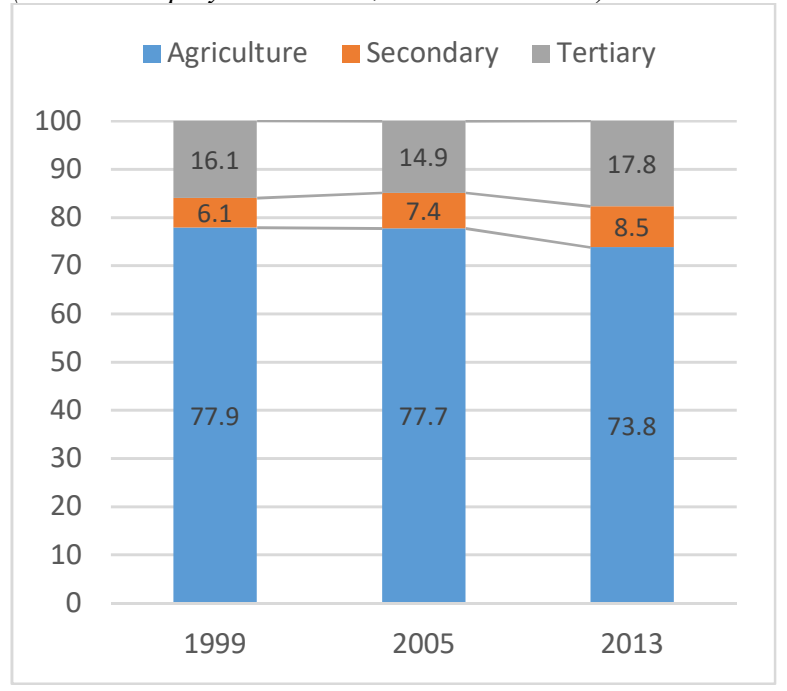

Source: LFS, 1999; 2013.

Table 9: An increase in wage employment between 1999 and 2013

(Share of workers by job category, 1999-2013)

\begin{tabular}{lcc}
\hline \hline Type of employment & 1999 & 2013 \\
\hline Agriculture & 77.7 & 73.6 \\
Self-employed farmer & 75.8 & 71.9 \\
Wage farmer & 1.9 & 1.7 \\
Non-agriculture & 22.2 & 26.5 \\
Wage nonfarm & 7.1 & 10.1 \\
Self-employed nonfarm & 15.1 & 16.4 \\
\hline \hline
\end{tabular}

Source: LFS, 1999; 2013.

Rapid population growth partly explains why the big absolute increase in nonfarm employment only resulted in a modest increase in the nonfarm employment share ${ }^{45}$. Ethiopia's working-age population is increasing by two million per year, which means that even large absolute increases in nonfarm employment (from a low base) merely make a dent in overall employment shares. Slower population growth would mean that similar increases in nonfarm employment translate into larger changes in the relative composition of employment. Population growth is expected to remain relatively high in the medium term given the sticky fertility rates: The total fertility rate decreased only marginally from 4.8 in 2011 to 4.6 in $2016^{46}$. The persistently high fertility rates mean that the cohorts of young people joining the labor force will only become larger over the coming decades, adding to the jobs challenge ${ }^{47}$.

\footnotetext{
${ }^{45}$ The low base of nonfarm employment also partly explains this.

${ }^{46}$ Based on the 2011 and 2016 DHS. The total fertility rate refers to the number of live births that a woman would have had at the end of the reproductive period if she were subject to the current age-specific fertility rates.

${ }^{47}$ It also means that the cohorts of children entering the education system will become ever larger.
} 


\section{Limited structural shifts mainly driven by young men through rural-urban migration}

The increase in nonfarm employment was mainly driven by young men. The share of young male workers with a main occupation outside agriculture increased by over seven percentage points between 1999 and 2013, with only a modest increase for young women. The increase in nonfarm employment only happened since 2005. Men in their late twenties in 2013 were significantly less likely to work in agriculture than men of the same age in 2005 and 1999 (Figure 43). The picture for women less clear, though also shows a slight drop in agricultural employment for women in their late twenties (Figure 44). Instead of agriculture, young men are increasingly likely to be engaged in wage-employment in the nonfarm sector (Figure 45), and-to a lesser extentnonfarm self-employment. The trend towards increasing wage-employment in the nonfarm sector is also discernible for young women (Figure 46).

Figure 43: Young men are becoming less likely to work in agriculture...

(Share of agricultural workers by time and age-men)

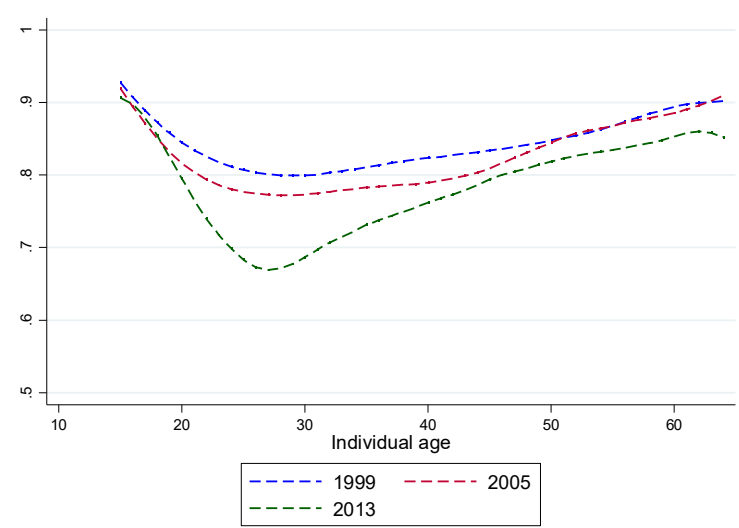

Source: LFS, 1999; 2005; 2013.

Figure 45: Instead, young men are more likely to be wage employed in the nonfarm sector...

(Share of men in non-waged employment, by time and age)

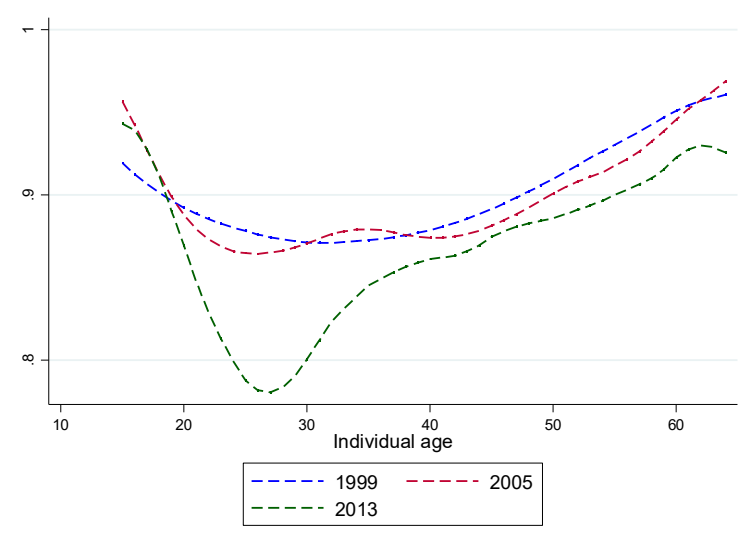

Figure 44: But the picture is less clear for women

(Share of agricultural workers by time and age-women)

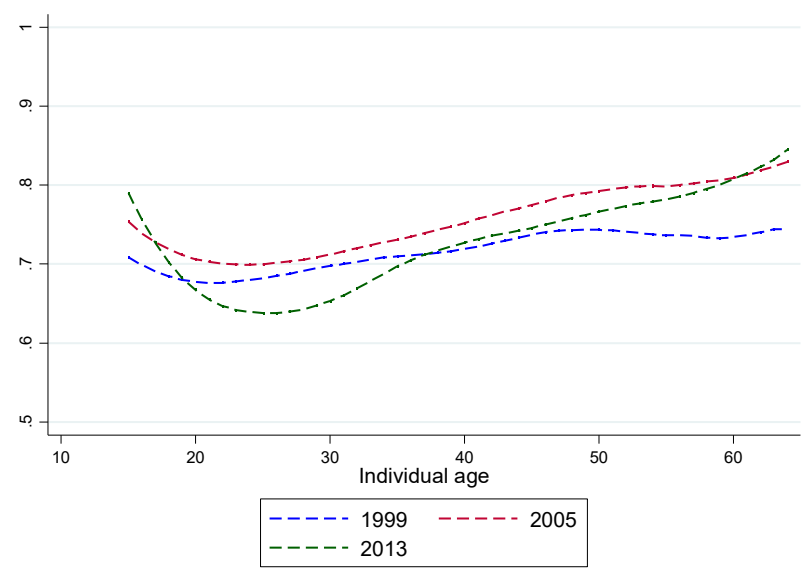

Source: LFS, 1999; 2005; 2013.

Figure 46: As are young women

((Share of women in non-waged employment, by time and age)

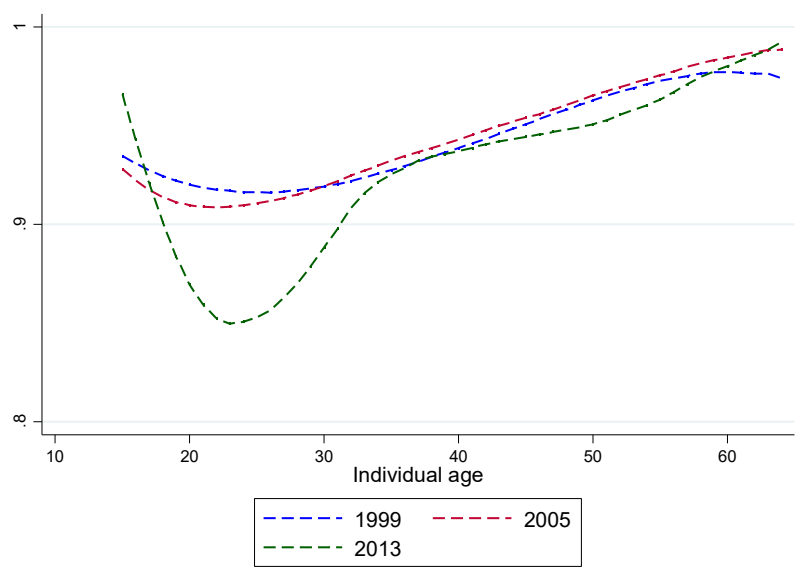


Younger workers that were already active in the labor market in 1999 were also more likely to transition to nonfarm employment. While Figure 43 and Figure 44 compare young workers in 1999 with young workers in 2005 and 2013 (different cohorts), Figure 47 and Figure 48 follow same cohorts of men and women through time, from 1999 over 2005 to 2013. For men who were in their late teens or early twenties in 1999, we observe a slow but steady move out of agricultural employment as they grew older (downward-sloping lines to the left of Figure 47). For men who were already 30-years or more in 1999, the lines are flat, indicating that sector of employment is fairly definitive once a man reaches age 30 . Women workers do not experience a clear move out of agriculture as they grow older (Figure 48).

Figure 47: Men that were in their late teens in 1999 have tended to move out of agriculture since (Share of agricultural workers by cohort, time and agemales)

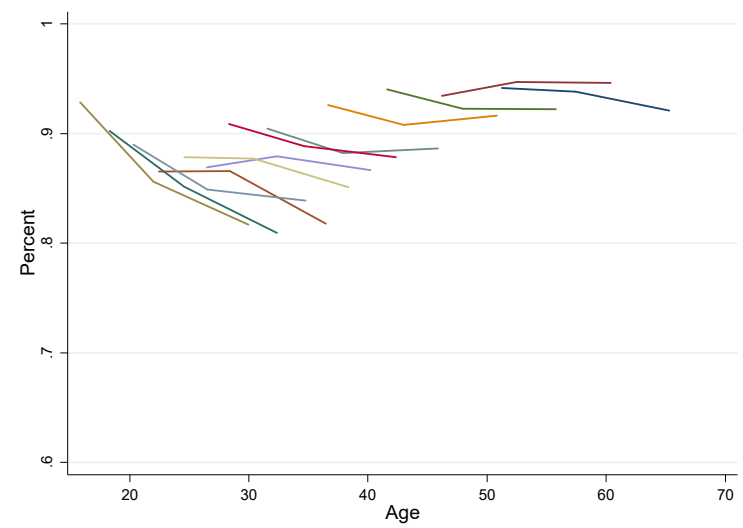

Source: LFS, 1999; 2005; 2013.
Figure 48: Women largely stay in agriculture as they get older

((Share of agricultural workers by cohort, time and agefemales)

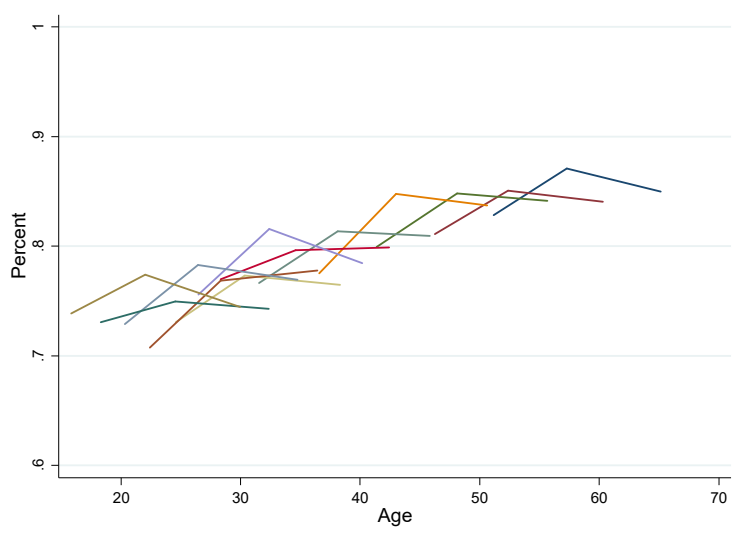

Source: LFS, 1999; 2005; 2013.

The observed shifts to nonfarm and wage-employment have been closely associated with rural-urban labor mobility. The share of the labor force living outside the 21 cities identified in the LFS decreased marginally from 93 percent in 1999 and 2005 to 90 percent in 2011. The migration module included in the LFS confirms that rural to urban migration has increased from a low base since 2005: While the rate of internal migration has remained largely stable at a low level (about five percent) between 1999 and 2013, the share of migration that goes from rural to urban areas increased from 23 percent in 1999 and 2005 to 35 percent in 2013 (Table 10). Between 2008 and 2013, rural to urban migration has become, for the first time, the dominant type of internal migration. 
Table 10: Rural to urban migration has picked up since 2005

(Internal migration by type, 1999-2013)

\begin{tabular}{lccc}
\hline \hline Extent and type of migration & 1999 & 2005 & 2013 \\
\hline Recent migration (\% of population) & 4.3 & 6 & 4.7 \\
Rural to urban (\%) & 23 & 24 & 35 \\
Rural to rural (\%) & 36 & 45 & 24 \\
Urban to rural (\%) & 16 & 12 & 17 \\
Urban to urban (\%) & 24 & 17 & 24 \\
\hline \hline Note: A recent migrant is defined as a person who changed zone of residence in the five years prior to \\
the survey. Source: LFS, 1999; 2005; 2013.
\end{tabular}

The increased move from rural to urban areas since 2005 coincides with the modest changes in the employment structure. Between 1999 and 2005, the sectoral composition of employment did not change while rural to urban migration remained at a constant low level. Since 2005, agriculture's share of employment started declining modestly as rural to urban migration picked up (Figure 42 and Table 10). Decomposing the decrease in agriculture's share of employment since 1999 , we find that more than half (56 percent) can be accounted for by the increased share of the labor force in urban areas (the "population-shift" effect). Similarly, more than half (53 percent) of the increase in paid employment between 1999 ( 9 percent) and 2013 (13 percent) can be accounted for by the population-shift effect. As shown in Chapter 1, this population shift effect has contributed to the growth in value-added per worker and GDP per capita.

Migration has been an important channel through which workers, especially young workers, in Ethiopia move into nonfarm employment. The cohort graphs presented in Figure 47 and Figure 48 showed that younger cohorts, and in particular males, were more likely to move into nonfarm occupations. Comparing this graph with the evolution of the share of the cohort that lives in cities is telling: Cohorts in which a higher share of persons moved to cities (mainly young male cohorts - Figure 49) also experienced a higher move to non-farm employment (or a higher move out of agriculture, the way the graph is structured). Women were less likely to move to cities (Figure 50), which may explain their relatively static employment structure (though young women also move to cities in substantial numbers). Formalizing this using a longitudinal cohort analysis (see Annex 4 for details), we find, controlling for unobservable fixed effects, that cohorts in which a higher share of people moved to cities tended to move out of agriculture and into paid employment $(\text { Table } 11)^{48}$. All else equal, a 1 percentage point increase in the share of a cohort living in urban areas was associated with a 1.4 percentage point decrease in agricultural employment in the cohort and a similar increase in the share of paid employment in the cohort.

\footnotetext{
${ }^{48}$ Cohorts are defined in terms of birthyear, gender, and education (see Annex 4).
} 
Figure 49: Young men have moved to urban areas as they grew older

(Share of cohort living in cities, by time-males)

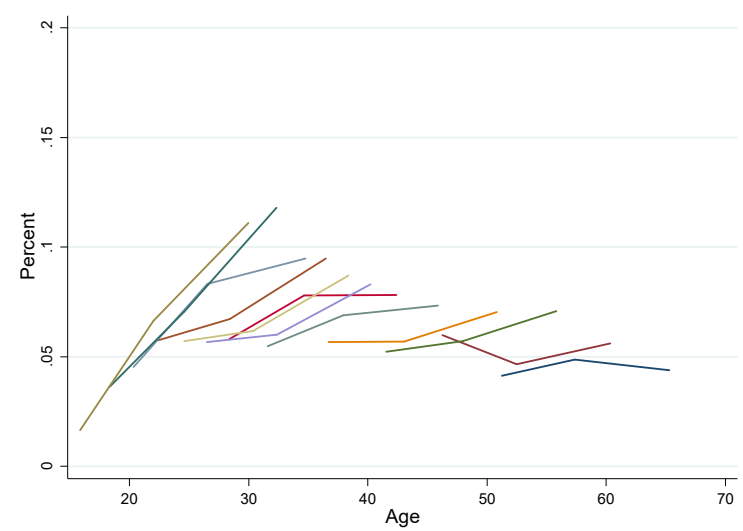

Source: LFS, 1999; 2005; 2013.
Figure 50: Young women as well, but much less so

(Share of cohort living in cities, by time-females)

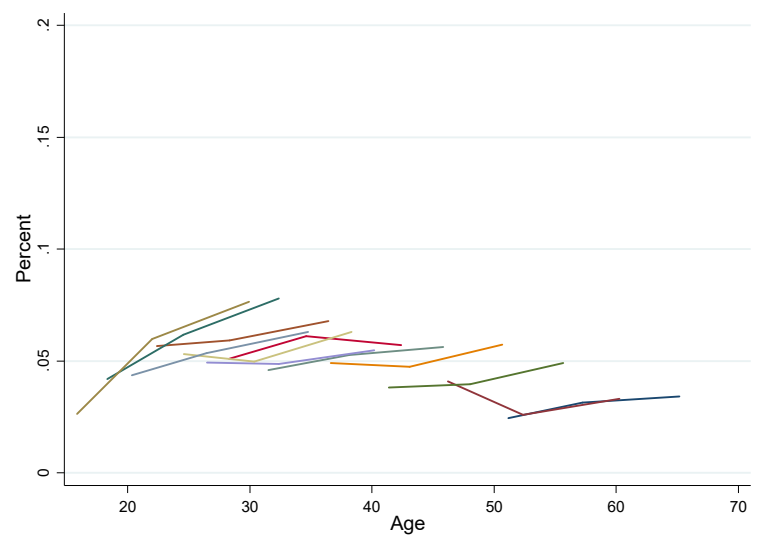

Source: LFS, 1999; 2005; 2013.

Table 11: At the cohort level, urbanization was associated with a decrease in agricultural employment and an increase in paid employment

(Cohort-level fixed effects panel regression of agricultural and paid employment on urban share)

\begin{tabular}{lcc} 
(Cohort-level fixed effects panel regression of agricultural and paid employment on urban share) \\
\hline \hline & $\begin{array}{c}\text { Share of cohort in } \\
\text { agricultural employment }\end{array}$ & $\begin{array}{c}\text { Share of cohort in paid } \\
\text { employment }\end{array}$ \\
\hline Share of cohort in urban areas & $-1.358^{* * *}$ & $1.357^{* * *}$ \\
Constant & $0.156]$ & {$[0.113]$} \\
& $0.826^{* * *}$ & 0.013 \\
Fixed effects & {$[0.014]$} & {$[0.010]$} \\
Observations & Yes & Yes \\
Groups & 320 & 320 \\
R squared (within) & 136 & 136 \\
\hline \hline Note: In each survey round, cohorts were defined based on birthyear, resulting in 136 unique non- \\
overlapping cohorts. These cohorts are followed through time between 1999, 2005 and 2013 to examine \\
whether cohort migration is linked to employment outcomes. For a detailed exposition, consult Annex \\
$* * *:$ Statistically significant at 1\%. Source: LFS, 1999; 2005; 2013.
\end{tabular}

\section{A largely static employment structure in rural areas}

Within rural areas, the employment structure barely changed between 1999 and $2013^{49}$. Agriculture accounted for about 80 percent of rural/small town employment in all three survey rounds. If any, the main observation from Figure 51 is the slow but steady increase in wage employment in the nonfarm sector (the grey sections in the Figure), presumably driven by small rural towns.

49 Due to the difference in sampling frames, rural/urban definitions are not comparable across the three LFS rounds. Each of the rounds does however identify 21 cities and major towns. For the sake of comparability, we define all areas outside these 21 urban centers as "rural and small town" and use this consistently across the three rounds. 
Figure 51: No notable changes in rural employment structure

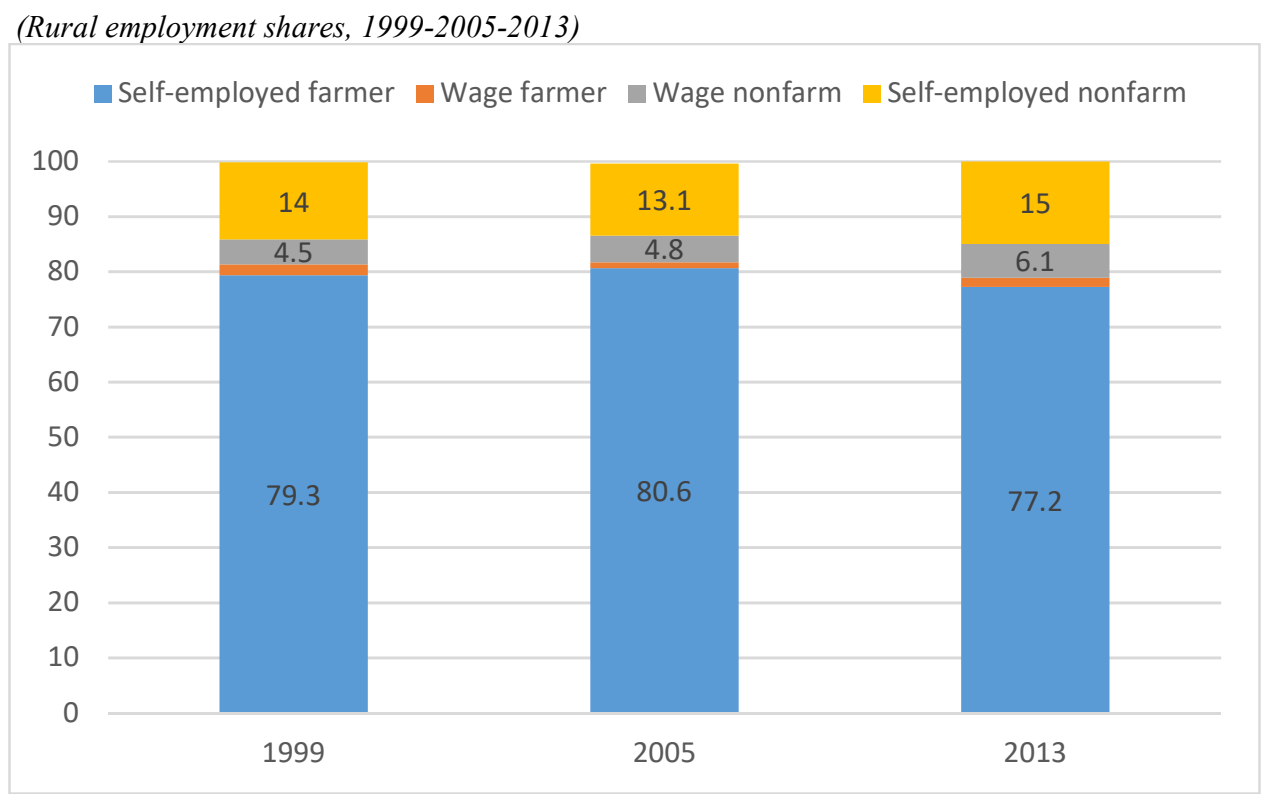

Source: LFS, 1999; 2005; 2013.

The few changes there have been in rural areas have been driven by young workers, in particular young men. The share of young men in rural areas that have a main job in agriculture dropped by six percentage points, due to a decrease in the share of young men self-employed on the farm (Table 12). Rural young men are now more likely to be engaged in wage- and selfemployment in the nonfarm sector. Young women in rural areas did not experience a move out of agriculture, but also became more likely to be wage-employed in the nonfarm sector.

Table 12: A timid move to nonfarm activities for young men in rural areas

(Share of young workers by job category and gender, 1999-2013)

\begin{tabular}{lcccc}
\hline \hline & \multicolumn{2}{c}{ Young Men } & \multicolumn{2}{c}{ Young Women } \\
\hline Type of employment & 1999 & 2013 & 1999 & 2013 \\
\hline Agriculture & 88 & 82.1 & 71.7 & 71.6 \\
$\quad$ Self-employed farmer & 83.8 & 78.4 & 70.8 & 70.7 \\
Wage farmer & 4.2 & 3.7 & 0.9 & 0.9 \\
Non-agriculture & 12 & 18 & 28.4 & 28.5 \\
Wage nonfarm & 4.4 & 7.8 & 4.2 & 6.2 \\
Self-employed nonfarm & 7.6 & 10.2 & 24.2 & 22.3 \\
\hline \hline
\end{tabular}

Source: LFS, 1999; 2013.

Interestingly, the decrease in the share of young men who are "self-employed farmers" is due to the decline in "independent farmers" (people cultivating their own fields). Though the LFS do not include data on land ownership, data from the ESS surveys show that the share of young men who have their own land decreased sharply between 2012 and 2016 (Figure 52). It is possible that shortage of land explains the decrease in "independent farming" among rural youth ${ }^{50}$.

${ }^{50}$ On the other hand, it may also be that rural youth are marrying later due to factors other than land shortage, which would explain why they are less likely to be classified as independent farmers (most youth inherit land when they marry). 
Land shortages also came up prominently during the qualitative research as one of the main push factors for young men to migrate to towns and cities.

Figure 52: Land ownership has decreased, mainly among younger men

(Share of rural men owning at least one parcel of land, 2012-2014-2016, by age)

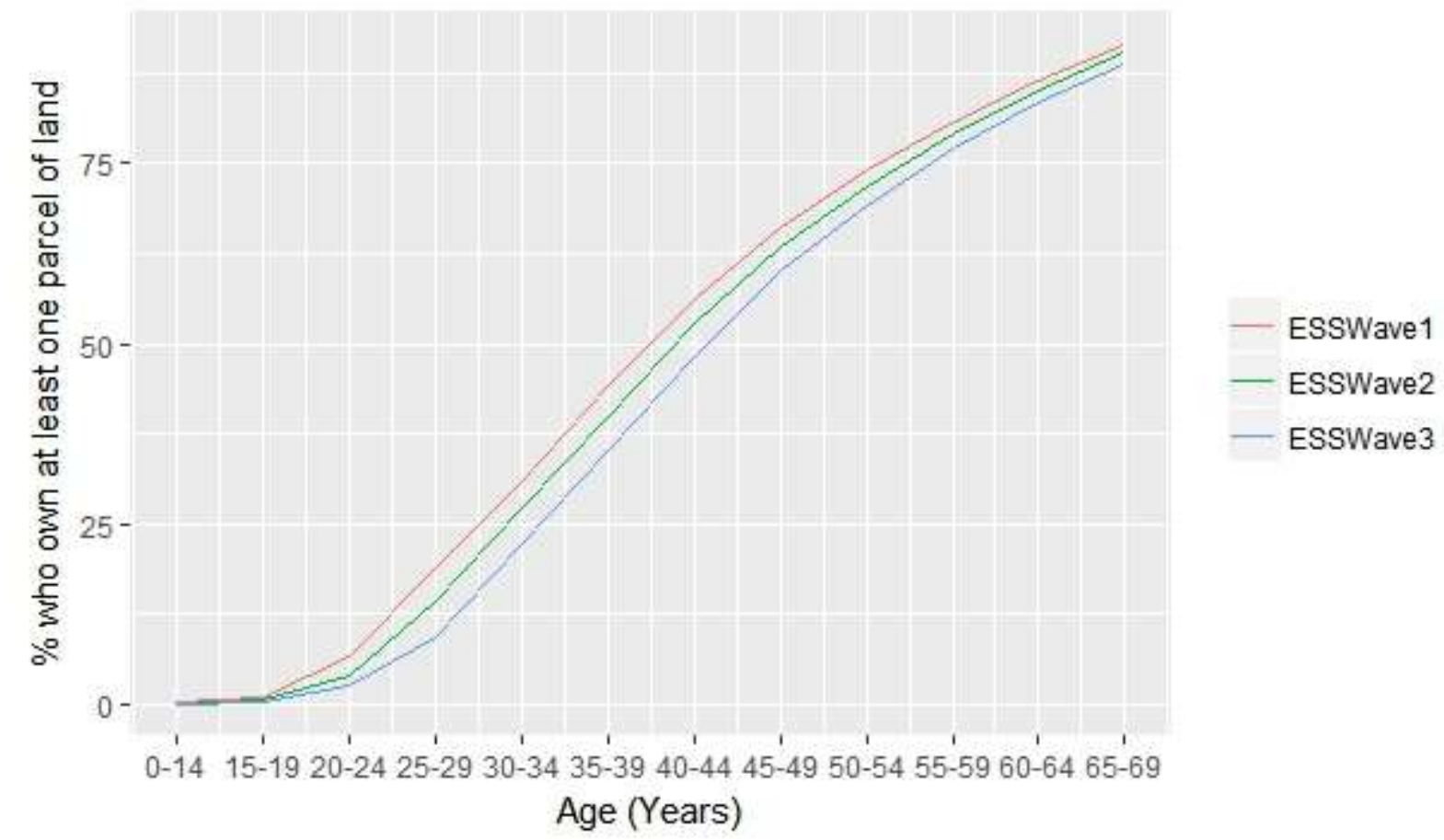

Source: ESS1; ESS2; ESS3.

\section{An increase in wage earnings, mainly for low-earners}

Between 2005 and $2013^{51}$, median wage earnings increased by 24 percent, from ETB 788 per month to ETB 979 per month in 2013 (equivalent to about US\$140 in PPP terms) ${ }^{52}$. Median hourly earnings increased by less than total earnings, pointing towards an increase in working hours for wage workers. The increase in wage earnings was particularly strong for low earners, reflecting the increase in agricultural productivity: monthly earnings doubled at the tenth percentile and increased by 74 percent at the $25^{\text {th }}$ percentile (Table 13). In contrast, both total and hourly earnings decreased in real terms at the $75^{\text {th }}$ and $90^{\text {th }}$ percentile. As also explained in the fifth Ethiopian Economic Update, the decrease in real wages at the upper end of the distribution can be explained by the wage freeze in the public sector, which accounts for most of the workers with relatively higher wage earnings.

\footnotetext{
${ }^{51}$ The 1999 LFS did not include information on wages.

${ }^{52}$ The reader is advised to keep in mind that wage employment only accounts for about 12 percent of total employment in Ethiopia. The figures in this section thus only refer to a small share of workers.
} 
Table 13: Wage earnings increased at the lower end of the distribution

(Monthly earnings by selected percentiles in 2013 prices, 2005-2013)

\begin{tabular}{|c|c|c|c|c|c|c|}
\hline & 10th & 25th & 50th & 75th & 90th & Gini \\
\hline & \multicolumn{6}{|c|}{ Monthly earnings } \\
\hline 2005 & 118 & 276 & 788 & 1,774 & 3,173 & 0.546 \\
\hline \multirow[t]{2}{*}{2013} & 250 & 480 & 979 & 1,700 & 2,800 & 0.475 \\
\hline & \multicolumn{6}{|c|}{ Hourly earnings } \\
\hline 2005 & 0.7 & 1.6 & 4.4 & 10.3 & 18.8 & 0.570 \\
\hline 2013 & 1.2 & 2.4 & 5.3 & 10.2 & 16.9 & 0.513 \\
\hline
\end{tabular}

Source: Authors' calculations based on 2005 and 2013 LFS data.

The distributional change in wage earnings is reflected in different dynamics across sectors. Wage workers in agriculture-who typically have the lowest earnings-experienced the strongest increase in earnings (though they remain low), while public sector workers experienced a decrease. Manufacturing wages remained mostly flat, while construction and especially commerce experienced a strong increase. Wage workers in transports and communications and financial-and business-oriented services experienced a decrease in real wages, mainly related to the large share of the public sector in those two industries. Overall, the share of workers earning below the national poverty line dropped substantially between 2005 and 2013.

Table 14: Wage earnings increased at the lower end of the distribution (Monthly earnings by selected percentiles in 2013 prices, 2005-2013)

\begin{tabular}{lcccc} 
& \multicolumn{2}{c}{ Median monthly earnings } & \multicolumn{2}{c}{ Low-earnings rate } \\
& $\mathbf{2 0 0 5}$ & $\mathbf{2 0 1 3}$ & $\mathbf{2 0 0 5}$ & $\mathbf{2 0 1 3}$ \\
\cline { 2 - 4 } Total & & & & \\
\hline Agriculture & 788 & 979 & 32.9 & 52.0 \\
Manufacturing & 205 & 350 & 60.1 & 19.7 \\
Construction & 788 & 800 & 27.8 & 14.3 \\
Commerce & 710 & 900 & 26.8 & 27.9 \\
Transports and communications & 473 & 700 & 42.6 & 25.9 \\
Financial and business oriented services & 1269 & 897 & 15.1 & 3.6 \\
& 2,089 & 1719 & 5.0 & \\
Public & & & & 5.5 \\
Formal & 1,589 & 1,427 & 15.8 & 11.6 \\
Informal & 808 & 1,000 & 22.0 & 32.2 \\
Domestic Worker & 473 & 600 & 41.6 & 74.9 \\
\hline
\end{tabular}

Note: Some workers cannot be classified in any of the sectors (5.3 percent in 2005 and 7.3 percent in 2013). The overall average is calculated on all workers including those that cannot be categorized in any of the sectors.

Source: Authors' calculations based on 2005 and 2013 LFS data. 
Returns to education declined between 2005 and 2013. Median monthly and hourly earnings declined for all educational categories except for workers without schooling (Table 15) ${ }^{53}$ Returns to education declined particularly sharply at relatively higher levels of education: Returns to complete secondary and post-secondary education went down by 41 and 55 percentage points between 2005 and $2013^{54}$. Though such a large reduction could potentially be due to a large inflow of workers with higher education levels (the number of labor force participants who completed at least secondary more than doubled between 2005 and 2013), the wage freeze in the public sector is the more likely culprit: Almost 60 percent of workers with completed secondary or more work in the public sector, which means a public sector wage freeze will translate into decreasing returns to education ${ }^{55}$. In addition, the unemployment rate among higher educated people decreased since 2005 , which is inconsistent with an increasing surplus of educated workers.

Table 15: Earnings declined for all wage workers, except for those without schooling

(Median monthly and hourly earnings by educational attainment and year, 2013 ETB)

\begin{tabular}{lcccc} 
& \multicolumn{2}{c}{ Monthly earnings } & \multicolumn{2}{c}{ Hourly earnings } \\
& 2005 & 2013 & 2005 & 2013 \\
\cline { 2 - 5 } & & & & \\
No education & 237 & 400 & 1.6 & 2.2 \\
Primary incomplete & 552 & 500 & 2.8 & 2.6 \\
Primary complete & 907 & 700 & 4.5 & 3.6 \\
Secondary incomplete & 1025 & 900 & 5.2 & 4.6 \\
Secondary complete & 1601 & 1200 & 8.3 & 6.6 \\
Post-secondary & 2614 & 1750 & 15.5 & 10.9 \\
Adult literacy & 710 & 550 & 3.6 & 2.8 \\
\hline
\end{tabular}

Source: LFS, 1999; 2013.

\section{Conclusions}

Employment in Ethiopia remains dominated by agriculture and non-waged labor. In 2013, about 70 percent of workers in Ethiopia had a main job in agriculture and closed to 90 did not earn wages for their labor. Employment in the nonfarm sector is roughly evenly split between wageand self-employment, with higher-educated workers more likely to work in wage-employment, mainly in the public sector. Women and youth appear particularly disadvantaged: The bulk of women and youth are self-employed on the household farm or in a nonfarm activity, their unemployment rates are higher and their earnings lower.

Employment outcomes have nevertheless improved, in particular since 2005 and mainly in urban areas. After stagnating between 1999 and 2005, agriculture's share of employment decreased modestly between 2005 and 2013. This was driven by strong employment growth in the nonfarm sector, mainly in services and urban areas. The decrease in the employment share of

54 See Annex 8

55 Repeating the analysis without public sector wage workers also results in decreasing returns to education. This can potentially be explained by the role of the public sector as a wage-setter for the formal sector. Given that the public sector accounts for the largest share of wage employment, the formal private sector may index their wages to those of the public sector. This is merely hypothetical though. 
agriculture was associated with increased rural-urban mobility of young workers since 2005 . Though nonfarm employment grew stronger in relative terms, in absolute terms agriculture still absorbed most of the new workers between 1999 and 2013. Real wages steadily grew between 2005 and 2016, further highlighting that urban areas have done relatively well in terms of employment since 2005 (as most of the wage employment is in urban areas).

In terms of employment structure rural areas appear to have been largely static. 80 percent of rural workers were self-employed in agriculture, both in 1999 and 2013. Two notable trends in rural areas have been the decline in the share of young men working as independent farmer, presumably related to land scarcity, and a timid move towards more nonfarm wage-employment. Overall, the rural nonfarm economy in Ethiopia remains however small, and rural accessibility remains low in spite of big infrastructural improvements. 


\section{Chapter III. Youth in Ethiopia's labor market}

\section{Introduction}

This chapter zooms in on the employment patterns and trends of youth in Ethiopia. Throughout this chapter, we define "youth" as people between 15 and 29 years of age, and "young workers" as youth who are employed. Though we will mainly be concentrated on the labor outcomes of rural youth, and the changes therein over time, we will also sketch some general findings on urban youth. Readers specifically interested in urban labor markets can refer to the fifth Ethiopia Economic Update ${ }^{56}$.

The challenge of youth employment in Ethiopia is daunting due to the sheer numbers. More than 70 million of the country's estimated population of close to 100 million are below the age of 30. Youth account for more than half of the total working-age population. 13 million young Ethiopians are currently between 10 and 14 years old and will join the labor force over the coming five to 10 years. While this youth bulge could be a boon for growth, Ethiopia's youth remains largely unskilled despite the improvements in access to education, and mainly employed in lowproductivity occupations.

This chapter proceeds as follows: Section 2 summarizes the employment situation of youth and highlights the main changes since 1999. Section 3 describes and analyzes recent youth transitions, focusing mainly on moving out of NEET and on diversifying out of agricultural employment. The final section concludes. Parts of this chapter are based on a qualitative research study with rural youth in Ethiopia. The design of this research is summarized in Annex XX.

\section{The employment situation of youth}

\section{Youths are more likely to be unemployed and are overrepresented in unpaid labor}

As in many countries, standard labor market indicators in Ethiopia are worse for youth than for the overall working-age population. Youth have lower labor force participation rates and employment rates than older workers, and are twice as likely to be unemployed ( 7 percent of youth were unemployed in 2013, compared to 3.5 percent of older people - Table 16). Youth in wage employment earn substantially less than older workers, and are twice as likely to earn wages below the poverty line (low-earnings rate of 29 percent for young workers, compared to 13 percent of older workers). Employment outcomes are particularly bad for young women: Employment rates are lowest, and unemployment and underemployment rates highest, for women between 15 and 29 years of age. Young women in wage work also have the highest low-earnings rates (more than one-third of young women in wage employment earn below the poverty line).

56 http://www.worldbank.org/en/country/ethiopia/publication/fifth-ethiopia-economic-update-why-idle-wages-employment-crowded-labor-market 
Table 16: Key labor market indicators, by age, gender, and region (2013)

\begin{tabular}{|c|c|c|c|c|c|c|c|c|c|c|c|c|c|}
\hline & & \multicolumn{2}{|c|}{$\begin{array}{l}\text { Labor force } \\
\text { participation }\end{array}$} & \multicolumn{2}{|c|}{$\begin{array}{l}\text { Employment } \\
\text { ratio }\end{array}$} & \multicolumn{2}{|c|}{$\begin{array}{l}\text { Unemployment } \\
\text { rate }\end{array}$} & \multicolumn{2}{|c|}{$\begin{array}{l}\text { Underemployment } \\
\text { rate }\end{array}$} & \multicolumn{2}{|c|}{$\begin{array}{l}\text { Low-earnings } \\
\text { rate (waged } \\
\text { workers) }\end{array}$} & \multicolumn{2}{|c|}{$\begin{array}{l}\text { Working hours } \\
\text { (median) }\end{array}$} \\
\hline & & $15-29$ & $30-64$ & $15-29$ & $30-64$ & $15-29$ & $30-64$ & $15-29$ & $30-64$ & $15-29$ & $30-64$ & $15-29$ & $30-64$ \\
\hline \multicolumn{2}{|l|}{ Total } & 81.9 & 89.6 & 76.3 & 86.5 & 6.9 & 3.5 & 22.5 & 21.8 & 28.7 & 13.3 & 31.0 & 33.0 \\
\hline \multirow{7}{*}{ Gender } & Male & 85.6 & 97.0 & 81.6 & 95.4 & 4.7 & 1.6 & 19.3 & 19.4 & 24.3 & 10.9 & 36.0 & 39.0 \\
\hline & Female & 78.5 & 82.4 & 71.3 & 77.7 & 9.2 & 5.7 & 26.0 & 24.6 & 34.6 & 19.5 & 26.0 & 26.0 \\
\hline & Tigray & 81.2 & 87.7 & 74.7 & 83.4 & 8.0 & 4.9 & 21.0 & 23.6 & 26.1 & 14.9 & 28.0 & 27.0 \\
\hline & Afar & 84.0 & 87.5 & 76.8 & 81.5 & 8.6 & 6.9 & 12.0 & 9.1 & 29.5 & 17.8 & 40.0 & 45.0 \\
\hline & Amhara & 86.1 & 90.9 & 81.3 & 88.5 & 5.6 & 2.7 & 22.8 & 24.0 & 32.4 & 19.5 & 28.0 & 28.0 \\
\hline & Oromia & 84.3 & 90.8 & 79.9 & 89.2 & 5.2 & 1.8 & 24.4 & 22.8 & 29.8 & 14.4 & 33.0 & 35.0 \\
\hline & Somali & 63.8 & 80.4 & 59.1 & 78.0 & 7.4 & 2.9 & 8.7 & 6.9 & 17.9 & 5.9 & 42.0 & 47.0 \\
\hline \multirow[t]{6}{*}{ Region } & $\begin{array}{l}\text { Benishangul } \\
\text { G. }\end{array}$ & 84.3 & 93.3 & 80.6 & 91.5 & 4.4 & 1.9 & 18.8 & 21.5 & 16.2 & 9.0 & 30.0 & 32.0 \\
\hline & SNNP & 80.1 & 89.8 & 74.9 & 87.4 & 6.5 & 2.7 & 24.6 & 22.6 & 30.7 & 17.3 & 28.0 & 33.0 \\
\hline & Gambela & 67.7 & 89.6 & 62.8 & 87.5 & 7.2 & 2.4 & 13.9 & 12.9 & 9.9 & 4.8 & 23.0 & 34.0 \\
\hline & Harari & 69.8 & 88.3 & 60.8 & 82.1 & 12.9 & 7.0 & 10.8 & 9.1 & 14.5 & 7.4 & 40.0 & 42.0 \\
\hline & Addis Ababa & 64.6 & 81.0 & 46.5 & 64.0 & 28.0 & 21.0 & 5.9 & 5.8 & 24.4 & 6.0 & 48.0 & 48.0 \\
\hline & Dire Dawa & 70.5 & 84.8 & 56.1 & 73.8 & 20.4 & 13.0 & 10.6 & 9.4 & 27.8 & 9.9 & 42.0 & 44.0 \\
\hline
\end{tabular}

Source: LFS, 2013. 
Though youth unemployment is fairly low due to Ethiopia's largely rural nature, it is high in urban areas. In 2013, 22 percent of urban youth was unemployed, compared to 17 percent of the urban working-age population in general. Youth unemployment in urban remained relatively stable in recent years, at 23 percent in 2015 (CSA, 2016). Though still high, youth unemployment in urban areas has decreased substantially from 35 percent in 2005 and 44 percent in 1999. Urban youth unemployment declined virtually across the board, but mostly in Bahir Dar, Adigrat, Nekemte, Jijiga, Nazreth, Arba Minch, and Gambela (Annex Figure 2). Open youth unemployment in rural areas and small towns has remained constant at slightly over five percent. About two-thirds of Ethiopia's unemployed youth lives in urban areas.

Young workers in rural areas are mainly involved in self-employment on the household farm, while nonfarm wage employment dominates in urban areas. In rural areas, young men are almost uniquely involved in farming, while young women are relatively more involved in nonfarm self-employment (Figure 53). This mainly consists of water and firewood fetching. In urban areas, half of youth are wage-employed in the nonfarm sector, with an additional 40 percent being self-employed, mainly in small nonfarm enterprises (Figure 54). The employment structure in urban areas is fairly similar for young men and women (though young women face higher unemployment rates). As shown in the previous chapter, the employment structure of rural youth did not change since 1999, despite clear aspirations to do so (Box 7).

Figure 53: Rural youth are mainly employed as unpaid workers...

(Share of rural youth by employment category, by gender)

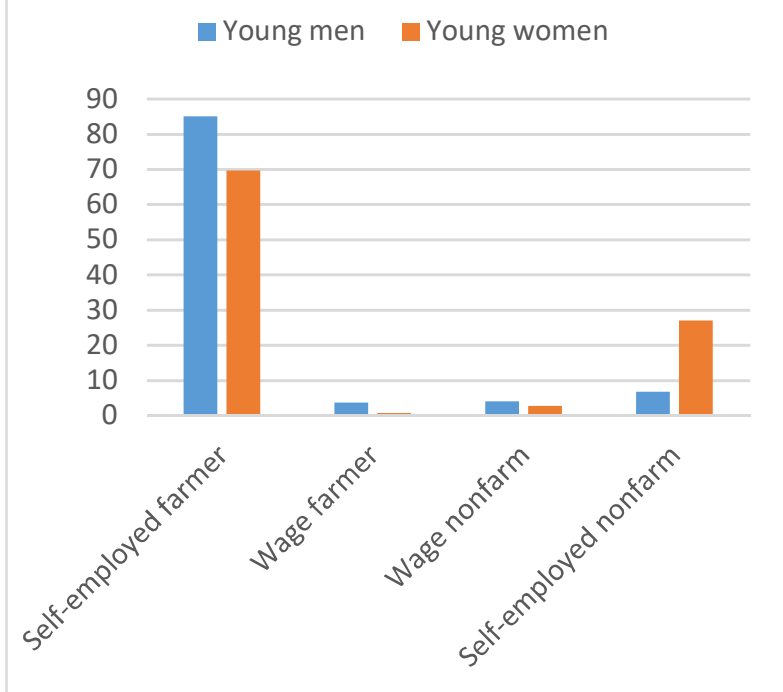

Source: LFS, 2013.
Figure 54: While urban youth tend to be wage- or selfemployed in the non-farm sector

(Share of urban youth by employment category, by gender)

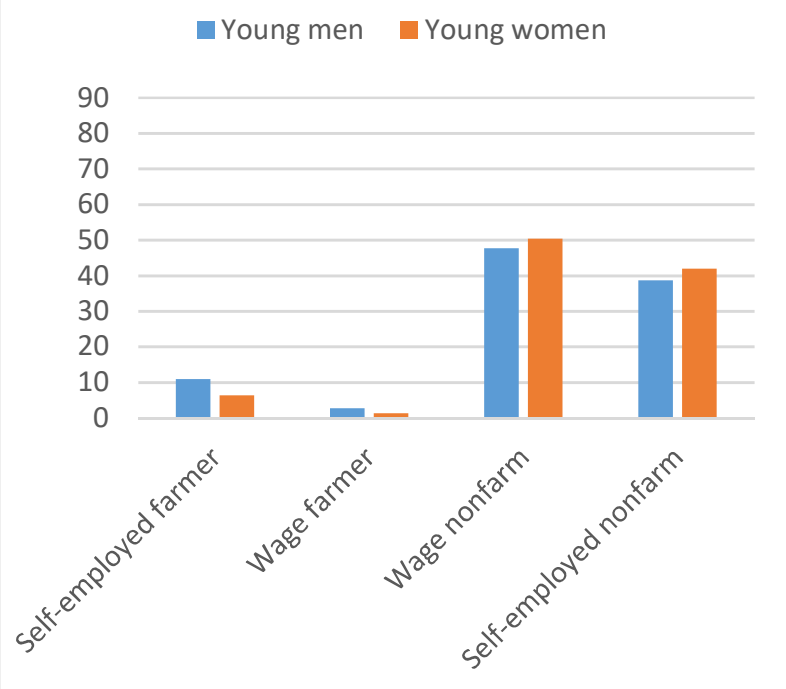

Source: LFS, 2013.

\section{Box 7}

\section{Aspirations and preferences of rural youth} Insights from focus group discussions

Focus group participants articulated their aspirations in ways that reflected the influence of the natural resources in their surrounding environment, the immediate challenges faced by their communities, and their previous exposure to types of economic activities.

Farming: "I want to engage in farming and produce in a modern way." 
If constraints to accessing working space and finance were removed, most rural youth, whether male or female, say they would like to engage themselves in meaningful farm employment. They see farming as an honorable occupation that can lead to an improved life and a sustainable livelihood, and seem to understand that what matters most is the application of modern farming methods and the availability of appropriate inputs. Though farming is still seen as a desirable occupation, the obstacles youth face in accessing land increasingly makes this a less viable option.

Trading: "If we vend butter, cheese, tea, and injera it would be profitable. But the challenge is finance."

In the absence of available farmland (and in some kebeles, because of declining rainfall and production), youths' aspirations have shifted from farming to trade. This tendency is particularly pronounced in those kebeles that are relatively connected to other towns, as youth are more frequently exposed to a range of non-agricultural economic activities, and therefore have relatively more dynamic aspirations. During the focus group discussions, many expressed their desire to branch into the trade of agricultural products, livestock, and manufactured goods. Some discussed exploiting the natural resources in their surrounding environment to access markets. A few spoke of providing catering services.

Wage employment: "Since there are natural resources like soda ash here, if a factory comes, I want to work in that factory."

Many focus group participants expressed their desire to be employed by a factory so that they can earn a salary, and frequently lamented the unavailability of factories in their kebeles. Some cited places like the Hawassa Industrial Park as somewhere to move to find wage employment, while others mentioned commercial farms in Ziway or Awash Valley.

\section{Education: "I want to become a teacher when I complete my education."}

Some participants aspired to go to school and come away with tangible skills that they can use as salaried employees in service industries or government employment. This is especially true in kebeles where there is no infrastructure or finance available to support their dreams of starting their own businesses. Desired jobs include teaching, health care provision, agricultural extension services, and the civil service. Simultaneously, there is an increasing awareness among focus group participants that education no longer guarantees employment.

Migration: "If there are job opportunities here, we would like to work here, but, since the kebele is not productive, we want to migrate abroad."

Youth feel compelled to migrate when they cannot access land or finance to start their own businesses, particularly in areas where there is no infrastructure to support businesses that can offer wage employment. All focus group participants described youth migration as prevalent in their kebeles, and noted that migrants are typically male, although a considerable number of females also migrate. Migration to urban areas is more common than to other rural areas or countries abroad. Youth perceive that although both the educated and uneducated migrate, the rate of migration for those uneducated is greater.

\section{Fairly high levels of NEET, especially at low education levels}

While youth unemployment is low at the national level, NEET is fairly high. In 2016, 20 percent of youth in Ethiopia were not in employment, education or training, reflecting the relatively high share of youth who are inactive and not in school (Figure 55). Though NEET is highest in cities and towns (about 30 percent), 14 percent of rural youth are NEET, many times higher than the share of rural youth who are formally unemployed (about three percent in 2013). The majority (56 percent) of youth who are NEET live in rural areas, mainly in Oromiya and SNNP. The share of youth who are NEET is however highest in the developing Regional States of Afar, Somali, Benishangul and Gambella: Taken together, 37 percent of youth in these states, mainly young women, are not in employment, education, or training. The high incidence of NEET in the Developing Regional States is mainly attributable to Afar and Somali (Figure 56). 
Figure 55: A sizable share of Ethiopia's youth is not in employment, education, or training

(Share of youth who are not in employment, education, or training, by region, sex and education)

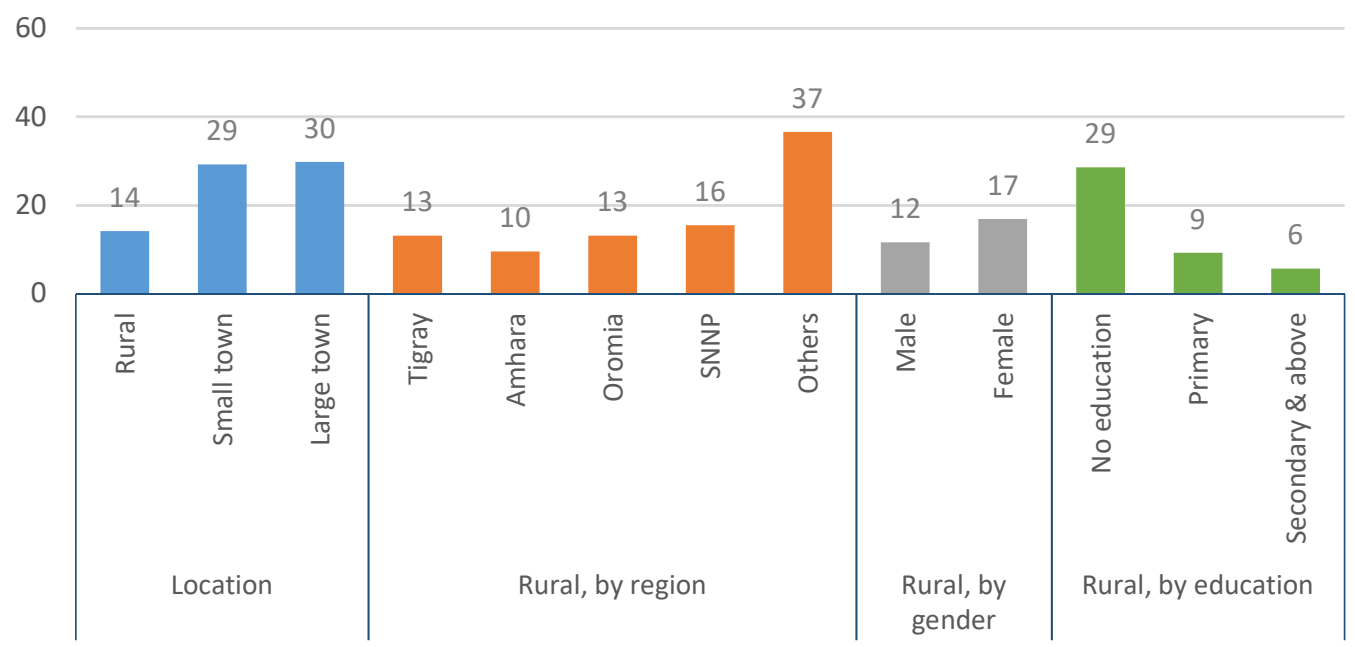

Source: ESS3.

NEET mainly affects little-educated youth. 29 percent of rural youth without any education are not in employment, education, or training (same rate for both young men and women), compared to 9 percent of youth with primary and 6 percent of youth with secondary education or more (Figure 55). Given the large share of youth in rural areas who have no education, the cohort of uneducated youth accounts for over 60 percent of NEET in rural areas. NEET thus predominantly affects little-educated individuals (in rural areas), which is a marked contrast from unemployment, which mainly affects better-educated individuals ${ }^{57}$. Employment rates for rural youth are highest for those with secondary education or more ( 83 percent), and lowest for those without education (71 percent). The large cohort of uneducated youth in rural areas appears to be in a particularly vulnerable employment position.

${ }^{57}$ These are the findings from rural areas. Taking into account urban areas as well, NEET mainly affects the uneducated youth and the youth who completed secondary education but not more. This mirrors the finding from the urban labor market study that uneducated and secondaryeducated workers in urban areas have the highest unemployment rates (World Bank, 2016). 
Figure 56: Youth NEET is high in zones of Somali and Afar, more urban areas, and North Gondar (Share of youth who are not in employment, education, or training, by zone)

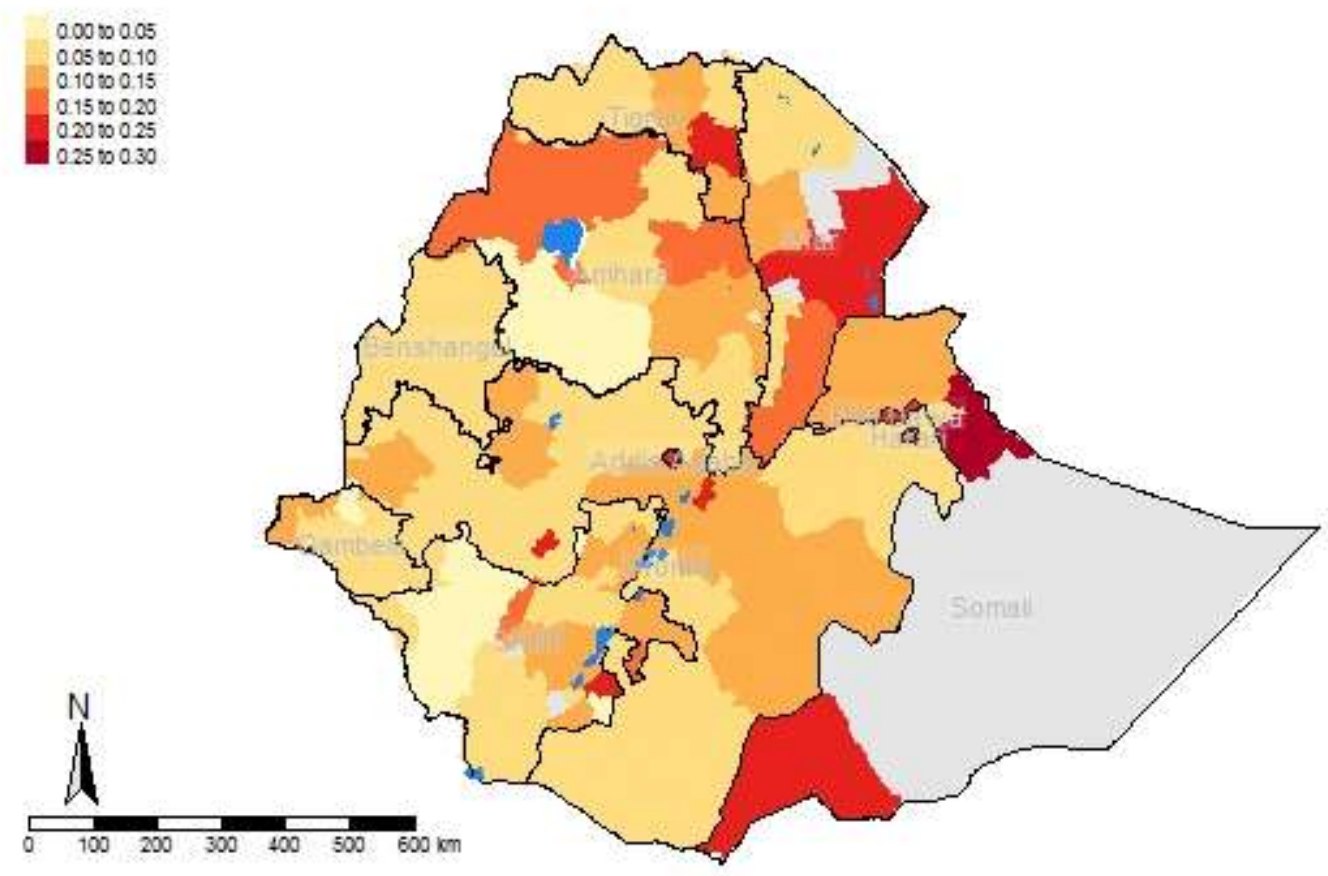

Source: LFS, 2013. Grey indicates no data. 


\section{Box 6}

\section{Why are youth in rural areas vulnerable to idleness?} Insights from focus group discussions

Two thirds of Ethiopia's rural youth are unpaid household workers, and 14 percent are NEET, many times higher than the share of rural youth who are formally unemployed (about three percent in 2013). The majority (56 percent) of youth who are NEET live in rural areas, mainly in Oromiya and SNNP. Participants of focus group discussions comprised of rural youth in Oromiya, SNNP, Tigray, and Amhara regions cited the following factors that contribute towards their inactivity:

\section{Access to land and natural resources: "Since I do not have land I cannot be a farmer."}

In almost all surveyed kebeles, youth described their chances of coming into land ownership as slim. Land is controlled by heads of families, who rely on it as their sole productive asset to provide for other children and family members. Distributing land ${ }^{58}$ to children is also not an option due to already diminished land sizes. Some kebeles are endowed with natural resources such as rivers, minerals, sand, and stones, but youth perceive their communities as inadequately supportive ${ }^{59}$ of their efforts to utilize these resources. Acquisition of communal land and sometimes wasteland has also been difficult. Despite the push from __ to allocate communal lands to youth in need of a work space, youth say their kebeles and communities are reluctant ${ }^{60}$ to follow through. In those kebeles where youth were granted access to hillsides, youth cite problems with the small quantity of land given.

Access to finance: "Youth do not ask for land because we have no finance to work with even if we were given land."

Focus group participants cited their lack of access to microfinance or government-funded loans as a primary difficulty, especially in those kebeles where youth had already gained access to land and natural resources. In some kebeles, youth reported that government officials had visited their kebele to talk with the youth and organize them into associations to initiate a saving scheme, but the process was discontinued as the officials did not return to follow up. For those in kebeles where credit is available, two difficulties arise: firstly, youth find the collateral or guarantee required for a government loan difficult to fulfill (collateral asked is often the landholding certificate for their family's farm, or 20 percent of the desired loan amount); and secondly, at 8 percent for groups and 15 percent for individuals, youth find the interest rate for the loans to be too high. Youth also perceive that nepotism and other corrupt practices complicate the lending process.

Poor infrastructure: "If electric power and road access were available, we can work on selling eucalyptus trees, and quarrying."

Youth cite infrastructural and transport problems - such as the lack of roads, electricity, and water services - as immediate causes for their inability to harness available natural resources. Lack of infrastructure typically correlates with the unavailability of wage employment within the kebele, as factories, offices, or hotels do not exist. This pushes youth to seek other solutions, and many migrate to urban areas.

Lack of information and transparency: "Even if there is a job somewhere, we do not hear about it. The information comes to the woreda and never gets down to the kebele."

\footnotetext{
${ }^{58}$ A range of traditional land inheritance rights exist: in some kebeles, a child must be married to inherit family land. In other cases, only married male children are eligible. In some areas, daughters cannot inherit family land so long as a brother exists. Still in other kebeles, married male youth are entitled to land rights, while married females are not.

59 For example, some youth report that wealthier community members, having a shared interest in those same resources, have gained the support of woreda and kebele officials to prevent youth from exploiting them.

${ }^{60}$ Farmers complain of youth encroaching on their grazing land, or neighboring kebeles dispute the allocation as it may infringe on their boundary.
} 
Focus group participants said they use friends, acquaintances, mobile contacts, and vacancy announcements in woreda towns and offices as sources of labor market information. Those who have contact with kebele officials and development agents also report that they learn about vacancies from them. However, participants noted that kebele officials are not reliable sources of information, as they perceive them to not be transparent in announcing employment opportunities and filling vacancies (i.e., they purposely delay publicizing job announcements or only do so as a formality, once the job has been secured by their own relatives or close associates).

Lack of legal identification: "Even if you want to have an ID card and go out to work in other areas, they do not give you an ID."

Identification cards are necessary to access to government services, open bank accounts, or legally engage in trading activities. However, youth in some kebeles report that officials do not issue identification cards to restrict their travel to other regions or towns.

\section{Too little education, but a weakening effect of education at the higher levels}

Ethiopia's youth remains largely unskilled, though there is a large disparity between youth in rural and urban areas. In 2016 (DHS), close to 30 percent of rural youth had never gone to school, 80 percent had not completed primary education, and a mere one percent had completed secondary or more (Figure 57$)^{61}$. Urban youth are better educated: 20 percent of urban youth had completed secondary or more in 2016, and 43 percent was still in school. ${ }^{62}$ Overall, the median level of education of Ethiopia's youth is incomplete primary (in 2016). These simple figures reveal a key aspect of Ethiopia's labor force: Though the current generation of youth is better educated than any generation before, education outcomes remain low according to any standard and are expected to remain so in the near future.

Figure 57: Ethiopia's youth remains little educated, particularly in rural areas

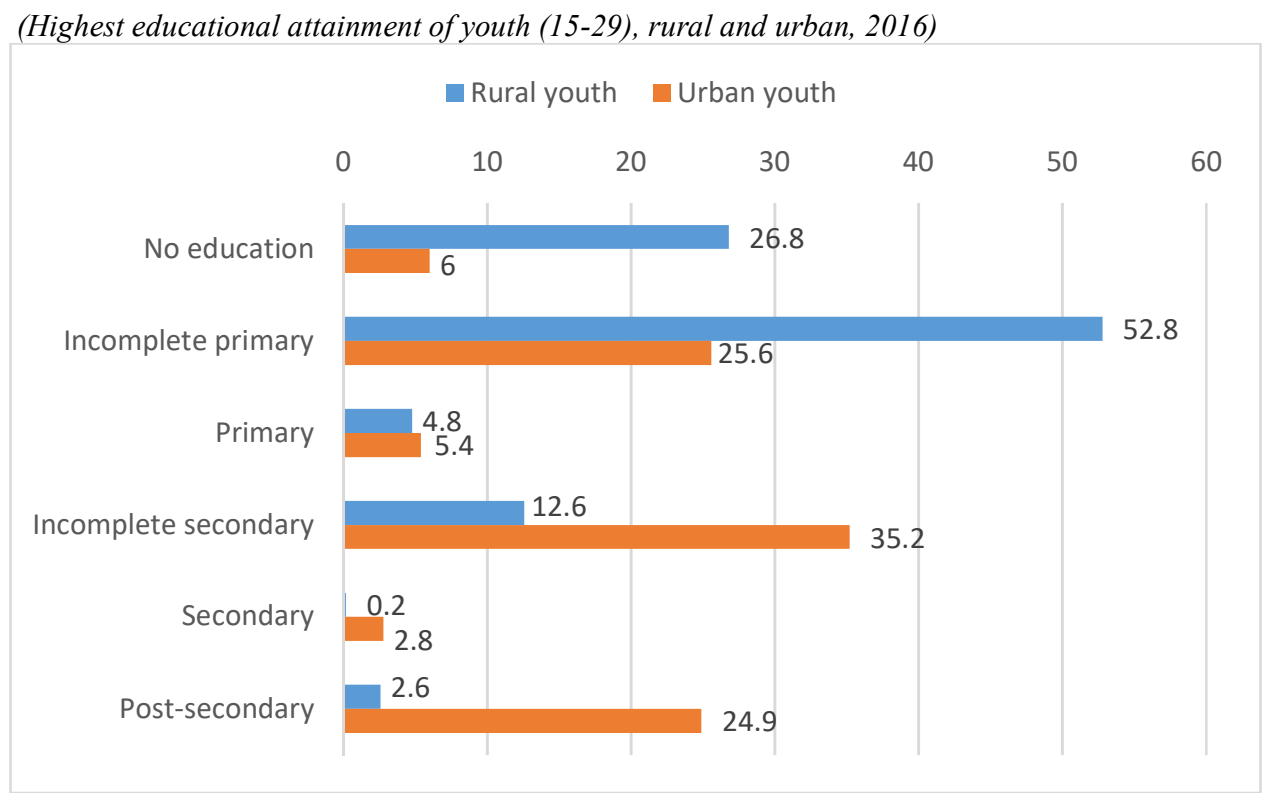

\footnotetext{
${ }^{61} 46$ percent of rural youth was however still in school at the time of the survey, so education levels are bound to increase as school-going children progress to higher grades. Better-educated rural youth also tend to migrate to urban areas, partly explaining low rural education levels. 62 The rural-urban education disparity is influenced by migration. In 2013, half of urban youth was an internal migrant, and of those migrants 60 percent came from a rural area. As more educated people have a higher propensity to migrate, rural education levels are biased downwards by the outflow of relatively better educated people.
} 
Despite higher education levels than the older generation, youth are overrepresented in lowskilled occupations. Breaking down jobs by skill requirements according to the four skill levels as standardized by the International Classification of Occupations (ISCO), Figure 58 illustrates that youth are largely employed in low-skills jobs (Box 5). In 2013, 37 percent of youth were employed in jobs belonging to the lowest skills category (skill level 1), compared to 21 percent of older workers (30-64). About 58 percent of youth were employed in jobs that require skill level 2 , compared to 74 percent of adults ${ }^{63}$. Though young workers completed on average more formal education than previous generations, they appear more likely to perform unskilled labor.

Figure 58: Youth are overrepresented in low-skill occupations

(Distribution of employment by skills content, 2005 and 2013)

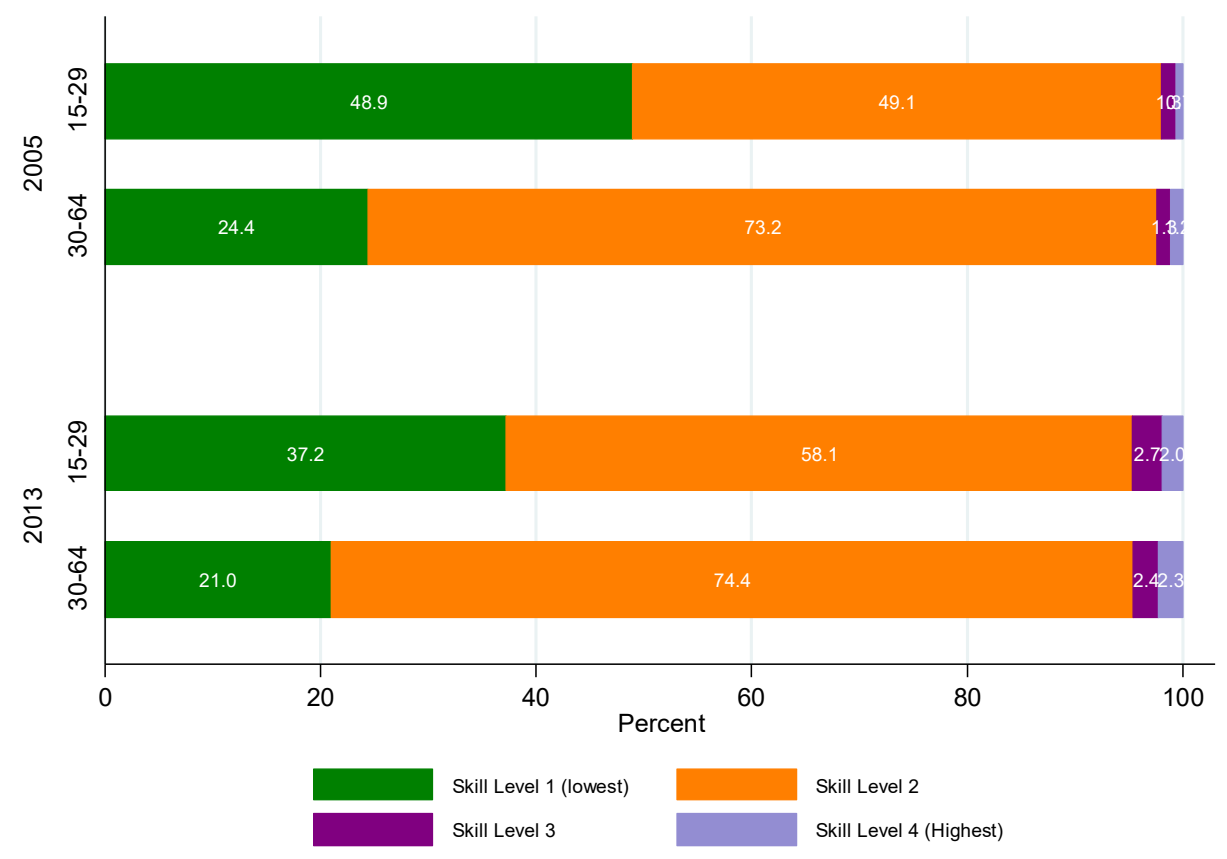

Source: LFS, 2013.

\section{Box 7}

\section{Definitions of ISCO skill levels}

- Skill Level 1. Occupations at Skill Level 1 typically require the performance of simple and routine physical or manual tasks. They may require the use of hand held tools, such as shovels, or of simple electrical equipment, such as vacuum cleaners. They involve tasks such as cleaning; digging; lifting and carrying materials by hand; sorting, storing or assembling goods by hand (sometimes in the context of mechanized operations): operating non-motorized vehicles; and picking fruit and vegetables. Many occupations at Skill Level 1 may require physical strength and/or endurance. For some jobs basic skills in literacy and numeracy may be required. If required these skills would not be a major part of the job.

- Skill Level 2. Occupations at Skill Level 2 typically involve the performance of tasks such as operating machinery and electronic equipment; driving vehicles; maintenance and repair of electrical and mechanical equipment; and

63 The ISCO skills requirements are illustrative and should be interpreted with caution. 
manipulation, ordering and storage of information. For almost all occupations at Skill Level 2 the ability to read information such as safety instructions, to make written records of work completed, and to accurately perform simple arithmetical calculations is essential. Many occupations at this skill level require relatively advanced literacy and numeracy skills and good interpersonal communication skills. In some occupations, these skills are required for a major part of the work. Many occupations at this skill level require a high level of manual dexterity.

- Skill Level 3. Occupations at Skill Level 3 typically involve the performance of complex technical and practical tasks that require an extensive body of factual, technical and procedural knowledge in a specialized field. Occupations at this skill level generally require a high level of literacy and numeracy and well developed interpersonal communication skills. These skills may include the ability to understand complex written material, prepare factual reports and communicate with people who are distressed.

- Skill Level 4. Occupations at Skill Level 4 typically involve the performance of tasks that require complex problem solving and decision making based on an extensive body of theoretical and factual knowledge in a specialized field. The tasks performed typically include analysis and research to extend the body of human knowledge in a particular field, diagnosis and treatment of disease, imparting knowledge to others, design of structures or machinery and of processes for construction and production. Occupations at this skill level generally require extended levels of literacy and numeracy, sometimes at a very high level, and excellent interpersonal communication skills. These skills generally include the ability to understand complex written material and communicate complex ideas in media such as books, reports and oral presentations.

Source: ILO 2012. International standard Classification of Occupations: ISCO-08, Volume I, Geneva.

Comparing young workers' education levels with jobs skills requirements suggests mismatches at both ends of the spectrum. Youth with up to and including secondary education are mostly engaged in low-skills jobs: About 40 percent of employed youth with no education or primary education worked in jobs that belong to skill level 1, whereas around 60 percent was involved in jobs of skill level 2 (Figure 59). Only among the highest educated youth, around 60 percent were employed in the top two skill levels jobs: 31 percent in skill level 3 and 35 percent in skill level 4. One-third of youth with post-secondary education is however engaged in activities that only require limited skills and do not warrant post-secondary qualifications. While this suggests that a certain share of young workers are actually overqualified for the jobs they are doing, the mismatch is much higher at the other end: Overall, in 2013 about half of young workers were under-educated for the jobs they were doing (in the sense that their educational attainment was lower than that required by their jobs) ${ }^{64}$, while about five percent were overqualified (particularly those with post-secondary education doing jobs that do not require such qualifications $)^{65}$. The skills deficit is highest at the lower end of the skills distribution, which highlights the importance of increasing quality and completion rates in basic education to increase productivity in the relatively low-skilled jobs most Ethiopian youth are engaged in ${ }^{66}$.

\footnotetext{
${ }^{64}$ Over-education is defined as the share of total workers whose educational attainments exceed those required by their job; (2) Under-education is defined as the share of total workers whose educational attainments are less than those required by their jobs. This indicator must be interpreted with extreme caution as the correspondence between occupational and educational level is not always perfect and would require a more detailed breakdown of educational attainment, in particular beyond completed secondary education. Moreover, as made clear in ILO (2008), "The use of ISCED categories to assist in defining the four skills levels does not imply that the skills necessary to perform the tasks and duties of a given job can be acquired only through formal education. The skills may be, and often are, acquired through informal training and experience. In addition, it should be emphasized that the focus in ISCO-08 is on skills required to carry out the tasks and duties of an occupationand not on whether a worker employed in a particular occupation is more or less skilled than another worker in the same occupation." ISCO-08 Volume I.

${ }^{65}$ Given that older workers are less educated but still do higher-skilled work than youth, the mismatches are even higher for older workers.

${ }^{66}$ This is also highlighted by the fifth Ethiopian Economic Update: Labor productivity of un- or low-skilled workers in Ethiopia is very low, but wages cannot adjust to these low levels due to subsistence reasons. Increasing productivity of low-skilled workers is key to increase labor earnings and unemployment.
} 
Figure 59: Young workers are often employed in jobs that do not match their levels of education (Skills content of jobs by education level of young workers, 2013)

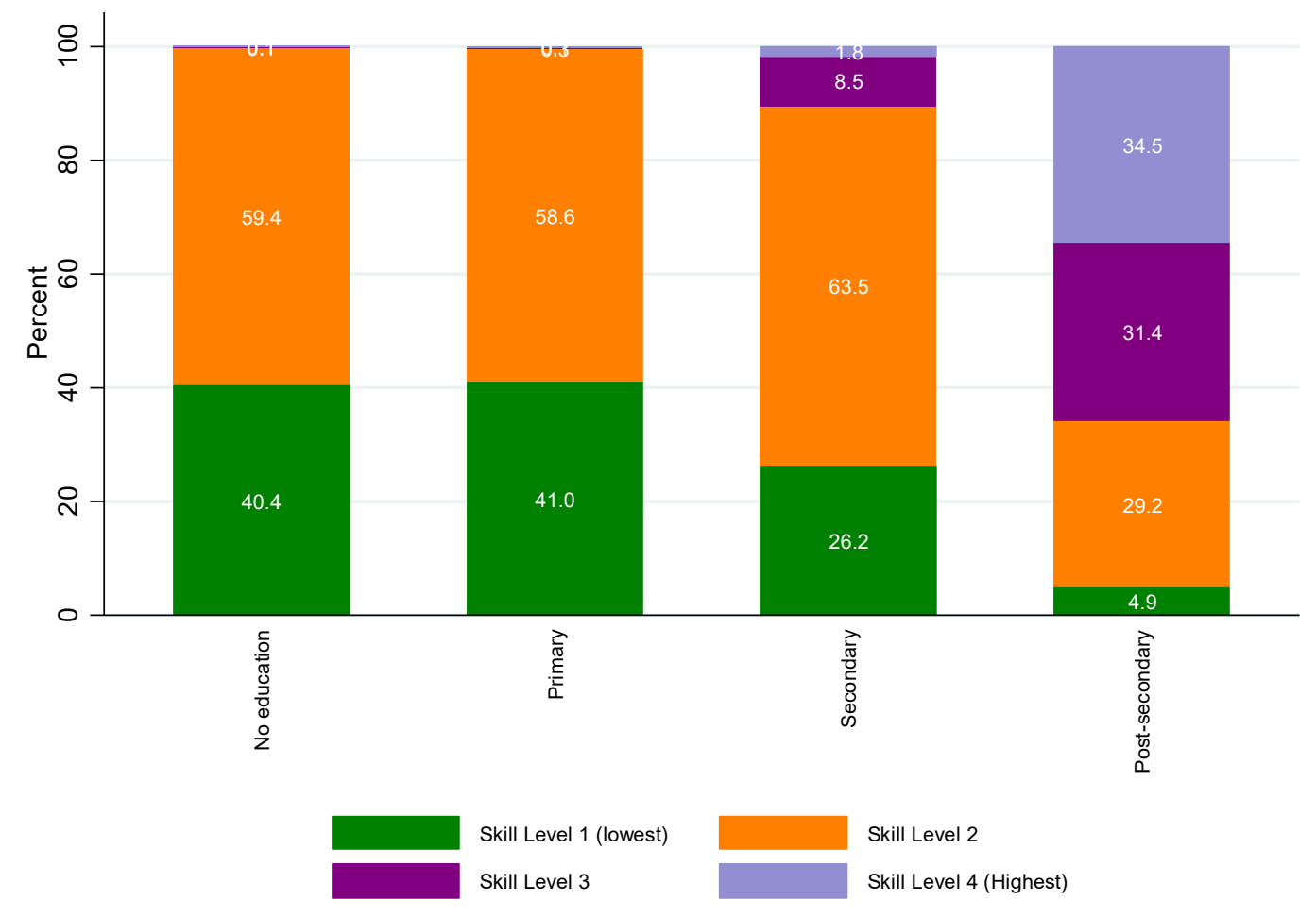

Source: LFS, 2013.

The discordance between young workers' education levels and the skills requirements of their jobs has widened since 2005. For instance, in 2005 more than half of young workers without education were engaged in the lowest-skills jobs, and this decreased to 40 percent in 2013. While this is in principle a positive signal-jobs in Ethiopia have become slightly more skilled-it suggests productivity could be substantially enhanced by increasing young workers' level of education, in particular at the lower end of the education spectrum. The match between job content and education has also weakened at the highest education level: In 2005, about 23 percent of young workers with tertiary education worked in jobs with the two lowest skills levels. By 2013, this had increased to 34 percent. This finding does however not need to be exaggerated: The volume of young people who complete tertiary education has increased significantly since 2005 , and in many countries university graduates tend to first be engaged in odd jobs as they are searching for a job that matches their interest and education level. The more important issue is sheer magnitude of young workers who remain almost completely uneducated, even despite the recent substantial improvements: In 2016, 70 percent of young workers had not completed primary education. 
Figure 60: Using a generic assessment of job-specific skills requirements, the mismatch between workers' education and their jobs' skills requirements has widened since 2005

(Skills content of jobs by education level of young workers,2005)

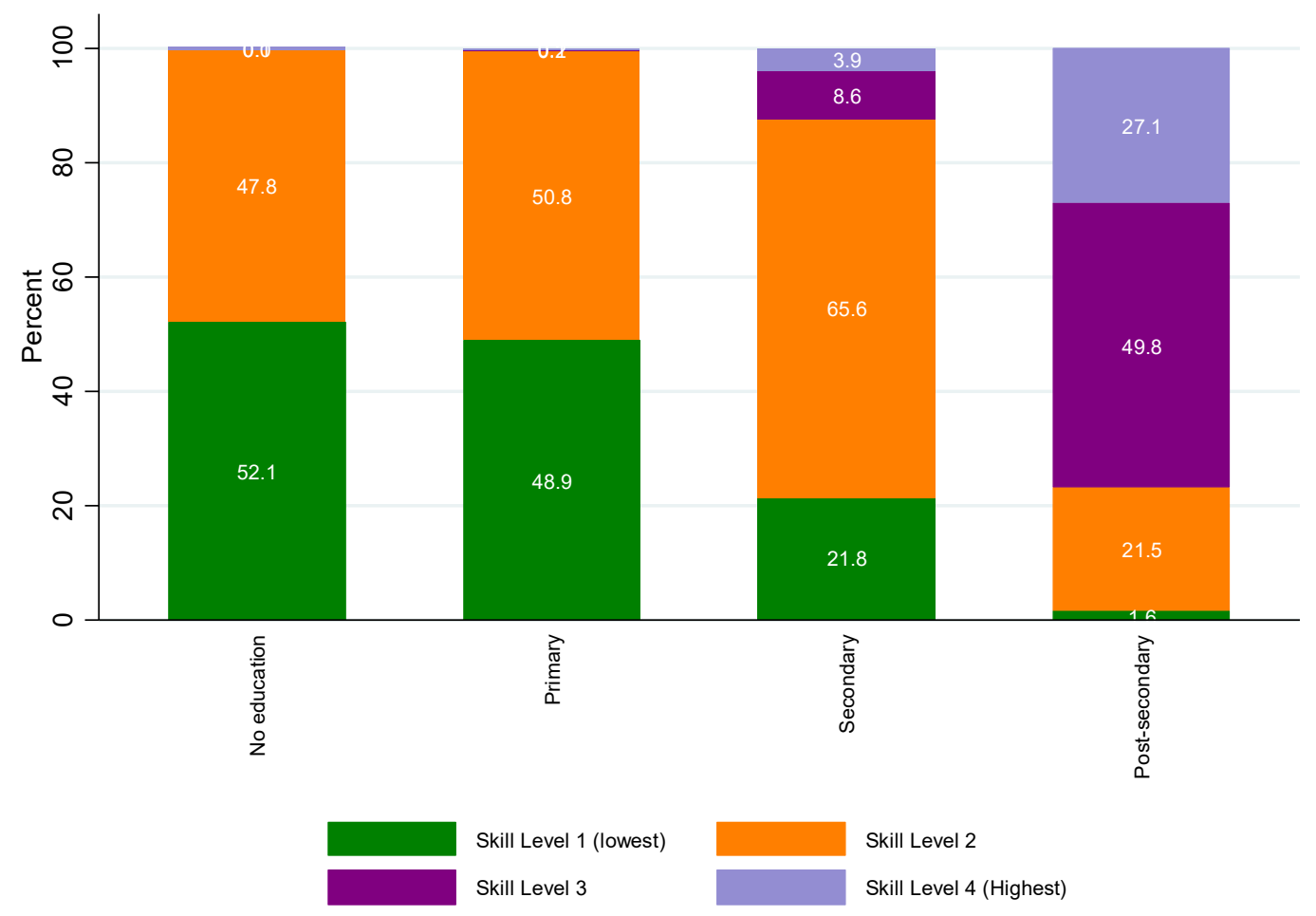

Source: LFS, 2005.

Though education levels of youths remain too low, the role of higher levels of education in securing good jobs appears to have weakened. In 2005, over 60 percent of young workers who completed secondary education were wage-employed in the nonfarm sector (Figure 61) ${ }^{67}$. This decreased to 50 percent by 2013. At the other end, the share of young workers with at least some secondary education employed as unpaid household worker increased (Figure 61). A regression analysis indeed suggests that the role of education in explaining employment type has weakened since 2005: All else equal, individuals with higher education levels were less likely to access public sector wage jobs in 2013 relative to 2005 (Annex 10), and more likely to be in unpaid labor (Annex Table 2). The effects are particularly outspoken for youth who went through secondary school (complete or not) but went no further: The share of these young workers primarily engaged in unpaid household labor increased substantially. For post-secondary-educated young workers, we observe a large increase in nonfarm self-employment (and corresponding decrease in nonfarm wage employment - see Figure 61). Whether this is due to insufficient demand for tertiaryeducated workers or a pull of higher-earnings opportunities in self-employment cannot be ascertained with the data. In the qualitative research, youth also mentioned that education, while important, does no longer guarantee a good job (Box 8).

67 Given the absence of earnings data in the LFS (except for wage employees), we make the assumption that non-farm wage employment is on average "better" (in the sense of procuring higher earnings) than other kinds of employment. Though this may be a leap of faith, empirical work consistently shows non-farm wage employment to offer the highest average earnings in low-income countries. 


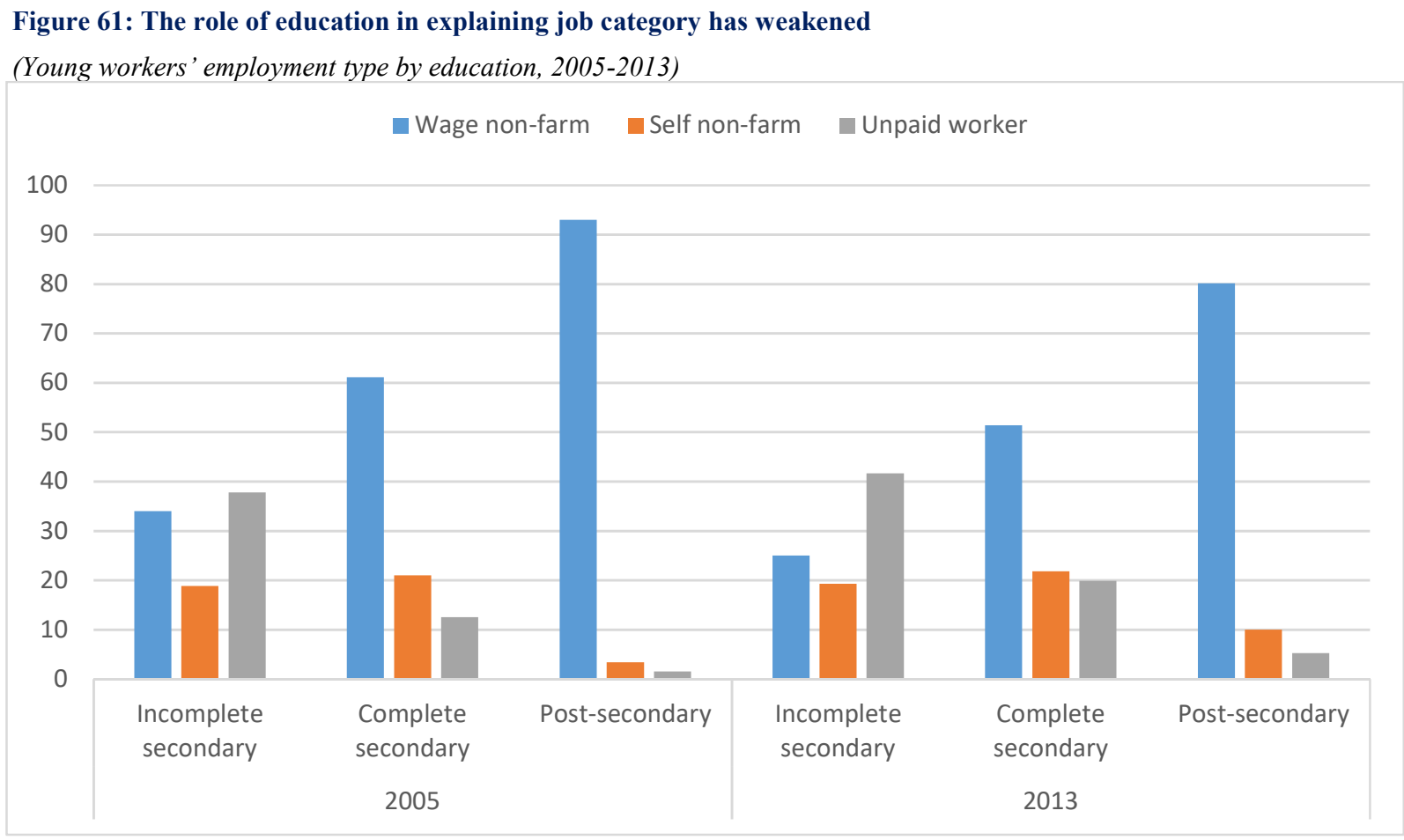

Source: LFS, 2005; 2013.

\section{Youth transitions}

\section{The transition from school to work starts early, especially for rural youth}

Transition is a defining feature of youth, and transitions from school to work and between types of employment is particularly difficult for young Africans (World Bank, 2014). Many young labor force entrants lack the means, skills, knowledge, or connections to achieve a smooth transition to productive employment. The transition from school to work starts early in Ethiopia, with 30 percent of 10-to-11-year-olds combining school and work and six percent being out of school and full-time employed (Figure 62). The transition to work starts in earnest at of the age of 13, with many children dropping out of school and entering the "work only" category (the sharp increase in the yellow surface at age 13 in Figure 62). At age 15-16, about two-thirds of youth are still in school, with the bulk combining school with work. The share of youth in school drops off sharply again at age 17-18, associated with completing primary school and not enrolling in secondary school. The share of youth who are NEET increases with age and peaks at 25 percent during the early twenties when most youth have ended their education but not yet transitioned to employment. 
Figure 62: The transition from school to work starts at a young age

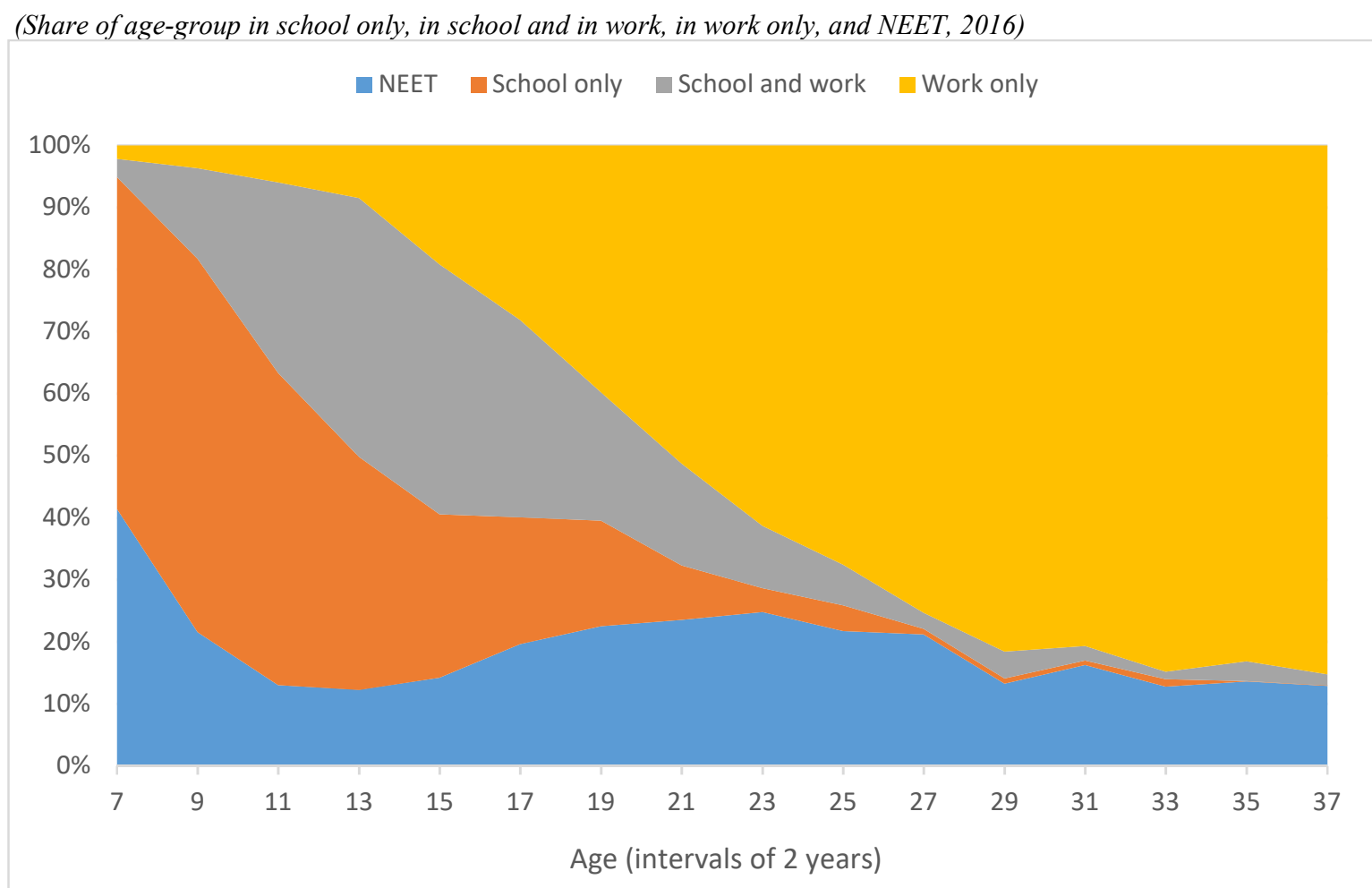

Source: ESS3, 2016.

The school to work transition differs substantially between rural and urban Ethiopia. In rural areas, the share of youth that is in school only (without working) tends to be lower than 50 percent in most age-groups and transitions to work start early. At age 9-10, 57 percent of rural children are in school only, but this drops to 29 percent for 13-14-year-olds. At age 15 in rural areas, a higher share of youth are out-of-school and in-work than the share in-school and not working. For the sake of comparison, 16 percent of 15-year-olds in rural areas are in school only, compared to 64 percent in urban areas. 23 percent of rural 15-year-olds are already working full-time, compared to five percent in urban areas. The share of youth that are not in employment, education, and training (NEET) also follows a distinct pattern: In rural areas, NEET peaks earlier, at the age of 19 , when most rural youth have completed their education but have no access to land or other types of livelihoods yet. In urban areas, NEET peaks at the age of 23-24, when 40 percent of youth are NEET (these are youth that have completed their education in urban areas but have not managed to get a job yet - Figure 63). At older ages, urban NEET drops off a bit but remains high. 
Figure 63: The school-to-work transition starts later in urban areas

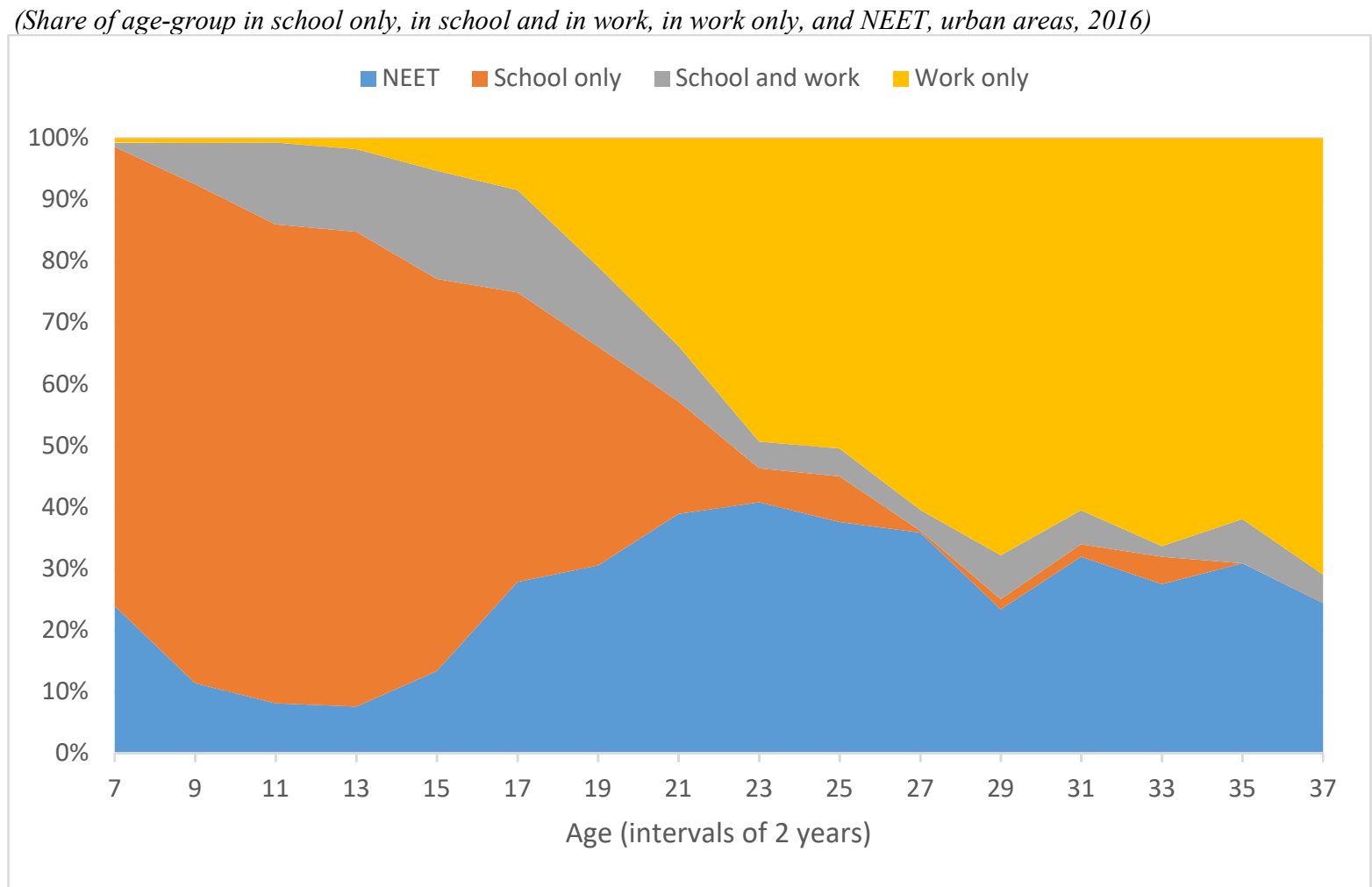

Note: Rural figure not shown as it mirrors the national image in Figure 62. Source: ESS3, 2016.

Transitions also differ by gender. Girls and young women are more likely to be only in school compared to boys of the same age, who are more likely to combine school with work or to be completely out-of-school. Though there are fewer girls out-of-school than boys, the girls that are out of school tend not to work, explaining the divergence in the share of NEET at very early ages (starting at age 11 - Figure 64). At older ages (early twenties), young women are equally likely to work as young men, but the share of women in work drops off towards the late twenties and early thirties, likely linked to childbirth and family responsibilities (Figure 64). NEET is higher among young women than among young men, and also stickier: At age 23, 22 percent of men and 27 percent of women are NEET. By age 33, four percent of men are still NEET compared to 23 percent of women. Though not examined here, the absence of affordable child care services probably contributes to the sticky levels of NEET among young women. In rural areas, young women report to benefit less from government-driven employment initiatives (Box 9). 
Figure 64: NEET diverges early, work diverges late

(Share of men and women that are NEET or in-work only, by age)

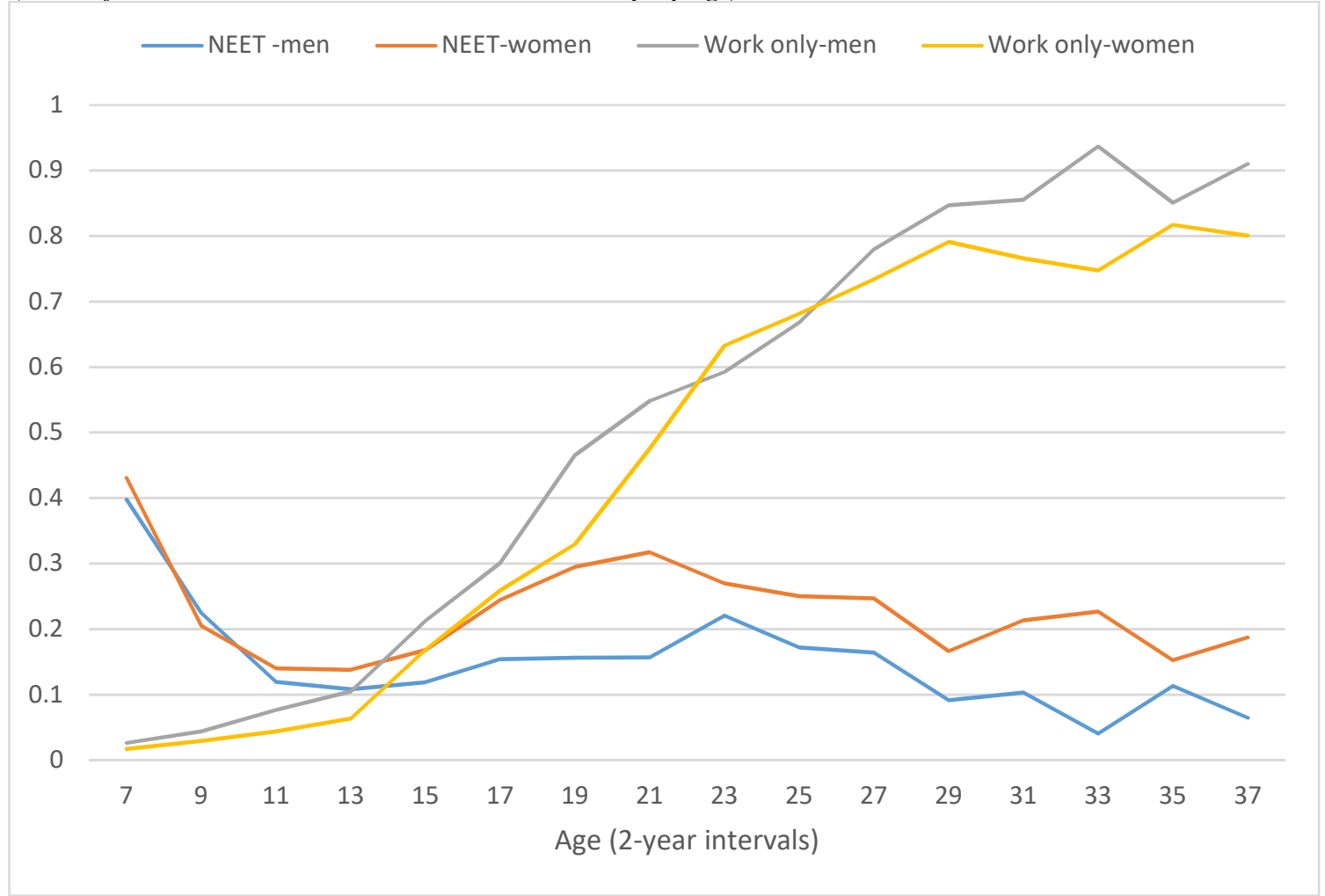

Source: ESS3, 2016.

\section{Box 9 \\ The role gender plays in rural youth unemployment Insights from focus group discussions}

"When we see the lack of collaboration and unity among the male youth, then we lose hope and we do not dare to do what the men failed to do,"-female focus group participant, who discussed the challenges females face when they attempt to access finance

Overall, the situation of female youth is more precarious than that of their male counterparts. Female focus group participants discussed the discrimination they face in various areas of life: from inheritance rights ${ }^{68}$, to the additional burdens they face with responsibility to their families. In some kebeles, focus group participants said they are disallowed from leaving the home (where they are responsible for almost all domestic tasks) to conduct business. Their lack of opportunity to organize leads to their inability to access financing from the government. This means that those who are interested in opening their own businesses must rely on the emotional and financial support from their families.

Societal expectations of women's roles also shape the opportunities they are afforded by the government. In one kebele, female youth described discriminatory lending practices, as the defaulting of a female cooperative on a government loan led the kebele to discriminate and not lend to other female cooperatives. During community

68 A range of traditional land inheritance rights exist: in some kebeles, a child must be married to inherit family land. In other cases, only married male children are eligible. In some areas, daughters cannot inherit family land so long as a brother exists. Still in other kebeles, married male youth are entitled to land rights, while married females are not. 
meetings with kebele officials, female focus group participants said they feel uncomfortable engaging in the discussion, as they believe even their husbands do not support their right to speak out. In some kebeles, female participants described being paid less for the same amount of labor as their male counterparts.

Youth transitions in and out of NEET are mainly influenced by education and household landholdings

The share of NEET youth has increased marginally since 2012. In rural areas and small towns, the share of youth who are NEET increased from 14 percent in 2012 to 17 percent in 2016, while in bigger cities it increased from 26 percent in 2014 to 31 percent in $2016^{69}$. Given that the ESS is a panel survey, we are able to follow youth across the three survey waves to look at NEET dynamics. Figure 65 summarizes changes in NEET status between 2012, 2014 and 2016, depending on the baseline status. Overall, the bulk of youth in rural areas ( 80 percent) are likely to remain employed (or remain "non-NEET") across the survey waves. This pattern is normal and reflects the dominance of agricultural and unpaid employment in rural areas. In small towns and larger cities, there is a higher level of movement in and out of NEET: In small towns, 14 percent of youth became NEET between 2014 and 2016, while 11 percent became non-NEET. In cities during the same period, twice as many youths became NEET than those who escaped NEET. Next to more mobility in and out of NEET, the share of youth who are persistently NEET is also higher in urban areas: 11 percent in small towns and 12 percent in cities.

Figure 65: Changes in NEET status among youth, 2012-14-16

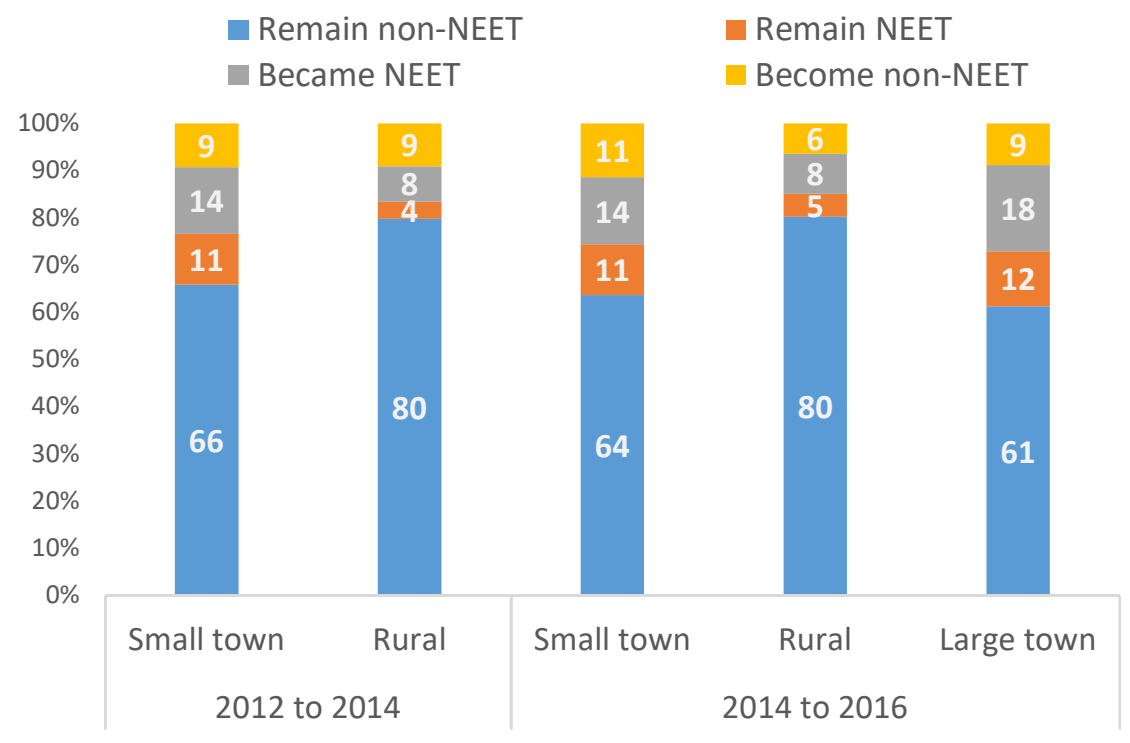

Source: ESS1, 2012; ESS2, 2014; ESS3, 2016.

In rural areas, little-educated youth, especially women, in land-scarce households with excess labor supply are most at risk of NEET ${ }^{\mathbf{7 0}}$. Young women are more likely to be NEET than young men, and each successive level of education reduces the likelihood of a youth being NEET (with

69 The increase in NEET in rural areas and small towns is not statistically significant. The increase is NEET between 2012 and 2016 was not linear: First, it increased substantially (from 14 percent in 2012 to 21 percent in 2014), and then substantially decreased between 2014 and 2016 (17 percent).

${ }^{70}$ This is based on a random, mixed, and fixed-effect regression of NEET. The approach and results are reported in Annex 12. 
the exception of completed secondary education, which does not reduce the risk of being NEET). Youths in land-poor households with a large number of adults are more likely to be NEET, as are youth in households who reported experiencing a natural shock in the year prior to the survey. When looking, in a fixed effects logic, at youth who experienced a change in NEET status across survey waves, the only variable significantly associated with a move out of NEET is the size of the household's landholdings: An increase in household landholdings per adult is associated with a higher likelihood of moving out of NEET.

Figure 66: Education is a good insurance against NEET

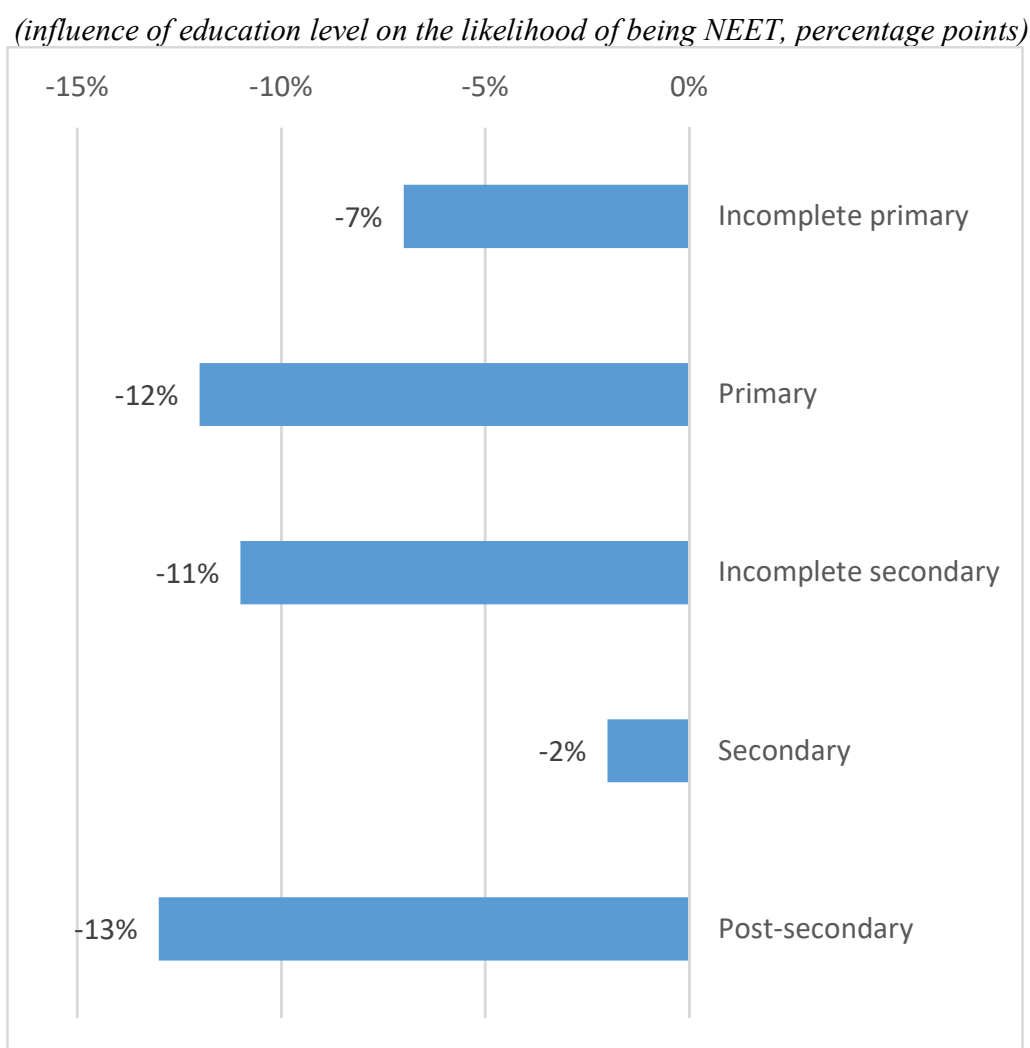

Notes: The figure shows marginal effects of education on the probability of being NEET based on the regression presented in Annex 12. Source: ESS1, 2012; ESS2, 2014; ESS3, 2016.

\section{Better-educated and land-scarce rural youth have diversified into nonfarm occupations}

Diversification into nonfarm activities is an important way through which households and individuals manage exposure to risk, and tends to be correlated with higher level of living standards. A limited number of studies have focused on the dynamics of diversification or the move out of agriculture in Ethiopia. Bezu and Barrett (2012) analyzed mobility of households from agriculture to low- and high-return non-farm activities, and found that initial asset holdings and access to credit/saving are important factors for transition into high-return non-farm employment, while shocks that reduce liquidity may trigger descents from high return into low-return non-farm employment. Woldehanna and Oskam (2001) studied changes in diversification away from crop farming 1989-1994 period and found that those households that initially had more diversified livelihoods subsequently experienced a relatively greater welfare gains, and those with initially 
less diversified livelihoods had greater subsequent increase in diversification. Bezu and Holden (2014) used panel data from 2007 and 2013 to study sectoral dynamics and migration, and found that rural youth in Southern Ethiopia are abandoning agriculture in search alternative livelihoods due mainly to the limited access to farmland, especially in the highlands where per capita land size has decreased considerably.

Rural youth in Ethiopia have been diversifying into nonfarm employment in considerable numbers $^{71}$. Of all rural youth who were exclusively employed in agriculture in 2012, about twothirds were still full-time farmers by 2016 ("No transition" in the last panel of Figure 67). About 23 percent of rural youth had however diversified into nonfarm activities, either partially (by taking on a nonfarm activity next to farming - 18 percent) or fully (by abandoning agriculture altogether - five percent). In small towns, the share of youth who diversified into nonfarm activities was higher, around 50 percent. Youth in towns were much more likely to fully transition out of agriculture than youth in rural areas: 21 percent of youth in towns fully moved out of agriculture between 2012 and 2016, compared to five percent in rural areas. A substantial share of youth who were employed in agriculture in 2012 became out-of-work by 2016 (11 percent in rural areas and 12 percent in towns). Compared to the 2012-14 period, there has been less diversification in rural areas between 2014 and 2016 but more in towns ${ }^{72}$.

Figure 67: There is substantial diversification into nonfarm activities

(Economic activity in survey wave 2 or 3 of youth who were exclusively engaged in agriculture in wave 1 or 2)

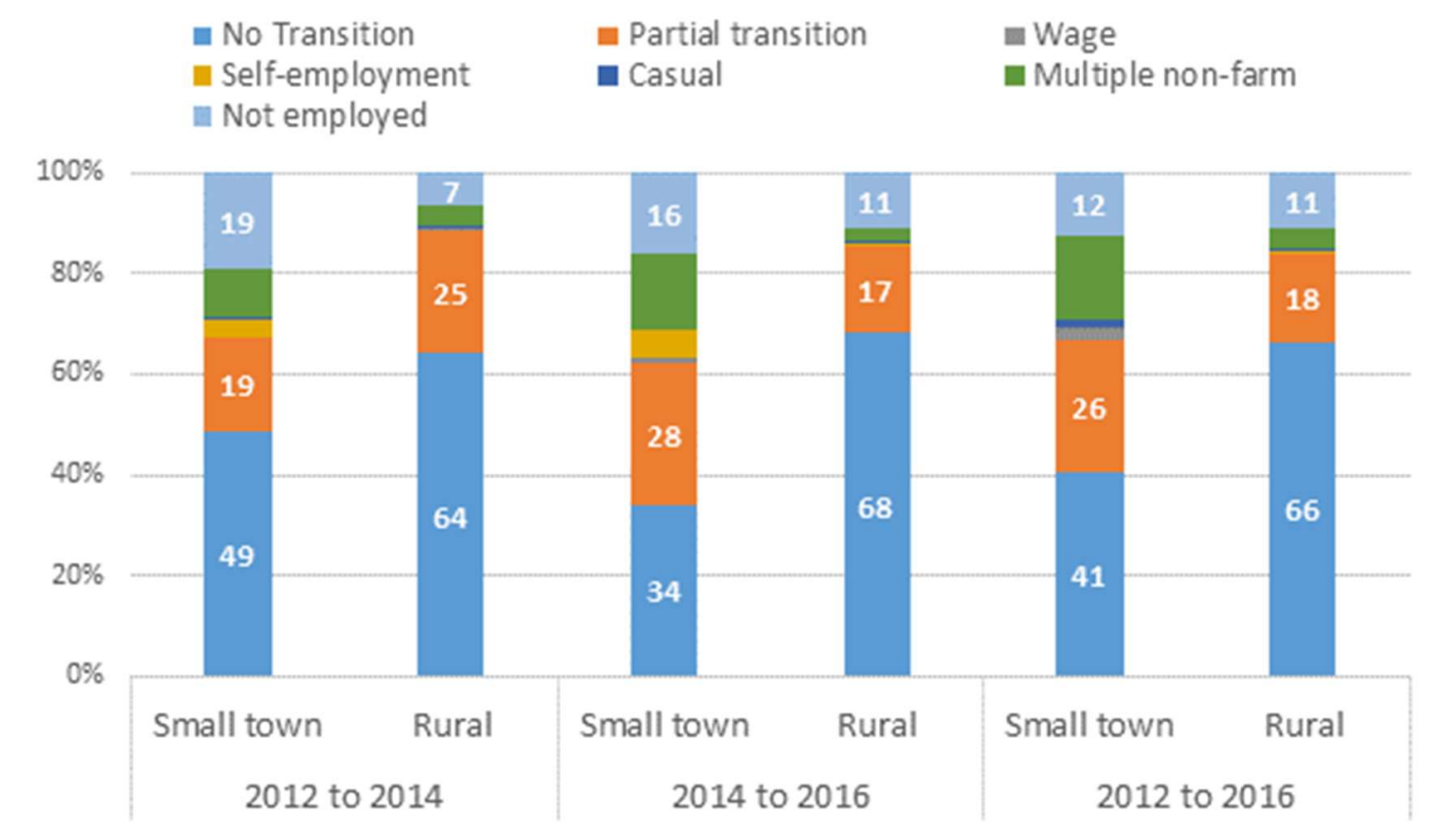

Source: ESS1, 2012; ESS2, 2014; ESS3, 2016.

Diversification into nonfarm activities in rural areas and towns mainly comes down to jumpstart self-employment in small household enterprises. The bulk of youth who partially

\footnotetext{
${ }^{71}$ At first sight, this may be at odds with the statement in the previous chapter that the rural employment structure has not changed much. That statement however is based on the main occupation only. Rural youth have however diversified into nonfarm employment as secondary occupations.

${ }^{72}$ These patterns are not restricted to young workers. When considering all workers and not only the youth, all patterns are qualitatively similar (Annex).
} 
transitioned out of agriculture between 2012 and 2016 did so by taking up self-employment in the nonfarm sector: 57 percent in towns and 46 percent in rural areas. Nonfarm wage employment is rare in rural areas, but more common in small towns: About 27 percent of youth in small towns diversified by taking up wage-employment between 2012 and 2016. In rural areas, casual work and PSNP labor were important means of diversification.

\begin{abstract}
Figure 68: Nonfarm diversification usually happens through self-employment in household enterprises
(Nonfarm activity of youth who partially diversified out of agriculture)
\end{abstract}

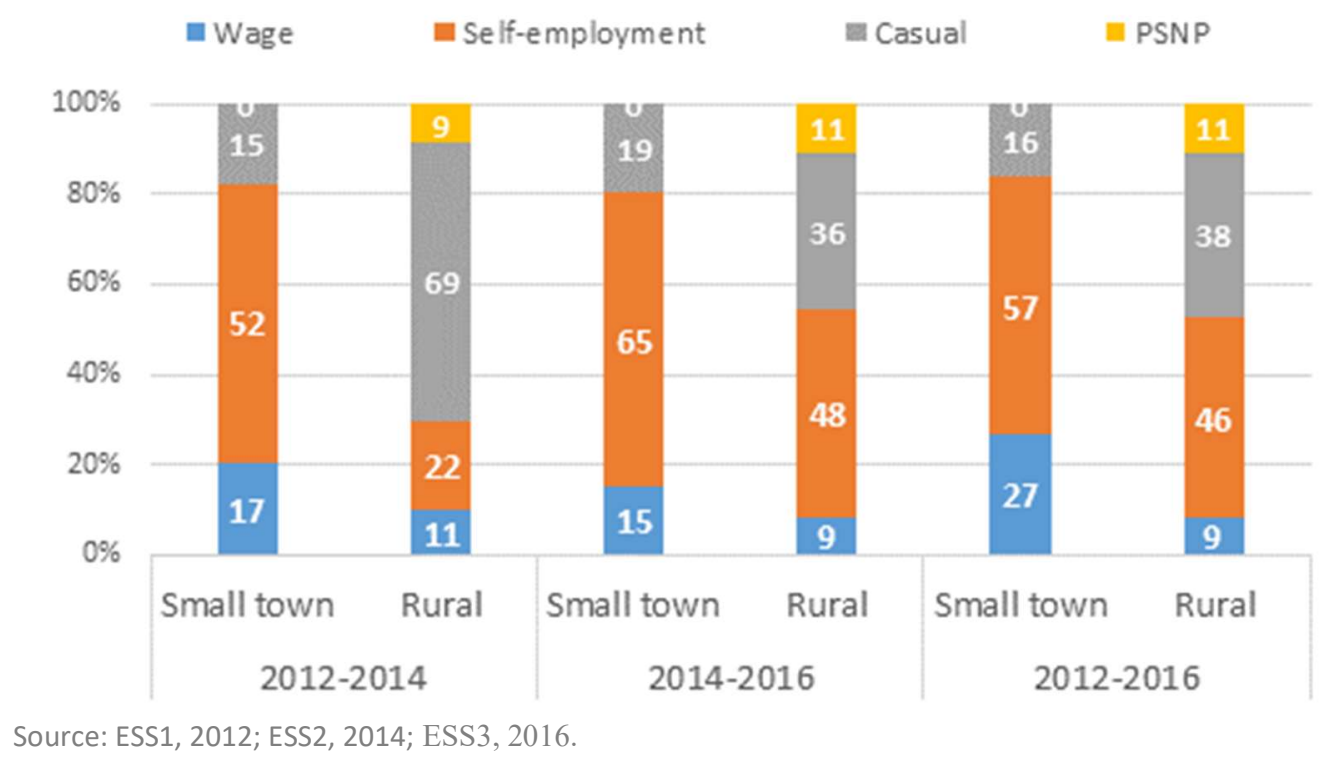

In Ethiopia as in other countries, diversification into nonfarm activities is driven by both push and pull factors. Education is by far the main factor associated with the transition out of agriculture, in particular at complete secondary and post-secondary levels: Relative to youths without education, youth who completed secondary or post-secondary have a 20 percentage point higher likelihood of transitioning to nonfarm employment, likely linked to the pull of higher returns to education in the nonfarm sector. Lack of land is a main push factor: Controlling for the influence of other factors, youths in land-scarce households were more likely to diversify out of agriculture, either partially or completely (see columns 4 and 5 in Annex Table 6). This squares with the results of the qualitative research, which highlighted the importance of land scarcity in influencing migration decisions of poor youth. At the other hand, given underdeveloped markets and existing regulations, youths in households with large plots of land are destined to remain in agriculture. Youths in households that experienced a natural shock in the year preceding the survey were also more likely to diversify into nonfarm activities, presumably to compensate for lower agricultural income following the shock. Young men were more likely to diversify out of agriculture than young women.

\title{
Box 9
}

\section{Constraints to non-farm self-employment for rural youth} Insights from focus group discussions

The rural non-farm sector is limited in its scope. The few nonfarm activities that focus group participants mention are influenced by the nature of their kebele's dominant activities and the opportunities for diversification that these 
allow along value chains. The dominant nonfarm activities are largely trade in agricultural products, livestock, and manufactured merchandise brought from towns. Catering services, such as coffee and teahouses, are mentioned but in a limited number of cases.

Major constraints to rural nonfarm self-employment include lack of access to a work space, finance to start and run a business (see Box 2), and infrastructure. Youth say they would prefer their work space to be in or close to an urban area. This is due to the greater market available in urban areas for goods and services, as well as the absence of necessary infrastructure - such as roads, electricity, and water services - in rural kebeles. However, an urban work space is difficult or impossible to attain for those who come from rural low-income families. Providing workspace and critical infrastructure in well-connected rural areas (rural areas adjacent to towns or urban centers) is flagged as important so that youth can create and run nonfarm activities without having to migrate far.

To lift these constraints, youth are aware that multiple actors must act. Focus group participants assigned responsibility to the government to solve coordination problems in credit availability, infrastructure development, and the provision of training and creation of awareness. They also recognized the important role communities play in recognizing and supporting youth, as well as providing work spaces wherever possible. Lastly, they noted their own responsibility in developing a culture of discipline, awareness, and commitment to work.

\section{Conclusions}

In general, youth employment outcomes in Ethiopia remain precarious despite solid improvements over the past decade. Youth are overrepresented in unpaid household labor, are more likely to be unemployed relative to older workers, are more likely to earn below the poverty line (for the few who actually earn wages), and are increasingly less likely to have access to land. Despite improvements, youth remain little-educated, with 70 percent of youth in 2016 not having completed primary education (80 percent in rural areas). A non-negligible share of Ethiopia's youth is not engaged in any productive investment or activity at all (in other words, is NEET: not in employment, education, or training), with the heaviest burden falling on the most vulnerable: The largely uneducated youth, mainly young women, from land-scarce households in rural areas.

Urban youth appear to have fared better than rural youth. Youth in urban areas are far better educated than their rural counterparts and are mainly employed in (nonfarm) wage employment. In the aggregate, they have benefited from sustained growth in real wages between 2005 and 2013 and a sharp drop in urban youth unemployment ${ }^{73}$. In contrast, rural youth remain largely uneducated and engaged in unpaid household labor. School to work transitions start early in rural areas, with 34 percent of rural 11-to-12-year-olds combining school with work and over 20 percent being completely out-of-school.

While education levels of the youth, in particular in rural areas, remain too low, the role of higher levels of education in securing "good" employment has weakened ${ }^{74}$. While completing secondary education or more is still associated with a sharply higher likelihood of being formally wage-employed, mainly in the public sector, the association between attaining higher levels of education and obtaining a public sector wage job has weakened between 2005 and 2013. Compared to 2005 , better educated individuals in 2013 were more likely to be self-employed in the nonfarm sector and more likely to be unpaid household labor. Though the data do not allow establishing the reason behind this, it is possible that the supply of relatively higher-educated workers is

\footnotetext{
${ }^{73}$ Median wages for wage-employed youth increased by 35 percent between 2005 and 2013, compared to 24 percent for the overall wageemployed population. The sample of young wage-workers in 2016 (ESS3) is too small to get a good estimate of recent youth wage trends.

${ }^{74}$ We consider formal sector wage-employment as "good" employment. On average, earnings in formal sector wage-employment are higher than in other sector or employment types.
} 
growing faster than formal nonfarm wage-employment, pushing relatively better educated people into other forms of employment. Formal sector wage-employment grew by approximately 1.1 million between 2005 and 2013, while the number of secondary-or-higher educated individuals grew by 1.4 million. This calls for the urban services sector to grow to generate more higher-skilled employment opportunities (people with high school or university degrees are unlikely to work in manufacturing).

Though young women do not appear to face particular difficulties in accessing or continuing education, they are far more likely to be NEET. Girls and young women are more likely to be only in school compared to boys of the same age, and are less likely to be out-of-school. The girls who are out of school however tend not to work, explaining the divergence in the share of NEET at very early ages. The higher incidence of NEET among young women does not appear to be due to particular constraints in education, but rather to factors complicating their participation in the labor force (such as the absence of child care for young mothers). 


\section{Going Forward: How to improve employment outcomes for Ethiopia's youth?}

The lack of employment opportunities for the rapidly growing youth populations of SubSaharan Africa is a main challenge shared by all of its countries. While the current generations of young Africans entering the labor force are the best educated ever, they are finding that their prospects for employment and upward economic mobility differ very little from those of their parents. Youth, particularly urban youth who are dissatisfied with labor market outcomes and disillusioned by unmet expectations and limited economic opportunities, have repeated taken to the streets in major urban centers across Africa. The majority of African youth however still reside in rural areas and small towns, and their employment and socioeconomic outcomes are often worse than those of their better-educated and more vocal counterparts in urban areas. Indeed, demonstrations of discontent of urban youth are only the most visible and audible part of the overall employment problem ${ }^{75}$.

The challenge of youth employment is not any different in Ethiopia. Ethiopia's labor force is projected to increase at 1.7 million per year, and employment creation for this rapidly growing youthful population is one of the most pressing development challenges that Ethiopia faces today. The Government of Ethiopia (GoE) acknowledges this challenge and expanding employment opportunities is a priority area in the second Growth and Transformation Plan (GTP II) ${ }^{76}$.

Successfully addressing the youth employment challenge will require interventions, improvements, and innovations in different sectors and dimensions. It will require attention to improving access to and completion of quality basic education and training to improve young people's productivity, while at the same time alleviating obstacles that currently constrain progress in agriculture, household enterprises, and the modern wage sector (including manufacturing). It will require acknowledging that youth are heterogeneous, and that the potential employment paths will be heterogeneous as well. It will require a critical review of the current employment strategies and interventions to assess whether they are effective and will also benefit from a more explicit integration of the needs of youth in local development plans (Box 11). It will require adopting an open mind and a trial-and-error attitude in designing novel interventions and employment pathways and course-correct them as necessary.

\section{Box 11 Perspectives on the Approach to Rural Employment Generation Insights from focus group discussions \\ “They ask us to save money, but the youth have no money or job.”}

Overall, rural youth who participated in focus group discussions expressed skepticism of the government's approach towards generating rural employment for youth-i.e., organizing youth into associations and cooperatives so that they can access microfinance and government-funded loans to start businesses. In some kebeles, focus group participants indicated their preference to borrow on an individual basis, rather than through a group. In other kebeles, youth complained that officials did not follow through with the provision of employment or loans, even after having organized them into cooperatives. To access loans, participants noted that cooperatives had to save what they perceived to be an "excessively high" amount of money, which, they believe, has the undesirable effect of excluding the poor. The collateral or guarantee required for a government loan is also difficult to fulfill (for example, the

\footnotetext{
${ }^{75}$ World Bank, 2014; Azeng and Yogo, 2013; 2015.

${ }^{76}$ The GoE also recently established an ETB 10 billion (US\$ 427 million) Revolving Youth Fund to expand financing to youth-centered projects with the aim of reducing youth unemployment.
} 
collateral required is often their family's landholding certificate, or 20 percent of the desired loan amount). In some kebeles, youth described the amount of finance available to them as too low.

"Every meeting is a meeting of old people. The youth are not given the chance to discuss our concerns. We are not asked our preferences - they just come here and tell us to organize."

"The only time kebeles want to discuss with us is when they are told to do so by higher government body."

Rural youth describe strained relations with kebele officials ${ }^{77}$, and identify administrative inefficiencies (such as their kebele's failure to issue identification cards) and corruption as primary reasons. Identification cards facilitate mobility and licensing for youth to legally engage in trading activities, and difficulties in obtaining them are especially pronounced in some woredas. Few opportunities exist for youth to dialogue with kebele officials, and those that occur are often are perceived to have occurred at the behest of a higher-level government body. Even if meetings are called, youth do not believe that their ideas are taken into serious account. Elders tend to dominate discussions, with female participants playing an even more marginal role. There is a perception that kebele officials are ambivalent towards the issues that concern youth, such as employment generation and their need for a place to work.

Some focus group participants in turn held the youth responsible for their inability to engage in productive dialogue with kebele administrations, citing their lack of organization and collective action on a common agenda. When asked, key informant interviewees from government TVET offices also described what they perceived as the inability of youth to take advantage of the resources they do have, such as the assistance from the woreda bureau, due to a poor work ethic and inability to cooperate with one another.

The objective of Ethiopia's medium- to long-term development plan is to increase employment in the nonfarm modern wage sector, especially in manufacturing, to bring about structural transformation. Even if the manufacturing push is as successful as it has been in Asia, it is necessary to recognize that this process will take time, given the small industrial base in Ethiopia and the rapidly growing labor force ${ }^{78}$. For that reason, short - to medium term strategies that address current challenges are needed, while laying the foundation for the long-run employment agenda to succeed. Following the framework of the 2014 Africa Youth Employment report (World Bank, 2014), the potential strategies can be categorized as "do now for now" and "do now for later". The first set of strategies consist of addressing the immediate constraints that hold youth back from being more productive, while the second set of strategies consists of actions that must be taken now to ease the youth employment challenge in the future. Existing research and literature, both from Ethiopia and beyond, suggest of number of potential interventions. These interventions should not be seen in isolation, but rather as complementary as part of a set of programs to improve employment outcomes for young people in Ethiopia.

\subsection{Do Now for Now}

\section{Access to land}

Though nonfarm employment has grown rapidly since 2005, these types of jobs tend to only be available for the better educated youth. Rural youth remain however largely uneducated,

\footnotetext{
${ }^{77}$ In some instances, youth describe an actively antagonistic relationship with government officials. In one kebele, youth perceived woreda officials as having sabotaged their opportunity to earn higher wages (the woreda requested the foreign investment company to pay lower wages). Youth also feel scapegoated by kebele officials whenever there is social unrest due to political tensions.
}

${ }^{78}$ With a rapidly growing labor force, noticeable shifts in the distribution of employment will take more time. 
implying that most youth who remain in rural areas will remain dependent on agriculture for a livelihood ${ }^{79}$. In addition, farming is still considered as a desirable livelihood by rural youth. Access to land is however a key issue for young people. According to the Ethiopian Socioeconomic Survey, the share of rural youth who have use rights over at least one parcel of land decreased steadily to 24 percent in 2016. Limited access to land was frequently mentioned as a major challenge for young men in the WIDE research, and has led to an increase in inter-generational tensions and sibling rivalries ${ }^{80}$. Limited access to land is also a major motivation for rural youth, in particularly men, to migrate out of the kebele ${ }^{81}$. Recent research by the International Food Policy Research Institute (IFPRI) shows that expectations of land inheritance have large effects on migration decisions: Youth who expect to inherit little or no land are more likely to migrate out of the woreda and into urban areas ${ }^{82}$.

Facilitating access to land will be a key component in any effective strategy to improve employment outcomes for rural youth in Ethiopia. Most land is currently controlled by older generations, which, combined with the limited opportunities for nonfarm employment in most rural places, constraints youth transitions, risking the creation of widespread disenchantment among the youth. While the rational response to land scarcity (migration) is in principle a good thing and can lead to better outcomes (see next subsection), research suggests that a substantial share of rural youth still prefer an agricultural livelihood but are pushed out due to lack of land ${ }^{83}$. Kosec et al. (2017) also find that the effect of low expectations of land inheritance on migration is weaker in places where land rental markets are vibrant, which is consistent with a share of rural youth still aspiring to stay in farming if they are given the opportunity to. Given that youth, despite education levels that are still low on average, are nevertheless better educated than their parents, they could make for more productive, energetic, and efficient farmers through adoption of new technologies and practices.

While there is no easy solution to the land issue, well-functioning and efficient land rental markets could facilitate youth's access to land ${ }^{\mathbf{8 4}}$. Land rental markets do exist but are thin and restricted by policy, though regulations differ across Regions ${ }^{85}$. Restrictions on the share of land that can be rented out, for instance, has the effect of reducing land access for tenants with complimentary non-land resources and tends to lower overall productivity, given that rentals tend to transfer land to more productive producers ${ }^{86}$. Available evidence from Ethiopia suggests that more flexible land rental markets with more long-term contracts can be a way to improve access to land for rural youth while at the same time securing a more reliable income for labor-poor and less efficient households ${ }^{87}$. More efficient land rental markets would also boost overall agricultural

\footnotetext{
${ }^{79}$ Of course, many rural youths, in particularly those who expect to inherit little or no land, are moving to towns and urban areas to seek a living (Bezu and Holden, 2014; Holden and Ghebru, 2016; Kosec et al, 2017).

80 Pankhurst, 2017.

${ }^{81} \mathrm{Kosec}$, et al., 2017. The qualitative research conducted in the framework of this report also suggests that lack of land and employment opportunities in general are main motivations for youth to migrate to towns and cities.

82 Kosec et al., 2017.

83 Bezu and Holden, 2014.

${ }^{84}$ Deininger, Ayalew and Alemu (2008) find that land rental markets in Ethiopia transfer land from older to younger households and substitute for administrative land redistributions.

85 The regulation of land rental differs by region. In Tigray Region, for instance, households cannot rent out more than half of their land and rental arrangements cannot span more than two years. In Amhara Region, the regulations are more liberal land can be rented out for up to 25 years.

${ }^{86}$ Deininger, Ali and Alemu (2013) find that land rentals redistribute land to more efficient producers but that this productivity gain is dampened by the inefficiency of contractual arrangements (sharecropping, the most common rental arrangement, is inefficient). Chen and Restuccia (2017) find substantial misallocation of land across farms in Ethiopia, which could be reduced through efficient rental markets.

${ }^{87}$ Holden and Ghebru, 2016.
} 
productivity, as they would allow farms to operate more closely to their optimal scale (Chen and Restuccia, 2017).

\section{Labor mobility and migration}

As Ethiopia develops and transforms to a nonfarm economy, poverty reduction will involve creating opportunities to reduce the number of farmers, including via migration ${ }^{88}$. Several studies have documented the positive effects of internal migration in Ethiopia. De Brauw, Mueller and Woldehanna (2013) find large increases in consumption for migrants relative to individuals in the same origin village who did not migrate. Overall, migration led to a 110 percent increase in consumption in their sample, with both rural-to-rural and rural-to-urban migration leading to an increase in consumption (though the effects are larger for rural to urban migration) ${ }^{89}$. Migration did not lead to losses for sending households: Out-migration of a household member may be hypothesized to have an adverse impact on agricultural productivity due to a lost labor effect, though this appears not to be the case (De Brauw, 2014) ${ }^{90}$. On a more general level, this report also found that the limited structural transformation of employment in Ethiopia has been closely linked to higher labor mobility to urban areas ${ }^{91}$.

Internal migration in Ethiopia remains however limited, possibly due to credit constraints. Less than five percent of working-age Ethiopians changed zone of residence in 2013, roughly the same share as in $1999^{92}$. Given the clear individual payoffs to internal labor mobility and the absence of negative effects for the sending households, the low mobility rates must mean that constraints of some sort are hindering migration. In general, migration can be limited by several factors (related to policy, credit, and information ${ }^{93}$ ), and the evidence in Ethiopia is consistent with credit constraints ${ }^{94}$. Migration needs to be financed, not only the cost of travel but also the cost of living as a migrant looks for employment in the destination. For many households and individuals, these costs are prohibitive. De Brauw (2014) finds a positive relationship between agricultural productivity and the probability of a household sending out a migrant, a pattern which is consistent with credit constraints ${ }^{95}$.

Alleviating credit constraints to labor mobility can have large payoffs. To illustrate, in Bangladesh, an NGO randomly assigned a small cash or credit incentive to rural households conditional on a household member migrating during the hunger season ${ }^{96}$. The incentive substantially increased the rate of seasonal migration to urban areas (where employment opportunities are more abundant) and led to large increases in consumption for the sending households. Gross returns to the initial incentive are estimated at 273 percent, indicating that incentivizing seasonal migration is a highly cost-effective intervention. In addition, individuals

\footnotetext{
${ }^{88}$ Collier and Dercon, 2013.

${ }^{89}$ The effect of rural-to-rural migration is 68 percent that of rural-to-urban migration. Migrants, however, did not consider themselves to be better off on a subjective welfare scale. This may be related to the disutility of migration (loss of family network, poor housing conditions in urban areas, uncertainty, etc. - see ).

${ }^{90}$ In contrast, de Brauw (2014) finds that income increases for households that sent out a migrant, but this effect is not robust to controlling for other household characteristics.

${ }^{91}$ In Tanzania too, labor mobility is causally related to faster consumption growth, especially (but not only) if the destination is an urban area (Beegle, De Weerdt, and Dercon, 2009).

92 It is possible that there is more population mobility across kebeles and woredas within zones, though this cannot be picked up with the Labor Force Surveys.

${ }^{93}$ For a more elaborate discussion, see World Bank (2015).

${ }^{94}$ De Brauw and Mueller (2012) show that the land tenure system in Ethiopia appears to be a constraint to migration, but the magnitude of the effect is quite small.

${ }_{95}^{95}$ The low levels of education in rural Ethiopia also act as a constraint to migration (World Bank, 2016).

${ }^{96}$ The incentive amounted to about US\$8.5, approximately the cost of a round-trip bus ticket to a nearby urban area.
} 
who were incentivized to migrate through the incentive were more likely to re-migrate one and three years after the program, indicating a learning effect. In the Bangladesh case, both the cash and credit incentive had similar effects on household welfare, and 80 percent of households were able to repay (without interest) the initial credit ${ }^{97}$. This is just one example, and credit constrains can also be alleviated through other means, for instance through improved productivity in agriculture or development of the rural nonfarm economy. The general point is that labor mobility in Ethiopia appears on average to be beneficial for the migrant, without evidence of adverse effects on sending households ${ }^{98}$.

\section{Box 12}

\section{Improving youth employment in Ethiopia}

Evidence from Ethiopia and beyond

"Do now for now"

Actions to affect current cohorts of youth
"Do now for later"

Actions to affect future cohorts of youth

Rationale
1. Improve functioning of land rental

markets to facilitate youths' access to land
Many rural youth still aspire to an agricultural livelihood but do not have access to (sufficient) land. Research shows that land rentals in Ethiopia increase overall productivity. A betterfunctioning land rental market could improve employment and increase agricultural output, and also act as a brake on distress migration.

2. Facilitate productive labor mobility

The limited structural transformation in employment has been driven by rural to urban migration. Research from Ethiopia and elsewhere show large private welfare effects from internal migration, both to rural areas or to towns and cities. As Ethiopia's cities and towns continue to grow and industrial parks are established, higher labor mobility can address the imbalances between where the jobs are and where the people are and speed up the structural transformation.

3. Facilitate access to finance
The qualitative research identified the lack of access to finance as one of the main obstacles to better employment in rural areas. MFI loans are all but inaccessible for rural youth from poor family backgrounds and youth did not consider the cooperative model of obtaining finance as an attractive option. For certain groups of youth, grants may be a better option than loans.

\footnotetext{
${ }^{97}$ Bryan, Chowdhury, and Mobarak (2014).

${ }^{98}$ Rural to urban migration is often seen as a scourge by governments, given the potential effects on urban unemployment, congestion, or even crime, or for its role in establishing an urban proletariat. Research from Ethiopia suggests that even at the bottom of the migration ladder, migrants are not doing that bad. Earnings of a sample of 445 rural migrants engaged in shoe-shining or coffee-vending in Addis Ababa and Hawassa are higher than the public sector minimum wage and many times the official poverty line (Bezu and Holden, 2015).
} 
While education levels of rural youth remain low, urban youth are increasingly better educated. While the manufacturing agenda will create wage jobs for low-skilled people, unemployment in urban areas is highest for the secondary-educated. Creating wage employment for increasingly educated urban populations will require an increase in labor demand in services in the private sector.

5. Improve basic education in rural areas

In contrast to urban youth, rural youth remain poorly educated, hindering both productivity improvements in agriculture and their diversification to higher productivity nonfarm activities. Improving basic education in rural areas is an absolute priority.

6. Towns and rural-urban linkages

7. Fertility and family planning
The rural nonfarm economy in Ethiopia is small, mainly due to remoteness and lack of market access. There are over 1,500 towns (less than 50,000 people) in Ethiopia, and infrastructure investments in and around towns to create bigger agglomerations and better link them with the rural hinterlands has the potential to substantially increase employment opportunities for the surrounding populations while also strengthening backward linkages through increased demand for agricultural products.

Due to persistently high fertility rates, Ethiopia's working-age population is projected to grow by 2 million per year in the coming 10 years. This not only adds to the employment challenge, but also means that the education system needs to absorb a larger number of children in every subsequent year. A critical review of the National Population Policy is warranted to look into the causes of the stalling fertility rates.

\section{Youths' access to finance}

Though the quantitative analysis in this report has not explicitly focused on access to finance, both the available evidence and the qualitative research suggest this is a large constraint. According to the most recent LFS, 30 percent of unemployed youth in Ethiopia would like to start their own business ${ }^{99}$. However, they are constrained by the lack of start-up capital: 56 percent of youth wanting to start a nonfarm enterprise mentioned lack of finance as the biggest constraint, while an additional 12 percent mention "lack of working space and finance". In the qualitative WIDE research, access to finance also came out as a key factor explaining individual economic success: "Being able to raise some form of initial capital was an essential prerequisite for

\footnotetext{
${ }^{99} 53$ percent of unemployed youth reported wanting to do "any type of available work", while only about 17 percent is looking for a wage job in the public (11 percent) or private sector (six percent). This suggests youth aspirations are realistic: Young people know that the chance of them getting a regular wage job is minimal, and that opening a small business is therefore the most realistic option.
} 
economic success" 100 . In the qualitative study that was conducted in the framework of this report, access to finance was, along with the land constraints, most frequently mentioned as the main obstacles faced by rural youth. Though micro-finance institutions are available in rural areas, they currently do not seem to offer services that are accessible to the bulk of the rural population ${ }^{101}$.

Improving access to finance for rural youth will need to take account of their heterogeneity. The approach of encouraging youth to form cooperatives or business groups, after which they can benefit from certain modes of government support, including financial, can work in certain cases and circumstances, but does not always seem to work well (as suggested by the considerable share of such cooperatives that are inactive or disbanded and/or are unable to repay loans). For the least educated and poorest youth in particular, access to finance may need to take the form of grants rather than loans, given the limited repayment capacity and impossibility to save the required amount upfront ${ }^{102}$. Recent rigorous research has shown the effectiveness of one-time cash grants, possibly combined with some form of business training, in promoting entry into nonfarm selfemployment and increasing labor earnings ${ }^{103}$. In Ethiopia, beneficiaries of an entrepreneurship program consisting of a cash grant (of about US\$300) and business training tended to move into nonfarm self-employment and increased earnings by one-third. While cash transfers will not be a panacea for everything, it can be an effective instrument in a broader policy aimed at improving rural employment outcomes through facilitating entry of small nonfarm enterprises (or indeed facilitating migration to towns).

\section{Facilitating the services sector}

The service sector accounted for about half of economic growth during Ethiopia's growth acceleration and created most of the jobs outside agriculture ${ }^{104}$. While the development of manufacturing has the potential to create many jobs for lower-skilled young people, the urban services sector has the highest potential to absorb the growing numbers of relatively highereducated youth and further decrease urban unemployment. Increasing labor demand in services will be required to create more wage employment opportunities for youth with secondary education or more, who currently face relatively high unemployment rates and who are unlikely to want to work in factories. While the services sector has considerable potential in Ethiopia, it is, according to the Enterprise Surveys, increasingly credit-constrained, holding back job creation in the sector. A less-constraining business environment and a review of formal trade barriers and domestic regulatory barriers would be warranted to boost job creation in the largely urban-based services sector.

\footnotetext{
100 Pankhurst, 2017, p. 409.

${ }^{101}$ According to the 2016 ESS, financial inclusion is low in rural Ethiopia. About 11 percent of rural adults have an account or registration at a formal financial institution (public or private bank. MFI, SACCO) and this drops to six percent for young rural adults (18-29). Microfinance in particular has a low penetration: Less than 4 percent of rural adults have an account at a MFI (2 percent for young adults).

102 In the qualitative research, rural youth said that it was impossible for them to save the required 20 percent of the loan value (the amount that needs to be saved before potentially being able to obtain a loan from an MFI). As most youth were involved in odd casual jobs, earning between ETB 30 and 40 a day, saving was close to impossible.

${ }^{103}$ To illustrate, in Northern Uganda, a one-off cash grant to underemployed youth led to investments in business assets and vocational training, with substantial and persistent effects on earnings (Blattman, Fialia, and Martinez, 2014). Beneficiaries of a cash plus business training and mentoring intervention in rural Kenya shifted time from leisure and household activities to nonfarm enterprise activity, leading to a 34 percent increase in per capita income one year after the intervention (Gobin, Santos, and Toth, 2016).

104 World Bank, 2016.
} 


\section{Quality basic education}

Despite strong improvements in enrolments, the state of basic education in rural Ethiopia remains poor. In 2016, 80 percent of rural dwellers between 15 and 29 years of age did not complete primary school. Net primary attendance rate amounted to 69 percent in rural areas, with a steep economic gradient: Attendance is 59 percent in the poorest quintile, compared to 84 percent in the wealthiest one ${ }^{105}$. Though access to education and enrolments have increased, levels of learning remain low, with little discernable evidence of a change in educational achievement for children of an equivalent age between 2006 and $2016^{106}$.

The low education level of rural youth is a key constraint for increased productivity and earnings. Schooling is not only associated with the sector in which youth work, but also with greater productivity and earnings in the job they end up doing. In agriculture, the sector where most of Ethiopia's youth will continue to work in, farmers with primary schooling tend to have higher profits than lower-educated farmers, even when assets are controlled for. More educated farmers are more likely to understand and adopt new technologies, boosting their incomes ${ }^{107}$. In Africa, research shows that returns to only a few years of primary education are low ${ }^{108}$. In contrast, completed primary education is associated with significantly higher earnings, both in Africa in general and in Ethiopia in particular. However, in 2013, the median young person in rural Ethiopia completed a mere three years of education, which only has marginal effects on earnings or productivity. Getting and, especially, keeping more children in basic education of good quality will be a necessary condition to improve the employment outcomes of youth, both on and off the farm ${ }^{109}$, and to break the intergenerational transmission of poverty ${ }^{110}$. Given the size of the cohorts coming into the education system (close to 15 million children are currently under age five), Ethiopia cannot afford to retain an education system that fails to include all and instill the skills needed to pursue sustainable livelihoods ${ }^{111}$.

\section{Market access, small towns, and the rural nonfarm economy}

Though market access has substantially improved over the past decade thanks to large investments in infrastructure, rural accessibility remains fairly low. In 2016, the Rural

\footnotetext{
105 Gross attendance in primary school is also low among the bottom quintile (73 percent in the 2016 DHS). This also comes out of the qualitative WIDE research: "...many poor people could not afford the costs associated with going to Health Centers (transport, drugs, time off work) or attending schools (uniforms, books, pens etc.)." (Pankhurst, 2017, p. 116).

${ }^{106}$ The Young Lives study finds that reading and math competencies of 12-year-olds in Ethiopia decreased significantly between 2006 and 2013 (Woldehanna and Gebremedhin, 2016). On the other hand, the Ethiopian National Learning Assessments find that learning outcomes at primary level increased modestly between 2011 and 2015 (World Bank, 2016).

${ }^{107}$ The WIDE project documents instances of farmers who have become wealthy by adopting new technologies such as irrigation and modern inputs, leading to increased differentiation and inequalities in rural areas.

${ }^{108}$ World Bank (2014) reviews the research on returns to education in Sub-Saharan Africa and finds that a few years of basic education yields much lower productivity gains in Africa than in other regions. In other words, the association between education and earnings or productivity is low at the incomplete-primary level.

${ }^{109}$ Many studies document the difference between being in school versus actually learning. For instance, in 200743 percent of sixth-graders in Tanzania and over 70 percent in Mozambique did not get beyond the "basic numeracy" level (World Bank, 2014). For basic education to be effective, it needs to be of sufficient quality.

${ }^{110}$ The low attendance rates of children in poor households is partly due to the important contribution young children make to household income. Increasing attendance and retention of poor children may require experimenting with (conditional) cash transfers to compensate poor households for the loss of household income incurred through keeping their children in school.

${ }^{111}$ Better basic education is also important for future growth and the success of the industrialization agenda. In examining the rapid growth and industrialization of the Asian Tigers between the early 1960s and 1990s, Page (1994) argues that better initial endowment of human capital and large public expenditures on basic education (with restraint on subsidies for higher education) were important ingredients in their success.
} 
Accessibility Index in Ethiopia amounted to 22 percent, meaning that 22 percent of the rural population had access to a road of "good or fair" condition within $2 \mathrm{~km}$ of their home. Higher rural accessibility is related to a more vibrant nonfarm sector, though only few woredas in rural Ethiopia are sufficiently accessible to benefit from these "mini-agglomeration" effects. The rural nonfarm economy in Ethiopia is small compared to other countries ${ }^{112}$, and the bulk of existing nonfarm enterprises mention lack of market access as their main constraint for growth: 56 percent of rural and small town enterprise owners in Ethiopia identify lack of market access and difficulty of obtaining market information as being the main constraint to growth of their enterprise ${ }^{113}$. Further improving rural connectivity and market accessibility, potentially through labor-intensive public works that will generate casual employment opportunities, will be important to stimulate the rural nonfarm economy, a sector with underexploited potential for employment creation and poverty reduction in Ethiopia ${ }^{114}$.

Small towns in particular can play an important role in creating rural nonfarm employment and reducing poverty. The type of employment typically available in small towns (unskilled and semi-skilled labor) is more compatible with the current low education levels of rural youth in Ethiopia than the higher-skilled jobs more in demand in large cities ${ }^{115}$. Migration to proximity towns is also less costly (compared to migration to a distant city) and allows the migrants to maintain closer social ties with the area of origin. Research has also shown that movements from rural areas (agriculture) into rural towns is associated with higher rates of poverty reduction and inclusive growth as compared to migration to big cities ${ }^{116}$. In Ethiopia, the employment structure in small towns is dominated by small nonfarm enterprises ("household" enterprises) that are usually tightly linked with the surrounding rural areas through supply (of inputs, nonfarm goods and services, etc.) and demand (for agricultural products, basic processing, etc.). Next to 43 cities with a population of over 50,000, there are an estimated 1,500 towns with population under 50,000 in Ethiopia (and 1,385 with population under 20,000) ${ }^{117}$. Infrastructure investments in those towns and incentives to encourage migration to small towns, either seasonal or permanent, may have large potential in creating employment opportunities for youth from the surrounding rural hinterland. This can be combined with interventions in access to finance to facilitate entry into nonfarm self-employment in towns.

\section{Fertility and family planning}

Ethiopia's youth employment challenge is complicated by a rapidly growing labor force. Under the "medium-fertility scenario", Ethiopia's labor force is projected to grow by 20 million in the coming 10 years $^{118}$. While the total fertility rate (TFR) declined from 5.5 in 2000 to 4.6 in 2016, rural fertility remained high at 5.2 children per woman. In addition, the fertility decline has stalled in recent years, with TFR being largely similar in 2016 (4.6) as in 2011 (4.8). The persistently high fertility rate means future youth cohorts will only become larger and the challenges for job creation only bigger. To illustrate, there are currently 29 million youth (15-29)

\footnotetext{
${ }^{112}$ In the six LSMS countries together (Ethiopia, Malawi, Uganda, Tanzania, Niger, and Nigeria), 42 percent of rural households run a nonfarm enterprise. In Ethiopia, this drops to 23 percent (Nagler and Naude, 2016).

113 Fuje and Ersado, 2016.

${ }^{114}$ As in other countries, rural households in Ethiopia that run a nonfarm enterprise have higher consumption levels relative to those without a nonfarm enterprise (Fuje and Ersado, 2016).

115 Unskilled and semi-skilled workers make up the vast majority of the workforce in rural towns in Ethiopia (Dorosh and Thurlow, 2014). In contrast, semi-skilled and skilled workers dominate the workforce in cities.

${ }^{116}$ Christiaensen and Todo, 2013; Christiaensen, De Weerdt and Todo, .

${ }^{117}$ Ethiopia Urbanization Review, 2015.

118 World Population Prospects, 2015 Revision.
} 
in Ethiopia. Ten years from now, there will be 38 million $^{119}$. Achieving faster declines in fertility through improved access to family planning, girls' education, and better female labor force participation will be required to manage the twin challenges of education and employment in the decades to come.

\footnotetext{
${ }^{119}$ Idem
} 


\section{References}

Azeng, T. and Yogo, T. (2013). "Youth Unemployment and Political Instability in Selected Developing Countries". African Development Bank Working Paper Series 171.

Azeng, T. and Yogo, T. (2015). "Youth unemployment, education and political instability: evidence from selected developing countries 1991-2009". Households in Conflict Network Working Paper 200. Brighton: The Institute of Development Studies.

Beegle, K., De Weerdt, J. and Dercon, S. (2011). "Migration and Economic Mobility in Tanzania: Evidence from A Tracking Survey". Review of Economics and Statistics 93(3): 1010-1033.

Bezu, S. and Holden, S. (2014). "Are Rural Youth in Ethiopia Abandoning Agriculture?”. World Development 64: 259-272.

Bezu, S. and Holden, S. (2015). Street-Based Self-Employment: A Poverty Trap or a Stepping Stone for Migrant Youth in Africa?". Norwegian University of Life Sciences, Center for Land Tenure Studies Working Paper 4/15.

Bigsten, A., Collier, P., Dercon, S., Fafchamps, M., Gauthier, B., Gunning, J., and Oduro, A. 2003. "Credit Constraints in Manufacturing Enterprises in Africa." Journal of African Economies 12 (1): 104-125

Blattman, C., Fialia, N., and Martinez, S. (2014). "Generating Skilled Self-Employment in Developing Countries: Experimental Evidence from Uganda". The Quarterly Journal of Economics 129(2): 697-752.

Bryan, G., Chowdury, S. and Mobarak, M. (2014). "Underinvestment in a Profitable Technology: The Case of Seasonal Migration in Bangladesh". Econometrics 82(5): 1671-1748.

Chen, C. and Restuccia, D. (2017). "Land Markets, Resource Allocation, and Agricultural Productivity". Working paper.

Christiaensen, L. and Todo, Y. (2014). "Poverty Reduction During the Rural-Urban Transformation - The Roelof the Missing Middle". World Development 63: 43-58.

Christiaensen, L., De Weerdt, J. and Todo, Y. (2013). "Urbanization and Poverty Reduction: The Role of Rural Diversification and Secondary Towns". Agricultural Economics 44(4-5): 435-447.

Collier, P. and Dercon, S. (2013). "African Agriculture in 50 years: Smallholders in a Rapidly Changing World?". World Development 63:92-101.

De Brauw, A. (2015). "Migration, Youth and Agricultural Productivity in Ethiopia". International Food Policy Research Institute, Conference Paper.

De Brauw, A. and Mueller, V. (2012). "Do Limitations in Land Rights Transferability Influence Mobility Rates in Ethiopia?'. Journal of African Economies 21(4): 548-579.

De Brauw, A., Mueller, V. and Woldehanna, T. (2013). "Does Internal Migration Improve Overall Well-Being in Ethiopia?”. International Food Policy Research Institute, ESSP Working paper 55. 
Deaton, A. (1985). Panel Data from Time Series of Cross Sections. Journal of Econometrics, 30: 109-126.

Deininger, K., Ayalew, D., and Alemu, T. (2008). "Assessing the Functioning of Land Rental Markets in Ethiopia". Economic Development and Cultural Change 57(1): 67-100.

Deininger, K., Ayalew, D., and Alemu, T. (2012). "Productivity Effects of Land Rental Markets in Ethiopia: Evidence from a Matched Tenant-Landlord Sample". Applied Economics 45(25).

Dorosh, P. and Thurlow, J. (2014) "Can Cities or Towns Drive African Development? Economywide Analysis for Ethiopia and Uganda". World Development 63: 113-123.

Gobin, V., Santos, P. and Toth, R. (2016). "Poverty Graduation with Cash Transfers: A Randomized Evaluation". Monash Business School discussion paper 23/16.

Holden, S. and Ghebru, H. (2016). "Land Rental Market Legal Restrictions in Northern Ethiopia". Land Use Policy 52: 410-421.

Kosec, K. Ghebru, H., Holtemeyer, B., Mueller, V. and Schmidt, E. (2016). "The Effect of Land Inheritance on Youth Employment and Migration Decisions: Evidence from Rural Ethiopia”. International Food Policy Research Institute discussion paper 1594.

Nagler, P. and Naude, W. (2016). Non-Farm Entrepreneurship in Rural Sub-Saharan Africa: New Empirical Evidence". Food Policy

Page., J. (1994). The East Asian Miracle: Four Lessons for Development Policy. In: Fischer, S. and Rotemberg, J. (Eds.). NBER Macroeconomics Annual 1994, Volume 9.

Pankhurst, A. (ed). (2017). Change and Transformation in Twenty Rural Communities in Ethopia. Ethiopia: WIDE.

Woldehanna, T. and Gebremedhin, A. (2016). "Learning Outcomes of Children Aged 12 in Ethiopia: A Comparison of Two Cohorts". Young Lives Working Paper 152.

World Bank. (2015). "Ethiopia Poverty Assessment." Washington DC: The World Bank.

World Bank. (2015). $5^{\text {th }}$ Ethiopian Economic Update: Why so Idle? Wages and Unemployment in a Crowded Labor Market. Washington DC: The World Bank.

World Bank. (2016). "Ethiopia's Great Run. The Growth Acceleration and How to Pace It." Washington DC: The World Bank.

World Bank. (2016). Striving for Excellence.

World Bank. (2016). Measuring Rural Access Using New Technologies. Washington DC: The World Bank

World Bank. 2014. Youth Employment in Sub-Saharan Africa. Washington DC: The World Bank

World Bank. 2015. Ethiopia Urbanization Review. Washington DC: The World Bank.

World Bank. (2016). Priorities for Ending Extreme Poverty and Promoting Shared Prosperity. Ethiopia Systematic Country Diagnostic. Washington DC: The World Bank 


\section{Annex 1: Enterprise Surveys and Credit Constraints}

The main datasets used in the analysis for Box 2 are the World Bank's Enterprise Surveys 2011 and 2015. The datasets provide information on firms classified with ISIC codes 15-37, 45, 50-52, 55, 60-64, and 72 (ISIC Rev.3.1). Formal (registered) companies with five or more employees in cities with major economic activity are targeted for interviews; firms that are fully governmentowned are not eligible. Service firms include those in retail, wholesale, hotels, restaurants, transport, storage, communications, and IT. The standard Enterprise Survey topics include firm characteristics, employment and ownership by gender, access to finance, annual sales, costs of inputs/labor, workforce composition, bribery, licensing, infrastructure, trade, crime, competition, capacity utilization, land and permits, taxation, informality, business-government relations, innovation and technology, and performance measures. While the majority of questions aim to objectively ascertain characteristics of a country's business environment, a subset assesses the survey respondents' opinions on what are the obstacles to firm growth and performance.

In the analysis for Box 2, firms are classified in three groups with regard to their credit demand. These three groups are: (1) firms with no demand for loans, (2) rationed firms with positive demand, and (3) firms whose demand is met (partly or fully). Firms in the first category did not apply for a loan because they stated that they had no need for a loan or found interest rates too high $^{120}$. These firms clearly had no demand for loans. Firms in the second category, those with unmet demand, are either firms whose application was rejected or firms that did not apply but provided reasons that clearly indicated a demand for a loan (e.g., they found the process too difficult, collateral requirements too high, size and maturity of the loan offered insufficient, or they did not believe that their application would be approved). The third group comprises firms that did apply and whose application was accepted. ${ }^{121}$

To see whether credit constraints hold back employment growth, we performed a regression of log employment on binary indicators of credit constraints for the subsample of firms in 2014 that registered some demand for credit. This regression was run separately by firm size, distinguishing firms with fewer than 25 employees from those with at least 25 employees, and by sector. In doing so, controls were employed for lagged employment ${ }^{122}$, firm age, location, city size, and 4-digit ISIC classification of the firm's main product.

\footnotetext{
120 Whether firms that did not apply because of high interest rates should be included in this group is somewhat contentious (Bigsten, et al. 2003). The reason stated suggests that these firms found prevailing prices too high, so they cannot be considered as having been rationed. Nevertheless, they could face the increasing part of the supply curve due to high monitoring costs, making credit too expensive for them. In the latter case, they may indeed be suffering the consequences of market imperfections. The present analysis considers both possibilities and found no major differences.

121 There was a small number of firms whose application was pending, that withdrew their application, or for which the reason for not applying was not clear. These were dropped from the analysis.

122 Conditioning on the lag of the dependent variable allows for an interpretation of the resulting coefficient estimate as the effect of removing credit constraints on firm growth. The coefficients on the lagged dependent turn out highly significant and close to unity in all regressions.
} 


\section{Annex 2: Rural accessibility in Ethiopia}

According to the World Bank (2016), rural accessibility in Ethiopia amounted to 21.6 percent, indicating that 21.6 percent of people in rural areas lived within $2 \mathrm{~km}$ of a road in good condition. There is substantial spatial variation, with sparsely-populated zones in the eastern, southern, and western periphery having the worst accessibility.

Annex Figure 1: Zonal level rural accessibility index, 2016

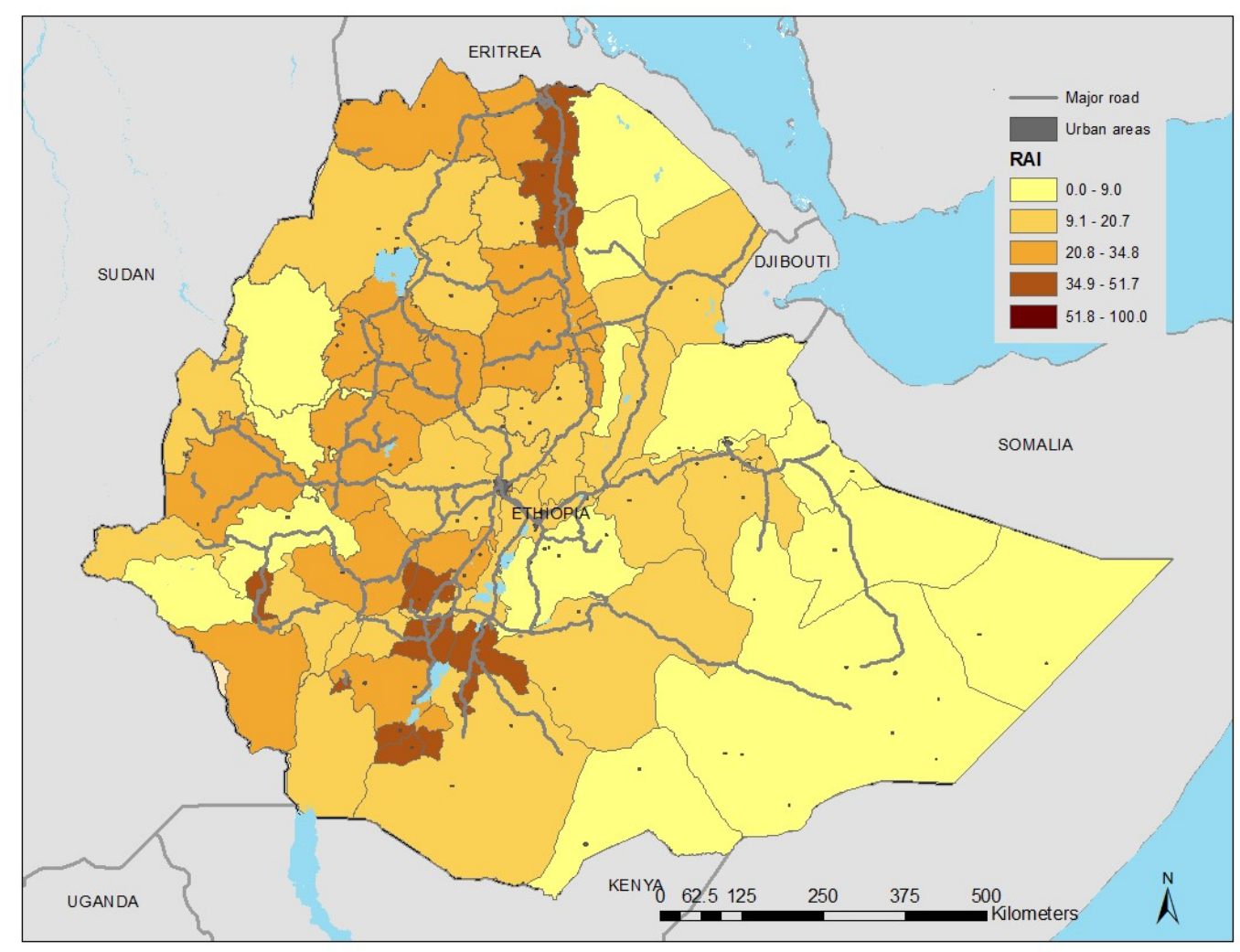

Source: World Bank, 2016 


\section{Annex 3: The correlates of nonfarm enterprise productivity}

To examine the correlates of labor productivity in small nonfarm enterprises, we estimate a regression of the logarithm of monthly sales per worker on a series of owner and enterprise characteristics. Results from the regression, based on the nonfarm enterprise data collected for the 2016 ESS, are presented in Annex Table 1. As the dependent variable is in logarithmic form, the coefficients can be interpreted as the percent change in labor productivity from having a certain attribute.

Annex Table 1: Correlates of labor productivity in small nonfarm enterprises

\begin{tabular}{|c|c|}
\hline VARIABLES & $\begin{array}{c}(1) \\
\log (\text { sales per worker })\end{array}$ \\
\hline \multicolumn{2}{|l|}{ Characteristics of owner: } \\
\hline Incomplete primary & $\begin{array}{l}-0.004 \\
(0.085)\end{array}$ \\
\hline Complete primary & $\begin{array}{c}0.138 \\
(0.153)\end{array}$ \\
\hline Incomplete secondary & $\begin{array}{l}0.354 * * * \\
(0.128)\end{array}$ \\
\hline Complete secondary & $\begin{array}{l}0.869 * * * \\
(0.192)\end{array}$ \\
\hline Tertiary & $\begin{array}{l}0.384 * * \\
(0.178)\end{array}$ \\
\hline Female & $\begin{array}{c}-0.650 * * * \\
(0.075)\end{array}$ \\
\hline Age & $\begin{array}{c}0.044 * * * \\
(0.013)\end{array}$ \\
\hline Age squared & $\begin{array}{c}-0.000 * * * \\
(0.000)\end{array}$ \\
\hline Characteristics of enterprise : & \\
\hline Town & $\begin{array}{l}0.280 * * * \\
(0.103)\end{array}$ \\
\hline City & $\begin{array}{l}0.889 * * * \\
(0.086)\end{array}$ \\
\hline $2-4$ years in operation & $\begin{array}{l}0.209 * * \\
(0.090)\end{array}$ \\
\hline $5-9$ years in operation & $\begin{array}{l}0.214 * * \\
(0.102)\end{array}$ \\
\hline 10 years or more in operation & $\begin{array}{l}0.251 * * \\
(0.104)\end{array}$ \\
\hline Economic sector dummies & Yes \\
\hline \# of hired workers & $\begin{array}{c}0.007 \\
(0.020)\end{array}$ \\
\hline \# of household workers & $\begin{array}{c}-0.296 * * * \\
(0.041)\end{array}$ \\
\hline Constant & $\begin{array}{l}6.248 * * * \\
(0.357)\end{array}$ \\
\hline $\begin{array}{l}\text { Observations } \\
\text { R-squared }\end{array}$ & $\begin{array}{l}1,809 \\
0.270\end{array}$ \\
\hline
\end{tabular}

Source: ESS, 2016. . ${ }^{* * *} \mathrm{p}<0.01,{ }^{* *} \mathrm{p}<0.05, * \mathrm{p}<0.1$ 


\section{Annex 4: The Correlates of Underemployment}

Table 7 in the main text summarizes the incidence of underemployment by gender, age, and occupation. To get a better sense of which factors are significantly correlated with the likelihood of being underemployed while other factors are controlled for, we estimate a logistic regression of the probability of being underemployed on a series of individual and spatial covariates. Annex Figure 2 plots the estimated marginal effects and the 95 percent confidence intervals. Workers aged between 25 and 34 years of age are more likely to be underemployed, everything else being equal, relative to workers in the 15-24 age group. Males are also less likely to be underemployed compared to their female counterparts. Relative to non-agricultural waged workers, any other type of employment relation carries with it a higher probability of being underemployed. For example, agricultural unpaid family workers have a 7.2 percentage points higher likelihood of being underemployed relative to non-agricultural waged workers. Working in regions other than Addis Ababa has a strong and positive impact on the probability of being underemployed, especially for Tigray, Amhara, Oromiya and SNNPR. For example, workers in the Tigray region have a 15 percentage points higher chance of being underemployed.

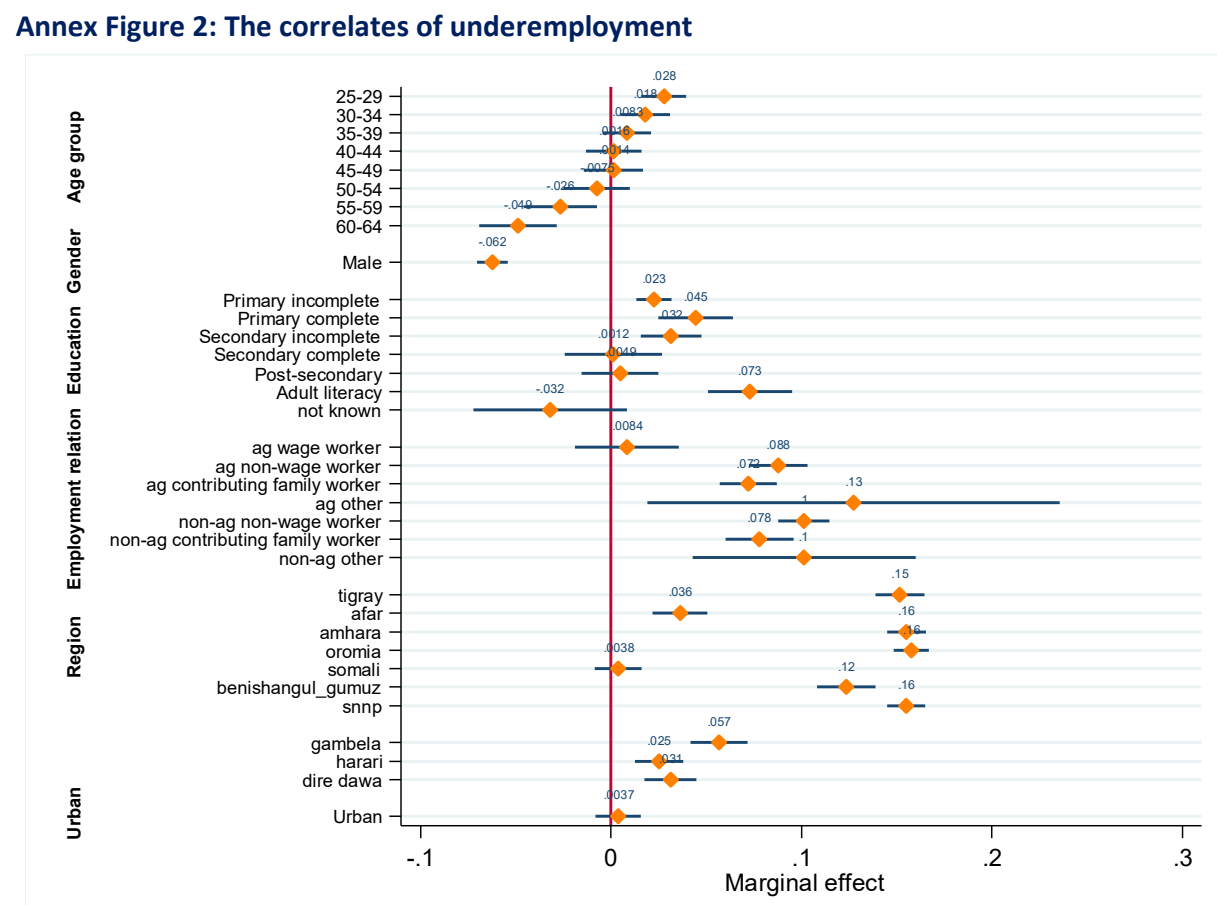

Note: The figure presents the point estimate of the regression (orange markers) and the $95 \%$ confidence interval (black lines around the marker). When the black confidence interval lines do no cross the red vertical axis, the association is statistically significant. Source: LFS, 2013. 


\section{Annex 5: Decomposition of Wage Differentials}

To examine whether differences in mean wages between two groups are due to differences in endowments or differences in returns to endowments, we apply the well-known Oaxaca-Blinder (OB) technique. OB decomposes the difference in the mean of a variable of interest (in our case: real wage earnings per hour) in a part that can be explained by differences in endowments between groups (such as differences in education, experience, sector of work, etc.) and a part that is "unexplained" by such differences (or explained by different returns to these endowments). If a substantial part of wage differentials between two groups or sectors cannot be explained by differences in observable endowments, this can point towards a segmented labor market (with the existence of a "privileged" sector characterized by entry barriers and particularly high wages) or discrimination (where one group receives a lower return on endowments than others). Note, however, that merely the fact of observing unexplained wage differences is not a sufficient condition to establish the existence of segmented labor markets or discrimination.

The decomposition is performed for three groups: (i) Public vs private sector, (2) formal vs informal private sector, and (3) men vs women. Overall, differences in hourly earnings between the public and private sector are mostly attributable to differences in endowments (of the difference of $0.891,0.793$ is explained). The largest part of the wage differential between the formal and informal private sector can also be explained by differences in workers' characteristics, though a substantial share (27 percent) remains unexplained. This indicates that there is sorting across sectors according to endowments (with the less endowed going into the informal sector), but that returns to the same characteristics are also lower in the informal sector (returns to education are lower in the informal sector). Finally, a large part (almost 40 percent) of the wage differences between men and women remain unexplained, even if controlling for industry and occupation, indicating that women earn less than men for the same types of jobs and similar qualifications.

\begin{tabular}{|c|c|c|c|c|c|}
\hline \multicolumn{2}{|c|}{ Public/Private } & \multicolumn{2}{|c|}{ Formal/Informal } & \multicolumn{2}{|c|}{ Men/Women } \\
\hline Public Sector & $\begin{array}{l}2.129 * * * \\
(0.0103)\end{array}$ & Formal sector & $\begin{array}{c}1.667^{* * *} \\
(0.0149)\end{array}$ & Men & $\begin{array}{c}1.691^{* * *} \\
(0.0124)\end{array}$ \\
\hline Private sector & $\begin{array}{l}1.238^{* * *} \\
(0.0118)\end{array}$ & Informal sector & $\begin{array}{c}1.122^{* * *} \\
(0.0305)\end{array}$ & Women & $\begin{array}{c}1.373^{* * *} \\
(0.0124)\end{array}$ \\
\hline Difference & $\begin{array}{l}0.891 * * * \\
(0.0157)\end{array}$ & Difference & $\begin{array}{c}0.545^{* * *} \\
(0.0340)\end{array}$ & Difference & $\begin{array}{r}0.318^{* * *} \\
(0.0175)\end{array}$ \\
\hline Explained & $\begin{array}{l}0.793 * * * \\
(0.0200)\end{array}$ & Explained & $\begin{array}{r}0.398 * * * \\
(0.0188)\end{array}$ & Explained & $\begin{array}{r}0.199 * * * \\
(0.0126)\end{array}$ \\
\hline Unexplained & $\begin{array}{l}0.0977^{* * *} \\
(0.0222)\end{array}$ & Unexplained & $\begin{array}{c}0.147 * * * \\
(0.0327)\end{array}$ & Unexplained & $\begin{array}{r}0.119 * * * \\
(0.0158)\end{array}$ \\
\hline$N$ & 24,469 & & 9,248 & & 25,827 \\
\hline
\end{tabular}

Notes: The dependent variable is the log of real hourly earnings from wage employment. Controls include a second-degree polynomial in age, gender, educational attainment, industrial sector, occupation, cohort of birth, dummy for whether current job is first job, payment type (cash, in-kind, both), and contract type (permanent, temporary, casual, other), region. Robust standard errors in parentheses. ${ }^{* *} \mathrm{p}<0.01, * * \mathrm{p}<0.05, * \mathrm{p}<0.1$. Source: LFS, 2013. 


\section{Annex 6: Effect of Different Treatment of Water and Firewood collectors in 2013}

In 2013, firewood collectors were considered as being in the labor force while this was not the case in 2005 and 1999. About 39 percent of "water and firewood collectors" (ISCO 9624) in 2013 were classified under industrial code (ISIC) 9820 ("Undifferentiated service-providing activities of households for own use"), which is considered as a non-agricultural activity. Including water and firewood collectors in 2013 (but not in earlier rounds) leads to a biased trend, suggesting a higher move out of agriculture: From 78 percent in 1999 to 71 percent in 2013 (left-hand side panel of Annex Table 2).

One potential alternative option would be to exclude water and firewood collectors from the labor force in 2013 (as in Schmidt and Bekele, 2016). Doing this however leads to a sharp drop in labor force participation rates (right-hand side panel of Annex Table 2), which would seem to suggest that water and firewood collectors were included in the labor force in earlier rounds as well (perhaps under a different occupation code). In the analyses of trends, we opted for a third alternative: To include water and firewood collectors in the labor force (it is an important activity: 10 percent of workers and 20 percent of women have their main occupation in water and firewood collection) but considered it as an agricultural (forestry) activity. In doing so, we obtain a trend in agriculture's share of employment that is similar to Schmidt and Bekele (2016)-a decrease of about four percentage points-while also obtaining a credible trend in labor force participation rates.

\begin{tabular}{|c|c|c|c|c|c|c|c|c|}
\hline & \multicolumn{4}{|c|}{ Into the Labor Force } & \multicolumn{4}{|c|}{ Out of the Labor Force } \\
\hline & 1999 & 2005 & 2013 & Change & 1999 & 2005 & 2013 & Change \\
\hline Labor force participation & 83.0 & 86.2 & 85.7 & 2.6 & 83.0 & 86.2 & 77.6 & -5.5 \\
\hline Unemployment rate & 3 & 2.5 & 2.3 & -0.7 & 3.0 & 2.5 & 2.5 & -0.4 \\
\hline Employment-to-working-age-population ratio (last 7days) & 76.1 & 81.4 & 81.2 & 5.2 & 76.1 & 81.4 & 73.1 & -3.0 \\
\hline Agricultural employment (\% of total employment) & 77.9 & 77.7 & 70.5 & -7.4 & 77.9 & 77.7 & 73.3 & -4.6 \\
\hline
\end{tabular}

Source: Authors' calculations based on 1999, 2005, and 2013 LFS data. 


\section{Annex 7: A pseudo-panel analysis of the move to nonfarm and wage employment}

Lack of panel data, in which there are repeated observations for the same unit (households, individuals, firms, etc.) has led to the development of pseudo-panel techniques, introduced by Deaton (1985). A pseudo-panel is formed by creating synthetic observations by averaging real individual observations with similar characteristics (so-called cohorts) in a sequence of repeated cross-sectional data. The cohorts of observations can be followed over time. Synthetic panels do not suffer from sample attrition because the samples are renewed every period. Averaging over individual observations eliminates individual heterogeneity and reduces issue of measurement errors.

The main drawback of pseudo-panels is related to the choice of clustering individual observations that carries with it an important trade-off between the number of cohorts and the number of observations in each cohort. The larger the number of cohorts, the smaller the number of observations in each cohort, thus questioning the representativeness of the aggregation exercise and its capacity to provide good estimates of the population cohort means. On the other hand, having a larger number of cohorts is definitely a big advantage so that the estimates based on the synthetic observation suffer less from small sample problems.

For our analysis, we create cohorts by combining year of birth, gender, and education of the individuals observed in the three rounds of the LFS (1999, 2005, and 2013). Though education is not a time-invariant characteristic, the binary way in which we define education (no education vs at least some education) almost makes it time-invariant: Adults with no education in 1999 will likely also have no education in 2005 and 2013. Given that we are interested in employment outcomes and in following same cohorts through time, we restrict the analysis to individuals aged 15-54 in the 1999 LFS, 15-60 in the 2005 LFS, and 15-68 in the 2013 LFS. This approach leads to 136 unique cohorts that can be followed through time. Each cohort is based on a sufficiently large number of individual observations (median of 731 observations per cohort). Since the number of observations per cohort varies substantially, the error term is heteroskedastic leading to biased standard errors. Heteroscedasticity is corrected by using weighted least squares estimation (by weighting each cohort with the square root of the number of observations in each cohort).

The estimated equation is the following:

$$
Y_{c t}=\gamma X_{c t}+\alpha_{c t}+\epsilon_{c t}
$$

Where $Y_{c t}$ is the share of workers in cohort $\mathrm{c}$ in time $\mathrm{t}$ that is employed in agriculture (or alternatively, wage-employed), $X_{c t}$ is the share of workers in cohort c in time $t$ that lives in urban areas, and $\alpha_{c t}$ is the average of the fixed effects for the individuals in cohort $\mathrm{c}$ in survey year $\mathrm{t}$. 


\section{Annex 8: Estimating returns to education}

To estimate returns to education, we perform a multivariate regression of log of real hourly earnings on a set of individual characteristics. Next to education, these characteristics include age (second-degree polynomial), gender, industrial sector, occupation, cohort of birth, dummy for whether current job is first job, payment type (cash, in-kind, both), and contract type. The regression also includes region dummies and a region-specific time trend. To examine whether returns to education have changed between 2005 and 2013, the 2005 and 2013 LFS are pooled and the education level interacted with a time dummy. As shown by Annex Table 2, returns to education decreased at all levels, mainly at higher levels of education.

Annex Table 4: Differences in the returns to education, 2005-2013 


\begin{tabular}{|c|c|}
\hline VARIABLES & $\begin{array}{c}\text { Logarithm of hourly } \\
\text { earnings }\end{array}$ \\
\hline Age & $\begin{array}{l}0.0739 * * * \\
(0.00708)\end{array}$ \\
\hline Age squared/100 & $\begin{array}{c}-0.0844 * * * \\
(0.00875)\end{array}$ \\
\hline Male & $\begin{array}{c}0.155^{* * *} \\
(0.0129)\end{array}$ \\
\hline Educational Level & \\
\hline Primary incomplete & $\begin{array}{l}0.346 * * * \\
(0.0353)\end{array}$ \\
\hline Primary complete & $\begin{array}{l}0.533^{* * *} \\
(0.0432)\end{array}$ \\
\hline Secondary incomplete & $\begin{array}{l}0.641^{* * *} \\
(0.0406)\end{array}$ \\
\hline Secondary complete & $\begin{array}{l}0.837 * * * \\
(0.0357)\end{array}$ \\
\hline Post-secondary and above & $\begin{array}{l}1.192 * * * \\
(0.0375)\end{array}$ \\
\hline Adult literacy & $\begin{array}{c}0.196 \\
(0.120)\end{array}$ \\
\hline Missing education & $\begin{array}{l}0.803 * * \\
(0.386)\end{array}$ \\
\hline Education*Year2013 & \\
\hline Primary incomplete*2013 & $\begin{array}{c}-0.230 * * * \\
(0.0496)\end{array}$ \\
\hline Primary complete*2013 & $\begin{array}{c}-0.230 * * * \\
(0.0604)\end{array}$ \\
\hline Secondary incomplete*2013 & $\begin{array}{c}-0.292 * * * \\
(0.0536)\end{array}$ \\
\hline Secondary complete*2013 & $\begin{array}{c}-0.347 * * * \\
(0.0490)\end{array}$ \\
\hline Post-s econdary and above*2013 & $\begin{array}{c}-0.438 * * * \\
(0.0474)\end{array}$ \\
\hline Adult literacy*2013 & $\begin{array}{l}-0.164 \\
(0.161)\end{array}$ \\
\hline Missing education*2013 & $\begin{array}{l}-0.601 \\
(0.401)\end{array}$ \\
\hline Year 2013 & $\begin{array}{c}0.338 * * * \\
(0.0650)\end{array}$ \\
\hline Constant & $\begin{array}{l}0.488^{* *} \\
(0.230)\end{array}$ \\
\hline $\begin{array}{l}\text { Observations } \\
\text { R-squared }\end{array}$ & $\begin{array}{c}45,608 \\
0.584 \\
\end{array}$ \\
\hline \multicolumn{2}{|c|}{$\begin{array}{l}\text { Additional controls include industrial sector, occupation, } \\
\text { cohort of birth, dummy for whether current job is first-time } \\
\text { job, payment type (cash, in-kind, both), and contract type } \\
\text { (permanent, temporary, casual, other), region and region- } \\
\text { specific linear trends. Robust standard errors in } \\
\text { parentheses } \\
* * * p<0.01, * * p<0.05, * p<0.1\end{array}$} \\
\hline
\end{tabular}




\section{Annex 9: Urban unemployment trends}

Annex Figure 3: Trends in urban unemployment by city, youth and older workers

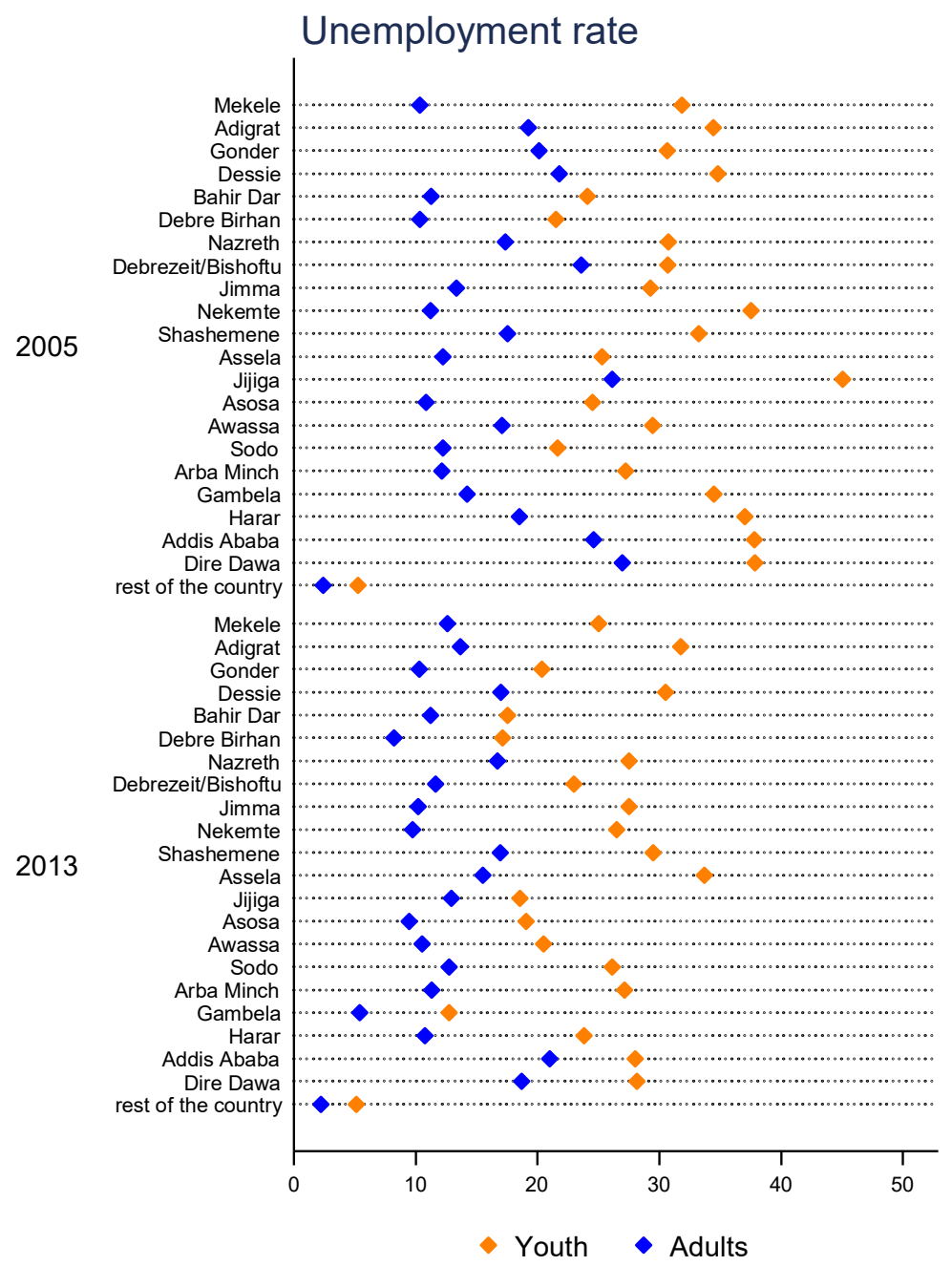

Source: LFS, 2005; 2013. 


\section{Annex 10: The role of education in explaining employment category}

Education has a strong effect on the type of employment an individual has access to. For instance, based on the 2013 LFS, an individual with post-secondary education was 69 percentage points more likely to work in the public sector compared to an individual without education. Conversely, someone with incomplete secondary education was 23 percentage points less likely to be a farmer. To see whether the effect of education on type of employment has changed between 2005 and 2013, we estimate a multinomial logit of employment type on age (second-degree polynomial), gender, region of residence, and education, and an interaction term between education and a dummy taking on 1 if the survey year is 2013. Annex Table 2 presents the coefficient estimates of the interaction between education and time period. Between 2005 and 2013, the role of higher levels of education in securing access to the public sector has weakened, as shown by the negative coefficients on completed secondary and post-secondary education in column (1). Instead, individuals with completed secondary and post-secondary education were more likely to be engaged in nonfarm self-employment in 2013 (column (7)). Compared to 2005, individuals with any level of education higher than none were more likely to be engaged in unpaid farm labor, even at high education levels (column (6)). 
Annex Table 5: Coefficients of the (education*2013 dummy) terms

\begin{tabular}{|c|c|c|c|c|c|c|c|c|}
\hline & (1) & (2) & (3) & (4) & (5) & (6) & (7) & $(8)$ \\
\hline & wage public & wage formal & wage informal & wage ag & ag self & ag unpaid & non-ag self & non-ag unpaid \\
\hline \multirow[t]{2}{*}{ Primary complete } & -0.006 & 0.003 & -0.003 & 0.002 & -0.023 & 0.049 & -0.008 & -0.022 \\
\hline & $(3.29)^{* *}$ & $(2.41)^{*}$ & $(2.11)^{*}$ & -0.95 & $(3.32)^{* *}$ & $(7.54)^{* *}$ & -1.61 & $(6.82)^{* *}$ \\
\hline \multirow[t]{2}{*}{ Primary incomplete } & -0.024 & 0.004 & -0.001 & 0.003 & -0.005 & 0.072 & -0.025 & -0.033 \\
\hline & $(3.19)^{* *}$ & -1.22 & -0.12 & -0.96 & -0.27 & $(4.87)^{* *}$ & -1.9 & $(4.47)^{* *}$ \\
\hline \multirow[t]{2}{*}{ Secondary incomplete } & -0.03 & 0.003 & 0.001 & -0.007 & 0.005 & 0.088 & -0.003 & -0.065 \\
\hline & $(2.55)^{*}$ & -0.67 & -0.16 & -1.96 & -0.33 & $(6.47)^{* *}$ & -0.22 & $(8.43)^{* *}$ \\
\hline \multirow[t]{2}{*}{ Secondary complete } & -0.086 & 0.016 & -0.002 & 0.004 & -0.015 & 0.062 & 0.07 & -0.051 \\
\hline & $(5.29)^{* *}$ & $(3.06)^{* *}$ & $(0.57)$ & $(0.87)$ & -0.84 & $(3.74)^{* *}$ & $(4.81)^{* *}$ & $(3.86)^{* *}$ \\
\hline \multirow[t]{2}{*}{ Post-secondary } & -0.105 & 0.007 & 0.008 & -0.004 & 0.015 & 0.075 & 0.035 & -0.036 \\
\hline & $(9.75)^{* *}$ & -1.41 & $(3.34)^{* *}$ & -1.83 & $(2.48)^{*}$ & $(10.12)^{* *}$ & $(4.78)^{* *}$ & $(6.97)^{* *}$ \\
\hline
\end{tabular}

Notes: The dependent variable is the log of real hourly earnings from wage employment. Controls include a second-degree polynomial in age, gender, educational attainment, industrial sector, occupation, cohort of birth, dummy for whether current job is first job, payment type (cash, in-kind, both), and contract type (permanent, temporary, casual, other), region. Robust standard errors in parentheses. ${ }^{* * *} \mathrm{p}<0.01,{ }^{* *} \mathrm{p}<0.05,{ }^{*} \mathrm{p}<0.1$. Source: LFS, 2013. 


\section{Annex 11: Qualitative study on rural youth employment}

In the framework of this report, a qualitative research study on rural youth employment was conducted in April and May 2017. Due to budget constraints, the study was only implemented in the four most populated regions (Oromiya, Amhara, SNNPR and Tigray), which however accounted for 94 percent of all rural youth in 2013. In each of the regions, four woredas were selected for the research, two relatively poor woredas and two relative better-off woredas. This resulted in a sample of 16 woredas, eight of which were relative poor and eight relatively better off (selected woredas are mapped below). Within each woreda, two kebeles were selected based on connectivity: One relatively well-connected kebele (connected to a road or a market town) and one isolated kebele. Within each Kebele, one Enumeration Area was selected that was also included in the Labor Force Survey, to be able to connect the qualitative and quantitative data.

Annex Figure 4: Woredas selected for the qualitative research

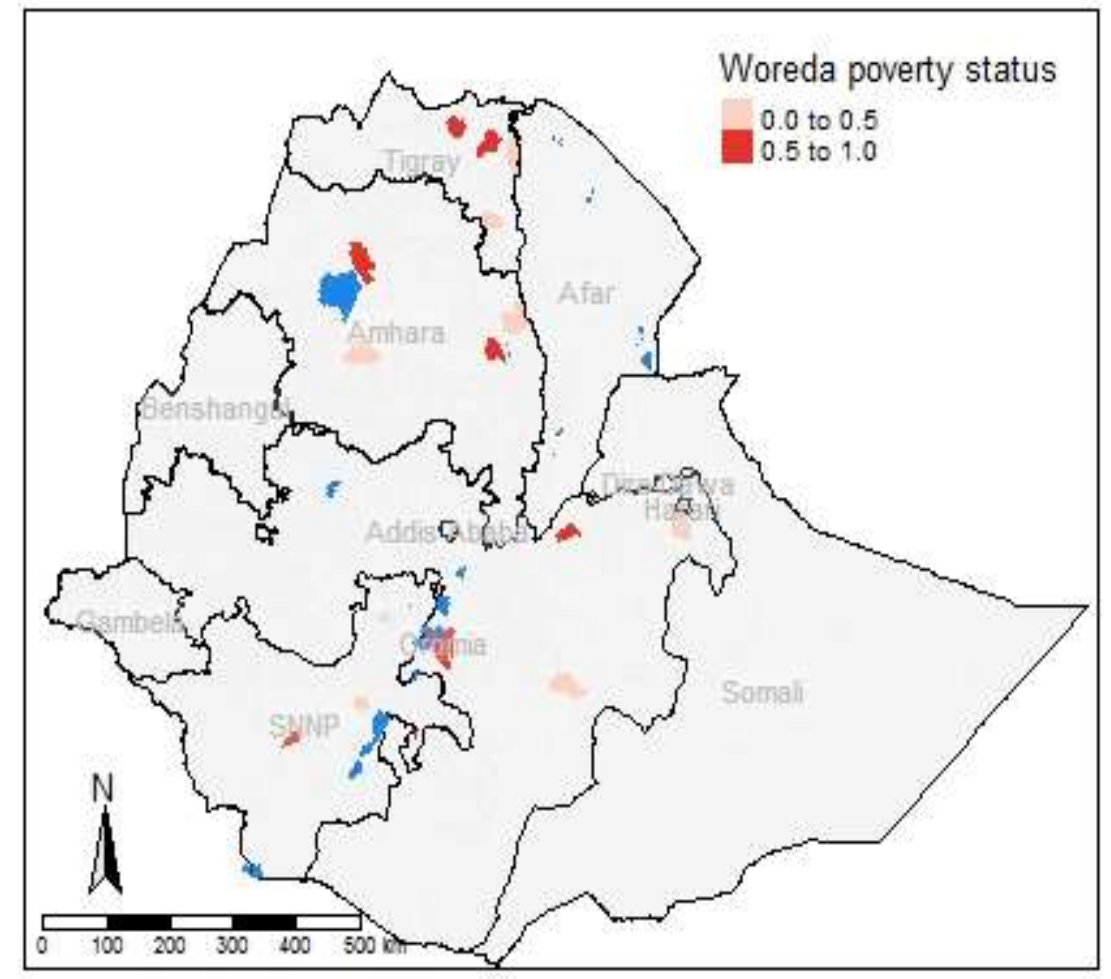

Note: Woreda poverty rates estimated using small area estimation on 2007 Census and 2010/11 Household Consumption Expenditure Survey.

Within each selected kebele, two focus groups discussions (FGDs) were conducted: One male and one female. All participants were between 18 and 29-years-old. Overall, 64 FGDs were conducted in 32 kebeles in 16 woredas in four regions. The FGDs focused on the following themes:

1. What are the aspirations of the rural youth with respect to their professional trajectory?

2. What are the opportunities available to the rural youth, both locally and elsewhere (through migration)?

3. Are the opportunities available commensurate with the aspirations?

4. What obstacles and barriers prevent the rural youth from achieving their objectives? 
5. How can existing obstacles be overcome, to improve employment outcomes of rural youth?

6. Are there any specific barriers to self-employment in the non-farm sector (small non-farm businesses in rural areas)? Which are those?

Overall, 64 FGDs were conducted. The FGDs were complemented by a number of key informant interviews (KIIs) at woreda, and regional level. At regional level, the micro and small enterprise development bureau, technical and vocational education bureau, and youth and children's affairs bureau were contacted. At woreda level micro and small enterprise development office, agriculture and rural development offices and officials associated with Children and Youth Affairs were interviewed.

The 16 woredas selected for the qualitative research are not much different from the average woreda in the four regions (Annex Table 6). If any, the woredas selected for the research are on average a little better-off, given the slightly better education levels (both for youth and for the labor force in general), the lower employment share of agriculture, and slightly lower unemployment rates. While this does not mean that the qualitative results can be generalized to the entire youth population in the four regions, it shows that the woredas selected are fairly typical, if somewhat better-off, than an average woreda in the 4 regions.

Annex Table 6: Selected vs non-selected woredas for the qualitative research

\begin{tabular}{lcc}
\hline \hline & $\begin{array}{c}\text { Woredas selected for } \\
\text { qualitative research }\end{array}$ & Woredas not selected \\
\hline Working-age population (\% of total population) & 49.9 & 49.7 \\
Women (\%) & 49.8 & 49.3 \\
Unemployment (\%) & 1.3 & 2.1 \\
Workers in agriculture (\%) & 79.8 & 83.2 \\
Share of public sector employment (\%) & 1.4 & 1.9 \\
Workers without any education (\%) & 50.6 & 53.8 \\
Workers with at least primary education (\%) & 16.8 & 13.9 \\
Youth who never went to school (\%) & 34.5 & 39.3 \\
Youth with at least primary education (\%) & 17.8 & 15.5 \\
Youth still in school (\%) & 29.7 & 28.6 \\
\hline \hline
\end{tabular}

Note: The tables compares the woredas selected for the qualitative research with unselected rural woredas in the 4 regions included in the study. Source: LFS, 2013. 


\section{Annex 12: The correlates of NEET for youth}

To characterize youth who are NEET, we estimate a panel logit model with a dummy dependent variable $N E E T_{i t}$, which is equal to one when individual $i$ is NEET at time $t$ and zero otherwise:

$$
N E E T_{i t}=X^{\prime} \beta+e_{i t}
$$

...where $t$ is 2012, 2014 or 2016, and $X$ is a vector individual $i$ 's characteristics as well as characteristics of the household and the community in which individual $i$ resides. The vector includes human capital endowment (education, age and age squared) and social indicators such as gender and marital status; individual $i$ 's household labor and land resource endowments such as proportion of adult and youth household members, and landholding per adult; and community level access indicators such as distance from permanent market, border post, and road.

The model presented in Equation 1 is a random effects (RE) model and assumes that individual specific effects $\left(\gamma_{i}\right)$ are random - not correlated with the independent variables in vector $X$-with zero mean and constant variance (i.i.d.), and includes them in $e_{i t}$ (i.e. $e_{i t}=\gamma_{i}+\varepsilon_{i t}$, where $\varepsilon_{i t}$ is the random error term). Mixed effects model, which utilize the feature of both RE and fixed effects (FE) models, divide $\gamma_{i}$ into two parts: one that is i.i.d. as in the RE model, and another that is potentially correlated to the variables in vector $X$.

Fixed effects (FE) model controls for the individual specific effects $\left(\gamma_{i}\right)$ in the model directly (i.e. Equation 1 becomes $\left.N E E T_{i t}=\gamma_{i}+X^{\prime} \beta+\varepsilon_{i t}\right)$. A unique feature of FE logit model is that it focuses on individuals who have seen change in $N E E T_{i t}$ over time, i.e. $N E E T_{i t} \neq N E E T_{i s}$ for any two period $t$ and $s$ such that $t \neq s$. In effect, the predicted probabilities in FE logit model impose an additional condition $\left(N E E T_{i t} \neq N E E T_{i s}\right) .{ }^{123}$ This reduces the number of observations substantially as only those individuals who have seen changes in their NEET status over time are included in the analysis. Annex Table 2 shows the results of the random effects (first column), mixed effects (second column) and fixed effects (third column) estimation.

Annex Table 7: Correlates of NEET for youth

(1)

Dep. Var: Probability of being NEET

Male

Age

Age squared

Youth
Random effects $-0.07^{* * *}$

$(0.01)$

$0.03 * * *$

$(0.01)$

$-0.00 * * *$

$(0.00)$

0.00

(0.00)
(2)

Mixed Model $-0.07 * * *$

$0.03^{* * *}$

(0.01)

$-0.00^{* * *}$

0.00

$(0.00)$
$0.04 * * *$

(0.02)

$-0.00^{* * *}$

$(0.00)$

0.00

$(0.00)$

\footnotetext{
${ }^{123}$ In REs logit model, the conditional probability is given by $\operatorname{Pr}\left(N E E T_{i t}=1 \mid X_{i t}\right)$. While, in FEs logit model, we have an additional condition that $N E E T_{i t} \neq N E E T_{i s}$ for some $t \neq s$, and hence the conditional probability is given by $\operatorname{Pr}\left(N E E T_{i t}=1 \mid X_{i t}, N E E T_{i t} \neq N E E T_{i s}\right)$. The additional condition restricts the data to the group of individuals who have experienced change in their NEET statuses.
} 
Education level (relative to those with no education):

Primary Incomplete

Primary complete

Secondary Incomplete

Secondary complete

Tertiary

Marital status (relative to never married):

Married

Divorced/Separated

Widow/widower

Household size

Proportion of adult $\mathrm{HH}$ members

Proportion of youth $\mathrm{HH}$ members

Landholding (ha) per adult

Has the HH experienced natural shocks last year?

Frequency of shocks in the past year (number)

Distance $(\mathrm{km})$ from:

Road

Permanent market

Border post

$\begin{array}{lll}-0.07 * * * & -0.07 * * * & -0.11 \\ (0.01) & (0.01) & (0.07) \\ -0.12 * * * & -0.12 * * * & -0.31 \\ (0.02) & (0.02) & (0.19) \\ -0.11 * * * & -0.10 * * * & -0.15 \\ (0.01) & (0.01) & (0.10) \\ -0.02 & -0.02 & 0.01 \\ (0.03) & (0.03) & (0.19) \\ -0.13 * * * & -0.13 * * * & 0.01 \\ (0.03) & (0.03) & (0.14)\end{array}$

0.00

(0.01)

$-0.00$

0.00

(0.01)

(0.06)

0.01

0.01

0.01

(0.02)

(0.02)

$(0.08)$

$-0.03$

$-0.03$

$-0.21$

(0.06)

(0.06)

(0.30)

$0.01 * * *$

$0.01 * * *$

$-0.00$

(0.00)

(0.00)

(0.01)

$0.10 * * *$

$0.09 * * *$

$-0.21$

(0.02)

(0.03)

(0.17)

$-0.01$

$-0.02$

0.05

(0.02)

(0.02)

(0.10)

$-0.13 * * *$

$-0.12 * * *$

$-0.29 *$

$(0.01)$

$(0.01)$

$0.03 * * *$

$0.03 * * *$

0.03

(0.01)

(0.01)

(0.04)

0.00

0.00

$-0.00$

(0.00)

(0.00)

(0.01)

$0.00 *$

0.00

(0.00)

(0.00)

$-0.00 * *$

$-0.00 *$

(0.00)

(0.00)

$-0.00 * * *$

$-0.00 * * *$ 


\begin{tabular}{llll} 
Number of individuals & 4,112 & 4,112 & 642 \\
$N$ & 8,881 & 8,881 & 1,734 \\
\hline
\end{tabular}

Notes: Dependent variable is a dummy taking on 1 if person is NEET in time $t$._The coefficients are marginal changes in probability. Standard error in parentheses: $*, * *$ and $* * *$ correspond to significant at $1 \%, 5 \%$ and $10 \%$ confidence, respectively. Source: ESS1; ESS2; ESS3. 


\section{Annex 13: The correlates of nonfarm diversification}

To study the partial or full transition out of employment in agriculture during 2012-2016 period, we use an ordered logit model. By starting with a sub-sample of individuals who were employed exclusively in family owned farms in the baseline period (2012), we analyze their transition out of agriculture. If individual $i$ is engaged exclusively in family owned farm in both $t$ and $t-2$ periods, she/he is classified as not experiencing employment transition $\left(T_{i t}=0\right)$. On the other hand, if individual $i$ starts to engage in non-farm activities on a part-time basis in time $t$, then she/he has experienced a partial employment transition $\left(T_{i t}=1\right)$. If individual $i$ abandons agriculture all together in time $t$ and engage in other activities in a fulltime basis, she/he has experienced full transition $\left(T_{i t}=2\right)$. In other words, transition $\left(T_{i t}\right)$ is defined as follows:

$$
T_{i t}= \begin{cases}0 & \text { No transition: } S_{i t-2}=1, S_{i t}=1 \\ 1 & \text { Partial transition: } S_{i t-2}=1,0<S_{i t}<1 \\ 2 & \text { Full transition: } S_{i t-2}=1, S_{i t}=0\end{cases}
$$

$\ldots$ where $S_{i t}$ is the share of labor time of individual $i$ spent on family owned farm in time $t$, and $t=2014,2016$.

Based on the definition above, we estimate a panel ordered logit model of transition (Equation 2) and extract the conditional marginal probability of partial (moving to $T_{i t}=1$ ) or full (moving to $T_{i t}=2$ ) transition out of agriculture:

$$
T_{i t}=X^{\prime} \beta+\varepsilon_{i t}
$$

...where $X$ is a vector of covariates described above; $\varepsilon_{i t}$ is the error term; and $t=2014,2016^{124}$. Annex Table 3 shows the results of estimating equation (2).

\begin{tabular}{|c|c|c|c|c|c|}
\hline & \multicolumn{3}{|c|}{ Transition (partial or full) } & \multicolumn{2}{|c|}{ Transition } \\
\hline & (1) & (2) & (3) & (4) & (5) \\
\hline & $\begin{array}{l}\text { Random } \\
\text { Effects }\end{array}$ & $\begin{array}{l}\text { Mixed } \\
\text { Effects }\end{array}$ & $\begin{array}{l}\text { Fixed } \\
\text { Effects }\end{array}$ & $\begin{array}{l}\text { Partial } \\
\text { Transition }\end{array}$ & $\begin{array}{l}\text { Full } \\
\text { Transition }\end{array}$ \\
\hline \multirow[t]{2}{*}{ Male } & $0.05^{* * *}$ & $0.06 * * *$ & & $0.04 * *$ & $0.00 * *$ \\
\hline & $(0.02)$ & $(0.02)$ & & $(0.02)$ & $(0.00)$ \\
\hline \multirow[t]{2}{*}{ Age } & $0.05 * *$ & $0.05 *$ & 0.00 & $0.04 * *$ & $0.01 * *$ \\
\hline & $(0.02)$ & $(0.02)$ & $(0.00)$ & $(0.02)$ & $(0.00)$ \\
\hline \multirow[t]{2}{*}{ Age squared } & -0.00 & -0.00 & -0.00 & -0.00 & -0.00 \\
\hline & $(0.00)$ & $(0.00)$ & $(0.00)$ & $(0.00)$ & $(0.00)$ \\
\hline
\end{tabular}

Annex Table 8: Correlates of nonfarm diversification for youth

Education level (relative to those with no education):

\footnotetext{
${ }^{124}$ We also estimate logit model using a dummy which is equal one if the individual has experienced partial or full
} transition, and zero if $\mathrm{s} / \mathrm{he}$ experienced no transition out of agriculture. 
Primary Incomplete

Primary complete

Secondary Incomplete

Secondary complete

Tertiary

Marital status (relative to never married):

Married

Divorced/Separated

Widow/widower

Household size

Proportion of adult $\mathrm{HH}$ members

Proportion of youth HH members

Landholding (ha) per adult year?

Frequency of shocks in the past year

Distance ( $\mathrm{km})$ from:

Road

Permanent market

Border post

Number of individuals
$0.07 * * *$

(0.02)

0.03

(0.04)

0.04

(0.03)

0.19 *

(0.10)

$0.21 * * *$

(0.07)

$-0.03$

(0.03)

0.07

(0.05)

0.11

(0.11)

$-0.02 * * *$

(0.00)

$-0.17^{* *}$

(0.07)

0.12 **

(0.06)

$-0.06^{* * *}$

(0.02)

$0.04 *$

(0.02)

$-0.01$

(0.01)

\subsection{0}

(0.00)

$-0.00$

(0.00)

$-0.00 * * *$

(0.00)

2,344

3,482
$0.07 * * *$

(0.02)

0.03

(0.04)

0.04

(0.03)

$0.24 * *$

(0.10)

$0.22 * * *$

$(0.08)$

$-0.03$

(0.03)

0.07

(0.05)

0.10

(0.12)

$-0.02 * * *$

(0.00)

-0.20 ***

(0.07)

$0.17 * * *$

(0.06)

$-0.06 * * *$

(0.02)

$0.04 *$

(0.02)

$-0.01$

(0.01)

0.00

(0.00)

$-0.00$

(0.00)

-0.00 ***

(0.00)

2,344

3,482
0.00

$0.06 * * *$

$0.01 * * *$

(0.00)

(0.02)

$(0.00)$

0.00

0.03

0.00

(0.00)

(0.03)

(0.00)

0.00

0.04 *

0.01 *

(0.00)

(0.02)

(0.00)

0.00

$0.21 * *$

0.03 **

(0.00)

(0.10)

(0.01)

0.00

$0.21 * * *$

$0.02 * * *$

$(0.00) \quad(0.07)$

(0.01)

$-0.00$

$-0.03$

$-0.00$

(0.00)

(0.02)

(0.00)

$-0.00$

0.05

0.01

$(0.00)$

(0.04)

(0.00)

0.00

0.11

0.01

(0.15)

(0.09)

(0.01)

$-0.00$

$-0.02 * * *$

$-0.00 * * *$

(0.00)

(0.00)

(0.00)

$-0.00$

$-0.15^{* *}$

$-0.02 * *$

(0.00)

(0.06)

(0.01)

0.00

0.10 *

0.01 *

(0.00)

(0.05)

(0.01)

$-0.00$

$-0.06 * * *$

$-0.01 * * *$

(0.00)

(0.02)

$(0.00)$

$-0.00$

$0.04 * *$

$0.01 * *$

(0.00) (0.02)

(0.00)

0.00

$-0.01$

$-0.00$

(0.00)

(0.00)

(0.00)

0.00

0.00

(0.00)

(0.00)

$-0.00$

$-0.00$

(0.00)

(0.00)

$-0.00 * * *$

$-0.00 * * *$

$(0.00)$

(0.00)

327

2,344

2,344

658

3,482

3,482 
Notes: The coefficient estimates are marginal probabilities with standard errors in parentheses. The stars *,** and *** indicate significance at $1 \%, 5 \%$ and $10 \%$ confidence level, respectively. Columns $1-3$ are from logit estimates a dummy dependent variable which is equal to one when the individual has experienced partial or full transition, and zero if there is no transition. Columns 4 and 5 are marginal probability of experiencing partial and full transition, respectively. These results are from a single order logit regression (Equation 3), using 'no transition' as a base outcome. Source: ESS1; ESS2; ESS3. 